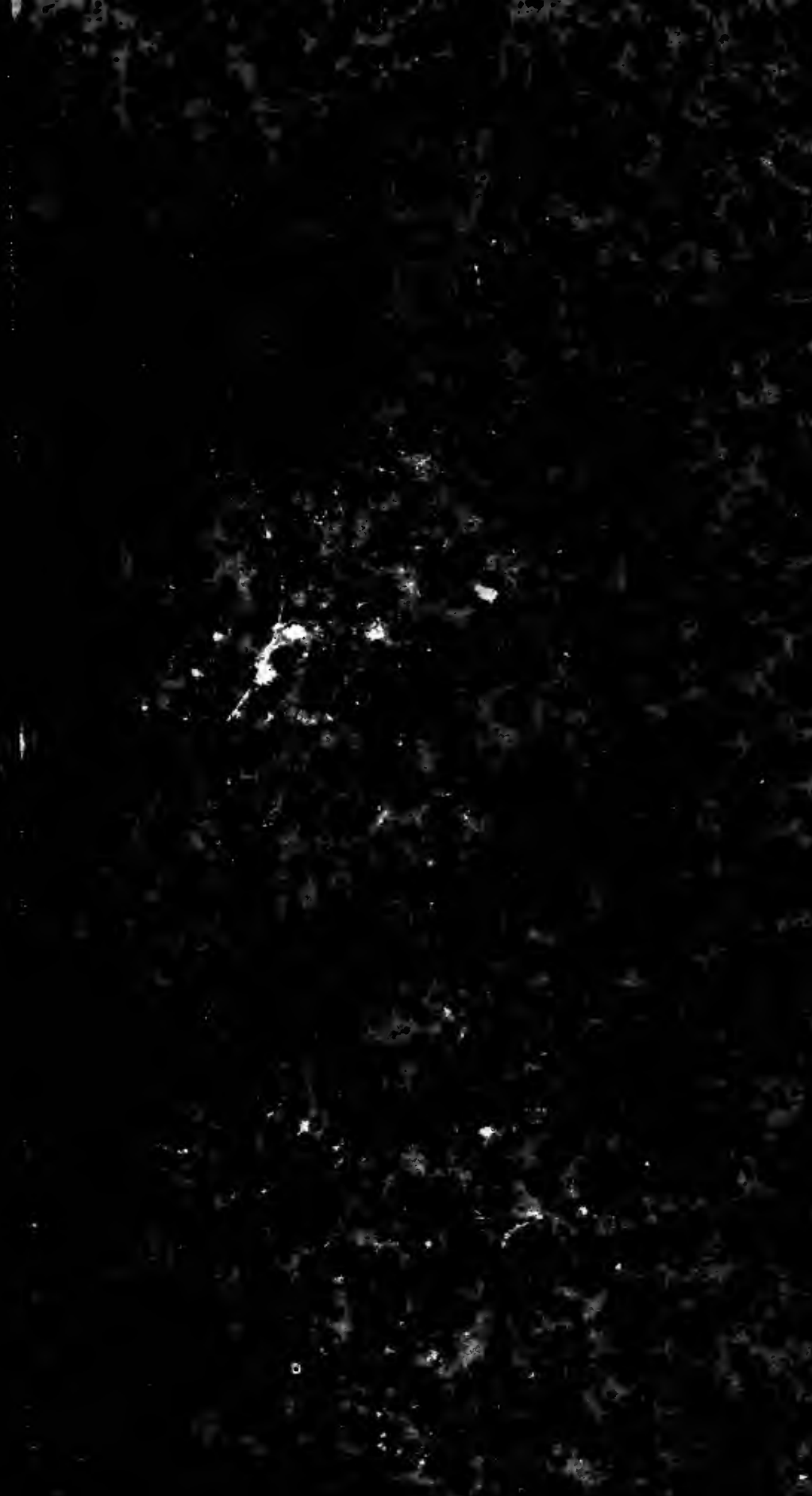

UNIV, OF

TORON'TO LHBKAKY 


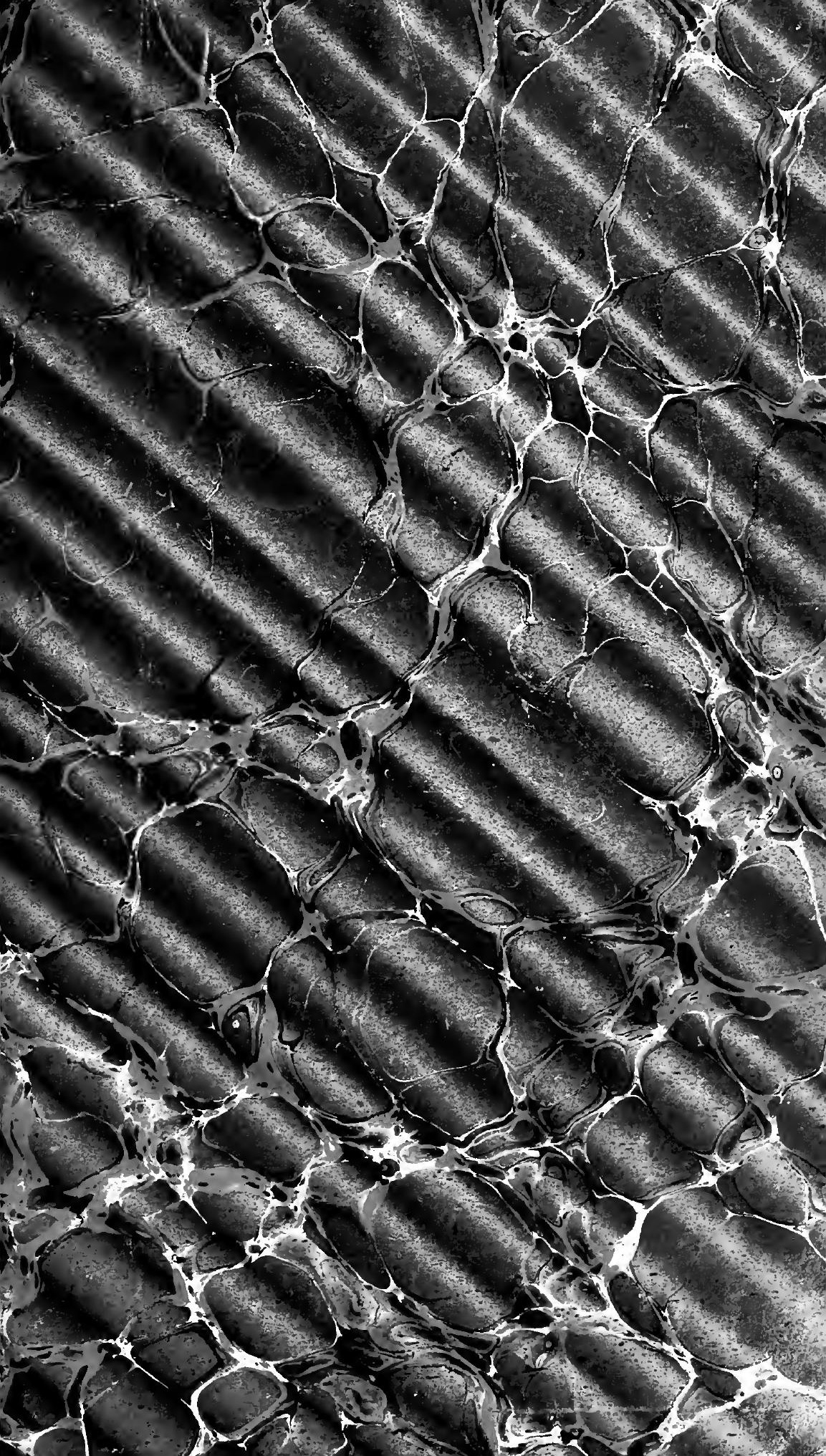




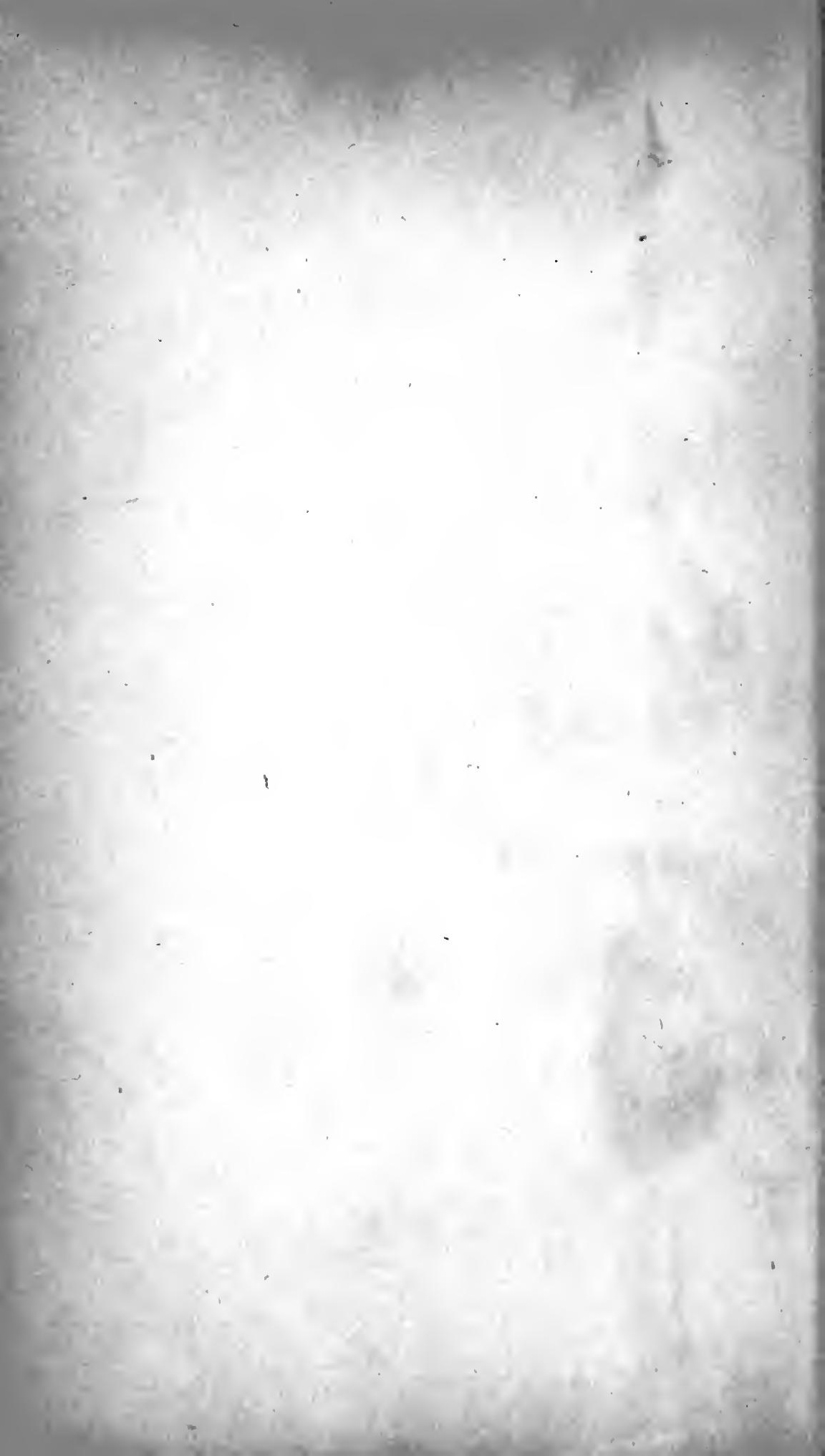





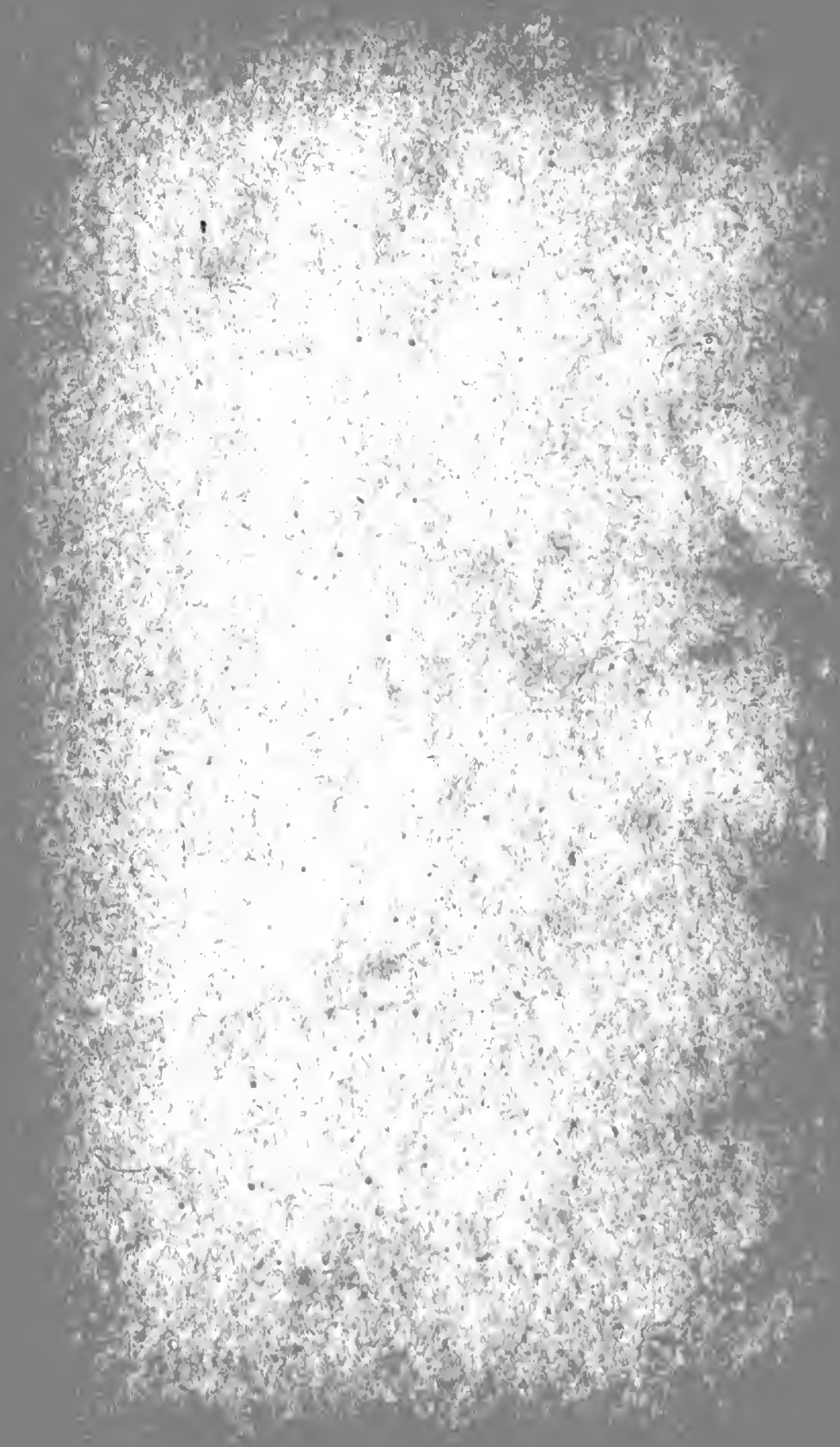




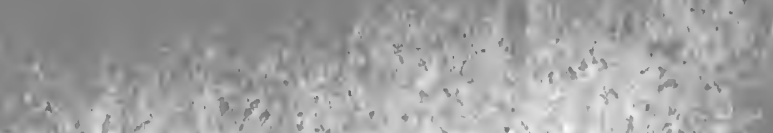

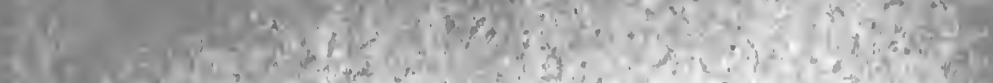

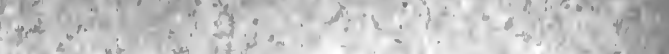

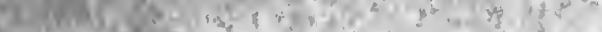

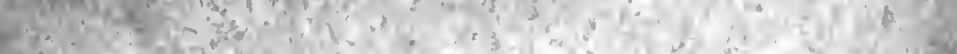

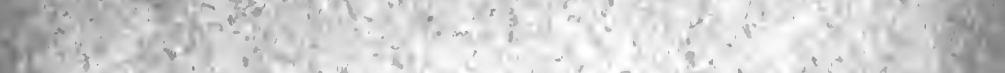

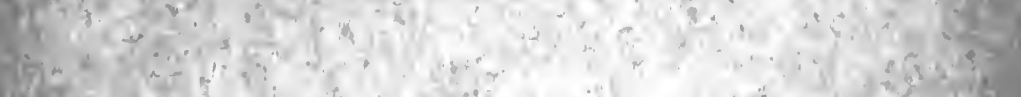

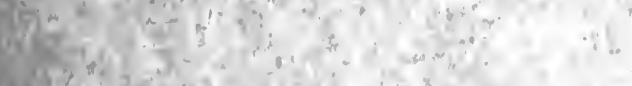

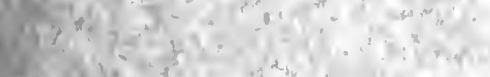

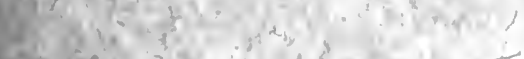
Q

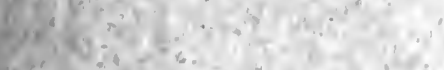

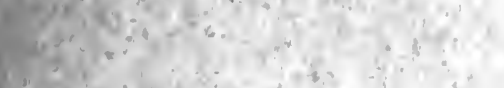

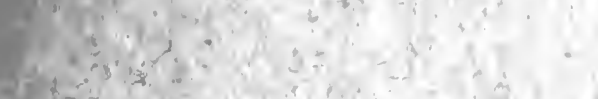

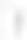

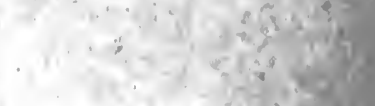

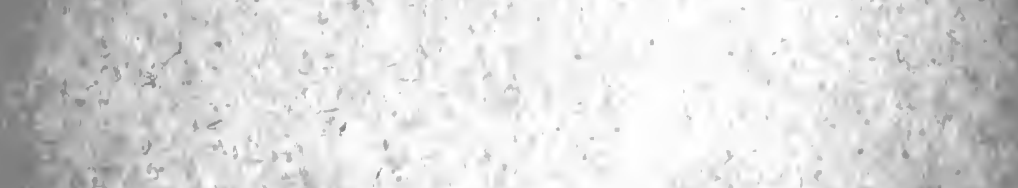

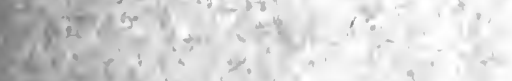

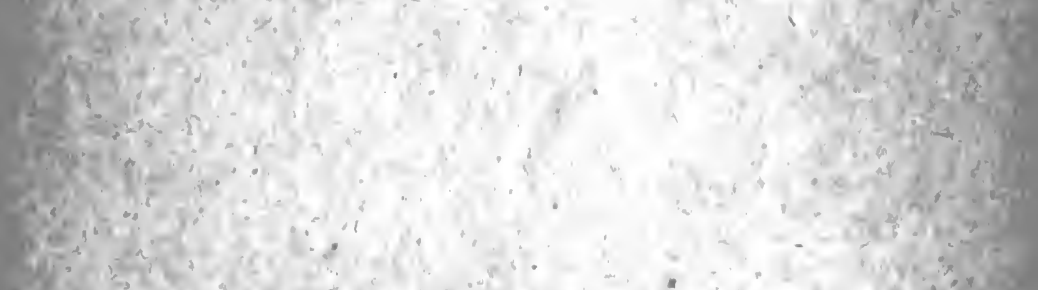

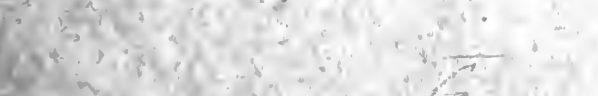

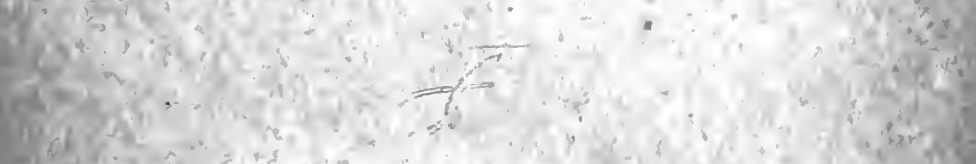
(15)

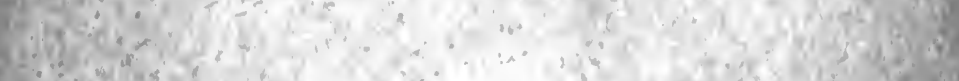

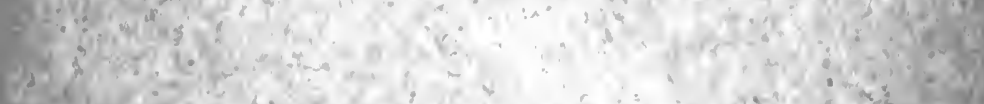

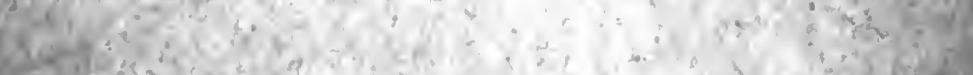

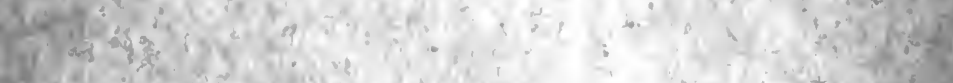

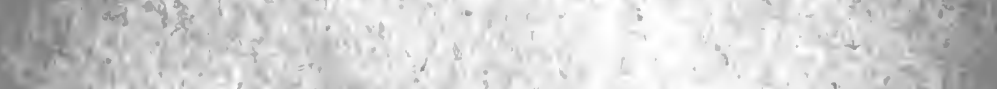

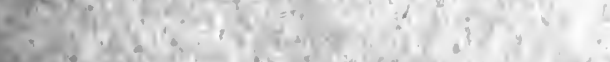

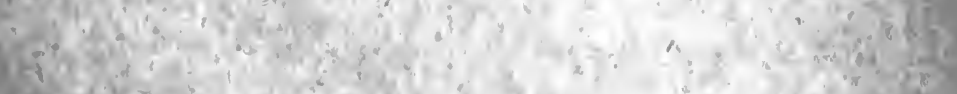

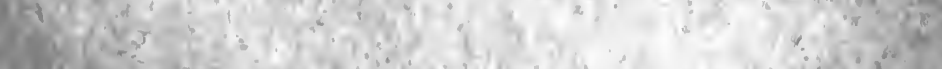

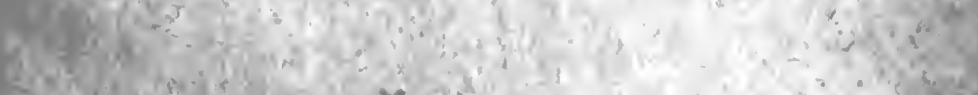

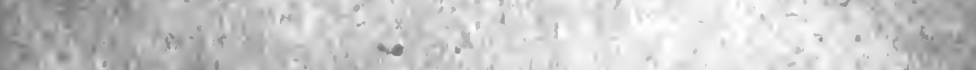
W.

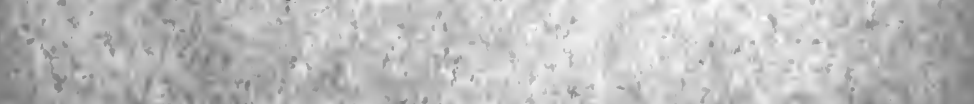

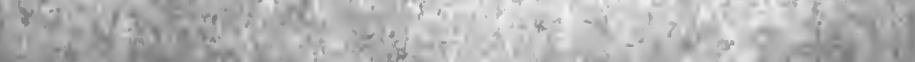

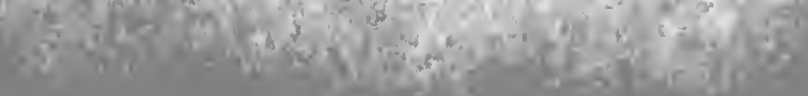




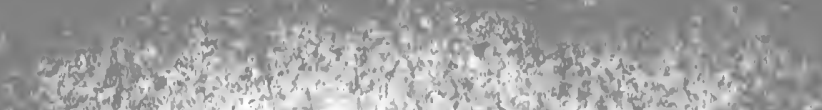

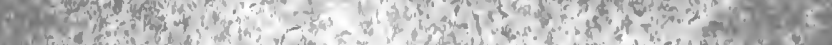

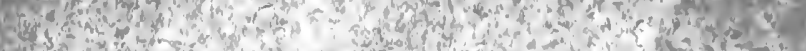

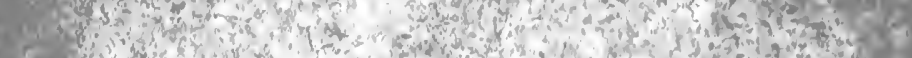
5. 25.

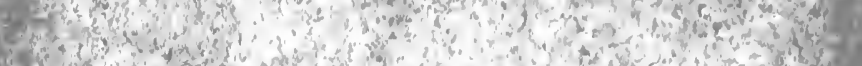

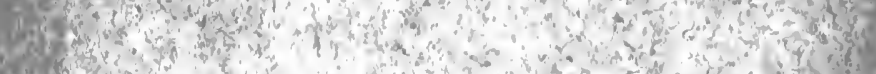

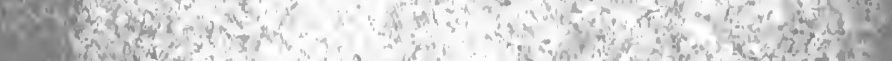
1.

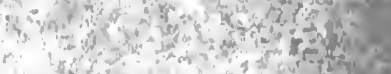

4. 4.

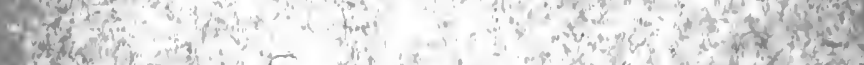
Q.

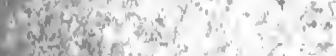

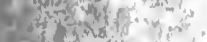

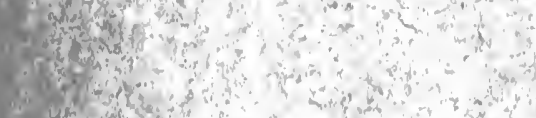
2.

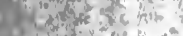

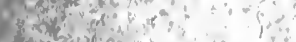

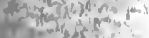

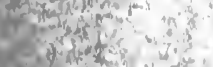

0 and 6) $103 x+4 x+3$

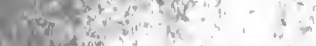

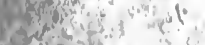

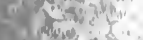
Nowe

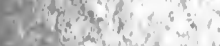
4.

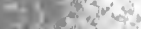

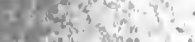

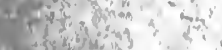

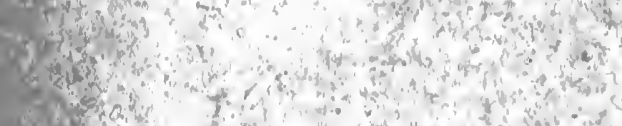

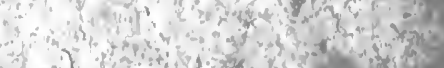
-i)

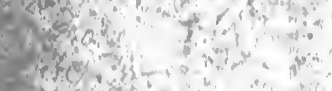

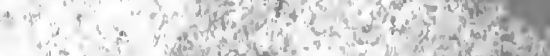

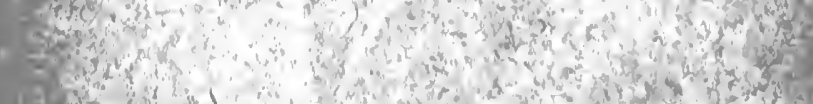
* "

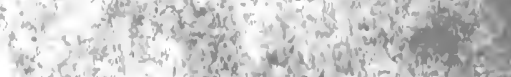

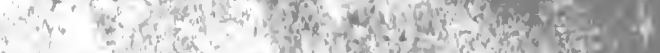

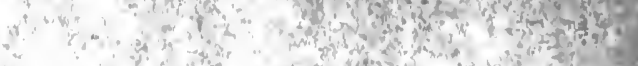

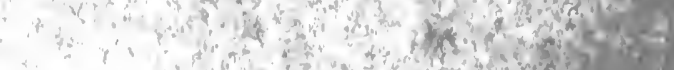

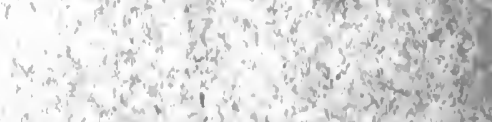

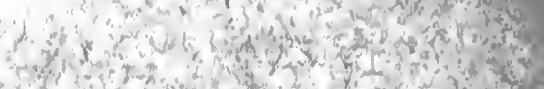

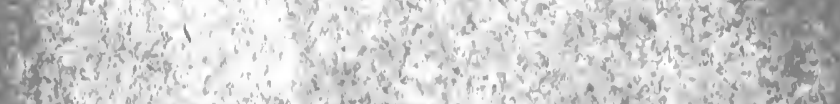

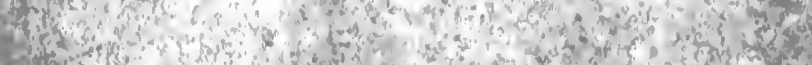

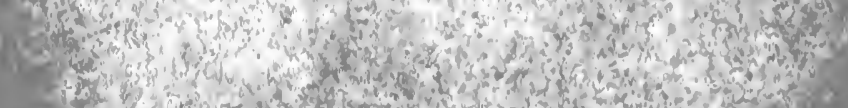

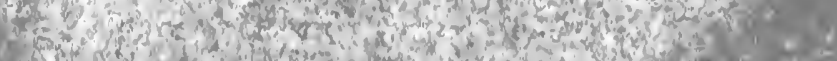

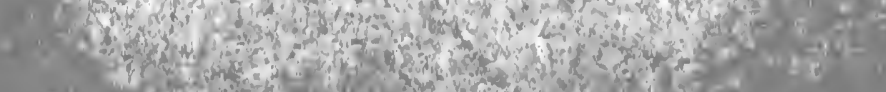

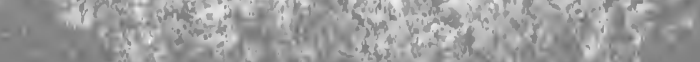

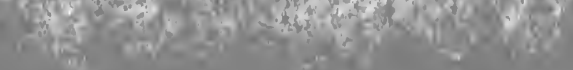


ESSAI COMPARATIF

SUR

\section{L'ORIGINE ET L'HISTOIRE}

DES RYTHMES 



$$
\frac{\frac{19976}{22 / 12 / 91}}{L_{e}}
$$




\title{
ESSAI COMPARATIF
}

\author{
Suk
}

\section{L'ORIGINE ET L'HISTOIRE}

\section{DES RYTHMES}

\section{QUESTIONS PRELIMJAIRES}

Ivant d'entrer dans le sujet propre de ce travail, il faut préciser d'abord la place qu'il occupe parmi des phènoménes semblables. Les phénoménes rythmiques ne touchent pas à la matière des choses, mais à la forme de leur existence. Or, le temps et l'espace ètant la forme la plus générale de l'existence, il faut lonc que les phènomènes rythmiques tombent aussi sous cette forme ou condition gènèrale.

On veut voir aujourdhui du rythme dans certains phénoménes de la nature: dans la chule cadencée des gouttes d'eau, tombant après la pluie du feuillage des arbres, dans le battement du cour, dans les mouvements de l'homme et des animaux. Telle est l'idée de M. Westphal sur l'origine du rythme en gèneral. Ignorant encore si la conception primitive du rythme dans l'art coïncide avec la forme des mouvoments naturels reguliers, nous devons nous borner au domaine lans 
lequel ces phénomènes se manifestent le plus, dans lequel ils ont une histoire, et ou ils sont placés par l'homme avec la conscience de son but et de sa volonté, en un mot, il faut nous borner au clomaine historique de l'art.

Les arts relévent nécessairement de la condition formelle de l'existence et se divisent en arts des mouvements dont les ouvres s'écoulent dans le temps, et en arts du repos dont les produits s'étalent et persistent dans l'espace. D'aprés cette division, établie pour la première fois par Aristoxène, disciple d'Aristote, la danse, la poèsie et la musique font partie du premier genre. la sculpture. la peinture et l'architecture du second '. C'est de la même division que Lessing a fait usage, avec tant de succès, dans ses recherches esthètiques.

Une des conditions fondamentales de l'arrangement des uns et des autres semble consister dans l'ègalisation des parties. C'est ainsi qu'on place les triglyphes, les colonnes, ou les fenètres à ègales listances; et que la mesure dans les pièces musicales, dans les danses et les pieds dans les mètres antiques sont ègaux. Cette égalité de construction peut ètre interrompue par une partie médiale, diffẻrant de toutes les autres, mais à condition que lharmonie soit maintenue de deux còtés par des suites égales de parties ègales. Nous arrivons ainsi á la symètrie, qui peut cependant aller plus loin et abandomnant l'égalité de toutes les parties, hormis la partie mediale, viser seulement a la correspondance des membres égaux par paires. et disposès de leux côtés d'une ligne mérliale. Seuls, les arts du repos comportent celte symètrie d'un degré superieur, pour cette raison, que persistant dans l'esplace, les ouvres de l'architecture, de la peinture et de la sculpture se prêtent á une contemplation longue et soutenue, tandis que les arts du monvement s'ècoulant dans le temps, effacent par les

'R. Westphal, Dic Jusik des griechischen Altherthums, 1883. 
parties suivantes l'impression de celles qui précédent. de sorte que la régularité de leur ordonnance devient difficile á saisir. Mais, soit que la rėgle innėe du développement porte tous les arts vers des formes semblables, ou que la construction des uns influence celle des autres. les artistes ont été portès à des compositions de cette symétrie supérieure mème dans les arts dı mouvement, notamment dans la haute lyrique des Grecs, oủ selon le tẻmoignage d'A ristides Quint. "Alia simili modo atque prior ordo se habent, alia contra. Et quidem simili modo ut cum pirimum metrum antistrophes redditur strophes primo, secundum secundo et caetera similiter; contra autem. ut cum primum ultimo, secundum penultimo, caeteraque secundum eamdem. rationem ". Récemment encore, Victor Hugo, dans son poème bien connu . Les Djinns, a fait choix du dernier mode de construction.

Toutefois les arts du mourement sont opposés á la construction symétrique, et quand ils aljandonnent l'ègalité des parties ils les font égales par paires, en en formant une suite de paires. Ils relévent mème l'unitè de paires par des périodes additionnelles. Cette forme de composition, particulière á la lyrique, et par conséquent á la musique grecque, et dont on retrouve encore les traces dans la musique moderne, ne fut jamais suivie dans les arts du repos, qui préfèrent la symètrie.

S'appuyant sur leur permanence, les arts du repos abaudonneront bientôt la symétrie parfaite. si caractéristique même pour la sculpture chez les Egyptiens; ils ne viseront désormais qu'à une symétrie, que je qualifierais volontiers de psychologique; ils contrebalanceront l'impression des parties opposées soit par des couleurs, soit par des lignes, par la force de leur expression.C'est ce que nous rencontrons dans presque toute la peinture, dans la sculpture et quelquefois, dans une certaine mesure, dans

1 Меıвом, Antiqua musicæ auctores septem, II, ว̈8. 
l'architecture mème. Nais les arts du mouvement suivent aussi cette direction, comme nous le montrent les odes monostrophiques antiques, les odes modernes.les poèmes a vers libres, beancoup de passages de la musique moderne. La tendance naturaliste renonce même á toute symétrie et ne cherche qu'ả produire l'effet du hasard de la nature. C'est le moment oú l'art ayant dépassẻ le point culminant de son développement touche à son déclin, commence á se décomposer, parce que la nature n'est dèsordonnée que pour quiconque l'envisage d'un point de vue ètroit : considérée de plus haut, elle nous révéle une harmonie profonde, un équilibre constant. L'univers est strophique dans son mouvement, il est symètrique dans son ètendue.

Cest à dessein que je me borne aux réflexions les plus proches, ce sujet pouvant nous entraîner loin el nous retenir longtemps. Qu'il suffise d'avoir établi, que le commencement de tous les arts, y compris les arts du mouvement, consiste vraiment dans l'égalisation dess parties. Aussi faudrait-il chercher lorigine du rythme, qui est la condition formelle et essentielle de tous les arts du mourement, dans une suite ordonnée des parties ègales. Mais ce n'est pas en cela seul que consiste son caractère: s'il en ètait ainsi nous devrions appeler rytlimique une suite de colonnes, de triglyplies, de fenêtres, placès à distances ègales. Selon la notion moderne du rythme, considéré comme une suite ordonnèe de temps forts et faibles, cela nous serait facile, en remplacant "le temps fort" par "l'espace rempli " et "le temps faible " par "l'espace vide ". Mais il est trés douleux que notre notion moderne ait èté la notion originaire. lit puis le rythme poètique est-il identique $\dot{a}$ celui de la musique et de la danse ? Et sil en est ainsi, d’ou vient cette ressemblance ou cette identité ?uels sont les phènomènes qui ont donné le substratum sensible de cette notion? Autant de questions qui attendent une réponse. 
Je ne saurais dire si ces questions ont été dejá posėes de la manière que je viens de le faire ici, mais on sait que les recherches des savants n'ont pu jusqu’a présent les résoudre d'une manière satisfaisante. Récemment encore M. Wilhelm Mayer, professeur à Gœettingue, ne pouvant trouver l'origine de la poésie rythmique latine dans la ry thmique classique, s'est avisé de la rechercher dans la poésie syriaque, supposant d'abord que cette versification est fondèe sur l'accent, et de plus que c'est dans laccent et dans le syllabisme que consiste la règle, non-seulement de la versification syriaque. mais aussi d'une versification hẻbraïque supposée. Cette suite de suppositions l'améne à attribuer à la rythmique latine une origine sèmitique. Nous ètablirons plus loin que sa première supposition est erronèe, et toutes les autres tomberont de même.

Nous ne sommes pas à la fin des suppositions qu'on débite dans le domaine de l'histoire littéraire. On ne se contente plus de supposer que le vers saturnien, c'esta-dire la forme primitive de la poésie latine, est fondé sur l'accent, mais on imagine déjá une poèsie aryenne primitive, on se figure une poèsie génèrale primitive commune a toutes les races, dont la forme aurait été rythmique, elle aussi, et fondèe sur l'accent. A vant tout, avouons que nous ne savons rien de cette poésie générale et primitive, rien d'une poèsie aryenne commune et très peu du vrai caractère de la poésie rythmique. Nous nous avançons de plus en plus dans le vide et c'est sur ce vide que nous ètablissons les bases de notre science.

En présence de tant de méprises, de tant d'efforts sté. riles, on en cherche la cause.Il $y$ a sans doute un défant de méthode, qui se contente de rapprochements hasardés et superficiels. Il est vrai que dans les recherches qui portent sur l'origine des phenomènes historiques, force nous est souvent de nous contenter de ressemblances éloignées. nourvu qu'elles soient liées par la 
logique, fondées sur la psychologie et appuyées sur des faits au moins analogues; mais pour reconmaître l'analogie il faut connaître le principe, la loi. Cest là que se cache la cause du inal.

Toutes les sciences reposent sur des idèes gẻnèrales, sur des hypothèses, qui ne sont jamais démontrèes dès le premier abord, mais qui deviennent principes quand elles se confirment de plus en plus par les faits. Sans ces ideees directrices, les recherches scientifiques sont presque impossibles.C'est une maniẻre de travailler peu flatteuse pour nous et pour la science, mais elle est intimement liée à la nature de l'esprit humain, et elle domne à l'humanité la douce certitucle rue la science n'aura jamais de fin. On estime les idées directrices aussi longtemps qu'elles protègent notre raisonnement, on les rejette dès qu'elles se montrent incapables d'èlucider la liaison des faits. C'est ainsi qu'on répudia le système de Ptolémée, respecté durant des siécles; c'est ainsi qu'on abandonna le systéme astronomique de Descartes, qu'on commence à s'attaquer au système de Newton, qu'on a changé de principes dans l'optique, dans la géologie. dans l'histoire naturelle, qu'on a tant de fois changè les systèmes philosuphiques. Nous arons dans les sciences historiques un bon nombre daxiomes incontestables, mais nous avons aussi des hypothèses, qui revètent même l'air de principes, quoique á mon avis, elles ne soient que des idees prèconçues, vagues, comme le romantisme qui les a fait naitre. Elles nous empêchent de trouver l'origine et le caractére du rythme, elles nous défendent presque toutes les recherches d'un but un peu plus lointain que la vérification d'une date, l'analyse d'un texte littéraire, ou mème une biographie; elles entravent la découverte et la comprèhension des lois qui régissent la vie des litteratures, sans lesquelles leur histoire ne sera jamais une science.

Pour y remédier. il faudrait d'abord dénoncer et 
combattre les idèes fausses, puis exposer les principes plus conformes á l'état des choses. C'est sans doute une tâche bien au-dessus de mes forces, mais je m'enhardis en pensant qu'une tentative, même faiblement réussie, ne serait pas sans profit pour la science dans son état actuel. Mon travail, cela est á prévoir et cer tain, fera surgir bien des contradictions, mais il est impossible de les éviter. On n'abandonne qu'avec difficulté et à contre-cour les idées qu'on a faites siennes. On ne peut d'ailleurs tailler tous les esprits sur le inême patron; il en est qui restent inquiets et mal satisfaits lá oí tant d'autres se reposent contents d'eux-mêmes. Toutefois je bornerai ma tàche, ne combattant que les idées qui nous empèchent de reconnaitre le caractère et la source de la rythmique, et n'exposant que les principes qui me paraissent être indispensables pour cette recherche.

On tient pour assuré d'abord, que les peuples aryens ont possédé une poésie dés avant leur séparation. Le nombre des partisans de cette idèe, qui est celle de J. Grimm, est légion. On la prend pour un fait hors de controverse, ne se souciant point de l'appuyer de quelques preuves. M. Westphal, seul, très èpris de cette belle idée, à ce qui semble, essaye de lui donner un appui scientifique. En comparant les vers dans les anciens monuments littéraires des peuples aryens, il attribue aux vers de seize syllabes dans la littérature védique et sanscrite et dans les gâthas du Zend-Avesta la même origine qu'au vers saturnien et á la "Langzeile " dans la poésie allemande et anglo-saxonne du moyen âge. Suivant son exemple, on trouva ensuite les clok ts de l'èpopée sanscrite parfaitement conformes au rann de l’ancienne poèsie irlandaise. C'ètait donc cette forme originaire qui a dù servir à la poésie aryenne commune, et qui a dù se maintenir dans la poésie des nations aryennes séparées. Rien de plus faible que cette. démonstration. 
Les vers sanserits et zends, dont nuus parlons, sont it syllabes comptees. comme les vers irlandais, mais les uns ont seizo. les autres quator\%e, ou deux fois sept syllabes. Séparés de celle sorte. ils le sont plus encore par lalliteration et la rime, essentielles aux rers irlandais, qui tirent leur origine plus probablement de la même source, d'ou dériva la rime et lalliteration dans la poésie européenne. Le vers long anglo-saxon et allemand n'a pas un nombre determine de syllabes, mais il contient l'alliteralion on la rime, pal' quoi il se détache nettement du vers sanscrit et zend, en se rapprochant du vers irlandais, arec lequel il n'est pas identique. Les vers saturnieus ne sont pas a syllabes comptèes non plus, el j'accepte l'opinion des grammairiens latins qui les regardaient comme des vers métriques, mais rudes, faits ál'imitation des vers grecs sans la connaissance de lois mètriques. L'hexametre enfin repose sur la notion du pied rythmique, notion qui est absolument absente de tous les vers précedenls. Ainsi disparait l'identité de formes, supposèes communes, et avec elle l'argument le plus solide en faveur de la probabilitè d'une poésie aryenne commune. Ajoutons encore que la haute antiquité attribuèe à l'ancienne poèsie de nos frères aryens orientaux n'est pas vérifièe.

Les savants allemands aiment $\dot{a}$ relier les anciens monuments de leur poèsie á une mytholngie originaire et commune $\dot{a}$ la race, dont les diverses nations aryennes conservent encore des souvenirs. On rencontre che\% tous ces peuples beaucoup de notions mythologiques semblables, mais il ne s'en suil pas qlielles soient toutes originairement communes. La terre considèrèe comme une vache, le ciel comme un taureau, telle est la conception mythologique fondamentale dans la Rig. $V e d a$, font l'Edda ne présente plus aucune trace. Quoj qu'en dise l'école de Berlin. MM. Bang et Bugge ${ }^{1}$ ont

1. Basa, Voluspa, 1880. - Btigr. Sturlien ̈̈ber die nordische Götter und IIeldensage, 1882. 
bien montré l'inlluence chrètienne dans le vénérable monument de la plus ancienne poésie scandinave.

Envisageant ce sujet á un point de vue plus général. nous pourrions croire que tout ce que l'Edda contient de primitif, de dérivé de la source commune, devrait se trouver aussi chez les peuples litou-slaves qui, plus proches du berceau commun, auraient dı̀ garder plus fidélement encore les traditions primitives. N'y trou. vant rien de semblable aux récits des anciennes poésies scanáinaves, nous sommes conduits à soupconner que ces derniers peuvent dériver d'un courant des traditions occidentales, qui, affaibli par la distance géographique, entraré de bonne heure par le clristianisme, n'a pas atteint l'Est de l'Europe.

De toutes les mythologies aryemnes, la mythologie grecque est la plus développée. Elle ne ressemble que parquelques traits bien faibles aux conceptions indigénes des peuples italiques. qui de leur côtẻ diffèrent notablement de celles des peuples scandinaves. Les diffẻrences $y$ sont bien plus grandes que les ressemblances et cela est important. Les idées mythologiques scandinaves et celles des Slaves sont disparates et cela ne nous étonne pas, mais nous sommes surpris du peu de res. semblance entre le ciel allemand et celui de l'Edda. Ce dernier se distingue jar les douze sieges et les douze dẻitès, en quoi il coïncide avec l'olympe gréco-romain, et comme il parait que l'idèe de douze dèités est sortie originairement de l'Égypte il s'en suit nécessairement. que les Scandinaves l'ont ernpruntèe aux traditions romaines. Les savants allemands ne mettront certainement pas en doute que Tacite ètait bien informe quand ll parle de Tuisco, de Munnus et de ses trois fils, or il faudra admettre conséquemment, qu'il n'a pas ėtè moins bien instruit lorsqu'il nous dit que le culte d'Hercule, de Mercure, de Mars, d'Isis et d'Vlysse ètait répandu en Allemagne. Linfluence romaine est donc également visible dans la mythologie scandinave, comme dans 
celle des Allemands, mais la tradition transmise aux premiers avait été plus savante et systèmatique, celle parvenue aux seconds plus sporadique et incohèrente.

Certains savants nous présentent l'époque primitive des peuples aryens comme un àge d'or sous le sceptre de Saturne, comme un ètat d'une félicitè idyllique, d'une sagesse simple mais profonde ${ }^{1}$. Il en est d'autres, qui le représentent comme un état d'une complète sauvagrerie, avec toutes les misères, toutes les cruautés qui

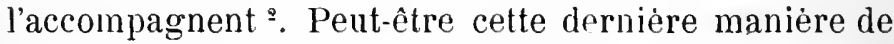
voir se rapproche-t-elle plus de la vérité, de même qu'elle saccorde mieux avec l'histoire. Un siecle avant notre ére, les Cimbres et les Teutons ne sentaient ni le dèsir, ni le besoin de courrir la nudité de leurs corps ; au temps de Tacile les femmes allemandes ne portaient pas de vêtements. Les historiens byzantins Procope et Theophylacte nous racontent que les Slaves, au sixième siècle encore, ètaient nus, sans expérience des armes ni de la guerre; Isidore de Séville ne nous fait pas un tableau flatteur des Francs : "Franci a feritate morum nuncupati putantur'; sunt enim in illis mores inconditi, naturalis ferocitas". Il faut se représenter un ètat de mœurs, d'habitudes. de connaissances correspondant à cette nudité, á cètte fèrocité tant de fois attestees par linistoire le ces peuples, á ce manque d'une vie domi. ciliee et en conclure qu'au temps de la communauté aryenne l'ètat des choses avait dî̀ ètre pire encore, et peu propre á l'invention et á la culture de ces doux arts que les Grecs appellaient musicaux.

Une autre idee préconcue entrave plus encore nos recherches. On veut croire que la poésie et les autres arts musicaux, c'est-ádire la musique et la danse.ont èté spontanèes et autochtones chez tous les peuples qui les

1. J. (ikmm. Gieschichte der dentschen Sprache. Pictet, Les origines indo-europeiennes.

?. V. Heнs, Verbreilung fler Culturpflanzen und Ilausthiere in linropa. 1877. 
possedent. Elles ont poussè sur le sol, oú on les trouve, comme pousse l'herbe, on ne sait comment, dit-on. Nais l'herbe ne pousse que sur un sol favorable; pour un grain qui germe, il en est des milliers qui meurent, et par combien d'époques la nature n'a-t-elle pas passé avant de produire des grains. Cette chose est certes plus facile á imaginer qu'elle ne l'est en réalité. Qu'est-ce que la poésie? Le reflet du monde dans une goulte de rosée, c'est-á-dire le reflet de la vie dans un fait. Il faut donc embrasser et la vie et les faits avant de faire de la poésie, il faut savoir placer un fait en rapport avec un sentiment, avec une pensée générale, il faut avoir beaucoup pensé, beaucoup senli. beaucoup vécu. En enmot, le sentiment poétique est le résultat d'une longue culture. Abordons encore le côtè positif:qu'est cequ'un vers? Un arrangement systematique des parties et des syllabes d'aprés certaines régles. Pour faire des vers il faut donc savoir distinguer les mots daus le langage, les syllabes dans les mots; il faut réflèchir, analyser. Quelque imparfait et rude que fùt le premier vers, il avait ètè précédè par ce moment analytique. Une chose rencontrée, faite par hasard. reste non trouvée, passe et périt si elle n'est pas saisie par la conscience, parce que c'est la pensèe consciente qui reconnait le principe, le pose, l’applique, le perfectionne. Or, oú nous rencontrons la réflexion, l'analyse et la pensée consciente, la spontanėité fait défaut. Le vers est un produit de la pensẻe, comme l'art tout entier, et, si le trait caractèristique de l'art consiste dans l'artificiel, il faut bien que cet èlément vive et agisse déjà dans les premiers mouvements, les premières manifestations de l'art.

Demandons á un homme instruit, mais qui n'a pas appris la musique, de nous chanter quelque chose! Je ne sais pas chanter, nous répondra-t-il. Chantez donc spontanément! Il pensera, et non sans raison, qu'on se moque de lui, ou qu'on n'est pas dans son bon sens. tellement la demande est ètrange et bizarre. Pour chanter 
il faut connaitre l'échelle musicale, qui est un systeme de sons. Ce système est artificiel. parce que la nature ne nous en offre nulle part le modèle. Il n'est pas non plus dèterminé par la structure de notre gosier: puisqu'il faut l'apprendre á force d'exercices mille fois rèpètès. Il n'est pas spontanè.

Les mêmes réflexions se présentent en ce qui concerne la danse, qui a pour base un composé de pas et de mouvements difficiles á apprendre, et plus encore à trouver. On peut parler, crier, hurler, courir, sauter d'une manière spontanée, mais non pas faire des vers, chanter ou danser. Outre leurs régles spéciales, les trois arts musicaux sont gouvernés par des lois rythmiques très difficiles à saisir: puisqu'il y a des peuples très cultivés qui ne sont pas arrivès á en acquèrir l'idée. Un point très important a noter c'est que la notion du rythme est inconnue dans la littėrature sanscrite.

J'insiste encore une fois sur la critique logique : la poèsie, la musique, la dlanse sont des arts; tous ces arts sont essentiellement artificiels aujourd'hui, et il faut bien que ce qui constitue leur caractère ait èté contenu dèjá dans leurs germes.

Passons à l'autochthonèite, - nous demandons pardon d’avoir forgé ce mot qui nous est nécessaire pour expliquer notre pensée,-c'est une afiaire d'amour-propre national.Chaque peuple se pique de posséder des arts issus de son esprit. Mais les faits y contredisent. Regardons la terre. les magnifiques dòmes romans dans la vallèe du Rhin, a Cologne, a Mayence, a Worms. à Spire : le nom indique la provenance de leur style. Regardons les superbes cathédrales gothiques dont s'est parée l'Allemagne: e'est Suger á Saint-I)enis qui en in venta la première construction.Ecoutons les profondes harmonies qui nous ravissent dans les neuvres de Beethoven, de Bach : elles sont basces sur les deux èchelles musicales modernes. dont la thèrie fut établie par Rameau. Parcourons les anciennes compositions de Zielenski, de Palestrina, de 
Goudimel, les mélodies de Gaucelm faidit: elles se fondent sur les échelles greçues. rendues obligatoires pour le monde chrètien par Grégoire le Grand. Considérons le vers le plus usité dans la poésie allemande: c'est un décasyllabe emprunté aux Anglais, qui ont imitè le décasyllabe francais. Analysons le vers principal dans la poèsie polonaise : c'est un vers de treize șllabes, calquè sur un vers rythmique latin. Voila notre autochthoneite, et si nous otions de la rie européenne tout entière, tout ce qui se ljase sur la tradition antique (y compris la tradition orientale amenée par le chrislianisme) et tout ce qui provient de linfluence romane, il n'en resterait que peu de chose.Qu'on me permette cette dernière assertion, sans mobliger i la prouver ici.

L'idée dont je viens d'indiquer le faible fondement. est très ètroitement lièe avec une autre, qui n'en est que la conséquence. Si les arts musicaux sont un produit spontané parmi le peuple, il s'en suit que la poésie, la musique et la danse populaires sont plus anciennes que la poésie, la musique et la danse artistique.Cette idée, il faut bien $y$ insister, est parfaitement incomnue des sarants anciens, qui cependant portaient un vif intèrèt à toutes les manifestations de la vie intellectuelle et qui connaissaient leur monde grec et romain ; elle est inconnue des chroniqueurs du moyen àge qui auraient pu ètre tèmoins de tous les emprunts faits de leur temps aux arts populaires; elle l'est ègalement des érudits des siècles passès. C'est un produit pur de la science moderne. Elle date de Herder ou plutôt de Percy lui-mème qui l’a déjả indiquèe dans son cẻlèbre recueil ${ }^{1}$. Sous l'impression de l'Ossianisme, il fait procéder les minstrels des anciens scaldes et des bardes. Mais il a puise les pieces de son recueil dans des manuscrits du dix-septième siècle et dans une collection dejá imprimèe avant lui, et non pas dans la tradition orale. Une grande partie de ces chants est d'origine purement littėraire, il $y$ en a

1. Reliques of ancient english Poetry. 176;.;. 
mème qui sont de traductions des romances espagnoles, d'autres encore qui ont des minstrels pour auteurs. Nous ferons remarquer que les minstrels ètaient tonsurés, qu'ils appartenaient aux ordres infërieurs de l'Eglise, qu'ils passaient par une école ${ }^{1}$.Il semble qu'ils étaient des " ministrants " à la messe. surtout aux messes chantées dans des églises de petites villes et villages qui ne possédaient pas d'orgues.Chanteurs et musiciens de profession, ils s'occupaient non seulement de l'art religieux, mais aussi de l'art profane. On peut les assimiler aux vagants, aux jongleurs. aux trouvères eux-mèmes. Le même art que les trouvères portaient dans les chàteaux, ceux-là le portaient aux foires et dans les rues des villes. Ils choisissaient des sujets qui pouvaient convenir au peuple, ils simplifièrent les formes et rendirent leur art populaire. C'est donc l'art du moyen àge popularisė qui se maintint parmi le peuple á travers les siècles de la Renaissance jusqu'á notre temps. La poésie de la Renaissance sur les hauteurs du Parnasse ne daignait pas descendre dans les basses rẻgions du peuple, elle ne savait pas l'intèresser à Jupiter, á Apollon et aux muses.

On sait quelle forte impulsion la poésie européenne avait reçue de la publication du recueil de Percy. Herder lui-mème se init à la recherche des chansons populaires, il publia "les Voix des peuples ", il inspira au jeune Gœthe le mème gouit pour ces productions, et fut suivi dans cette voie non seulement par les frères Grimm, mais directement ou indirectement par tous ces nombreux travailleurs qui s'occupent depuis de faire connaitre les rẻcits et les chants rẻpandus parmi les divers peuples. J'ai dit á dessein les récits, parce qu'on les considérait, il n'y a pas longtemps encore, comme des productions aussi bien spontanées et au-

?. V. l'étude sur la musique, au siècle de Saint-Louis, par M. II. Lavoix dans le "Recueil de motets français, 1882, vol. II." 
tochtones que les chansons, et cependant la plupart ont leur source dans la littérature sanscrite, source d'origine savante, puisqu'ils ont pour auteurs, d'après Burnouf et Benfey, des prètres bouddhistes; la voie par laquelle ils nous ont été transmis est savante aussi, marquée par les traductions en persan, en syrien, en arabe, en hébreu. en grec et en latin. La science ayant déjá réussi á tirer les récits de la nuit de la spontanéité, nous pouvons esperer que les chansons populaires sortiront aussi des ténèbres dans lesquelles l'hypothèse romantique les a plongèes. Placées sur le terrain de la tradition artistique, elles ne tarderont pas á nous livrer le secret de leur àge et de leur provenance.

Ces idées, à mon avis, sont fausses, et je leur reprocherais d'entraver les recherches litteraires. Peut-ètre n'ai-je pas encore suffisamment prouvé la thése que je soutiens, mais je continuerai ma démonstration en essayant de leur opposer des propositions tout à fait contraires, qui mériteraient peut-ètre plutòt le nom de principes.

Toute invention dans le domaine de l'art ou de la science, comme toute invention en génèral, me paraìt être toujours individuelle et personnelle, et procéder d'un esprit superieur en son genre à tous les autres, qui l'imitent ensuite. Je soutiens donc d'abord que chaque initiative est personnelle, et il pourrait sembler superflu de le vouloir prouver, tant cela est clair. Tout au contraire, on va jusqu'à prètendre que toutes les nouvelles idées sont le produit du peuple enıier, qu'avant d'entrer dans la littėralure, elles essaiment, bourdonnent dans l'air, en un mot, que tout le monde y participe et que les écrivains n'ont qu'á les bien énoncer. On òte aux esprits supérieurs le mérite de leurs veilles, du travail de leur pensée, pour le partager entre la foule qui ignore l'art difficile de la méditation.

Prenons un exemple: M. Taine vient d'énoncer des 
opinions nouvelles sur la Révolution française: est-ce qu'elles bourdomnaient dans l'air depuis longtemps, est-ce que la foule y arait songé? Le célèbre savant $y$ est parvenu a laide d'une nouvelle analyse des faits et d'une synthese également nouvelle. Seul de son opinion a l'heure de la publication de son ceurre, aujourd'hui il ne l'est plus probablement. Telle est toujours la relation cutre ta foule et lidec nouvelle. (niginairement sorties d'un esprit unique et peut-ètre solitaire, clies se propagent non seulement par les livres, mais encore par les journaux, par les liscours publics. par le théâtre; pen a peu elles simposent aux masses. Plus l'idèe est nouvelle,èlevèe, èloignée des idèes recues,plus difficilement elle se répandra et sera acceptéc: au contraire une idèe plus à la portée du public.c'est-i-dire moins èloignée des opinions établies, devient facilenent populaire.Il arrive alors qu'apres un certain temps un esprit infërieur la rencontre parmi la foule, et ignorant son origine, lui prête sa parole el sa plume, se fail le champion de celte idée trouvée parmi le peuple. C'est ainsi qu'en France nous voyons des écrivains attribuer au peuple des idées émises par Voltaire, par Diderol el par Rousseau.

Rien de plus rare qu'une nouvelle penseje. On pourrait en dire de même d'une nouvelle mèlodie, d'une nouvelle statue. d'une nouvelle facade. Partout nous trouvons des rèminiscences. Les wurres les plus indépendantes ne sont composées que d'èlements, de motifs connus. Une oouvre tonte nouvelle n'est qu'une nouvelle synthese, précede le plus souvent d'une analyse nouvelle; mais pour arriver à cette synthise ou à cette analyse, il faut connaitre toutes les syntheses et les ana. lyses dejja exécutèes, il faut connaitre ai fond le matèriel donné, le materiel des sons, des paroles, des pierres. C'est pourquoi une invention, chose possible en tous temps, n'est que rare, el toujours due a un esprit supérieur passionné pour la recherche, pour la méditalion. 
Les inventions modernes touchent $\dot{a}$ des choses déjà très spéciales, placées bien loin dans l’èchelle des formes; les inventions des temps passès étant plus simples n'en exigeaient pas moins d'efforts de la pensẻe et de la volonté, n'en ètaient pas moins difficiles á faire. La tradition grecque qui placait parmi les dieux les premiers inventeurs, ou qui attribuait les inventions aux dieux mèmes, nous est un vif témoignage de la reconnaissance de ce peuple unique envers ses bienfaiteur's et en même temps de sa conscience de la difficulté de chaque invention. Il faut donc regarder les premieres et les plus simples manifestalions de la poésie ou de la musique comme des inventions aussi ètonnantes et aussi rares que le sont aujourd'hui une tragédie ou une symphonie classiques. Si rudes que soient ces premières manifestations de l'art, conmme la prière des fieries Arvales, elles étaient dejaa des ouvres d'artistes sui generis, et le peuple d'alors les admirait autant qu'il admire aujourd'hui me ouvre de Victor Hugo.

si nous avons d'un côté les inventions d'un petit nombre d'esprits supẻrieurs, nous trouvons de l'autre cótè l'imitation de la multitude. L'imitation est cette forme du mouvement des esprits jar laquelle une sociètè donnée tend vers l'unitè. Très souvent néanmoins cette imitation produit une rupture, une discordance dans la société, parce qu'une assertion provoque une négation qui conduit de nonveau à une assertion plus contradictoire. Cette idée opposée a l'ètat donné des choses dispute la prédominance á lijèe régnante et rompt l'équilibre. Il surgit souvent une nouvelle idée intermédiaire, ou une autre encore plus opposée qui s'engagent toutes dans une lutte, chacune s'efforcant de gagner le plus d'adhèrents, c'est-i-dire d'imitateurs, chacune disputant a ses adversaires la domination des esprits.

Che\% l'homme la culture de l'esprit dèbute par l'imitation, nous la commencons etant enfants. imitant les HTHMES. 
mouvements, le langage, les mœurs de nos parents, de notre entoürage. Les parents, de leur còté, imitent le parler et les mœurs de la ville ou de la contrée qu'ils habitent, et quand ils ont la vue intellectuelle èlargie, c'est-à-dire quand ils sont instruits, ils imitent le langage et les mours de la capitale, de la classe élevée, de la littérature. C'est ainsi que les cours princières imposérent jadis leur langue et leurs mœurs à la capitale, qui de son côté fit rayonner son influence sur les centres provinciaux, imités à leur tour par les villes et les villages. Tout le monde sait que le dialecte de la capitale ou de la cour est devenu dans les États de l'Europe la langue du pays, au prẻjudice toujours croissant des dialeces locaux. L'autorité du Dictionnaire de l'Académie française n'est-elle pas fondée sur l'influence des esprits supèrieurs d'une part, sur l'imitation de l'autre?

L'imitation est la base de toute education, de toute instruction, de tout ajprentissage : c'est par elle que le progrès se propage et s'effectue ${ }^{1}$.

L'état actuel de la littérature et de tous les arts confirme d'une manière incontestable ce rapport entre les deux facteurs de la vie intellectuelle. Nous voyons partout des écoles qui se composent d'un maître inventeur et de disciples qui adoptent son principe, sa manière. II en était ainsi depuis des siècles. Mais les degrés de l'imitation sont très nombreux et diffèrents. Ils commencent par l'adhésion passive, et s'èlèvent jusqu'aux manifestations du plus haut talent. Quelquefois l'imitation produit une œuvre supérieure á l'original. Parmi de nombreux exemples, je ne citerai que le "Werther" de Gœthe, qui a fait école en France. oú on ne s'est pas aperçu d'abord que cette wuvre poétique était une imitation de la "Nouvelle Hélö̈se".

Je crois superflu d'insister davantage sur un principe

1 Cfr. M. Kawczroskr, Studien zur Jitteraturgeschichte des xvin ten Jahrhunderts, 1880.

G. Tardieu : Revue philosophique, 188. p. 489. 
aussi évident, et qui se confirme dans chaque individu, son langage, ses moeurs, sa tenue, ses règles de conduite, ses vêtements enfin.

Considèrons les conséquences. Si nous convenons que chaque invention est une wuvre individuelle, je veux dire exceptionnelle, artistiçue, résultant d'un grand $e^{f-}$ fort de la pensée et de la volontẻ, nous y trouverons une preuve de plus contre la géné:ation spontanée des arts musicaux parmi le peuple. Celui-ci n'ayant pu les inventer, comment expliquer qu'il les possède pourtant? Il les a acquis par imitation, et comme il s'ècoule toujours un temps assez long pour qu'une nouveautè parvienne jusqu'au peuple, il s'ensuit que les manifestations de la poésie, de la musique et de la danse populaires sont postérieures á la poésie, la musique et la danse artistisques. Cette assertion est dans un accord complet avec les faits historiques. Nulle part nous ne trouvons de monuments des arts musicaux populaires antérieurs aux arts proprement dits. Si on nous objecte que le peuple romain chantait et dansait dẻjá au septième, au huitième siécle, c'est qu'il n'avait pas encore oublié les danses et les chants que lui avait appris jadis la civilisation romaine. Ajoutons encore, que les commencements d'un art sont toujours aussi rudes, aussi informes que s'ils sortaient de l'esprit rustique, mais, qu'on ne s'y méprenne pas, ils sont l'œuvre des esprits les mieux douès de la nation á l'époque donnée.

Les forces agissantes dans l'univers comme dans la socièté sont toujours les mêmes. Pourquoi donc le peuple d'aujourd'hui n'invente-t-il rien? C'est parce qu'il n’a jamais rien inventé. Il n'est pas seulement capable d'améliorer la forme de sa charrue ou de sa voiture,dont il fait usage tous les jours. Mais d'un autre còlé le peuple est conservateur, il garde et conserve á travers des siècles ce qu'il a une fois appris et retenu. Les chants, qu il répete portent l'empreinte des siécles passés. Il paraît que ce fut au treizième, plus encore au quator- 
zième et au quinziẻme siécles que l'art des trouvères se répandit en France dans des cercles de plus en plus larges. Nous avons mentionné dèjả les jongleurs, les mėnestrels, les truands, les moines défroqués, qui le portèrent dans les cabarets, dans les foires. dans les fètes patronales. Parmi le peuple il se trouva des gens á l'esprit plus vif qui retinrent par cœur la mèlodie et les paroles; quelquefois mème ils parvinrent à substituer d'autres paroles à la mélodie donnée, ils ont pu arriver á une certaine labileté dans cet art imitatif et secondaire. C'ètaient surtout des organistes, des sacristains de la paroisse, liès en quelque manière à l'art savant; des musiciens de village qu'on peut regarder comme des successeurs des ménestrels; des mendiants ou des aveugles, qui passent toujours par un apprentis. sage, par une espèce d'école, c'ètaient enfin des gens qui avaient appris la musique, fût-ce á jouer du violon, du chalumeau, dela cornemuse. Nous voyons que les agents de l'art savant parmi le peuple sont très nombreux.

Je me suis efforcé d’éclaircir l'importance de l'imitation dans la sociètẻ humaine et sur cette base j'ai cherché á indiquer la relation qui existe entre l'art savant et l'art populaire,Or,ce mouvement imitatif ne se renferme pas dans les limites d'une nation ou d'un État, il les dépasse, il attire dans son courant les nations voisines qui les transmettent de plus en plus au loin. Il ne reste pas dans la sphère de l'inconscient, on s'y rend, on le suit de bonne volontè, on cherche á imiter les meilleurs exemples. Aujourd'hui on voit des manufacturiers aller faire leur apprentissage dans des pays ou leur profession se pratique d'une manière plus parfaite, on voit des savants, des artistes aller faire leurs ètudes dans des pays où la science et l'art fleurissent, on voit même des commissions officielles en royèes dans d'autres pays. pour y ètudier des améliorations spèciales. Comme les forces agissantes dans les sociètés humaines sont toujours les mêmes, il faut en conclure, que ce mourement 
imitatif ètait vif à l'époque la plus reculée, et que peutêtre il l'ètait mème plus qu'il ne l'est aujourd'hui. Il nous semble qu'un peuple sans culture propre mis en contact immèdiat avec une haute civilisation en devient nécessairement l'esclave. L'influence commence par l'adoption des outils, des ètoffes, des armes, des mœurs, des institutions, elle finit par l'adoption de la religion et de la langue même. Si donc les Croths, les Longobards, les Francs, quoique vainqueurs par les armes, finirent par se romaniser, nous pouvons en conclure qu'ils a vaient déjả auparavant épuisé toute l'échelle d'adoptions d'ordre infèrieur.

- Les influences dont je parle ici, s’effectuent par dela les frontières d'une manière pacifique, et l'exemple le plus marquant nous en est fourni par une race des plus hardies, des plus indépendantes, des plus violentes, je parle des Germains. Nous les voyons au temps de Bède et d'Aldhelme, de Raban Maur et de Walafrid Strabo s'exercer dans les hexamètres, les distiques ou les vers rythmiques latins, se servir de la langue latine même dans les lettres familières. On était èpris des livres antiques, qu'on allait chercher à Rome, qu'on recopiait assidûment. On imposait la langue latine au peuple même et il fallut un ordre exprès de Charlemagne pour qu'on se mît à enseigner les priéres et la confession de la foi dans la langue nationale.

Nous avons un précieux témoignagne historique d'Otfrid de Wissembourg, l'èlève de Raban Maurá Fulda, qui ètant en relation avec des moines distingués de StGall, avec l'èvêque de Bâle, l'archevèque de Mayence, avec l'empereur lui-même, á qui il adressa la dédicace de son poème, a vait pu être très bien instruit sur l'ètat de lettres en Allemagne au neuvième siècle. Voici ce qu'il en dit: "lingua enim haec (thiutisca) velut agrestis habetur, dum a propriis NEC ScRIPTURA, NEG ARTE ALIQUA ULLIS EST TEMPORIBUS EXPOLITA. Quippe qui nec historias suopum antecessoin ut multae gentes cete- 
rae, commendant memoriae,nec eorum gesta vel vitam ornant dignitatis amore, Quod si ruro contigit aliarum gentium lingua, id est latinorum vel graecorum potius explanant. Cavent aliarum et deformitatem non verecundant suarum. Stupent in aliis vel litterula parua artem transgredi et pene propria lingua vitium generat per singula verba. Res mira tam magnos viros prudentia deditos, cautela praecipuos, agilitate suffultos, sapientia latos, sunctitate praeclaros, cunctu haec in alienae linguae gloriam transferre et usum scripturae in propria lingua non habere" .

Ces paroles étonneront plus d'un lecteur. Nous connaissons par cour, pour les avoir vues citées mille fois, les paroles de Tacite et d'Eginhard, qui ont fait croître dans l'histoire litteraire toute une forèt de vieux chants èpiques germaniques. Cette forêt épaisse entourait tout l'horizon, masquait toute perspective. C'ètait un enchantement, comme le romantisme en connaissait beaucoup. On voyait des chansons dans tout historien, dans tout chroniqueur. Mais un enchantement produit par des paroles peut être levé par des paroles, et je crois que celles d'Otfrid en ont bien la force. Leur souffle puissant renverse la futaie, èclaircit l'horizon, ouvre une longue perspective, au bout de laquelle nous verrons peut-être - l'antiquité classique.

En examinant les paroles de Tacite et d'Eginhard, on pourrait remarquer que le premier n'a jamais vu l'Allemagne de ses propres yeux, que le second s'exprime d'une maniere obscure et, dans quelque mesure, contradictoire, mais je n̈iusisterai pas sur ces objections. $\mathrm{Au}$ temps de Tacite mème, les Allemands ètaient déjá depuis assez longtemps en contact avec la culture gréco-romaine, soit directement. soit par l'interıédiaire des Gaulois, pour avoir apluris quelque chose. $\Lambda$ dmettons donc l'existence de chants allemands antérieurs à Otfrid, je crois toutefois pouvoir affirmer denx choses; d'abord, que ces chants avaient dù ètre très insignifiants puis 
qu'ils avaient disparu complètement vers le milieu du neuvième siècle. L'assertion d'Otfrid, l'Allemand le mieux instruit et le plus patriote de son temps, est sur cette question trop précise pour être révoquée en doute. Elle se trouve dans une lettre adressée à l'archevêque de Mayence, et n'aurait pas manqué de provoquer un démenti si elle avait ètẻ en contradiction avec la vérité. Ai-je besoin d'ajouter encore expressèment qu'on doit regarder les monuments les plus anciens de la poésie allemande comme postérieurs à Otfrid, et qu'ils ne peuvent plus dès lors relever de la tradition d'une poésie germanique qui n'existait pas?

Mais envisagée à ce point de vue l'épopée française, que plusieurs savants trés distingués ont placée sur le terrain des traditions épiques des Allemands, se trouverait privée de sa base ? Mais non, car c'est ici que l'antiquité, entrevue au fond de la perspective, vient à notre secours. Je ne peux indiquerque les points les plus saillants: Est-ce que l'Enéide. la traduction latine de l'Iliade et les nombreuses épopées latines de Stace, de Lucain, de Claudien ne nous fournissent pas une base beaucoup plus solide et plus réelle que les chants germaniques qui nous avaient été imposés ? Ces poèmes n'ont-ils pas été lus et étudiés a videment au moyen âge ? Ne présentent-ils pas de nombreux exemples de combats singuliers,ce thème préféré dans les épopées de cette époque? Dans les vastes pays soumis á l'influence de la culture grecque ne continuait-on pas á clianter des morceaux détachés de l'Iliade, ou de l'Odyssée ? Est-ce que l'usage introduit par Pindare de chanter des louanges personnelles, l'usage des odes, des panégyriques y fut perdu complètement?

Fixons encore quelques points historiques: La noblesse du moyen àge n'est à mon avis qu'une copie re nouvelée de la noblesse romaine, l'ordo equester. Les généalogies qu'on dressait avec tant d'efforts dans les châteaux et dans les épopées du moyen âge ont leurs 
modẻes dans les arbres généalogiques de la noblesse romaine. Les traits a l'appui sont inépuisables, mais comme il faut savoil se borner je ne ferai plus qu'une remarque un peu plus gènèrale. L'ètat primitif des peuples germaniques et slaves consistait, d'après les indications des historiens, dans une parfaite égalité de l'ètat. mais c'ètait une ègalitè de bas ètage. L'organisalion de ces sociètès et des États germaniques et slaves s'est effectuée sur les modèles romains et byzanlins. L'idée de l'empire romain est l'idée fondamentale du moyan âge, et cela nous indique assez clairement ou ètait le centre. quel étaitl'idèal de ces époques, et n'entrevoit-on pas la nécessitẻ logique d'une concordance intime entre les traits spéciaux et le trait principal? L'idèe dominante n'a-t-elle pas dû déterminer l'organisation du corps entier ? Mais la vie sociale, les esprits, les tendances avaient changé; beaucoup d'intérêts particuliers inconnus de l'antiquité, ou qu'elle n'admettait pas, se firent jour. Le sentiment chrétien remplaçant l'élément païen dans toutes les institutions changea leur caractère. Il en fut de même dans la littėrature; ne pouvant plus s'inspirer des aventures d'Enée ou du combal des sept frères contre Thèbes, l'épopée chrètienne devint nécessaire et la France fut son berceau. Elle $y$ fut créée par ceux qui avaient le plus vif intérêt et presque le devoir de la substituer à l'épopée paienne, et qui ètaient assez instruits pour y réussir. Mais dans les deux cas ce fut la tradition artistique ancienne qui servit de base.

Qu'il me soit permis de prèsenter encore quelques remarques sur la littérature allemande considèrée au point de vue comparatif. Cette litterature est, on le sait, une des plus riches et des plus belles, son histoire cependant est pénétrée du faux principe de spontanèite. L'amour propre national est un manvais conseiller dans la science, aussi voyons-nous son histoire de plus en plus défigurée. Les suites en sont fàcheuses: d'abord nous devenous incapables de bien 
comprendre cette littėrature, et je crois qu'en faire comprendre l'objet est le but principal de toute science. En outre,l'influence de la manière de voir allemande réagit fortement sur l'histoire litteraire des autres peuples, qui s'efforcent chacun de prouver une spontanéité propre dans des produits oú on ne la rencontre pas.On conviendra qu'une pareille méthode défigure la science et rend l'explication des faits impossible.

Si on examine les traits les plus gènéraux de l'histoire de la littérature allemande, on peut dire qu'Otfrid, son vrai fondateur. la plaça sur le terrain de l'imitation des œu vres latines, et elle occupa cette place pendant toute la période de l'ancien haut-allemand.L'Allemagne,c'est incontestable,a donc devancélaFrance et lesautres pays romans dans la création des œuvres littéraires en langue nationale, et cependant telle n'était pas l'opinion d'otfrid, qui donne les Kriachi et les Romani comme modèles á ses compatriotes.Comment accorder cette contradiction? C'est que la littérature latine était toujours dans cette période la littérature nationale des pays romans. Il faut insister sur ce fait, important non seulement pour l'histoire littèraire. mais aussi bien pour l'histoire des langues romanes.

La période du moyen haut-allemand se caractérise par l'imitation de la littérature française et provençale. Les sujets, les genres et les formes de la lyrique allemande sont à peu près les mêmes que dans la lyrique franco-provençale, qui est incontestablement antérieure à l'autre (quoique une influence directe de la lyrique latine du moyen âge sur les origines de la lyrique allemande ne soit pas impossible). Presque tous les sujets et toutes les formes de la poésie èpique française: les romans de l'antiquité, les romans de la Table ronde, les romans d'aventures, les romans allégoriques se retrouvent dans des traductions ou dans des imitations allemandes. J'ai dit á tort : toutes les formes, parce qu'il faut en excepter la plus importante: les chansons de geste. 
Mais en est-il vraiment ainsi? Les célèbres chansons dont on s'inspirait non seulement en Italie, en Espagne, mais dans les pays scandinaves, l'Islande, cette terre lointaine, baignée de froides ondes, les chansons dont l'ècho lointain se fraya un chemin jusque dans les récits populaires de la Russie (Bœuves d'Hanstone) et qui, à mon avis, transmises par Venise, par la Dalmatie, par Raguse jusqu'aux Serbes y ont fait naître des chansons analogues, seraient-elles restées sans influence en Allemagne? Je ne le crois pas. Mais voici les Nibelungen, Gudrun, Ravenschlacht, Alpharts Tod qui se prêtent volontiers à une comparaison, qui veulent occuper une place dans les cadres psychologiques et historiques de la littérature générale de l'Europe. La chanson de Roland fut tellement goùtée en Allemagne qu'on en fit une traduction latine et allemande, cependant on s'aperçut bientôt que les chansons de geste, c'est-à-dire chansons d'histoire, de hauts faits accomplis par la nation, devraient avoir pour sujet les légendes, les traditions nationales historiques. On en chercha et on réussit à crèer une imposante poésie èpique.

Un des plus intéressants sujets d'investigation serait d'indiquer les èlèments dont ces traditions se composent. D'abord Sigfrid, qui tue le dragon, enlève un trésor, exécute de grands exploits, fait un voyage outre mer, etqui devenu le fiancé, presque l'époux de Brunhild la quitte pour épouser Kriemhild. L'abandonnée, qui est une sorcière, se venge. Malgré nous, le souvenir de Jason s'impose á notre esprit : lui aussi fait un voyage outre mer, tue un dragon, gardien du trésor, abandonne Médée, fille du roi, mais sorcière,pour épouser Créüse. L'abandonnée se venge. Le fond de ces deux fables est donc identique et n'allons pas penser que des récits tellement semblables puissent naître dans différents pays, chez différentes nations d'une manière indépendante. Cette disposition ne sera jamais admise par quiconque sait combien d'impressions, combien de réminiscences, de 
circonstances propices il faut pour qu'un récit pareil puisse se former. Est-il possible que toutes ces circonstances se reproduisent, d'une manière presque identique, sur un autre endroit de la terre et dans un état social différent et inférieur? Nous trouvons cependant dans le personnage de Sigfrid des traits empruntés à Achille et á Persée, et cela seul suffirait pour nous avertir que ce hèros n'est pas une personnification mythologique originale, mais qu'il est le produit d'une contamination de récits ayant pour objet les héros antiques. Ces récits oraux se sont confondus, démembrés, en passant de bouche en bouche chez des gens peu instruits, se sont assimilès aux notions déjá établies. pour devenir plus com préhensibles et vraisemblables pour les auditeurs, se sont joints enfin aux traditions vraiment historiques. Plus tard les poètes les ont ramenés à une unité épique, ils les ont enrichis de motifs et même de personnages empruntés aux chansons de geste françaises '.

C'est ainsi que l'épopée allemande et l'épopée slave entrent sans difficultè et même avec grâce dans l'unité de la littérature européenne. Je me permettrai d'ajouter encore une remarque sur leur forme: le vers employé dans les chansons serbes est de dix syllabes;le vers des Nibelungen montre, selon Fr. Diez, une forte ressemblance avec l'alexandrin. Nous ne pouvons faire mieux que laisser la parole au docte professeur : "Dic Aehnlichkeit swischen dem Alexandriner und unscrem Nibelungenvers ist allerdings überraschend, allein grade hicr vüre zu bedenken, ob die deutsche Form, als die jüngëre, ihre Ausbildung nicht der fronzösischen verdanken.Donc, selon lui,le vers allemand ètant plus récent peut dériver du vers français. Je ne me permettrai pas de le contredire.

Durant les siècles suivants la littérature allemande

1 Comparez p. ex. Guillaume d'Orange devenu moine et le moine Ilsan dans l'épopée allemande. 
resta intimement lièeả la littérature française. Les charmantes productions de la Renaissance italienne y furent introduites de bonne heure, c'est vrai, le thèâtre anglais $y$ fut bien accueilli par les classes populaires, mais les règles de la poètique française gouvernaient exclusivement le Parnasse allemand. Au dix-huitième siècle nous voyons encore Gottsched s'efforcer,mais sans succès, de renouveler et de renforcer linfluence française. Guidèe et inspirée par Lessing, par Herder plus tard, l'Allemagne travailla $\dot{a}$ une poétique nouvelle, sur la base de laquelle elle arriva á une littèrature indépendante et brillante créèe par Gothe, Schiller et l'ècole romantique. Ce fut au tour de la France á subir l'influence allemande. Aujourd'hui, cependant, l'influence française a repris le dessus dans le domaine du théâtre et du roman, les deux formes quon cultive le plus de notre temps.

Il serait superflu de vouloir montrer ici linfluence que la littèrature française et provençale exerça en Italie, en Espagne et en Portugal, ou celle réciproque qu'elle subit de la part de la littérature italienne et de la littérature espagnole. Ces faits sont connus et il suffit de les avoir mentionnès. Il en est de même de la littèrature anglaise, qui si riche et si belle qu'elle soit, est loin d'être indépendante du courant général de la littèrature europeenne et des influences particulières. Nous voyous l'esprit le plus puissant dans cetfe littèrature, IV. Shakespeare, se servir des motifs du théâtre espagnol, nous voyons Walter Scott inspire pour toute sa vie par une cuvre de Grothe, Byron enfin se modeler, lui-même et ses hẻros, sur Faust et Réné. De tous ces faits, que le lecteur voudra bien complèter lui-même,je crois pouvoir tirer un principe qui s'y manifeste clairement, á savoir : que les influences historiques sont plus fortes que les données naturelles et propres de chaque peuple.

Ce principe se heurte malheureusement a la théorie inoncẻe par un des plus célèhres savants contemporains, 
par M. Taine. Il attribue á chaque littérature un développement spontané, autochtone, qu'il fait dèpendre de la race, de la situation géographique, du milieu et du moment Il donne ainsi au romantique "Volksgeist" une interprètation réaliste. faisant agir ces facteurs d'une manière mécanique. Or, nous venons de voir que les faits ne confirment pas cette thèorie. Elle vient á l'appui des opinions qui diminuent le rôle et l'importance de la littèrature française dans l'histoire littėraire de l'Europe, elle brise la relation qui existe entre la culture moderne et celle de l'antiquilè, elle n'est applicable enfin que dans des cas exceptionnels. L'ancienne Égypte seule, peut-être, s'est développée suivant ses conditions naturelles, mais la Grèce, qui datait le commencement de sa culture de l'arrivée des hôtes ètrangers, de Danaüs, Kekrops, Kadmus et Pelops; mais l'Inde, qui avec l'ècriture sémitique a dù recevoir quelques idées, et qui semble avoir subi une forte influence grecque après l'invasion d'Alexandre; mais la Chine même, envahie par le Bouddhisme indien, tous ces pays se dèrobent $\dot{a}$ la théorie exposee par l'illustre savant.

Ils s'y soustraient, mais pas entièrement, parce qu'aucun peuple aryen n'accepte jamais complètement les idées, les motifs, les sujets qu'il reçoit des autres peuples. On prend les traits qu'on saisit le mieux, on les rapproche des notions dejả reçues. Ainsi transiormèes, les idées étrangères deviennent presque nationales. Les trois Parques, créėes par le gènie grec, sont devenues trois feees chez les peuples romains, elles se sont déguisees en trois filles-cygnes chez les Allemands. Chaque nation peut s'intéresser à ses sujets, à ses personnages poètiques sans se soucier de leur acte de naissance, mais la science a besoin de rechercher leur origine pour les comprendre. Il est incontestable que la diversité des races dépend de celle des conditions naturelles; il semble que cette cause aurait pu produire un effet semblable dans les littératures, ce qui n'eut pas lieu.Dans lunité 
actuelle, dans l'identité générale des formes et des sujets que nous présentent les littératures de toutes les nations européennes, cette diversité autochtonique ne se manifeste que par une différence dans le choix, dans le traitement, dans une préférence qu'on donne plutôt à tels sujets ou á telles formes quaux autres.

En voulant accorder avec la théorie de M. Taine les principes que nous exposons ici, on pourrait les classer dans la catégorie du milieu. Mais en les y plaçant nous changerions leur caractere, car les influences historiques agissent de loin par l'intermédiaire de personnages exceptionnels, avides de progrès, tandis que M. Taine entend par le milieu l'entourage le plus proche et permanent, dont l'expression est la société donnée. Ici surgit une question en elle-même très importante: si les esprits se modifient sous l'influence du milieu, comment ce milieu lui-même se modifie-t-il? La socièté une fois etablie sur certains principes a une tendance à se maintenir dans cet ètat. Prenons les paysans, c'est-à-dire la grande majorité de chaque nation, nous les voyons persister volontiers dans des idées et dans des formes une fois reçues. S'ils parviennent à les changer, c'est sous l'influence d'une littérature populaire, crẻèe à dessein, sous l'influence des journaux, des lois nouvelles, des agitateurs politiques ou sociaux qui colportent les idees d'un J.-J. Rousseau, d'un Proudhon ou d'un Saint-Simon. Donc la modification de la société est due à l'influence des hommes dominants, exceptionnels. Il nous resterait encore à expliquer comment les esprits exceptionnels parviennent à des conceptions, à des pensèes nouvelles, souvent mauvaises, mais cette question m'entraînerait encore plus loin et je n'y entrerai pas ici, ayant d'ailleurs indiqué déjả plus haut mon opinion.

Je crois donc pouvoir mantenir le principe que les influences historiques sont plus fortes que les conditions naturelles. Il faudrait pourtant l'élargir encore. Les mêmes forces sociales agissant toujours, nous pou- 
vons admettre que des influences semblables d'une nation civilisée sur des nations barbares eurent lieu avant leur contact immédiat, dont nous parlent les histoires, qu'il y a eu des influences prèhistoriques. Il est á supposer que les peuples germaniques et slaves avant de prendre du service dans les legions romaines, avant de connaître la culture antique, en reçurent quelques notions par les marchands grecs ou italiques. Les objets nombreux de cette provenance trouvés dans les tombes prẻhistoriques, armes, bijoux, monnaies, nous prouvent suffisamment que les relations commerciales avaient étè très fréquentes à cette èpoque. Il est fort probable. qu'outre des objets de trafic, ils recurent par cette voie des notions de culte, d'industrie et d'art même. C'est ainsi que les arts utiles et les beaux arts, les traditions. les contes, les moeurs et les cultes se répandent d'un seul centre enfermant dans leurs cercles, toujours s'élargissant, des pays très reculés.

Dans cette sorte d'influence, qui s'exerce aujourd'hui encore par le commerce, par les voyages d'exploration il y a une forme particulière à observer. Les explorateurs abordent et parcourent de préférence des pays inconnus, situés loin de la sphère naturelle de l'action civilisatrice de leur pays natal. Ils $\mathrm{y}$ laissent partout quelque souvenir de leur passage, quelques impressions, quelques exemples qu'on retient. La migration des idées ressemble donc á la migration des plantes, que les oiseaux sèment à de grandes distances. Les oiseaux, cependant, sont bornès dans leurs voyages par les climats diffèrents, obstacle que les idèes seules surmontent.

Arrivé au terme de mes questions préliminaires, je me vois en opposition avec des savants cèlèbres aux plus justes titres. Mes opinions auront donc bien de la peine à se faire accepter, d'autant plus qu'on ne les jugera pas démontrées. Mais elles ne peuvent l'ètre que par l'application. Si les faits s'élucident mieux à l'aide 
de ces principes, c'est alors qu'ils seront vérifiès, démontrès. Ils demandent donc d'être appliqués a mille questions spéciales. Je les ai tirès des faits, je les ai apercus en considèrant l'histoire litteraire des peuples europèens dans son ensemble, et je crois que ce point de vue est juste. J'ai tàché d'èclaircir le passè par le présent en les reliant par des lois psychologiques qui persistent. Chaque recherche conduite sans ègard aux idees préconcues contribuera à les confirmer, je le crois, et j'espère aussi que l'essai suivant leur fournira un appui. Pour offrir plus de prise á la critique j'ai donnẻ la forme de thèses anx titres de mes chapitres. C'est peut-être du choc des opinions contraires que jaillira l'étincelle de la vèrité,et c'est à ce but que tend le présent travail.

'Qu'il me soit permis en terminant de m'adresser au savant dont les paroles m'ont encouragé à soumettre mon travail au jugement de la science française. En analysant la dernière dissertation écrite sur l'origine du décasyllabe francais, M. Gaston Paris a dit qu'il faut avant tout chercher le principe sur lequel la rythmique du moyen àge s'est établie. Je crois $y$ voir déjá quelque hésitation en face des opinions exposées d'une facon si sèduisante dans la lettre adressèe à M. Léon Gautier. La larg'eur d'esprit et l'amour de la vèritè du cèlèbre prufesseur ètant connus, j'ose le prier de vouloir bien prendre sous sa bienveillante protection cet essai, ou j'expose une nouvelle méthode destinée à expliquer les phẻnomènes en litige. 
Le vers est issu de la proposition et le vers rythmique est né du vers syllabique.

Je voudrais me placer dès le commencement sur le terrain de la tradition établie, mais malheureusement nous n'en avons pas sur l'origine du rythme. Ce défaut est la cause de cette tendance au vague ou nous sommes conduits par les hypothèses courantes. Je veux l'èviter autant que possible, tout en n'abandonnant pas la solution du problème qui nous attire par la difficultė qu'il présente, et par le mystere dont il est enveloppé.La solution n'en sera peut-ètre pas impossible à trouver,pourvu qu'on ne la cherche pas ou elle n'est point. Je crois donc que ce n'est pas d'un sentiment gènèral pour le rythme que celui-ci est né, mais d'une observation sensible qui s'est gènèralisée. Je crois que ce n'est pas partout quon est arrivè a la faire, mais bien dans un cas particulier. Le rythme a ètè une découverte ou plutôt une invention, et il faut qu'elle ait ète faite comme toutes les inventions. Il me parait probable enfin que cette observation sensible et particulière a èté faite sur l'objet même où elle s'est dèveloppée le plus et le plus clairement. a savoir sur le vers.

L'origine du vers ètant aussi obscure que l'origine du rythme, nous sommes en présence d'un nouveau problème. Vouloir tirer le vers de la musique c'est se charger d'un probleme de plus. C'est sortir du crépuscule pour se plonger dans la nuit sombre, parce que notre ignorance sur l'origine de la musique est encore RYTHMES. 
plus grande que sur celle du vers. La musique consistait originairement dans le chant, la musique instrumentale originaire ne faisait que répèter le chant en l'accompagnant, or, ce qu'on chantait c'étaient des vers. Loin de l'avoir engendrée, la phrase musicale s'est modelée sur lui.Nous verrons ce point démontré plus tard; en attendant, remarquons qu'aujourd'hui encore c'est sur des paroles que le musicien compose sa mélodie et non pas le contraire. Je pense donc que la même relation entre la mélodie et la parole a dù toujours exister, parce que les relations psychologiques ne changent pas.

Aprés nous être dèfendus de la siréne musicale qui a dejjà entraîné tant d'autres dans un précipice scientifique, nous pouvons marcher avec plus de sùreté sur le terrain des vers. La tradition littėraire nous a légué des vers métriques, des vers syllabiques et des vers irréguliers dont les auteurs ne savaient pas garder un nombre de syllabes déterminé. Nous nous trou vons donc en présence de formes de diffẻrents degrès de perfection. La forme la plus parfaite doit être jugée postérieureà celles qui le sont moins. La littérature grecque ne nous a malheureusement pas conservè les formes qui doivent avoir précédé l'invention des vers métriques, et qui n'y manquaient pas probablement. Créés avant l'usage de l'ècriture, ces vers imparfaits furent abandonnès, ou refaits après l'invention des vers plus artistiques. Il faudra donc suppléer á ce défaut par des formes qu'on trouve chez d'autres peuples aryens, qui tous ont parcouru des voies, je ne dirai pas pareilles, mais analogues vers le perfectionnement, de manière que leurs vers, quoique plus récents quant à la date, ne laissent pas de représenter des degrẻs archaïques quant à la pensée, quant à l'art qui s'y manifestent. Ces raisons psychologiques nous permettent donc de placer les vers irréguliers au premier degré sur l'échelle de la perfection, les vers syllabiques au second, les vers mètriques au troisième.

Il s'agit maintenant de trouver l'origine du vers irré- 
gulier. Celui-lá n’a pu sortir que de sa matiére, de la langue même, de cette forme de la langue qui lui ressemble le plus, c'est-á-dire de la proposition. En effet, le parallélisme entre les vers et les propositions est manifeste dans les monuments les plus anciens de toutes les littératures. Ce parallèlisme se maintient non seulement dans les vers syllabiques, mais encore dans beaucoup de vers métriques, dans les ver's gnomiques par exemple. L'enjambement est un produit d'une époque postérieure oú la mesure du vers fut fixée à ce point qu'on cherchait á éviter sa monotonie par un retour á l'allure naturelle du langage. L'exemple de Malherbe nous prouve cependant que la tendance vers un parallèlisme entre les vers et les membres syntactiques est profondėment enracinée en nous et nous est presque naturelle.

Il s'agit á présent de trouver la force, la cause première (n'en déplaise aux mécanistes) qui a amené la conversion de la proposition en vers. Selon Aristote, la cause première des phénoménes est en même temps leur but, et la philosophie n'a pas trouvé de véritè plus profonde. Le but des premiers vers ètait donc leur cause première et leur force motrice, qui n'a pu être que psychologique. Il faudrait donc savoir ce qu'ètaient les premiers vers. Si nous nous en rapportons aux documents les plus anciens qui nous sont parvenus, ils consistaient en prières et en formules magiques qui s'adressaient aux noms divins.Or, la chose n'était pas facile. Il fallait connaître les dieux, il fallait savoir auquel demander telle chose, en quels termes il le fallait faire pour que l'offrande, la prière fussent acceptées, et que le suppliant ne s'attirât pas la colère de ces ètres puissants qui disposaient du tonnerre et d'autres armes terribles, car les dieux de ces temps-lá étaient capricieux.

Il faut aussi ne pas oublier qu'on attribuait jadis aux paroles une singuliere puissance, une force magique. Cela se manifeste dans les formules d'incantations que 
nous connaissons. Les paroles de l'incantation possèdaient la force de faire disparaître le mal, d'attirer le bien, n'ètait-il pas indispensable qu'elles fussent disposées avec le plus grand soin?

C'ètait l'affaire, la science du prêtre. Le peuple ne connaissait pas bien les dieux, ni la manière de leur parler. La parole du peuple était alor's aussi indolente que sa pensẻe, et sa pensée l'ètait tout comme elle l'est de nos jours. Ces choses-là lui étaient ètrangères, il ne les méditait pas, et ceux-lá même2 qui, dans le peuple, s'y trouvaient portès devenaient précisẻment enchanteurs, prêtres: gens dominant par la parole. Nous voyons encore dans l'Hliade et dans l'Odyssèe, combien l'on y estime le rare don du juste et clair langage, nous voyons comme les poètes tragiques grees développent les harangues de leurs principaux personnages.

On peut avec assez de probabilitė considerer les formules d'imprécation comme les premiers efforts faits pour ordonner la pensée et la langue en les formes réflèchies, et en cela tant soit peu artistiques. Leur caractère primitif est d'ailleurs attesté par leur forme rudimentaire. Nous y voyons le frère arvale implorer d'abord les lares. réputés les dieux les plus proches et les plus propices aux hommes : "c nos Lases jurate ". S'ètant assurè de leur protection. il osait ensuite invoquer le redoutable Mars: "Neve lueve Mama" sins incu"rere in pleoris ", etc. '. Quoique probablement postèrieure, quant a la date, aux hymnes grecs, la prière arvale ne laisse pas de représenter un ètat de formes antérieur, au point de vue psychologique, à tous les autres monuments aryens connus. La prière conservèe par Caton² est dẻjá plus èloquente, plus développée, mais en vain voudrions-nous diviser l'une on l'autre en ver's

I Jordan, Kritische Beiträge. efr. Westphat, Veber die Forn der ältesten römischen l'oesic.

: De re rustica l.fl. chr. Westriat. l.e. 
plus ou moins réguliers, ce n'est qu'en propositions qu'elles se laissent dèmembrer.

Le second degrẻ de composition de ce genre approchera d'une certaine ègalité dans la longueur des propositions, l'inègalité trop apparente trahissant une nègligence qui ne pouvait que nuire à leur effet.Je citerai comme exemple une des formules d'incantation connue sous le nom de Merseburger Zaubersprï̈che'.

Phol ende Uodan ruoron zi holza

Nombre de mots Nombre do accentués: syllabes :

Du uuart demo Balderers volon sin fuozbirenkit $: ; . \quad$ l.

Thù biguolen Sinthgunt, Sunna era suister $\quad 5$.

Thù biguolen Friia, Volla era suister 12.

Thù biguolen Uuodan, sô hê uuola conda. 6.

En voici la traduction : Apollon et Odin se rendirent au bois:- lá se démit le pied du poulain de Balder :alors l'enchanta Sinthgunt et Sunna, sa sœur; - alors l'enchanta Friia et Volla, sa soeur; - alors l'enchanta Odin, qui savait très bien le faire. - Comme nous le voyons par le dernier vers, l'art de charmer y est considèré comme une science que personne ne possèdait au même degrè qu'Odin lui-même. Cette science se révèle, entre autres signes, par un arrangement plus soigneux des paroles. Chaque vers y contient une proposition achevée. L'auteur de ce charme, connaissant Apollon?, possédait probablement quelque notion des vers latins, ce qui l'a aidè á donner à ses propositions une longueur à peu près égale. Il les agrémente même d'allitèrations. Ainsi, quoique ces vers ne proviennent pas de l'époque antérieure al vers métrique, cquant a la date, ils sont le produit d'un ètat de l'esprit correspondant à une époque très reculèe chez les Grecs.

Au degré suivant les vers devraient s'approcher plus

1 Muellenhorf und Scherer, Denkmäler deutscher Poesie und Prosa aus dem VIII-XII Jhdt.

- C'est ainsi que les philologues allemands interprètent le nom phol. 


\section{$-38-$}

encore de cette égalité, qui est la condition de tout art. Cette égalisation avait pu consister dans un nombre égal de mots, qui sont de beaucoup plus faciles à distinguer dans la ṕroposition que les syllabes. Rappelons-nous qu'on liait primitivement tous les mots dans l'écriture, ne s'arrêtant qu'à la fin de la proposition. On les liait, parce qu'on ne savait pas les distinguer. Les vers aux mots comptès auraient donc été un perfectionnement considérable.

Je pourrais me permettre de citer quelques vers saturniens comme exemple de vers règlès d'après le nombre de mots, d'autant plus que MM. Keller et Thurneysen ont émis une opinion semblable qui a èté approuvée par M. Westphal.
Malum dabunt Metelli
Duello magno dirimendo
Naevio poetae : regibus subigendis :
Magnum numerum triumphat hostibus devictis etc.

Il est toutefois un point très important dans la théorie des savants cités ci-dessus que je naccepte pas. Ils prennent le nombre d'accents pour base, moi le nombre de mots; on verra plus loin pourquoi l'accent n'a jamais pu servir de base rythmique dans le vers de cette èpoque.

Le vers saturnien va nous arrêter encore un moment. Un bon nombre de philologues très savants persistent a le considèrer comme un vers métrique, mais quelle que soit la règle métrique qu'ils lui imposent, il y a toujours plus d'exceptions que d'applications régulieres. Il se peut pourtant que les saturniens ne soient qu'une vague imitation de vers grecs. Les grammairiens latins, très experts en fait de métrique: Caesius Bassus, Terentianus Maurus, Marius Victorinus, $A$. Fortunatianus nous l'attestent d'une manière positive. Peut-être que les poètes latins de l'époque saturnienne tâchaient, dans leur ignorance des pieds métriques, de sapprocher du vers metrique par le nombre de mots. Cela est d'autant plus possible. que nous retrouvons la 
même tendance, quelques siècles plus tard,chez Virgilius Maro, le représentant de l'école des rhéteurs toulousains à la fin du VI ${ }^{\bullet}$ siècle. Voici ce que nous lisons dans sa troisieme lettre : dz metris" : Prosa quidem sunt per brevitatem, sicuti in Enea lectum sit:

Phoebus surgit, caelum scandit, Polo claret, cunctis paret.

Hi duo versus octo metra habent; primum enim metrum PHOEBUS est, secundum suRGIT, et sic per caetera phona . Il regarde donc les huit mots, dont se composent les deux vers, comme autant de membres, qu'il appelle mètres. Il est vrai qu'il compte aussi les syllabes en les appelant pieds : "et ita duo hi collecti sedecim pedibus fulciuntur" ", mais nous verrons plus loin qu'il construit encore d'autres vers sur la base du nombre de mots. Cette base rudimentaire est donc admissible, el c'est ce qu'il nous fallait prouver.

Pour arriver aux vers parisyllabiques il fallait savoir compter les syllabes. Si aisé que cela nous paraisse aujourd'hui il n'en était pas ainsi à ces époques. Nos sens, notre esprit n'arrivent à distinguer les éléments d'une donnée naturelle qu'ả force d'exercices, par une expérience varièe, et grâce au perfectionnement des sens et de l'esprit même. Otfrid, le fameux auteur du premier poème allemand, qui avait passé par une bonne école latine à Fulda, trouva néanmoins d'insurmontables diffi. cultès à la composition des vers allemands syllabiques. Il nous raconte ses soucis dans un passage de sa lettre adressée á Luitbert, archevêque de Nayence, passage instructif à plus d'un ègard. Nous y apprenons en même temps que les difficultès qui s'opposent á l'application des lettres aux sons d'une langue non encore écrite et barbare, sont des plus embarrassantes. Voici ce qu'il en dit: "huius enim linguce (theotiscae)barbaries, ut est

1 Axgelo Mai, Auct. class., V. 
inculta et indisciplinabilis atque insueta capi regulawi freno grammaticae artis, sic etiam in multis dictis scripto est propter litteranum aut congeriem aut incognitam sonoritatem difficilis. Nam interdum tria u u u ut puto, quaerit in sono. Priores duo consonantes, ut mihi videtur, tertium vocali sono manente. Interdum vero nec A, nec $\mathrm{E}$, nec I, nec $\mathrm{U}$, vocalium sonos praecavere potui, ibi y graecum mihi videbatur ascribi. Et etiam hoc elementum lingua haec horrescit interdum, nulli se caracteri aliquotiens in quodam sono, nisi difficile, iungens. Patitur quoque metaplasmi figuram nimium, non tamen assidue, quam doctorcs grammatice artis rocant synalipham, et hoc nisi legentes praevideant, rationis dicta deformius sonant. Litteras interdunt scriptione seruantes, interdum vero ebraicae linguae more uitantes quibus ipsas litteras ratione synaliphac in lineis, in quidam dicunt.penitus amittere et transilive moris habetur... Hic saepius I et o cactereque similiter cum illo vocales simul inveniuntur inscriptae, interdum in sono divisae vocales manentes. interdum coniunctae, priore transeunte in con. sonantium potestatcm". On excusera la longueur de ce passage en raison de l'importance capitale du tèmoignage qu'il apporte sur le moment oú une langue est sur le point d'être rendue pour la première fois par des lettres. Il n'existe nulle part un autre document semblable.Nous y voyons qu'il n'y a qu'un esprit disciplinè dèjà par une langue littèraire qui soit capable d'adapter des lettres aux sons d'une langue barbare. C'est ainsi que Cyrille, le premier écrivain slave, ètait un savant grec, c'est ainsi qu'Ulfilas. le traducteur de la Bible dans la langue gothique, ètait de race grecque et nourri de la science occidentale.

Avant d'ajouter quelques observations sur les vers d'Otfrid, j'en donnerai un échantillon : 
Nombre de syllabes:

$\begin{array}{ll}\text { Uuas líuto fílu in flìzé, } & 8 . \\ \text { In mánagemo ágaléizé, , } & 9 . \\ \text { Sie thaz in scríp gilileiptîn, } & \mathbf{7} . \\ \text { Thaz se íro namon breitîn ; } & \mathbf{8 .} \\ \text { In buáchon mán gimeintí } & 7 . \\ \text { Thio íro chúanheiti. } & \mathbf{7}\end{array}$

Lauteur lui-même ne dit sur la forme de ses vers que les paroles suirantes: "Yon quo series scriptionis huius metrica sit subtilitate constricta, sed scema omoeoteleaton assidue querit". Il pensait donc aux vers métriques, mais il ne se tenait pas a leur forme exacte; il cherchait assidûment la rime.

Quelle était donc la forme de laqquelle Otfrid voulait s'approcher ? Les vers riment par paires, on pourrait les regarder comme des vers brefs et les écrire comme je l'ai fait ici. C'est suivre l'opinion de M. Bartsch qui incline á $\mathrm{y}$ voir une imitation du dimetre iambique. La philologie allemande, en gènéral, maintient toujours la doctrine de Lachmann pour qui les vers d'Otfrid étaient des vers longs "Langzeilen" avec quatre accents de chaque côté de la césure. Il voulait les rapprocher ainsi des vers longs allemands et anglo saxons a allitération, $y$ voyant un vers germanique prẻhistorique. Je crois qu'il a vait raison, mais seulement en partie. Ce sont des vers long's. Leur ressemblance avec les vers allemands et saxons a allitération est évidente, mais ni les uns ni les autres ne sont prèhistoriques. Examinons d'abord les accents : Lachmann en a placé huit dans chaque vers long; je les ai marquès dans les vers cités ci-dessus. Deux de ces accents tombent d'après les règles du fondateur de la critique littéraire allemande sur la rime, c'est-á-dire sur des syllabes toujours atones dans Otfrid, ils ne comptent donc pas, n'ètant ni accents, ni ictus.

Les trois qui nous restent dans chaque hémistiche ne se placent pas arec facilité dans chaque vers. Il y a chez Otfrid des hemistiches qui ne comptent que cinq sylla- 
bes, dont quatre sont accentuées. Il y en a qui ne consistent qu'en un seul mot. souvent même non composé, qui toutefois est chargé de quatre accents par Lachmann, En voici quelques exemples tirès du premier livre d'Otfrid :

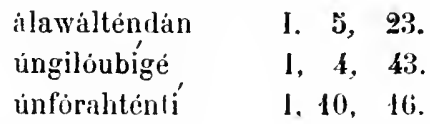

J'ajoute quelques exemples ou l'hèm istiche ne se compose que de quatre syllabes :

\begin{tabular}{|c|}
\hline fúazfállóntí, \\
\hline máhtig druihtín \\
\hline
\end{tabular}

C'est une ètrange manière d'accentuer, qui n'est ni antique, ni moderne, et qui ne suit ni les règles de la langue, ni celles d'une versification rythmique raisonnable. La rythmique basée sur un tel mode d'accentuation ne peut être elle-même qu'ètrange, j'ose le dire.C'est pourtant de lá qu'est sortie la théorie d'une rythmique fondée sur l'accent, qu'on pourrait appeler prèhistorique,et qu'on applique aujourd'hui non seulement à la versification du moyen âge, mais aux vers saturniens, aux vers aryens prèhistoriques en gènèral ${ }^{1}$ et même aux vers sémitiques. Lachmann y fut entraîné par les signes d'accents quon trouve dans les manuscrits du poème d'Otfrid, et qu'on suppose avoir èté placés par l'auteur lui-même. Mais les accents d'Otfrid ne s'accordent nullement avec les règles de Lachmann. Ils sont destinès à prèvenir une contraction inadmissible, un déplacement des accents dans la prononciation, dans la lecture, le manuscrit presentant une "scriptio continua". Souvenonsnous de la plainte d'Otfrid :"Propria lingua vitium generat pene per singula verba". Il est certain, qu'Otfrid

${ }^{1}$ Usener, Altgriechischer Versbau, 1887, p. 68. 
lui-même ne pensait pas à une rythmique fondée sur l'accent, et il serait très étonné de voir Lachmann lui attribuer une douzaine de règles accento-quantitatives, dans lesquelles l'accentuation naturelle de la langue est fortement violée. Il faut que je le répète encore ici, en renvoyant le lecteur á un des chapitres suivants: l'accent n'a pas pu servir de base rythmique au temps d'Otfrid.

Le moine de Wissembourg a dès labord renoncè à toute subtilité métrique : "Non quo series scriptionis huius metrica sit subtilitate constricta, sed scema omoeoteleuton assidue querit. . dit-il. il ne cherche que la rime, et il est très probable qu'il a suivi. quoique de loin. quelque modèle latin que nous aimerions connaitre. M.Bartsch penche pour le limètre iambique, ce qui semblerait admissible si une assez forte difficultè ne s'y opposait, á savoir, que les dimètres n'avaient pasencore au neuvième siècle la rime constante et obligatoire ${ }^{\text {, }}$ tandis que les hexamètres furent dotès de la rime intérieure d'assez bonne heure. Citons la définition de l'homoeoteleuton donnèe parBède: "Homoeoteleuton. id est similis terminatio, dicitur quotiens media et postrema versus, sive sententiue simili syllaba finiuntur.., Hac figura ct poetac et oratores saepe utuntur. poetae hoc modo:

Pervia divisi piatuerunt caerula ponti.

L'auteur anglo-saxon déclare donc que l'homoeoteleuton se rapporte surtout á la consonance finale avec la consonance du milieu du vers ou de la proposition, d'où je conclus qu'otfrid imitait les hexamètres léonins, mais sans aucune autre règle que la rime intérieure et finale, la tàche qu'il s'imposa n'ayant pas été moins lourde pour cela. Cela explique peut-être la variabilité du nombre de syllabes dans ses vers et ses hémistiches.

Dans le passage sur Otfrid, qui précéde, j’ai fait entrer

1 Voy. cependant Boucherie, Mèlanges latins et bas-latins. 
quelques questions secondaires que jaurais mieux fait d'omettre ici pour m'en occuper plus tard, mais craignant de ne pas y arri rer, j'ai mieux aimé m'arrêter sur ma route que de les passer sous silence. J'ai compté sur l'indulgence du lecteur, dont je n'abuserai plus.

Les poètes allemands qui imitèrent le vers octosyllabique des romans francais ne parvinrent pas a donner à leurs vers un nombre de syllabes dèterminé. Cela les gênait trop probablement. En roici la règle exprimée par un rimeur du quatorzieme siecle ':

Uuch ich diss getichniss t'inı

Uef die zal der silben zùne.

Sechse. sibene, achte. nùne.

Il rime son ècrit,dit-il, sur le nombre des syllabes,dix, six, sept, huit ou neuf. Le seul rythme qu'on donnait à ces ver's consistait donc dans la rime.

Je crois que ce degrè inférieur de composition du vers est suffisamment éclairci, et nous pouvons passer au degrè suivant ou les vers sont dejá ramenès á un nombre de syllabes dèterminé. Il me paraît hors de doute que cela a ètè un pas vers la perfection, très important et difficile à faire. Aussi les mêmes vers allemands, dont nous parlions tout à l'heure, n'y furent portés qu'au seizième sieccle. Il serait superflu d'ajouter que d'autres nations atteignilent i cette perfection de bien meilleure heure.

Le chemin que nous avons parcouru est assez considerable. De la forme la plus rudimentaire, qui ne se distinguait en rien de la proposition, nous sommes dejjà arrivé aux vers tout á fait réguliers. Cette dérivation se présente presque comme naturelle et la seule possible. Nous pourons nėanmoins l'appuyer de la grande autorité de Quintilien. qui paraît avoir eu une idée semblable sur l'origine des vers,quand il dit: "Sicutpoëma nemo dubitaverit imperito quidam initio fusum, et

1 Nicol.ues rox Jeroscun, Reimchronik. 294-96. ef. $247-255$. 
similiter decurrentium spatioram obsereatione esse generatum '...."

Mais nous ne sommes pas encore arrives aux vers rythmiques. Souvenons-nous, pour nous en approcher, combien ètait fin le sentiment que les peuples antiques possédaient de la durée des syllabes. "In versu quidem. tota theatra exclamant, si fuit una syllaba ant bre vior aut longior". Le public ne connaissait pas les règles de la quan tite : Tamen omnium longitudinum et brevi tatum in sonis indicium ipsa natura in anibus nostris deposuit ". Vuila ce qu'atteste Cicéron ", parlant dupublic romain. Les Grecs y ètaient plus sensibles encore d'aprés le tèmoignage de Denys d'Halicarnasse ${ }^{3}$. L'alphabet sanscrit marque chaque voyelle longue et brève de signes diffèrents, l'alphabet grec fait la même distinction pour les sons $e$ et $o$; les Romains tenterent d'introduire dans leur orthographe un signe de longueur (apex) et quoique cette tentative nait pas réussi. nous savons néanmoins que la diffẻrence entre les voyelles longues et bréves ètait trés marquée dans la prononciation romaine.

Supposons maintenant qu'i une époque oú on ètait déjá très exercè dans l'art de compter les syllabes du rers, un esprit inquiet et avide de perfection ait rencontré par hasard un vers compose tout entier de syllabes longues. Cela eût dû le choquer, parce qu'un tel vers paraissait a l'oreille plus long que les autres et, $\dot{a}$ cette èpoque on saisissait les vers presque exclusivement par l'ouïe. Cette réflexion, que nous supposons avoir été faite á un moment oú la longueur et la brièveté des syllabes ètaient encore très accusées, ne doit pas être jugée improbable, puisqu'elle fut réellement faite et énoncèe beaucoup plus tard, alor's que cette qualitėdu langage n'è-

${ }^{1}$ De oratoria institutione; I. IX, c. IV.

2 Orator, 5 l.

${ }^{3}$ De comp. verborum, XI. 72.75. 
tait plus également apparente. Nous la trouvons dans Las Flors del gay saber: Quar si tu pauzas un bordo d'aytals sillabas o dictios retardivas (l'auteur parle de syllabes longues par nature ou par position) et aprop aquel un autre de planas, la us seia vistz plus loncs que l'autres oa vesetz ayssi:

l'hilips es hels reys, casts, francs, pros.

Anı cor humil e piatos.

Et en ayssi vezetz que fan aspra sonoritat entre lor e retardo la votz et la pronunciatio en tan que fan dessemblar lo compas dels bordos per la plus longa demora quom fay en la una que en l'autre. C'est ainsi qu'à des époques diffèrentes peuvent se rencontrer sur le même sujet les mêmes réflexions.

Un vers qui. par accident ne contiendrait que des syllabes brèves, aurait dù faire une impression tout á fait contraire. Le pas qui nous sépare encore d'une alternance réguliére des syllabes longues et bréves n'était plus difficile á faire pour un esprit sagace et créateur. Il pouvait espérer qu'un hymne composé de cette manière plairait infiniment mieux á Zeus, et á tous les dieux, que les autres construits d'une façon plus négligèe.

En vérité, force nous est, á nous-même, de trouver belle l'impression que produit cette alternance régulière des syllabes longues et bréves. Nous y voyons cette ègalité des parties qui semble constituer la condition primitive de tout art, et en outre une configuration de ces parties qui forme le trait caractėristique á chacune d'elles. Ce que nous appelons rythme se rèvéle plutôt dans l'alternance régulière de syllabes longues et brèves, c'est-á-dire dans la configuration de ces parties que dans leur égalitè. Mais le rythme ne consiste-t-il que dans celte ègalitè et cette alternance?

Il ressort asse $z$ clairement de ce que j'ai avancẻ dans les questions prèliminaires que je suis disposé á regar-

1 Ed. Gatiex-Arollt, I, 64. 
der la notion du rythme comme un produit de l'esprit grec, puisqu'elle ne se retrouve pas même dans la littérature sanscrite, si célèbre par ses grammairiens d'une sagacité peu commune. Ce sont aussi les Grecs qui créerent tout un șrsteme rythmique et le portèrent á un développement qui n'a jamais èté surpassė depuis. Toutes les nations modernes ne possedent que le mot grec pour une idée, qu'elles ont puisée á la mème source. Cherchons donc avant tout quelle notion possédait ce peuple unique touchant ce point de lart.

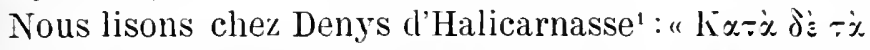

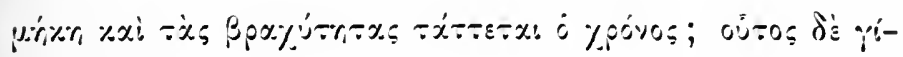

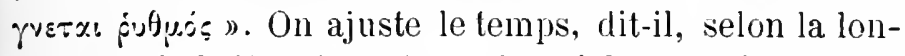
gueur et la brièveté, et c'est cela qui donne naissance au rythme. La définition donnèe par Phaedrus et rappor-

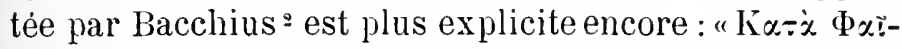

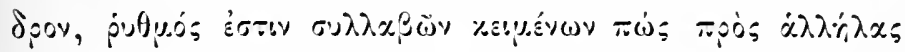

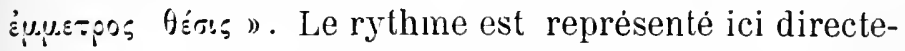
ment comme l'alternance réglée des syllabes longues et brèves, et ce qui est plus remarquable: Phaedrus parait n'avoir connu que le rythme syllabique. La définition que nous donne Aristide Quint. ${ }^{3}$ s'accorde avec les précédentes et surtout avec celle de Deny's d'Halicarnas-

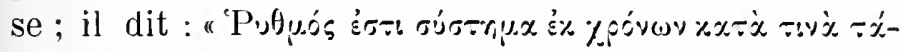

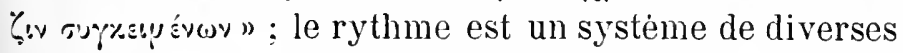
durées de temps, mises dans un certain ordre. Voilá ce que nous trouvons dans toutes les définitions du rythme que nous a léguées l'antiquitè. Partout on le représente comme un système, nous pourrions dire comme une alternance des temps ou des syllabes longs et brefs. On y parle de temps ou de syllabes; le dernier cas est rare et nous serons obligés plus tard de rechercher la cause de cette intéressante distinction.

1 De admirabili vi dic. Demost, c. 48.

2 Ed. Meiвом, p. 22.

3 Ed. Меiвом, p. 31. 
Arrivés au vers rythmique. apres être sortis de la proposition, nous rejoignons de nouveau Quintilien, qui termine d'une manière remarquable l'énonciation dẻjà citèe plus lant : "Sicut poema nemo dubitaterit imperito quidam initio fusum, et similiter decurentium spatiorum observationo osse generatum - mox in co repertos pedes". En trouvant le pied on a trouvè le rythme, car le rythme est donné par le pied : "Idcm. vero pedem et rhythmum voco". dit Denys d'Halicarnasse '.

Nous pourrions encore toucher ici a une question,á savoir quel pied rythmique a èté remarquéle premier. Selon la tradition grecque, qui regardait l'hexamètre comme le mètre le plus ancien $\%$. ce fut le pied dactylique, mais en vèrité il n'en a pu être ainsi. Le vers syllabique une fois admis comme condition psychologique indispensable pour la création du vers rythmique, le dactyle perd sa propriète. parce qu'il est susceptible d'ètre contracté en un spondèe déjá fréquent dans Homère. Il se montre donc un peu éloignè du principe syllabique et doit céder sa prioritè au trochaïque ou iambique, qui admet une concordance plus constante avec le nombre exigé de syllabes. Supposons que ce soit le pied trochaïque; on trouva alors le pied ïambique par l'inversion du trochee, puis le dactyle par l'elargissement du trochèe, l'anapeste par linversion du dactyle, etc. Toutefois je ne tiens que faiblement a cette supposition, qui n'est pas d'accord avec la tradition grecque; en la présentant je ne voulais que placer la création de divers genres des pieds rythmiques sur le terrain de l'art et de l'invention consciente. Mais j'ai le droit d'in. sister davantage sur ce fait, que ni la rythmique grecque, ni celle des Romains n'admettaient de rythme continuel en pyrrhiques, en tribraques ou en procé-

1 De comp. verborum, 219

2 Christ, Metrik, I. p. 30 \&. 
leusmatiques. En furent également exclus les spondèes, les molosses, en un mot. tous les pieds qui ne contenaient pas l'alternance des syllabes longues et bréves. Il faut donc bien que le rythme classique se caractérise surtout par cette alternance. Nous y avons une égalisation des parties et en même temps une configuration de ces parties, configuration caractéristicue pour cet art spécial. Y entre-t-il encore d'autres éléments. comme on le soutient généralement? Le rythme antique en avaitil besoin? Ce sont autant de questions que nous allons examiner dans les chapitres suivants. 
Le mètre n'était originairement qu'une mesure, un terme fixe du rythme.

Une des plus graves erreurs de la philologie moderne consiste à chercher pour la métrique ancienne un autre principe que pour sa rythmique. Une suite déterminée de pieds ou de groupes de syllabes longues et brèves, voilá un mètre. dont le rythme est formé par l'ictus, qui marque le temps fort de chaque pied, son arsis, dit-on. Nous venons de voir dans le chapitre précédent, que ce qu'on suppose être essentiel au mètre. l'avait été plutôt au rythme. C'était bien la rythmique antique qui avait pour principe la quantité de syllabes, l'alternance des syllabes longues et bréves. Il nous faut donc examiner maintenant ce qu'est le mètre et le rôle que remplissait l'ictus dans la métrique ou dans la rythmique ancienne.

Le pied appartient aussi bien à la métrique qu'á la rythmique, mais pour parler plus exactement. il nap. partient proprement qu'à la rythmique.

Denys d'Halicarnasse nous a dit déjà : "Idem vero pedem et rhythmum voco ". "Pes igiturest pars totius rhythmi, per quam totum percipimus ", dit Aristide Quint.'. "Pes sine rythmo esse non potest", c'est-à-dire, sans l'alternance des syllabes longues et brèves, enseigne Marius Victorinus ?.

Le caractére du mètre s'accuse par son nom; le mètre

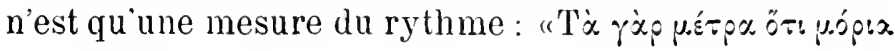

'Ed. Meib., p. 34.

2 Gram. latini, ed. Kell, VI, p. 374. 


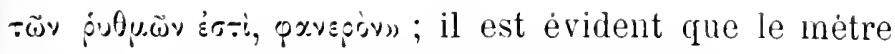
n'est qu'une partie du rythme, dit Aristote'.

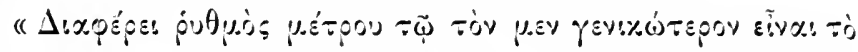

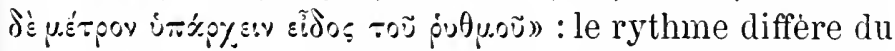
mètre en ce que le premier est le générateur du genre dont le second n'est que l'espèce, dit Suidas `.

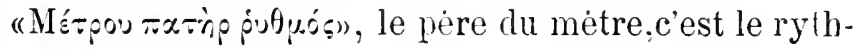
me, dit Longin ${ }^{3}$.

"Metrum, systema ad longitudinem mediocrem. diferre a rhythmo, ut a toto partem; sectionem enim rhythmi metrum dicunt ", dit Aristide Quint. ${ }^{4}$.

"Rhythmis libera spatia, metris finita sunt, et his certae clausulae, illi quo modo coeperant, currunt usque ad metabolen, id est, transitum in aliud genus rythmin, dit Quintilien ". Le sens de cette proposition est qu'un métre contient toujours un nombre déterminé de pieds, tandis que le rythme. fondé sur le même pied, peut dépasser ce nombre á volonté jusqu'a ce qu'il se change en un rythme fonde sur un autre pied.

"Nihil est enim inter rhythmon et metron nisi quod rhythmos est metrum fluens, metrum autem sit rhythmos clausus", dit Charisius ${ }^{6}$.

"Vides, dit Saint-Augustin s'adressant à son èléve ', quam recte utrunque nomen his rebus sit impositum; nam quoniam illud pedibus certis provolvitur, recte appellatus est rhythmus, id est numerus; sed quia ipsa provolutio non habet modum, nec statutum est in quoto pede finis aliquis emineat, propter mullam mensuram continuation is non debuit metrum vocari. Hoc autem utrumque habuit, itaque non solum me-

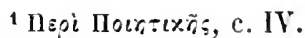

- Vincent, Notices et extr. des manusc., p. 198.

${ }^{3}$ Fragm. III.

4 Ed. Meib. p. 49.

Inst. or., IX., c. IV. rec. HALM, p. 178.

6 Gram. lat. I., p. 289.

- De Musica, III, Patrologia, t. XXXII. 
trum propter insignem finem, sed ctian rhythmus est propter pedum rationabilem connexionem. "Nous voyons dans chaque mètre un enchainement raisonnè de pieds, or c'est bien ce qu'il tient de la rythmique, tandis qu'il n'est mètre que "propter insignem finem".

Citons encore Diomède ': "Distat enim metrum a rhythmo, quod metrum certa qualitate ac numero syllabarum tempormimque finitur. certisque pedibus constat ac clauditur, rhythmus autem temporum ac syllabarum pedumque congruentia infinitum multiplicatur ac proftuit."

La même doctrine nous est présentée dans les Fragmenta Parisiana : "Dicimus autem rhythmum esse, ubi tantum legitimi pedes sunt e mullo modo certo fine; metrum esse, ubi pedes legitimi certo fine coercentur.

Ce n'est pas sans raison que j'ai réuni ces témoignages. D'abord ils ont plus de force que les suppositions des philologues, puis leur unanimité résout la question d'une manière décisive : il n'existe pas de différence de principe entre le metre et le rythme, au contraire, le inètre n'est ici que ce qu'il est ailleurs, une mesure, une certaine coupure. Tous les caractères que les philologues attribuent généralement à la métrique sont précisément ceux qui appartiennent á la rythmique.

Exposer la théorie entiére sur le rythme, comme nous la trouvons dans Aristide Quint, par exemple, sur le $\%$ póvos, les pieds et les différents genres de leur $\delta: x p o p \dot{x}$ :

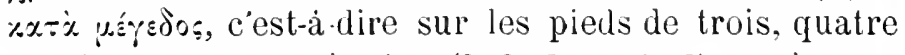

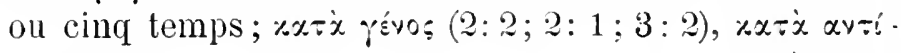

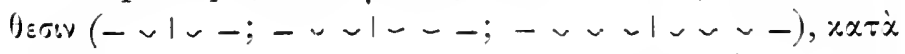

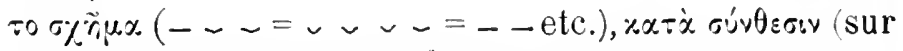

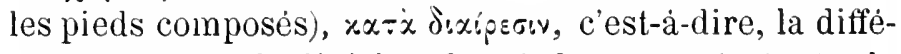
rente manière de division des pieds composés, tout cela

1 Gram.Jat., I, p.474.

*Gram. lat., Vi, p. 631 . 
n'entre pas dans le cadre du présent travail et peut être supposé connu '. On voit qu'il ne s'agit ici que de prèciser la vraie relation entre le rythme et le métre. Les anciens semblent s'étre représenté le rythme comme un long ruban, ou une chaîne composée d'anneaux égaux. c'està-dire de pieds rythmiques ègaux, et le mètre comme une partie déterminée de cette chaîne. Mais cette manière de voir n'est qu'une généralisation théorique postérieure. Le rythme est le genre dont les différents métres ne sont que des espéces: toutefois ce n'est pas le ruban rythmique qu'on inventa le premier, mais plutot le mètre fourni par le vers syllabique qui lui avait servi de base, et dans lequel on a remarqué, pour la premiére fois, des pieds rythmiques. Supposé que ce pied ait été le pied iambique, on s'était construit une chaîne d'iambes dont on a pu couper six membres ou un senaire, quatre membres ou un dimètre. trois et demi ou un dimètre catalectique, et ainsi de suite.

En réfléchissant sur la forme du mètre ou du vers le plus ancien, nous nous trouvons en présence d'une théorie qui rattache le vers originaire á la longueur d'une haleine, et qui cherche ainsi la résolution d'un problème historique sur le terrain physiologique ${ }^{2}$. Nous acceptons volontiers qu'aucun vers ne doit dépasser la longueur d'une respiration, mais cette condition laisse l'étendue du vers encore bien incertaine. L'hendécasyllabe, aussi bien que le senaire ou le tétramètre y trouvent leur place. Mais auquel donc de ces vers donner avec certitude la premiére place? M. Becq de Fouquières veut que ce soit l'alexandrin français, parce qu'il répond exactement á la condition respiratoire. Nous. qui nous tenons surtout á la tradition historique, nous n'avons à choisir qu'entre le senaire. le tétramétre ou l'octonaire et l'hendécasyllabe. Le dernier, qui est apparemment plus récent que les autres peut ètre exclu dès l'abord. il ne reste donc

1 Christ, Metrik.

- Beco ue Focquieres, Traité général de versification frangaise. 
que le senaire et le tétramètre (l'octonaire). Tous les deux remplissent assez bien la longueur d'une respiration, et si l'un la remplit plus complètement, l'autre pourrait être regardé comme plus commode á réciter. Ce principe ne nous explique donc rien.

Quel est donc le vers primitif ? Les anciens semblent opter pour le senaire, á en juger d'après les paroles suivantes de Terentianus Maurus ${ }^{1}$.

Hexametros tradit genitos duo prima retustas;

Herous ille est, hunc vocant iambicum,

Nam pedibus senis constare ridemus utrumque.

Il est intéressant de voir l'hexamètre envisagé ici comme un senaire. En véritè, il me parait possible que l'hexamètre ait pu se former sur un senaire trochaïque, dont il garde encore le dernier pied et la césure principale, analogue à celle du senaire iambique. C'est peutêtre, pour avoir èté transformé en senaire dactylique, qu'il disparut lui-même de la versification grécoromaine.

Mais la césure des deux senaires qui se trouve au milieu d'un pied me paraît être plus artificielle, et par cela même plus récente. Celle du tetramétre, qui se trouve, à la fois, à la fin du pied et du mot, peut pour cette raison étre considérée comme plus naturelle, comme primitive. Elle se rapproche davantage de la construction naturelle de la proposition dont nous tirons l'origine du vers en général. La proposition se divise naturellement en deux membres: le sujet avec ses compléments et le prédicat avec les siens; aussi n'y a.t-il pas de vers qui contienne plus de deux cola:

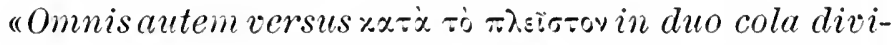
ditur, dit Marius Victorinus ${ }^{2}$. Mais il y a des propositions qui ne sont pas assez pleines pour être divisées

1 Gram. lat., VI, p. 372.

2 Gram. lat. VI, p. 5\%. 
en membres, ainsi $y$ a-t-il des vers sans césure. Cette analogie, sans être décisive, accuse pourtant une ressemblance assez étroite entre les propositions et les vers, pour qu'on soit logiquement forcé de regarder les vers comme des propositions ramenées á l'égalitè de mesure.

Considérant la rythmique comme appartenant à un autre ordre de phénoménes que la mètrique, la philologie exigeait un principe distinct pour la rythmique. Ce principe, on déclara l'avoir trouvé dans l'ictus. On en assigna un á chaque arsis (c'est ainsi, au lieu de l'appeler thesis) du pied métrique. On lui trouva un caractére semblable à l'accent naturel du langage, selon l'expression de M. Christ qui, lui même, si discret qu'il soit, n'a pas su se défendre de tomber dans l'erreur génèralement reçue. Il nous enseigne : "Der künstliche Versictus war gewiss auch bei den Griechen mit dem natürlichen Accent der gewöhnlichen Rede verwandt" '. Nous allons voir qu'il n'en ètait pas ainsi. La thesis ètait génèralement formée par une syllabe longue, et ressortait par elle-même assez distinctement, pour n'avoir pas besoin d'un renforcement iclique qui eut rendu sa prononciation désagréable et rude.

Ce qui importe, c'est que les anciens eux mêmes ne disent rien d'un ictus vocal. Les nombreuses définitions du rythme que nous avons rapportées n'en contiennent aucun indice. Mais comme c'est dans l'arsis qu'on le suppose contenu, il nous faut donc examiner ce qui en est. Nous lisons dans Bacchius jun. ${ }^{2}$ : "Quam dicimus esse arsin, sive elevationem? cum pes est sublatus, ubi incedere voluerimus; quam positionem, sive thesin? cum est depositus. La même définition se retrouve dans presque tous les rythmiciens de l'antiquitè, qui tous rapportent les mots techniques: arsis et thesis au mouvement

Metrik, p. う̌.

2 Мегвом, p. 23. 
du pied ou du doigl avec lequel on battait la mesure. Nous y retrouvons même le mot ictus, mais avec un rapport direct au même mouvement du pied ou du doigt. Terentianus Maurus explique : "Pollicis sonore vel plausu pedi discriminare qui docent artem so. lent".Quintilien dit bien arant lui: "Et pedum et digitorum IGTU intervalla signant'. Les expressions : "Bxiver o ó pupos, scanditu».percutitu»" se rapportent uniquement au mouvement des pieds ou des doigts. Cette signification de larsis fut reconnue déjả au commencement du siècle dernier par Capperonnier, professeur de littérature grecque à Paris. Voici en quels termes il en parle dans son excellente et vraiment savante èdition de Quintilien : Ex quibus patet inv äpoเv apud rhythmicos usurpari de pedis manusve sublatione in moderandis musicac numcris (vulgo : en battant la mesure) non autem. de vocis ipsius elatione, ut multi recentioni perpcram explicamut ${ }^{\circ}$. Or il me paraît inadmissible de faire exécuter aux anciens par la bouche ,e qu'ils faisaient avec le pied.

Les productions choriques surtout exigeaient un fort battement de la mesure, afin d'obtenir des exécutants un ensemble parfait, il était aussi nécessaire aux écoliers et aux solistes pour s'accoutumer á l'égale mesure des pieds rythmiques. Quant à la prononciation vocale, il fallait qu'elle marquât distinctement la longueur et la brièvetè, parce que c'était dans cette alternance que consistait le principe de la rythmique ancienne.

On marquait une partie de chaque pied rythmique par l'élévation du pied ou du doigt, l'autre partie par leur abaissement et, d'après la règle. l'aluaissement ou thesis correspondait à la partie qui contenait les syllabes longues, l'élévation à la partie soutenant les syllabes brèves. Mais enfin il était indifférent que telle ou telle

1 Inst. or., IX, IV.

- l'arisiis, 172\%, p. 997 , note 207. 
partie fut signẻe de telle manière pourvu qu'on battit la mesure. Aussi trouvons-nous que quelques rythmiciens changent la signification des noms, en appelant arsis la première partie de chaque pied, thesis la seconde sans tenir aucun compte des longues ou des bréves quelles pouvaient contenir. On pouvait même indiquer par un ictus les deux parties de chaque pied et cette manière de battre la mesure est non seulement attestée par certains rythmiciens, mais elle se maintint dans la rythmique byzantine. et jusqu'á nos jours dans les chants liturgiques grecs oú l'on marque par un frappé plus ou moins prolongé chaque syllabe de l'hymne '.

Il est des philologues, comme Bentley, Ritschl, Huemer, qui s'efforcent de nous démontrer que les anciens cherchaient á réunir l'ictus métrique avec l'accent naturel, Christ paraît être du même avis. Lucien Mueller nous déclare au contraire que les anciens cherchaient á ne pas laisser coïncider l'ictus avec l'accent. Comment accorder des opinions si contraires? En rejetant les unes et les autres. Car sipposons que la syllabe thétique soit marquée par un ictus. et que celui-ci ressemble á l'accent naturel. et comptons maintenant les ictus et les accents dans les pieds du vers suivant:

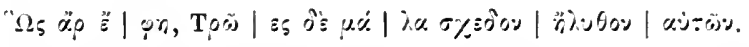

Le premier pied contient trois accents et un ictus, en somme trois ictus ou trois accents, puisqu'il n'y a pas de diffèrence phonétique entre eux; le troisième pied nous en présente trois également - or quel rythme cela donne-t-il ? Cet entassement se retrouve presque dans chaque vers, qui tous cependant resteront irréprochables au point de vue rythmique si nous osons rejeter l'ictus, et si nous admettons que l'accent n'avait rien de commun avec le rythme. Comme le dernier point sera le sujet du chapitre suivant je n’insisterai pas davantage.

1 Christ, Anthologia, Préface. - Westphat: Griechische Rhythmik, 1883, s 24 . 
Rien donc dans la théorie rythmique de l'antiquité ne justifie la supposition d'un ictus vocal. Examinons maintenant les raisons sur lesquelles les inventeurs ont échafaudé leur théorie. Il faudrait ici remonter jusqu'à Bentley, qui pourtant n'en a parlé qu'incidemment. Godfried Hermann, le véritable auteur de la doctrine, l'a exposée dans ses Elementa doctrinae metri$c a e^{1}$. Il y procéde d'une manière purement déductive. il veut nous convaincre par la force de sa logique. En le suivant sur son propre terrain, qu'il me soit permis d'accompagner ses raisonnements de mes réflexions, parce qu'autrement les erreurs qui s'y cachent seraient plus difficiles à indiquer.

"In effectorumserie»,dit-il, «quum prima atque absoluta caussa ea sit, quae illa serie non continetur, sed aliunde accedit, ideoque non ut effectus, sed tautum modo ut caussa apparet; caussa autem ommis quae tantum ut caussa, non etiam ut effectus consideratur, in vi aliqua sit posita: apertum est, caussam absolutam non nisi in vi aliqua cerni posse. D'après lui la cause d'une série d'effets est toujours hors de cette série,et il faut toujours la chercher dans une force quelconque. Il a seulement oublie que la force ne se manifeste que par ses effets, et que hors de ses effets elle est insaisissable, elle n'existe même pas.

"Quod si qui sunt numeri, qui initium habere videantur, in ipsis aliguid reperiatur necesse est, quod indicium faciat initiin. Les rythmes, dit-il, se caractérisent parce quils ont un commencement; il faut donc qu'ils contiennent un indice de ce commencement. On conviendra que cette phrase, bien que latine, n'a pas le sens commun. Tout, indistinctement, a un commence ment, et de mèrne que nous n'avons pas besoin d'un indice du commencement d'une maison ou d'une rue, nous ne saurons jamais comprendre pourquoi les

1 Ed. de 1816, p. 9. 
rythmes en auraient besoin, s'ils sont quelque chose. Remarquons encore que cette proposition joue le rôle d'une mineure d'un syllogisme, dont la majeure porterait sur la force qui doit être toujours hors de son effet. Or ces deux propositions n'ayant pas de membre commun ne sont pas admissibles comme prémisses. Néanmoins le savant allemand ne laisse pas de conclure: "Itaque in numeris illis vis aliqua absoluta reperiatur" necesse est, quod indicium faciat initii . Cette conclusion n'est qu'une répétition de la phrase précédente, et partage la faiblesse de son fondement. Godfried Hermann prend maintenant les trois phrases citées comme des prémisses, et il en tire cette nouvelle conclusion : "Ita est autem. Nam numeros ita demum videmus initium habere, si quem ICTU vocamus in is animadvertimus, quo manifesta fit in una aliqua numeri parte vis quaedam, quae a caeteris abest ». C'est-à-dire : si nous marquons le commencement d'un rythme par l'ictus,alors ce commencenent sera marque, et les autres parties ne le seront pas.

Cela est vrai, mais peu profond. Si nous mettons un ictus dans un rythme, alors il y aura un ictus, voilá ce que l'auteur s'est donné la peine de prouver, mais il a pris un rythme comme donné, il a fait une pétition de principe.

Ayant trouvé le commencement: “Invento initio",l'auteur se met à chercher la fin : de fine queri potest.Quae res nihil habet difficultatis. Illud tempus, in quo ictus est. R. Bentleius arsin, tempora cutem ea, quae carent ictu, thesin vocavit, ducibus Prisciano et Martiano Capella". Nous savons dejá que c'est une doctrine sophistiquée qui ne trouve aucun appui dans la théorie antique. Guidé par son invention de l'ictus, le philologue allemand va encore plus loin, il rejette les rythmes qui commencent par des syllabes brèves, à savoir le rythme iambique et l'anapestique en les ramenant au rythme trochaïque et au dactylique avec des "anak»usis " inventées 
a propos. C'est une destruction du systeme rythmique des anciens. C'est lui aussi qui a imaginé les accentuations comme miseria, fámiliam, tétigeris, rédiero'. Il est clair enfin que Godfried Hermann, aussi bien que son prèdécesseur R. Bentley, ignorent la vraie théorie antique sur le rythme et la remplacent par une doctrine imaginée à prior $i$. arbitraire. qui n'est fondée que sur des sophismes.

Il reste à expliquer comment de vrais savants, car ils l'étaient sans doute tous les deux. ont pu tomber dans des erreurs si graves. D'abord ils n'ont pas remonté jusqu'aux sources, et ensuite ils ont établi leur doctrine d'après les notions modernes du rythme.

Il faut distinguer dans la rythmique moderne deux courants sèparès, l'un dans la versification. l'autre dans la musique. Tous les deux dérivent de la rythmique ancienne, comme nous le verrons plus tard, mais ils se sont diffèrenciès suivant le diffèrent sujet auquel ils s'appliquent. Parlons d'abord de la rythmique dans la versification moderne. qui n’est parfaite que lá où il s’agit d'imiter les pieds antiques. Ce sont les Allemands qui ont réussia à crèer, dans leur poèsie, des vers réguliers iambiques, trochaïques, dactyliques etc. Les syllabes atones remplacent ici les brèves, les syllabes accentuées les longues antiques. Elles les remplacent a un titre assez juste, parce qu'en général, je dis : en général, l'accent moderne prolonge la syllabe tonique, non-seulement dans la langue allemande, mais dans toutes les langues européennes. Donc il ne remplace pas lictus antique mais bien la longue antique. Encore faut-il remarquer que la versification métrique allemande, bien qu'utile dans la traduction des poèsies antiques, ne s'est pas popularisée dans la poèsie nationale allemande, tant le sentiment artistique se refuse á reconnaitre un principe arbitraire et hètérogène au fond. Néanmoins séduits par cette pro-

' L. c., p. 64. 
priété que posséde laccent moderne de se prêter á la configuration des pieds rythmiques, beaucoup de philologues s'efforcent, mais á tort, de l'introduire comme principe dans la rythmique originaire. Quant à l'ictus, les vers modernes nen contiennent ancune trace.

Il en est autrement dans la musique. Notre rythmique moderne musicale différe de la rythmique antique principalement en ce qu'elle n'évite pas les pieds pyrrhiques, les proceleusmatiques répudiés par la rythmique ancienne. La musique moderne non-seulement ne les évite pas, mais elle les recherche, elle construit de longues périodes musicales, des piéces entières, qui ne consistent qu'en pyrrhiques, ou en proceleusmatiques.

Il y a plus: notre virtuosité musicale aime à placer quatre, huit, seize, trente-deux notes égales dans une mesure, dans unesuite de mesures.Le principe antique,à savoir l'alternance des syllabes longues et bréves. s'y trouve ainsi effacé. Ce qui fut exception dans l'antiquité, devient presque règle chez nous. Comment marquer la limite entre des mesures de telle composition? C'est ici que l'ictus devient presque indispensable. Il n'est donc qu'une création, qu'une application moderne. Sorti du bâton du chef d'orchestre il entra dans l'exécution même au fur et á mesure du développement de la virtuosité. Mais, encore ici, mieux l'orchestre est dirigé, moins il marque lictus même dans les cas en question.

Ces deux applications modernes introduites dans le systeme de la rythmique antique, qui ne les connaissait pas, l'ont profondément gâtée.

Nous espèrons que les chapitres qui vont suivre confirmeront les opinions que nous avons émises dans celui-ci. 
L'accent antique formait la mélodie du vers et semble avoir donné naissance au système musical grec.

Accent. accentus, veut dire adcantus. Ce nom indique déjá que l'accent antique a dû diffèrer notablement de l'accent moderne. Le mérite de cette découverte revient à MM. Benloew et Weil ${ }^{1}$. Leur opinion fut bientôt acceptée par Corssen, Scherer, Sievers. Seelmann ₹ etc; mais en théorie seulement, parce qu'elle est loin d'être comprise dans son importance et d'être appliquée-à la théorie des arts musicaux de l'antiquité classique. Nous distinguons maintenant un accent chromatique ou musical fondé sur la hauteur du ton, et l'accent respiratoire ou d'in. tensité, fondé sur la force de l'expiration. C'est le dernier qui gouverne les langues modernes, quoique non sans une certaine participation á l'accent chromatique qui avait été jadis un trait caractèristique de toutes les langues aryennes á une époque déjà bien reculée et qui, dans la prononciation le la plupart des peuples et des individus. n'est pas encore entièrenent effacé.

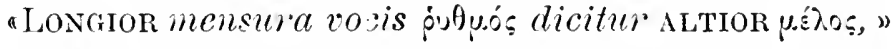
dit Aulu Gelle ${ }^{3}$ en distinguant d'une manière très nette les deux éléments qui influençaient la prononciation aryenne. Le caractère de l'accent ressort très bien

1 Théorie générale de l'accentuation latine.

2 Scherer, Zur Geschichte der deutschen Sprache. p. 134. - Sievers, Phonetik, 1885, p. 200. - Seelmann, Die Aussprache des Latein, p. 15-64.

${ }^{3}$ Noctes atticie, XVI, 18. 
de la définition qu'en donne Diomède ${ }^{1}$ : Accentus est acutus vel gravis, vel inflexa elatio orationis, vocisve intentio vel inclinatio, acuto aut inflexo sono regens verba. Nam ut nulla vox sine vocali est, ita sine accentu nulla est; et est accentus velut anima vocis. Accentus est dictus ab accinendo,quod sitquasi cuiusque syllabae cantus ; apud Graecos quoque ideo rop-

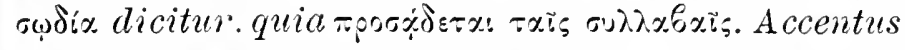
quidam tenores, vel tonos appellant, non nulli cacumina retinere maluerunt .Les paroles du grammairien latin demandent une certaine réflexion si l'on veut bien comprendre la véritable nature de l'accent antique. Nous disons que chaque mot a son accent, mais les anciens enseignaient que chaque syllabe en possède un puisque chacune se prononce avec une certaine élévation de la voix. Chaque syllabe se chante d'une certaine manière, dit Dioméde, en ajoutant que quelques-uns les appelent tons ou tenores. L'élévation de la voix ne reste pas égale sur toutes les syllabes du mot, elle monte sur les unes pour tomber plus bas sur les autres. "A ccentus namque est certa lex ex regula ad elevandam et deprimendam syllabam uniuscuiusque particulae orationis, dit Priscien ${ }^{2}$.

On distinguait trois sortes d'accents : l'accent aigu, l'accent grave et l'accent circonflexe. "Ex his acutus in correptis semper, interdum in productis syllabis versatur, inflexus in his quae producuntur.gravis autem per se nunquam consistere in ullo verbo potest.sed in his in quibus inflexus est, aut acutus, ceteras syllabas obtinet."

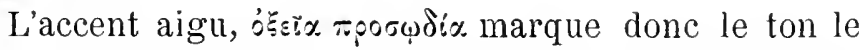
plus élevé entre les sons, dont chaque syllabe est accompagnée dans la prononciation. C'est le tonus summus ou superior d'après Nigidius Figulus, " Acutus, quod acuat sine elevet syllabam», selon Priscien ${ }^{3}$.

1 Gram. lat., I, p.430.

Gram. lat., III, p. 517.

L. c. p. 520 . 


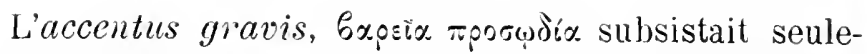
ment à côté de l'aigu ou du circonflexe. Il donnait aux syllabes qu'il affectait un son plus bas. On le qualifie de depressus, gravis, depositus, piger, minus sonans!

L'accent circonflexe était appelé par les Grecs dírovos

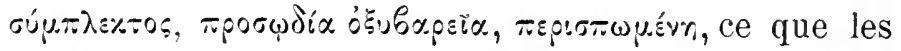
Latins traduisaient par duplex, inflexus, circumflexus, ex acuto gravique fictus. C'était un accent de deux sons, il commençait par une note élevée pour finir par une plus basse : . "Prima erecta russus in gravem flectitur, dit Servius '. Il ressemblait à l'accent sanscrit appelé svarita, qui commençait même plus haut que l'aigu pour tomber ensuite sur l'aigu ou sur le grave, selon les circonstances. Encore aujourd'hui, les Brahmanes emploient dans la prononciation des syllabes marquées par le svarita d'une espèce de roulade ${ }^{3}$.

Outreles accents dont il a été question, certains grammairiens comme Sergius ${ }^{4}$, qui suivait en cela l'opinion de Tyrannion, en admettaient un de plus. Ils l'appe-

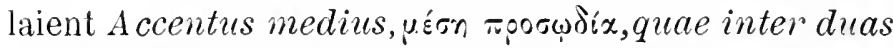
quasi limen est, gravioris quam acutioris similior. Corssen le compare à l'accent secondaire, Nebenton.

La langue grecque possédait en outre une $\dot{\alpha} v \leftarrow x \% \lambda x \zeta_{0}-$

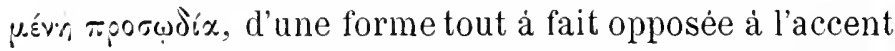
circonflexe, parce qu'on commençait ici par un ton bas, pour s'élever à un plus haut. Cet accent se trouvait dans les syllabes contractées. dont la première possédait le

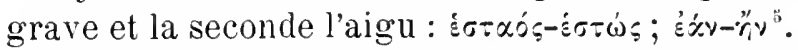

Ces éléments musicaux. assez nombreux, faisaient pourtant partie du langage ordinaire en y formant déjá une certaine mélodie, comme l'atteste Aristoxéne lui-

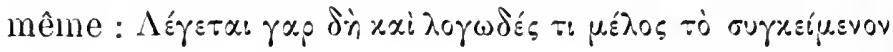

1 Corssen, II, p. 820.

2 L. c., $§ 24$.

3 WhitNey : Altindische Grammatik, p.90.

4 Gram. lat., IV, p. 529.

s Corssen, II, p. 803. 


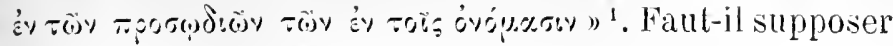
que le parler des Grecs ressemblait á un chant? Il ètait certainement plus mélodieux, plus sonore que le nôtre. Il possèdait des accents doubles que nous ne connaissons plus, des voyelles longues qui retenaient la voix, prolongeaient les sons. Il n'a fallu à cette langue que des vers rythmiques pour prolonger les sons plus encore, pour les separer, pour faire ressorlir les intervalles. C'est la rythmique rles vers qui, i notre avis, a claange les acents en mélodie par l'exacte mesure, par la prononciation emphatique qu'elle exigeait.

L'imporiante question de l'espace, dans lequel les tons de tous les accents étaient contenus, est assez bien èlucidée par le passage suivant de Denys d'Halicar-

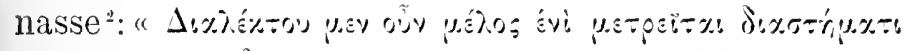

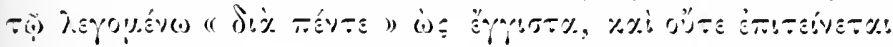

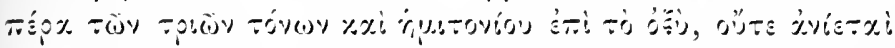
- \% \% \% les accents grecs changeaient done dans l'espace d'une quinte. Il laisse l'accent aigu s'èlever à la hauteur de trois tons et demi, puis retomber de ce mème intervalle dans le grave, ce qui domne une quinte. Mais cet inter. valte était, à ce ru'il semble, seulement l'extrème limite des accents. Un pouvait s'arrèter a la quarte, et nous savons qu’a l’èporque originaire la musique grecrue ne dejuassait pas cet intervalle. G'est un fait historique dont il fitut tenir compte.

Nous avons maintenant tous les éléments nécessaires pour la composition d'une mélodie d'après les accents, et c'est á quoi nous allons procéder en prenant pour texte le premier vers de liliade.

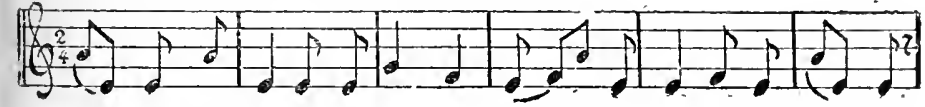

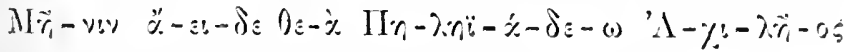

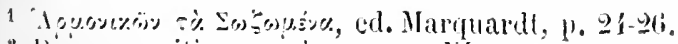

2 lé compositione veriorum, c. Xl.

J.YTH S. 
C'est à peu prés ainsi que les aèdes chantaient le courroux d'Achille, obligés qu'ils ètaient, bon grẻ mal gré, par le rythme de changer la prosodie sगvध\%: pour une prosodie $3 \% \delta$ s.r.

Après avoir établi quelle a pu être la mélodie formèe par les accents de la langue. il nous faut examiner ici la relation existant entre les accents et lamusique en général, et voir si les anciens avaient almis quelque rapport entre la prosodie, c'est-á-dire l'accentuation, et la musique, ainsi que les opinions qu'ils ont pu émettre sur cette question. "Prosodia musices imago", la prosodie ou le systime des accents est l'image de la musique, selon une expression rle Varron rapportee par Servius. "Let est accentus "mima rocis et seminarium musices, quod sonis molulatio e.x frestigiis vocum gravitateque componitur, ideoque accontus quasi adcantus dictus est ", dit Nartianus Capella '. En outre, saint Iugustin, examinant la part qu'on doit attribuer á l'esprit humain dans l'weuve de transformation des sons naturels en musique sexprime ainsi : "Videbat autcm hanc materiam esse vilissimam, nisi cestadimensione temporum acuminis gravitatisque moderata varietatem soni figurarentur. Recognovit hinc esse illa semina, quae in giammatica, cum syllabas diligenti consideratione versaret, pedes et accentus vocaverat.

L'opinion que nous prèsentons ici se trouve donc confirmée par les anciens. Toutefois, le petit nombre de témoignages que nous possédons sur cette question s'explique par l'intervalle qui sépare la science grecque de cette époque, bien lointaine. qui a ru naitre les pre. miers arts. La recherche des origines $y$ fut d'ailleurs entravèe par la tradition, cléjà établie, qui attribuait l'invention de la musique à Apollon, à Hermès. Mais enfin, nous avons trouré des traces des opinions qui mettaient la musique en rapport avec les accents, et en les suivant

1 De muptiis Philologine et Mercurii, 1II, 63. 
nous pourrions remonter jusqu'á la source de la musique grecque qui est pour nous, nous osons le dire, la mére de la musique européenne. La question prèsente des difficultès, et nous ne croyons pas la résoudre completement, cependant nous devons donner quclques explications sur notre facon de l'envisager.

Nous savons dejai que la langue grecque possédait trois accents d'une tonalité diffèrente : l'aigu, le grave et le moyen; aussi la lyre primitive semble n'avoir possédè que trois cordes. "Organum quondam habuit tres intentiones, grarem, mediam et acutam; inde Musac quoque tres olim existinatae: Hypate, Mese, Nete (ce sont les noms des trois cordes principales) nunc in ampliore numero soni considerantu" ", dit un auteur anonyme $^{1}$, et il est évident qu'il étaljlit ainsi la relation intime entre les trois accents el les trois cordes de la lyre. Nous savons aussi que le ton inférieur ètait originairement séparé du supérieur par l'intervalle d'une quarte. Voilá la position de deux tons ou deux accents, l'aigu et grave, établie : il reste á placer le troisiéme accent ou le troisième ton. Était-il á la seconde ou à la tierce, ou n'ètait-il pas flottant, indécis peut-ètre. Ce dernier cas est possible, parce qu'il faut se représenter tous les accents tant soit peu indécis, llottants de nature. Ce fut la lyre qui, ne possèdant d'abord que trois cordes sur lesquelles le musicien répétait exactement les tons du chanteur, amena celui-ci á préciser ses accents, á les changer en notes fixes parce que les cordes une fois ajustees, et ne pouvant domner chacune qu'un son, exigeaient une concordance complete entre les accents du chant ct les sons de l'instrument.

Dans le sens que nous venons d'exposer, nous acceptons la premiere proposition de M. ('ievaërt: " l’art musical proprement dit débute par la culture régulière des ins" truments a cordes ", mais nous nous permettrons de re-

1 Cexsonunts, Gram, lat., VI, p. 610. 
jeter la seconde partie de la thèse du savant musicien, á savoir: " le systéme musical primitif est engendré par une progression harmonique de quintes et de quartes enchainèes, limitèes á cinq lermes et renfermèes dans l'étendue d'une octave. "Cette explication ne nous satisfait pas, et cela pour les raisons suivantes : il est incontestable que le systéme musical primitif chez les Grecs ne dépassait jas la limite d’une quarte et que la lyre ne possedait originairement que trois ou quatre cordes, c'est-á-dire quatre sons. Il s'ensuit que dans un systeme tellement limité, et á l'aide d'instruments tellement primitifs, une progression de quintes on de quartes était inexécu table.

Arrètons-nous un moment sur ce point. Selon M. Hehnholtz' le système des gammes, des modes et de leur enchainement harmonique ne repose pas sur des lois naturelles invariables, il est la conséquence de principes esthètiques variables. M. Gevaërt semble partager cette opinion, mais il a cherché la solution du probléme plutùt du cóté technique. Seulement, il suppose une technique trop avancée, trop perfectionnée pour ètre probable, ou mème possible, à l'époque rudimentaire dont nous nous occupons. En présence de sarants de cette valeur, nous ne pourons émettre notre opinion que trés modestement. Nous nous tenons au point de vue historique, - car la musique, onure de lesprit humain, appartient sans aucun doute di ce domaine. De l'antre cité nous pouvons prononcer en axione, gue l'homme ne peut rien crèer. Il peut changer, lievelopper. perfoctionner, idèliser: il pent jar des combinaisons, jar des syntheses nouvelles, produire rles or ures ètomnantes, presque toucher i la creation, mais an fond de toutes ces prorluctions nons tromverons toujours une donnée de la nature on de la rie. Il faut done que la musique repose anssi sur une donnéc naturelle. Or, nulle prar nous n'en trourons de plus convenable, de plus capable de développement.

1 Thiorie phrsiologique de lil musigue. p. :306. 
de plus intime au sentiment que les accents, dont la fonction, il faut le reconnaitre, ètait arant tout. nous dirons même, exclusivement affective.

Cette signification affective, lètymologie du mot, les opinions des savants de l'antiquité, le caractère éminemment musical des accents nous obligent a chercher l'origine de la musique grecque, et de la musique en génèral, dans les accents mèmes.

Si ce point capital pouvait encore faire naitre des doutes. le passage suivant d'un des meilleurs archèologues de l'antiquité, de Denys d'IIalicarnasse. servirait à lever tous ceux qui persistent encore. Nous savons que le passage qui va suirre a été dèja citè á l'appui done opinion contraire, mais il n'a pas éte bien compris et on rerra que lidie. que le fond jsychologique sont un témoignage de plus en notre fareur. " Dictiones praeterea con-

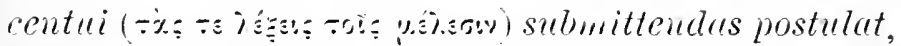
"ton auten dictionibus concentum : quod cum ex multis aliis apparet, tum praecipue ex hou Euripidis contico.quo freit in oreste ut ad chom un uteretur Electro.

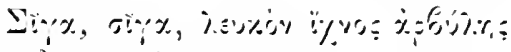

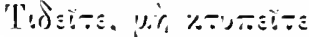

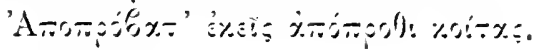

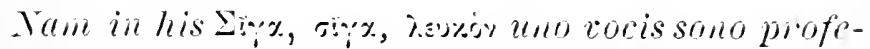
puntur (j.sicods:-a:s); tres illur licet dictiones. suas unuquaeque, quan uintas, quam grarers, labeant intensio-

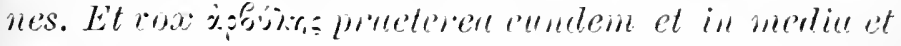
terliu syllabu tomum habet : elsi fie'ri minime putest. ut una dirlio dues habeat acutes. Quin et vocabuli prima graviorest syllaba: lluae uutem quae sequwntu. acutum habent accentuin, eundemque solum. Huins etiam \%s, syllabae dune extensionc proferuntur. A true illud de-

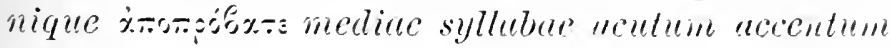

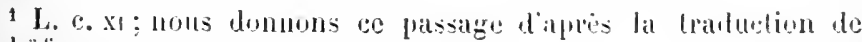
Sehäler. 
non recipit, sed in quartam usque syllabam tertiaereiicitur intensio. Déjá au temps d'Euripide les accents ne saccordaient pas avec la mélodie, et dans les cas de désaccord cètaient eux qui devaient se sommettre. Les exigences artistiques de la mélodie l'emportaient sur les èléments naturels de la mélodie; ainsi, les trois premiers mots du chant que nous venons de ciler se chantaient du même ton, malgré la diffèrence des accents. Dans le mot xpbijins on appliquait le mème ton à la seconde et á la troisième syllabe quoiqu'il soit improssible qu'un mot prèsente deux accents aigus de suite. Lauteur relève de pareilles discordances entre la mélodie d'Euripide et les accents dans tous les mots du chant, prouvant ainsi que l'idèe d'une concorlance parfaite entre les deux facteurs lui ètait familière. Nous verrons bientôt la cause de la rupture de l'accord primitif entre les accents et la mèlodie au temps d'Euripide.

Le tétracorde primitif, dont les tons extrèmes ètaient déterminés par l'accent aigu et le grave, prèsente celte particularité très remarcquable, commune d'ailleurs á toutes les harmonies grecques, qu'il contientl'intervalle d'un demi-ton. Il nous semble que la présence de ce demi-ton ne peut ètre expliquée autrement que par une qualité propre á l'accentuation grecque. Ce sont des ac-

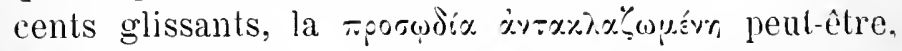
qui l'ont produit. Ce ton a pu ètre renforcè par l'accent moyen, gravioris quam acutioris similior. La tierce peut être le produit de l'accent aigu abaissé à la fin des mots, qui pourtant ne pouvait retomber jusculau véritable grave, puisqu'il conserve toujours sa fonclion.

Après quelques hesitations et quelques titomnements, les Grees étaient arrivés i doubler leur tétracorde, en ajoutant à $e, f, g, a$. un second tetracorde d'une construction identique. Ce dèveloppement donnè au systeme et à l'instrument a dì amener un changement de plus en plus considérable dans les mèlodies, qui commencerent désormais à dépasser les bormes des accents. Plus tard 
on ajouta á l'octocorie deux tétracordes de plus, un en lıat, l'antre en bas de l'octocorde, auquel ils furent reliès chacun par un ton commun. Cela donna enfin le système suivant:

$$
\text { e f g a h c d e (diezeugm.) }
$$

(synem.) he d e e f g a (synem)

(prosl. a) h c d e f $g$ a h c d e f $\stackrel{g}{c} a$

C'est ici que finalement le jour se fait dans le passage de Denys. Aussi longtemps que le systeme musical grec fut enfermé dans les bornes d'un tétracorde, la mèlodie a dû concorder avec les accents, mais á mesure que se développa le grand système que nous venons d'exposer, les mélodies cornmencérent ci sortir de leur limite originaire, elles ne s'accorderent plus avec les accents, dont on finit par ne plus tenir connte. llenys constate et explique ce phènoméne.

Nous ne prètendons pas exposer ici le systeme musical grec dans ses dètails. Cela d'ailleurs a èté fait dans ces demiers lemps, avec un savoir peu commun, par M. Westphal et par M. Gevä̈lt: nous nous bornerons seulement á indiquer ce qui nous est nécessaire pour soutenir la these que nous dèveloppons dans ce chapitre. Ainsi il faut mentionner queles mélodies fondées sur l'échelle: $e, f, g, a, h, c, d, e$, s'appelaient doriques, cquand elles finissaient par $e$, lyypodoriques, ou éoliennes finissant par ॥. Dans le dernier cas elles correspondaient á nos mélodies en mineur. L'harmonie, ou l'èchelle ly-

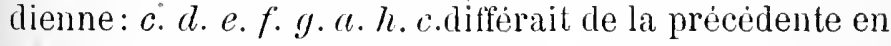
ce que le demi-ton formait son troisième ou dernier intervalle. Les mélodies se terminant en $c$ ètaient appelées lydiennes, ou hypolydiennes quand elles se terminaient par $f$. Dans le premier cas elles étaient égales á nos mélodies en majeur. Jans l'octocorde: $d . e . f . g . \iota . h . c . d$, le demi-ton se trouve au second ou au sixième intervalle et les mélodies sappelaient ici phrygiennes ou hypophrygiennes $(d-g)$. Toutes ces échelles se ressemblent en 
ce qu'elles sont fondées sur des tètracordes dont chacun contient undemi-ton, elles différent par la place occupée par celui-ci. Ce demi-ton forme leur trait caracteristique, or, il se retrouve dans nos deux èchelles musicales modernes. Est-il déterminé par la nature? Non, puisque les Grecs eux-mêmes ont essayé plus tard de diviser leur tétracorde en trois intervalles égaux. Il paraît que ce tétracorde Ptoléméen fut introduit dans la pratique musicale, mais seulement en Egypte, ou il est encore aujourd'hui en usage chez les musiciens arabes ambulants, tandis que les autres Arabes se servent des échelles Pythagoriciennes ${ }^{1}$.

Pour expliquer l'existence de ce demi-ton, nous avons eu recours a l'accentuation, qui nous servira aussi pour èclaircir l'apparition de trois sortes d'échelles contenues dans le système musical grec. L'échelle dorienne peut bien être propre à la nation hellénique, tandis que les autres sont sorties, arec la petite différence qui les caractérise, d'un mode d'accentuation un peu différent et propre aux Phrygiens et aux Lydiens. Les trois tétru'cordes primitifs étaient done à notre acis des mélodies primitices. constantes et uniques. formées par les accents de la langue de ces peuples roisins et upporentés. Eilles ont èté accueillies par les (irecs et insèrées dans leur systéme musieal, dont l'établissement leur demanda plusieurs siecles. Jls se servaient dans ce but du monocorle dont, si nous en croyons la tradition. l'èlurle assidue fut recommandèe par Pythagore à ses disciples, a son lit de mort.

Nous avons done cherché diubord it ètablir que les accents antiques ètaient d'un calractère essentiellement mélodique, ce qui écarte d'un seul coup toutes les contradictions dans lesquelles la philologie moderne s'est égarè Les anciens ne cherchaient ni a faire coünciler les accents arec lictus. comme le veulent les uns. ni a

1 IIELMHOLT\%, I. ค., P. 339. 
éviter celle coïncidence d'après les autres. Les accents n'avaient aucun rapport ni avec l'ictus, ni avec le rythme. Leur caractère mélodique était alors tellement recomu, qu'on se servait des signes des accents pour la notation musicale. Ils étaient encore en usage au moyen àge. I. de Coussemaker nous l'apprend en ce qui regarde le moyen àge lalin. où les signes de laccent aigu, du grave et du circonllexe furentemployés comme neumes fondamentaux. "De ces trois signes combinès ensemble sont nès tous les autres neumes "'. Ce mème fait est constaté par M. Christ " pour.le moyen àge byzantin : Adeo autem hanc socictatem accentum et musicam notarum iam codicum librarii persenserunt ut quotiescunque not is musie is verba carminum instruebant, accentus syllabarum scribere supersederunt. On s'y souvenait toujours que les tons du chant nètaient que d'autres accents, qui remplacaient les accents ordinaires. Cette ètroite liaison entre les accents et les notes musicales, cette vivante tratition de la doctrine antirue auraient-elles permis au moyen ige de fonder une nonvelle rythmique sur les accents:" Cela est presque impossible et il n'y en a vait pas.

Nous avons tiché ensuite de faire deriver le systeme musical des anciens du systeme de leur accentuation. Que notre explication ne porte aucun préjudice au principe mème. qui ne nous paraît pas doutenx. Aussi, estil certain que notre accent modierne. šil n’est pas rlejá entiérement cliangé, a perdu beaucoup de son caractére primitif. Nous nous permettrons d'èmettre encore une opinion sur la cause de cette transformation. car nous croyons qu'il est nécessaire de commencer par des explications plausibles pour arriver enfin it la raisemblance. Un système musical sètant foncte sur la basedes accents, un chant, une musique indépendante s'ètant

1 L'Arl harmonique aux XIle ef Xllle sieches, p. 160. planche 37.

2 Anthologia graeca Carminum Christianorum, [?. L.X.XI. 
dẻgagès d'eux, l'èlément musical y est levenu superflı, insignifiant. La semence des accents a produit tout un parterre de jolies fleurs, mais les plantes-méres se sont flètries. Il ètait devenu de mauvais goùt, ridicule même, de garder les accents, de les chanter dans le parler ordinaire, puisqu'on avait appris dejjá a chanier mieux. Ne reproche-t-on pas aujourd'hui encore à certaines personnes, ou a certains dialectes une accentuation trop chantante, que depuis longtemps on s'est efforcé. et qu'on s'efforce encore, de restreindre?

Nous avons, soutenu enfin que la musique moderne provient de la musique greçue. Sans échelle musicale il n'y a pas de musique. Les èchelles grecques ont èté élaborées pas a pas, perfectiomnées à l'aide d'essais et d'expériences innombrables. La cirice nous fournit des témoignages sans nombre sur cette suite ininterrompue d'efforts tendant à l'établissement d'un systéme musical auquel les meilleurs esprits prenaient part. Or, li ou nous ne trouvons aucune trace de travaux semblables, ou les esprits sans culture nètaient pas capables de se livrer ḋ les exercices de mème ordre, lá, nous n'arons, disons-110us, nulle raison de supposer une création indigéne d'un système nusical indèpendant, et nous devons laisser aux (irees le mérite auquel ils ont droit, sans vouloir lattribuer aux ancètres de chaque nation européenne: l'amour-propre national introluit dins la science a toujours pour effet de la faire dévier.

Sous l'influence des idées, que nous nous sommes efforcé de combattre daus les questions préliminaires, beaucoup de savants trourout la musique européenne différente déjá an moyen âge de la musique antique. Ils accentuent les petites diversitès en perdant de vue les ressemblances profondes et foudamentales. Ces ressemblances consistent rlans l"ülentité de nos deux échelles arec deux échelles grecques, ef dans la présence de deux demi-tons dans nos échelles comme dans tontes celles de l'antiquitè classique. 
D'ailleurs le chemin parcouru par le système musical grec de l'époque antique jusqu'aux temps modernes est visible et facile á suirre. Ce système, dẻjá connu en diverses parties par nos ancètres aux temps païens, nous a èté définitivement transm is par l'Eglise. Persécutée à son origine et obligèe á se refugier dans les catacombes, l'Eglise ètait dans l'impossilsilité de s'occuper du chant, intimement liẻ au culte et aux moeurs païens. Les sectaires: les Thèrapeutes. les Ariens, les Bardesaniens l'employèrent les premiers dans leur liturgie, ce qui fut une raison de plus pour l'Eglise catholique de l'exclure complètement de son culte. On se bornait à y prier, on n'avait pas d'hymnes. les psaumes $y$ ètaient récités. Seules, certaines églises, comme celles d' llexandrie ou de Syrie,ne purent se passer de cet art si beau et si cher au peuple.

Devenue la religion officielle de l'Etat romain, nayant plus rien à craindre du paganisme, l'Eglise romaine accepta enfin l'art grec musical pour domner plus de solennité aux offices. L'exemple donné d'abord par quelques èglises orientales, et qui s'ètait de plus en plus répandu, fut suivi par St-IIilaire à Poitiers, St-Ambroise à Milan, St-Augustin a Hippone, les premiers en Occident. Les formes cliancelantes du chant religieux furent ensuite réglèes par le pape Crégoire le Grand, qui divisa les échelles grecques en authentiques et plagales, entre lesquelles parait se trouver la mème relation que nous avons remarquée entre le mode dorique et hypodorique, le lydien et l'hy polydien.etc.C est lui aussi qui prit pour modéle du chant ecclésiastique non pas le chant mètrique, mais, á ce qui semble, le chant rythmique transformé, constituant ainsi le plain-chant. La culture, l'enseignement, la propagation du chant et de la musique devinrent desormais obligatoires dans l'Fglise callolique. Toutes les missions pour la propagation de la foi furent en mème temps des missions de l'art musical. Des chantres romains furent en royès à 
diverses reprises en Gaule, en Angleterre, en Allemagne, enseignant la musique d'après les traitès de Boèce et de Martianus Capella. Autant de temples, autant d'écoles de chant.

Les savantes recherches de M. de Coussemaker.ètaJ)lissent que depuis le $X^{\circ}$ siécle la Gaule,et Paris surtout, derinrent le centre d'une culture trés assidue de l'art musical. La direction imposée ici à la musique conduisit vers le chant figuré et vers la symphonie ou harmonie. Le chant harmonique, ou les roix ne suivent pas les mèmes figures musicales, exigeait qu'on assignàt à chaque note une durée, une valeur dèterminèes. Tel est le point de départ d'une nouvelle rythmigue musicale, qui pourtant fut modelée sur l'exemple de la rythmique ancienne.sm la valeur de temps dans les piedsantiques.

La musique persista pendant plusieurs siecles dans celte tendance symphonique et figurative, qui la conduisit a certaines innovations trés remarcquables. On sapercut rue la tierce et la sexte domnaient une consonance trés agréable quon établit comme accord principal. on remarrua l'affinité de l'accord de la dominante rers la tonique, ce qui constitue la base principale de l'harmonie, et plus encore de la composition moderne. Un accepta définitivement un $b$ rond, connu dailleurs aux anciens.à coté d'un si ou d'un $b$ quarré,ce qui permit de former des accords de septicme.'Toutes ces découvertes et ces modifications amencrent une fusion des échelles grégoriennes qui se transformerent peu a pen en nos deux échelles modernes,contenues dejai dans le système des anciens, comme nous l'alons dil.

Il faut entin remarquer labsence de différences systimatiques entre la musique savante et la musique populaire, et aussi entre la musique populaire des diverses nations européennes. La musique européenne est partout ètablie sur les échelles grègoriennes ou les echelles modernes. La gamme i cind tons, qu'on croit reconnaitre dans d'anciens chants de certains peuples, et 


\section{$-7 \%$}

qui omet les deux demi-tons, accuse par ce procédé sa dèpendance de la gamme avec les demi-tons. Elle a ite d'ailleurs connue et employée en Grèce. Les diffèrences caractèristiques dans les chants et les danses populaires nationales proviennent de l'ẹpoque oú on y introduisil et popularisa la musique, elles proviennent du choix que chaque nation fait entre les mulliples inflexions et cadences musicales, en n'acceptant que celles qui expriment le mieux son sentiment dominant.

Nous nous bornons a ces remarques générales, ne pouvant entrer dans le détail d'un aussi vaste sujet. 
La mesure rythmique ayant à répondre à trois différents objets, trois rythmizomena, a èté amenèe à une abstraction qui provoqua une séparation entre la rythmique et la métrique. Les Romains écartèrent cette division en soumettant les rythmes aux lois mélriques.

Nous croyons avoir ècarté l'erreur fondée sur la supposition d'un principe rythmique différent et indèpendant du principe mètrique, du moins en ce qui concerne la thèorie antique, qui considérait le métre comme une partie déterminée du rythme. On a voulu sappuyer sur une rythmique musicale qui serait nèe spontanement, et en même tempss que la musique et le chant, mais le mancue absolu d'idées sur lorigine de la musique a empêchè de se rendre compte également de celte rythmique. L'explication que nous venons de domer sur l'origine de la musique, raméne du même coup le rythme musical sur le terrain du rylhme de la versificalion. Le premier début te la musique consistant dans le chant, qui sest fondé sur les accents contenus dans le vers, il en résulte que ce chant a dì suirre des l'abord le rythme du vers. formè de l'arrangement des syllabes selon leur durée. Il a dù nécessairement participer au rythme de la malière qui le fit naitre. P'our les écrivains grees et latins, il y a ègalitè parfaite dans le rythme métrique et le rythme musical, et cela est décisif. Ils reconnaissent entre cux des diffírences, il est vrai, mais elles ne sont que secondaires et posterieures, comme nous le verrons plus tard. 
Passons à la danse. Il va de soi que l'homme, lorsqu'il ètait encore sans culture, ait manifesté sa joie par des cris et des bonds, mais de mème que nous ne pouvons qualifier du nom de chant les cris saurages qu'il poussait, de mème nous ne saurions domner celui de danse à ses courses, ses sauts ou ses bonds déréglés.

La tradition historique la plus ancienne nous montre. chez les Grecs, la llanse etroitement liée au chant et aux

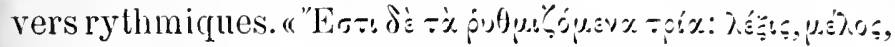

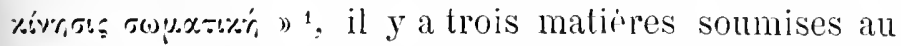
rythme: le texte poétique, la mélodie et les mou vements du corps, mais Aristoxéne ne connait gu'un genre de ry thme, commun a tous. Aristide nous enseigne la même

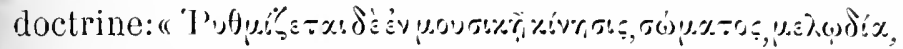

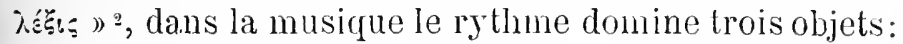
le mouvement du corps, la mélodie et le texte poétique.

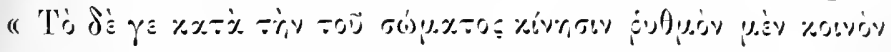
danse) a uli rythme commun avec le mouvement de la voix (le chant), dit Platon d'une maniere positive ${ }^{3}$. On dansait au chant, puisque \% $\%$ signifie chanter et danser en mème temps, mais le chant suivait le rythme des paroles. Platon décrit la danse comme une associa-

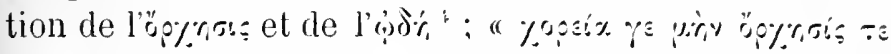
«xi ف

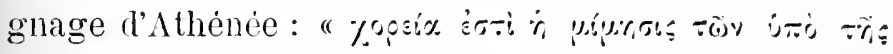

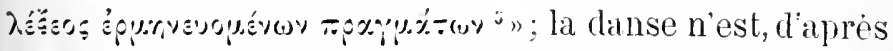
lui, que la représentation imitative des paroles du texte poétique. La danse grecque ètait donc avant tout pantomimique, et Platon, Lacion et Athénée lui mème paraissent n'en avoir pas connu d"autres". Son origine,

1 Aristoxexos, èl. Marquardt, 99.

2 L. c. II, p. 32 .

3 Leges, (77:3, D).

- Leges, (j), I) ; efr. 66:3.

s. I, İ, D.

- Leges 6:3\% ; Lcatex : de saltationibus; Athexsels : Deipmosophista, lil. I, XIV. 
nous parlons de l'origine d'une danse règlée par la rythmique, se trouve peut-ètre dans les processions du chueur, qui exprimait ses sentiments, non seulement par les paroles, mais aussi par des mouvements de pieds et de mains, réglés selon la longueur et la brićveté des syllabes du texte. Plus tard, la pantomime se développa jusqua se dégager lu texte, mais ses mourements resterent toujours soum is i la rigle les picks rythmiques, c'est-à-dire ru'jls se composaient de mouvements longs et brefs. Nen est-il jas ainsi encore aujourdhui? Le menuet, la gavolte, la contredanse, quoirque hien éloignés deja de l'expression des danses grecques, ne suivent-ils pas le mème principe? El si nous ne nous trompons, ce sont les danses orientales et le fandango qui ont le plus conservé le caractére de la clanse anlique. Parmi les dauses orientales, il en est de stationnaires,

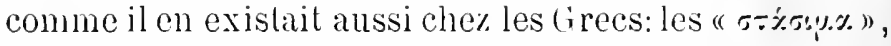

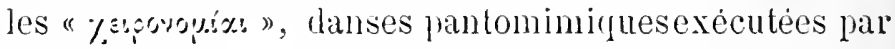
des gestes mesurés, les pieds restant immoljiles.

It elait absolument impossible de marquer lictus dans une telle pantomime, il n'y en avail donc pas, non plus que dans les rythmes.

Tout le ryllme artistique lire son origine du rers rylhmique, tel est maintenant le point principal. si cela n'est pas encore assez dénontré par tont ce qui précéde, si la définition re Bacchius, dejá citéc, ne suffit pas, quoiqu'il dise que le rythme est une suite rle syllubes riglee selon la longueur et la brieveté, nous dommerons un tèmoignage plus explicite encore rapporté par Psellus':

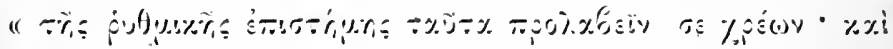

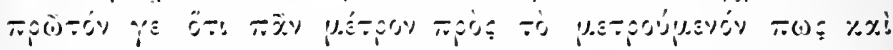

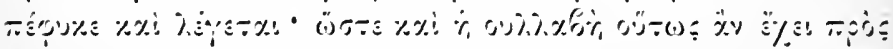

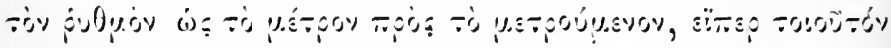
हо-

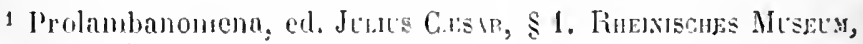

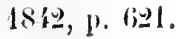




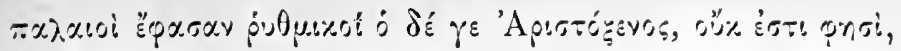

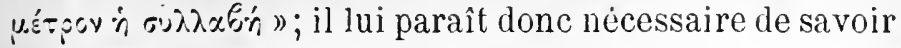
que dans la science rythmique chaque mètre. c'est-ádire chaque mesure, est toujours désigné et choisi selon la nature de l'objet á mesurer, donc, la syllabe se rapporte au rythme, comme la mesure á l'objet qui est à mesurer. Elle est donc applicable à la mesure du rythme. Cette doctrine était celle des anciens rythmiciens, tandis qu'Aristoxéne déclara que la syllable n'est pas la mesure du rythme. Ce passage est des plus importants : il nous apprend que si Aristoxéne ne fut pas le premier á proclamer une nouvelle doctrine sur la mesure, sur le premier élément du rythme, qui lui est bien antérieure, au moins la défendit-il avec la plus grande énergie. Mais à côté de lui, dautres rythmiciens persistaient à regarder la syllabe comme la mesure du rytlme, et en cela ils suivaient une tradition bien plus ancienne. Elle datait encore de ce temps oủ l'on savait que tout rythme prenait naissance dans le vers métrique, et que les autres sujets rythmiques étaient subordonnès à ce rythme originaire et unique. Platon encore a dù passer par l'étude des syllabes pour arriver á celle du rythme'. Les trois rythmizomena se subordonnaient d'autant plus facilement, quils restaient ètroitement liés á la matière dominante dans celte période rle leur évolution.

Aristoxéne, de son còté, ne manquait pas de bonnes raisons pour changer ce point de la doctrine. De son temps on jouait de la flùte ou d'autres instruments en n'accompagnant plus aucun texte, on dansait des pantomimes qui représentaient la fable d'Orphée. majs sans réciter ces beaux vers que tout le monde connaissait.

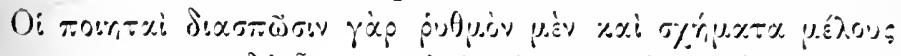

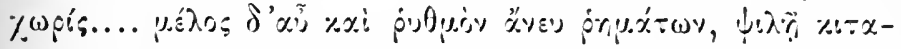

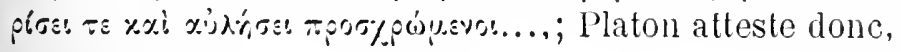

1 Cratylus, 424. 
$-82-$

ce que nous venons de dire, notamment, que les poètes séparaient les pas et les mouvements rythmiques de l'accompagnement musical, d'un autre côté, ils composaient sans texte poètique des airs de danse pour la lyre ou la flûte seulement. Il ne laisse pas de blâmer ce procédé, le déclarant sans goût et le comparant au jeu des

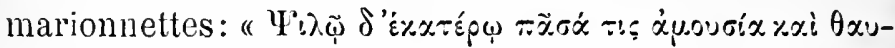

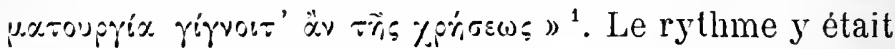
toujours gardé, cependant on ne pouvait plus le mesurer par les syllabes du texte. On se mit donc á chercher une mesure également applicable á chaque rythmizomenon séparé. On la trouva en réduisant la mesure syllabique à une abstraction, en lui enlevant son élément matèriel et ne lui laissant que la forme, c'est-à-dire le temps.

Rien d'abord, sauf le terme, ne fut changé à la théorie rythmique. Au lieu de syllabe longue ou brève, on disait dès lors un temps long ou bref, mais la valeur restait la même. Toutefois, les auteurs de vers parlaient plutôt de la mesure syllabique,les musiciens de celle du temps. Enfin l'usage s'établit d'appeler les uns rythmiciens, les autres métriciens, sans qu'au fond il y eût différence de principe. Cet état de choses nous est attesté par le passage suivant de Servius" : "Longitiido verbornm duabus in rebus est: tempore et syllabis. Tempus ad rhythmicos pertinet, syllabae ad metricos. Inter rhythmicos et metricos dissensio nonnulla est, quod rhythmici in versu longitudine vocis tempora metiuntur et huis mensurae modulum faciunt tempus brevissimum in quocunque syllaba enuntiata sit... Metrici autem versuum mensuram syllabis comprehendunt et huius modulum syllabam brevem arbitrantur, tempus enim brevissimum intellegi,quod enuntiatione brevissimae syllabae coluaerens adaequaverit. Itaque rhytmici temporibus syllabas, metrici tempora sylla-

${ }^{1}$ Leges, 670.

2 De accentibus, p. 532 : Eichenfeld-Erdicher, Analecta grammatica, 1837. 
bis finiunt, neque enim refert tempus in syllaba esse, an in tempore syllabam dicamus. dummodo discendi causa concessum est, eam moram, qua brevis syllaba dicitur unum et brevissimum tempus vocare; que vero longa profertur, duo tempora appellare ipsa cogit natura, cum loquimur. "Ce passage important confirme l'ètroite concordance entre la mesure de syllabes et la mesure de temps. Mais nous pouvons sur son autorité constater une division qui s'était opérée dans le domaine de la rythmique ancienne. Il y avait des poètes, qui composaient des vers rythmiques mais sans mélodies; on les appelait métriciens; il y en a vait d'autres qui composaient des vers rythmiques pour le chant, accompagnès souvent d'une pantomime; c'ètaient les rythmiciens. Un métricien n'etait qu'un poète, un rythmicien était á la fois poète et musicien. Le principe rythmique ne subissait aucun changement et, comme nous le voyons, dans cette nouvelle periode de l'art grec, il se fondait toujours sur la longueur et la brièveté.

Il est certain qu'il existe entre la rythmique des grecs et leur mètrique une différence plus grande qu'elle ne parait d'après ce que nous venons d'en dire. Je saisirai l'occasion qui se présente ici pour y constater quelques diversitès. Toutefois le but principal de ce travail étant d'éclaircir l'origine des formes rythmiques dans la littèrature du moyen àge et dans la littérature moderne, je ne m'occuperai qu'autant que l'exige ce sujet de la ry thmique antique.

Nous ne pouvons exposer ici toutes les conséquences de la mesure rythmique abstraite qui. sous une identité apparente, cachait des tendances divergentes. Mais. pour les bien saisir, il nous faudra auparavant éclaircir d'autres questions se rapportant a notre sujet. En attendant nous nous bornerons á l'époque classique.

La base commune á la métrique et à la rythmique classiques reste toujours le pied. On pouvait le mesurer 
par les syllabes ou par les temps. La régle primitive exigeait que le pied iambique fut composé d'une syllabe brève et d'une longue; la règle d'Aristoxéne y demandait trois temps. Le pied dactylique devait contenir d'après la régle originaire une syllabe longue et deux brèves; daprès la régle abstraite il lui fallait quatre temps.

Le pied est la base, la première unité rythmique, aussi bien dans les vers que dans la musique. Cependant après un pied nous ne savons pas encore d'une manière certaine à quel genre rythmique nous arons affaire, et ce n'est que la répétition du même pied qui nous le fait connaître. La seconde unité est le pied double, ou plutòt le colon, dont l'étendue varie selon le genre rythmique. Certains cola sont devenus des mètres, comme le dimètre iambique ou trochaïque; la plupart des metres pourtant sont composés de deux cola, et d'après Marius Victorinus ils n'en peuvent contenir davantage. ' Deux cola, de quelque genre qu'ils soient, rẻunis dans un mètre, perdent leur existence indépendante; ils cessent de représenter des unités rythmiques, qui se transmettent sur le mètre entier.

Les mètres diffèrent selon le nombre et le genre de pieds qu'ils contiennent, mais une fois fixés, détachés du ruban rythmique. ils sont toujours employés dans cette forme ètablie. Voilá des vers, voilá le domaine métrique. Tout y cöncide avec les lois rythmiques et après la séparation déjà indiquée entre la rythmique et la métrique, c'est lá qu'elles furent le plus strictement observées. Les rẻgles métriques sont en vèrité les rẻgles rythmiques originaires.

Parmi les mètres il en est quelques-uns qui proviennent de l'époque postérieure à la séparation, parce que nous y trouvons des pieds qui appartiennent plutòt à la rythmique, soumise deja á la loi des temps. qu’a la ry thmique originaire. Il s'agit des pieds choriambiques et ioniques, qui remplacent hien deux pieds iambiques ou

1. L. C. 
trochaïques, puisqu'ils contiennent six temps bref's, mais dans lesquels l'ordre des thèses et des arses se trouve déjá interverti.

Tous les mètres enfin furent employés généralement

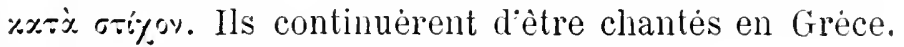
ils ne les furent probablement plus á Rome.

Je passe á la rythmique. Elle a pour base les mêmes pieds que la métrique, mais il y a ici une grande liberté de substitution des pieds pourvu qu'ils satisfassent à la loi des temps. Les pieds se combinent en cola, qui conservent ici une certaine indépendance et ne se soumettent qu'à l'unité supérieure des périodes. Les périodes á leur tour entrent en qualité de membres dans les strophes. Ni le nombre des pieds dans les périodes, ni celui des périodes dans la strophe n'étaient fixes, le genre rythmique même pouvait changer dans l'intérieur de la strophe. C'était au poète d'en déterminer la forme se'on son gout artistique. Quelques-unes des strophes, il est vrai, comme la strophe saphique, furent arrêtées, fixées dans leur forme, mais cette stabilité les transportait de mème dans le domaine de la métrique. La rythmique conservait toujours sa liberté de composition.

Nous avons dejjá observé que pour saisir le genre du rythme, il faut que le pied soit répété; le métre doit l'être aussi, pour qu'on le saisisse dans sa qualitè de régle. La même condition gonverne aussi les strophes et c'ètait probablement la raison qui fait que, nonobstant la liberté accordée á la rythmique, les Grecs laissaient dans leurs compositions une antistrophe répondre à chaque strophe. Nais comme il est rare que l'esprit humain clans la poursuite d'un principe artistique ne dépasse pas la borne du beau, des poètes grecs rythmiques s'aviserent de briser cet ordre encore saisissable el doux a loreille, pour faire répondre. comme nous l'a dit Aristide Quint. la derniére strophe à la première, l'avant-dernière á la deuxième et ainsi de suite. Il nous faut complèter le témoignagne re cet au- 
teur par celui de Marius Victorinus, qui dit: "Praéterea reperitur nonunquam huius modi compositio, non ut prima compositio secundae, sicut in strophe et antistrophe respondeat, sed ut prima tertiae, secunda quartae similes habeantur" ". De cette extravagance sortirent des compositions ou ne figuraient plus de strophes correspondantes. Voilà le terrain de la rythmique dans le sens postérieur et non pas originaire du mot.

Nous examinerons dans la suite le sort de la rythmique parvenue à ce point extrème de son développement; en attendant, notons encore quelques remarques de Marius Victorinus, dont nous aurons besoin plus tard " : Hoc loco non supersederim dicere esse brevia cola, quae post strophen et antistrophen supercini moris est, quaem iam non epodoe sed ephymnia dicentur, ut est ir raix, haec enim vel hymnis vel dithyrambis supercini moris est. quae si quando prae. ponuntur, prohymnia, si antem post antistrophen collocentur, methymnia muncupabuntur., Le grammairien latin atteste que la forme d'éphymnion avait jour berceau la poésie hièratique, ou le peuple, qui n’aurait su chanter l'hymne ou le dithy rambe mème. renforçait la prière ou la louange prononcée par le prètre d'une fervente exclamation poussée en chceur. Cette exclamation additionnelle pouvait ètre placée à la fin cle chaque strophe, ou aprés chaque couple de strophes, ou même au conmencement de chacune d'elles. comme dans le psaume de Saint Augustin. Il existait en outre une autre forme additionnelle, bien plus développée, qu'on ne plaçait qu'à la fin de la composition entière. "Cui vavietati, dit le mème auteur, solent illud adiungere, ut postrema epodos cunctis dissimilis aliquando iungatur, quod non tantum tragici sed ot lyrici auctores in epodis saepe fecerunt."

1 L. c., 59.

2 L. c., 59 . 
Outre leur théorie musicale. les Romains acceptèrent des Grecs toute la thèorie rythmico-métrique, sur laquelle ils fondèrent toute leur versification, mais ils exclurent de leur littérature les compositions lyriques dont je viens de parler. Cette observation importante a été faite par M. Benloew dans les lignes suivantes ': "Horace n’osa pas marcher sur les traces de Pindare et désespéra d'imiter, á l'aide du rude instrument dont il disposait, ces édifices strophiques si vastes. si grandioses. si merveilleux de complication et de régularitè». La raison que $\mathbf{M}$. Benloew donne de ce fait est bonne sans doute, bien qu'elle ne soit pas unique. Avant de l'exposer ajoutons que la même tendance vers une composition stichique ou métrique a été remarquée par M. Christ dans les choeurs de Plaute et Térence.

Citons d'alıord les opinions des écrivains anciens sur le sujet en question. Cicéron en parle dans les termes suivants: "Sed in versibus resest apertior, quamquam etian a modis quibusdain cantu remoto, soluta esse videtur oratio. maximeque id in optimo quoque eorum poetarum qui lyricoi a Graecis nominantur, quos cum cantu spoliaveris, nuda pacne remanet oratio,quorum similia sunt etiam apud nostros, quae nisi cum tibicen accessit, orationis sunt solutae simillima. at comicorum senarï propter similitudinem sermonis sic saepe sunt abiecti.ut non numquam vix in ens numerus et versus intellegi possit ". A en juger d'après ces mots, il semble que les Romains aient préférè le rythme métrique exact á la liberté des rythmes méliques.

Cicéron n’a pas èté le seul á juger désarantageusement des formes de la haute lyrique, dans lesquelles les poètes grees ont fini par trop abandonner le principe rythmique ordinaire. Denys d'Halicarnasse en parle avec plus de sévérité encore ${ }^{2}$ : "Melici vero,

1 Précis d'une théorie des rythmes, I, 11.

2 De comp. verb., ed. Schaeffer, 419. 
qui strophas sibimet respondentes faciunt, cum membra unius cuiusque inaequalia sint inter se acdissimilia.factis itidem dissimilibus inaequalibusque divisionibus, ob utraque haec iustam numerorum perceptionem non sinentes ut animo teneamus. multam odariis suis cum soluta oratione similitudinem adscivere". En continuant. il blâme non seulement la négligence du texte, mais aussi les mélodies trop changeantes, trop diversifièes : "quin et dithyrambici modos immutarunt dorios et phrygios et lydios eodem cantico adhibentes, alias etiam aliasque fecerunt melodias, modo enharmonicas, modo chromaticas, modo diatonicas; nec non multa usi libertate, sed legibus solutos potius rhythmos efformarunt, Philoxenum dico, atque Timotheum et Telestem ${ }^{1}$ ".

Il s'est donc opéré dans le monde ancien et surtout chez les Romains une réaction contre la trop grande liberté dans les rythmes de la haute poésie lyrique.qui dètermina Horace à s'en tenir á la régularité mètrique, et décida Sènéque á. s'en rapprocher dans les chœurs de ses tragédies. Il les compose presque $\% \propto-\dot{\alpha} \sigma \sigma i \%$ ov, car s'il ose quelquefois varier ses chants, ce n'est qu'en entremêlant des mètres différents. Les vers d'Horace sont connus de tout le monde, mais voici une liste des mètres dont se sert Sénéque dans les chœurs de ses tragédies? Nous y relevons :

1. Des hexamètres (GEdipe, 851, ed. Peiper et Richter);

2. Des septenaires (Médée, 749);

3. Des senaires (Médée, 763);

4. Des asclépiades (Hercule fur.. 528);

5. Des dimètres iambiques (Agamemnon, 796);

6. Des dimètres iambiques catalectiques (Médée.882);

1 M. II. Lavolx se trompe done en disant que la modulation n'existait pas dans la musique ancienne; roy. Recucil de motets ed. G. Raynaud, 1I, 237.

- Je n'affirme pas que cette liste soit complètc. 
$\%$ Des tétramètres anapestiques brachycatalectiques (Hercule fur., 125);

8. Des hendécasyllabes saphiques (Hercule fur., $865)$.

On ne saurait trop insister sur l'importance historique de ce fait, car nous rencontrons des rythmes qui furent changés en métres et qui sont en même temps des métres redevenus rythmes. C'étaient des rythmes, puisqu'ils avaient été employés dans les chours et dans les odes, c'est-á-dire dans des compositions mèliques; c'ètaient des métres, puisqu'ils sont soumis á la sévérité métrique et employés $\% x \tau \%$ r $\%$ \%v. Les deux dumaines sont près de se confondre et nous devons nous attendre à les voir échanger et entremêler leurs qualités respectives. 
La rhétorique latine contient quelques notions et quelques éléments particuliers qui se retrouvent dans la poésie latine et surtout dans la poésie du moyen âge.

Les éclaircissements que les théories de la rhétorique pourraient fournir á l'histoire rle la poèsie sont interdits à quiconque cherche l'origine des arts musicaux dans une poésie et dans une musique spontanées et populaires. Mais pour celui cependant, qui. comme nous, les a placés dés l'abord sur le terrain artistique. cette direction des recherches est non seulement permise mais encore commandée. Tout art peut, cela est vrai, subir l'influence d'un autre art qui lui est voisin. Nous allons examiner si, véritablement, les thèories de la rhétorique nous permeltent d'élucider quelques points obscurs de notre sujet.

Dans les harangues primitives l'orateur ejprouvait déjả trop de difficultés á énoncer ses pensèes dans un certain ord re logique et persuasif. pour qu'il songeat a les embellir par des figures de rhétorique recherchées et surtout par les cadences rythmiques des paroles. Mais la matiere rythmique. c'est-i-dire lessyllabes longues ef brèves se rencontrent aussi bien dans la prose, dans la langue usuelle, que dans la poèsie et. après l'ètablissentent d'une théorie r'ythmique pour la poésie, il était á prévoir qu'un esprit avide de progrès el de nouveautè appliquerait de quelque façon cette théorie á la rhétorique. qui avait élé instituee dans l'intervalle. Des poètes lyriques qui ètaient en même temps rhéteurs s'emparèrent de cette 
nouvelle branche de l'art et introduisirent dans la rhétorique des élèments de la rythmique poétique. Cicèron, qui semble avoir une connaissance approfondie de l'histoire de son art, nous dit que les cola du dithyrambe, servaient d'ornements à tous les discours." "Inde ille licentior et divitior fuxit dithyrambus, cuivs membra et pedes ut ait idem (Theophrastus) sunt in omni locupleti oratione diffusa. "I socrate, a vait donnè le premier exemple de cette nouvelle application, il fut suivi par Naucrate. "Namque haec duo musici, dit Cicéron," qui erant quondam eidem yoetae, machinati sunt ad voluntutem versum atque cantum, ut et verborum numero et vocum modo, delectatione vincerent aurium satietatem. Haec igitur duo, vocis dico moderationem et verborum conclusionem. quoad orationis severitas pati posset, a poetica ad eloquentiam traducenda duxtrunt ". Le célèbre écrivain parle ici de deux innovations introduites dans la rhètorique: d'abord quelque rythme : verborum numerus. conclusio, versus, en outre quelque chant: vocum modus, cantus, moderatio. Examinons ces deux nouveaux éléments en commençant par le second.

Les discours des orateurs de l'antiquité accusent-ils des traces de chant? Les accents formaient sans doute une certaine mélodie. mème dans les discours familiers, où elle était pourtant moins marquée. Elle fut rehaussée dans les discours publics lors de l'introduction de cadences rythmiques, et cette étroite liaison entre le rythme et le chant est une nouvelle preuve en faveur de l'induction que nous avons exposée plus haut.

Pour mettre mieux en èvidence, l'importance dont jouissait l'élément mẹłodieux dans les langues et spécialement dans les discours oratoires antiques, je citerai un passage de Quintilien:" "nam C'icero illos ex Lycia

1 De oratore, III, 48.

2 L. c. III, 44.

3 Institut., XI, c. 3. 
et Caria rhetores pene cantare in epilogis diait. Nos etiam cantandi severiorem paulo modum excessimus... Quid ergo? non et Cicero dicit esse aliquem in oratione cantum obscuriorem?" Puis il continue, en combattant l'excés du chant dans les discours: "Quod si omnino recipiendum est, nihil causae est, cur non illam vocis modulationem fidibus ac tibits, imo mehercule;quodesthuicdeformitatiproprius, cymbalisadiuvemus... Ostendam non multo post ubi et quatenus recipiendus sit in oratione hic flexus, et cantus quidem, sed quod plerique intelligere nolunt, obscurior". Tout en s'opposant $\dot{a}$ l'abus du chant dans les discours oratoires, il reconnait qu'il $y$ entre pour une grande partie.

Il nous faut recourir de nouveau á Cicéron pour apprendre de quelle façon se manifestait le rythme dans la rhètorique, question dont nous allons nous occuper. Voici ce qu'il en dit: "neque vos paeon ant herous ille conturbet,ipsioccurient orationi, ipsi, inquam, se offerent et respondebunt non vocati. Senarios vero et hipponacteos effugere rix possumus, magnam enim partem ex iambis nostra constat oratio. On pourrait craindre, à en juger d'aprés ces paroles, que le discours ne fut changè en vers. Mais il n'en est pas ainsi : "in quod illud est vel maximum, ajoute Cicéron, quod versus in oratione si efficitur coniunctione rerborum, vitium est, tamen etian coniunctionem sicuti versum NUMEROSE CADERE et quadiare et perfiei volumus. ${ }^{2}$ Outre la rectification que nous attendions, nous trourons dans le passage précédent les mots numerose cadere,expression très remarquable, que plus d'un philologue a cherchè à expliquer sans y réussir. On croit gẻnéralement qu'elle se rapporte à un rythme fondé sur l'accent, mais il n'en est pas ainsi. Cicèron l'oppose au veisus, dautres grammairiens a numemu servare, ce qui forme la même antithèse. Nous venons d'apprendre en outre, que le nu-

1 L. c., 49. 
avant toute trace de poésie arabe en général. M.Fuchs ${ }^{1}$ et $\mathrm{M}$. W. Grimm ${ }^{2}$ ont été les premiers à recueillir de nombreux exemples de la rime dans la poésie antique. Mais comme elle apparait aussi dés le début de la poésie allemande, dans Otfried, et qu'on ne voulait pas reconnaitre son origine latine. on eut recours à la poésie populaire, croyant que e'ètait lá qu'elle avait pris naissance spontanėment. On n'a pas voulu constater que dans les vers composés par des gens du peuple, même encore de nos jours, la rime fait complètement défaut, ou est très imparfaite, parce que de tout temps elle a été assez difficile à trouver.

Il eùt été plus simple de faire dériver la rime européenne de la source oú elle se manifeste le plus tôt et le plus fortement. c'est-á-dire do la littèrature latine, et les travaux de M. Fuchs et de M. Grimm auraient dù nécessairement conduire á cette source. Mais voici M. IV. Meyer de Goettingue qui ne voit lá qu'une pure illusion, en déclarant : "der Reim, velcher bei Commodian und Augustin auftritt ist ohne Beispiel in der quantitirenden Poesie ${ }^{3}$ ". Il est vrai que la rime n'est pas employée, dans la poésie métrique, á la manière de Com. modien et de saint Augustin, toutefois, elle s'y trouve et dans une forme bien plus parfaite. Voici celle qu'elle revêt dans Plaute:

Non internosse posset quae maman dabat Neque adeo mater ipsa quac illos pepererat Ut quidem ille dixit mihi, qui paeros viderat Ego illos non vidi, ne quis vostrum censeat.

Une autre maniẻre de rimer se trouve dans Properce $^{3}$ :

1 Die romanischen Sprachen, 1849, p. 23\%, seqq.

2 Zur Geschichte des Reims. Mbhg. d. k. Ak. zu Berlin. I85̈l, p. 521,627 , seq.

3 Abhg. d. k. hayr. Mk. tome IaI, p. 371.

4 Menaechmi, 20-24.

¿ $111,32,85$. 
Haec quoque profecto ludebat lasone Varro

Varro Leucarliae maxima flamma suae Haee quoque lascivi eantarunt seripta Catull $i$

Lesbia quis ips $a$ notior est Ilelen $\iota$

Haee etiam doet $i$ confessa est pagina Calv $i$

Cum caneret miserae funera Quintiliae.

Il est évident que Properce cherche à embellir son éloquente période par l'assonance, semblable á celle de Commodien et de saint Augustin. et qu'il en poussel'application jusqu'á la dernière limite permise clans l'art antique.

Malgrè les nombreux exemples. dans la poésie antique, de vers metriques rimés d'une façon similaire, bon nombre de savants s'obstinent á déclarer que la rime n'y est quaccidentelle. Pour les convaincre, il suffira de démontrer que lart antique possédait une conscience claire et nette de cet embellissement, et les témoignages sont si nombreux qu'on n’a que l'embarras du choix. Dejaa Cornificius, le plus ancien des rlèteurs latins, distingue deux genres de rime ${ }^{1}$ : "exomatio similiter cadens, et exomatio similiter desinens. Similiter desinens est, quom tametsi casus non insunt in rerbis. tamen similesexitus sunt, hoc pacto: turpiTER auDEs f $a$ GERE, nequiTER stuDHs dicERE: viv Is inviDIOsE, delinquIS stuDIOSE, loquerIS ODIOSE; item auducITER territas, humillTER placas.

Similiter cadens exomatio appelatur, quom in eadem constructione verborum duo aut plura sunt verbu, quae similiter isdem casibus ecferuntur, hoc modo: homin EM faudEM egent EM virtutrs abundantEM felicitat rs ? etc. Ces deux genres de rime ont un très grand rapport de forme et il était aisé de les confondre: "haec duogenera inter se vehementer conveniunt, et ea ve qui his bene utuntur plerumque simul ea conlocant in isdem partibus orationis.

Dans les exemples donnès par Cornificius, nous trou-

1 Rhetorica ad Herennium ed. Kayser, IV, y2. 
vons non seulement des rimes, mais dejá des rimes accumulées, comme dans quelques compositions du moyen âge. Mais lui-même blâme la trop fréquente application decel ornement, en disant: "hacc proxuma genera exornationum per raro sumenda sunt quom in veritate dicimus, propterea quod non haec videntur reperiri posse sine elaboratione et sumptione operae, eius modi studia ad delectationem quam ad veritatem videntur. adcommodatiora". L'usage de la rime était donc plus libre, selon lui, dans les genres qui servaient au plaisir, ad delectatıoncm, par exemple dans la poésie: que dans la prose oratoire qui était plus sévére. Ceci prouve que la rime dans les vers attribués á Ennius: " haec omnia vidi inflammARI... evit ARI... turparI "; ou dans les hexamètres de Cicéron :

Cedant arma togae. Concedant laure a linguae

O fortunatam natam me consule Romam.

ou encore dans les sénaires de Varron: "neque orthophallica attulit psalteria... dicter'IA... exordIA, que dans tous ces cas et dans d'autres encore, la rime n'était pas accidentelle mais placèe à dessein.

Il faut nous rappeler maintenant la règle observée quelquefois dans la rhétorique, qui donne aux membres des propositions la même longueur, et jusqu'au même

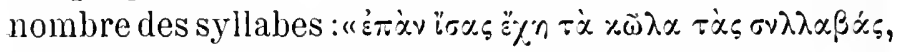
dit Démétrius ${ }^{1}$. On les appelait alors isokola, mais quand, outre leur égalité approximative, elles étaient ornėes de la rime, alors on les nommait parisa ou compares: "compar appellatur, quod habet in se membra orationis quae constant ex pari fere numero syllabarum hoc modo:

In praelio mortem parens oppetebat

Domi filius nuptias comparabat

Haee omnia graves casus administrabant .

1 l)e elocutione, 59 \%.

2 Consilicies, l. c. 
Un autre rhèteur, Aquila Romanus, nous en domne l'exemple suivant: ${ }^{1}$

Neque gratia et divitiis locupletum corruptus

Neque minis et denuntiatione potentium perteritus

Neque difficultatibus et magnitudine rei a proposito deiectus.

Les cola oratoires se rapprochent ainsi de vers rimés. Mais il y a plus : les mots similiter desinentes et cadentes avaient en même temps la même quantité dans les syllabes finales et c'est ce qui, joint á l'ègalitè approximative des cola, constituait le rythme oratoire selon ce que dit Gicèron lui-même: Formae vero quaedam sunt orationis, in quibus ea concinnitas est ut sequatur numerus necessario, nam cum aut par pari refertur, aut contrarium contrario opponitur ${ }^{2}$, aut quae similiter cadunt verba verbis comparantur, quicquid ita concluditur, plerumque fit ut NuMEROSE CADAT ". Il $\mathrm{y}$ avait donc dans la rhetorique latine des cadences ry thmiques, qui étaient obligatoires à la fin de certaines propositions. Ces propositions étaient assez souvent d'une ègale longueur entre elles et, sourent aussi, ornées de la figure de rhétorique du similiter desinens et du similiter cadens, qui, consistant en des formes de flexions ègales, ètaientá leur tour presque toujours d'ègale quantité, et formaient un pied rythmique final régulier. La cadence finale des propositions en question ètait donc á la fois rytlmique et rimée, et cette coïncidence éclaire la transformation du mot $r$ hythmus et de son sens dans celui du rims (prov.) avec la signification de la rime.

Cette excursion dans le domaine de la rhétorique ne nous en̂t-elle valu que cet éclaircissement, elle ne serait pas restèe sans fruit; mais nous y avons trouvé en mème temps la preuve que la rime du moyen àge ne peut avoir d'autre source que la rhétorique latine. Qu'il nous soit permis dy insister fortement, parce que cette lé-

1 Rhetores latini minores ed. Hac.M, y. 30 .

"Cicéron parle de l'antithesis, à laquelle on domnail wolonticrs une égalité de longueur. 
monstration constitue une preuve incontestable contre toute spontanèité, et une autre non moins forte en faveur de nos opinions.

En établissánt que l'allitération dans la poèsie du moyen âge nous semble aroir la même origine, nous nous trouverons sans doute en présence d'une plus vive opposition, mais nous espèrons l'atténuer par des témoignages importants.

Il serait superflu de vouloir prouver par de nombreux exemples que l'allitération avait ètẻ fréquemment employée par les poètes latins depuis Ennius, puisque les travaux de Nacke, Fuclıs, Theobald, Lorch, Buchholtz; Huemer et surtout ceux plus rẻcents de MM. Landgraf et Woelfflin ${ }^{1}$ l'ont non seulement constaté. mais, de plus, ont relevé l'immense étendue de l'application de cet ornement dans la poésie aussi bien que dans la prose latine. Surgit alors une question nouvelle, celle de savoir si la langue populaire latine, qui se transforma plus tard en langues romanes, contenait, elle aussi, de pareilles allitèrations. La réponse fournie par les recherches de Mme Caroline Michaelis ${ }^{2}$ et de M. Leiffoldt "a èté affirmative.

Ici encore la rhétorique latine nous fera connaître la manière dont les Romains envisageaient cet agrément de leur style. Aquila Romanus + l'appelle rapovoux aix et l'interprète par levis immutatio: "Haec figura, dit-il, ite ornat orationem, ut in nomine aut in verbo interdum syllaba, nonnunquam litera immutata diversa significet, ut si velis sic enuntiare : Pr.玉Tor iste vel potius PR.Do sociorum. Et frequens illud apud reteres eius modi est: cui quod LIBET, hoc LICET. "

Julius Rufianus " donne a cette figure un sens un peu

t La littèrature concernant ce sujet se trouve spécifiée dans le travail de M. WöLFFLIx; voy. Sitzungsberichte der philos. philologischen Classe d. k. Ak. zu München, 1881.

"Studien zur romanischen Wortschöpfung, 1876.

3 Etymologische Figuren im Romanischen, 1883.

- Rhetores latini ed. H+L., p. 30.

: L. c., 5̃l. 
différent, en disant: "latine dicitur adnominatio rel adfictio, et est $\pi$ xo povop.r.six secundum praedictum verbum positio alterius, ipso poscente sensu, ut apud 'Terentium: nam inceptio est amentium hand amantium, et: Tibi erunt parata verba huic homini verbera. "Le premier exemple contient une véritable adnominatio, mais le second n'en a plus que l'apparence. Le sens de cette figure de rhétorique échappait á notre auteur.

Un autre rhétoricien interprète $\pi x$ povop.osix par denominatio, quae simulitudinem verbi conflectit ad anditoris affectum. Impressionner l'auditeur, tel est le vrai but de cette forme d'èlocution.

Il paraît que du temps de Martianus Capella l'usage de cet ornement ètait dèjả trés répandu, car en en décrivant plusieurs formes il blâme l'abus auquel il donne lieu. "Jam cornpositionis praecepta percur'am, cuius vitium maximum est, hiulcas et asperers; fienos etiam, iotacismos, mytacismos, labdacismos, homoeoprophora non vitare, vel cuinslibet litterale assiduitatem in odium repetitam, ut: sale sata sonabant, et: casus Cassandra canebat.

Mytacismus est, cum verborum coniunctio Itterae assiduitate colliditur, ut si dicas: mammam ipsam amo quasi meam animam. Labdacismus, ubi $\mathrm{L}$ plurimum dissonat ut si dicas: sol et luna luce lucent alba leni lactea; Iotacismus ut si dicas: Junio Juno Jovis iure irascitur. Polysigma, ubi s litera crebrius geminatur: Sosia in solario soleas sarciebat suas. Homoeoprophoron est, cum dicitur: o Tite tute Tati tibi tanta tyranne tulisti.. Ce qui a vait été adnominatio dans Julius Romanus est devenu ici une adliteratio qui envahissait non seulement les initiales des mots, mais encore leur intérieur. Bien qu'on aimât mieux répéter les sons duratifs, comme $m, l, r, s$, on n'excluait, á ce qui semble, aucune lettre de cette application.

1 L. c., 474 . 
Le blâme de Martianus Capella, qui portait surtout sur cette allitèration intèrieure, paraît n'ètre jas restẻ sans influence, car Bède ne connaît plus cette abusive répétition du même son dans l'intérieur des mots. Voici ce qu'il enseigne: "Paronomasia, id est denominatio, quotiens dictio paene similis ponitur in significatione diversa, mutata videlicet littera vel syllaba." Cette règle ne donne pas toujours l'allitération, par exemple: spes - res; mais elle la donne tres souvent: praetor praedo. Bède continue : "parhomeon est, cum ab isdem litteris diversa verba ponuntur. "C'est la viaie règle de l'allitération. L'écrivain anglo-saxon préfére puiser ses exemples dans la Bible, ce qui a contribué sans doute á les faire accepter par les poètes clırétiens de toutes les nations.

D'après les tèmoignages que nous venons de citer, on peut distinguer plusieurs formes diffèrentes qui conduisaient à l'allitèration, et qui toutes. se rencontrent dèjà dans les premiers écrivains latins, dans Ennius, Livius Andronicus, etc. Les unes appuient le sens des mots, les autres les sons, en quoi elles ressemblent à la rime, qui appuie aussi les sons. Mais la rime reléve les voyelles qui sont faciles à prononcer et agréables à entendre, tandis que l'allitération reléve les consonnes, dont la qualitè est entièrement opposée á celle des voyelles. Laquelle de ces deux formes adnominatio, ou bien adliteratio est donc la plus ancienne? Nous votons pour la première, parce qu'il est très facile de trou ver une explication satisfaisante de son origine, tandis que l'autre n'est plus, à notre sens, qu'un enfantillage. L'adnominatio était dans son origine plutòt une adradicatio ; elle consistait dans la répétition du même radical dans des formes diverses. Par cette répétition on voulait ren. forcer la notion principale, on voulait impressionner l'auditeur: Tortore tortus, venena venenorum, occidione occidi, fidus fidelis, liber liberalis, etc. La pro- 
babilité de cette explication est augmentée par l'apparition de la mème figure dans le Rig-Veda: ${ }^{1}$

vasúyavo vasupate casînàm....

dämanvato adämànah sudaman....

Ajoutons encore quelques exemples slaves : " 0 stavljat menja gorjuš goregorkuju : na vieki-to menja da viekoviećnyj. »"

Le souvenir de cette figure expressive s'est conservé chez les Romains dans l'adnominatio. Ilscrèèrent bientòt à côté d'elle une autre figure où ils accouplaient deux mots à la signification complèmentaire et au son semblable. mais qui ne derivaient plus du mème radical : vinctus - verberatus; viduitatem - vastitudinemque; fruges - frumenta; vincta - virgultaque; pastores - pecuaque. On voit que cette figure, d'une force encore très considèrable, remplaçait dans certains cas la figure originaire, qui n'ètait pas applicable partout, toutefois elle ne laissait pas de conduire vers la simple allitération, au parhomoeon, forme dejá très alambiquée qui ne contenait plus ru'une ombre de la forme primitive et perdait toute sa signification originaire.

Notre explication vient de recevoir, d'un autre côté encore, un nouvel appui. Les travaux de MN. Landgraf et Wülfflin ${ }^{3}$ ont prouvé que c'etail la forme originaire. de cet ornement oratoire qui s'était le plus répandue et maintenue dans la langue latine. On la remarque aussi fréquemment dans les littératures romanes du moyen àge: le moulin moulait; li venz venta; vantent tuit li vent; le tuen regné regne; bean mariniers qui marines; la tor qui vers le ciel torelle; li chevalier's qui chevancha; or morrons la mort; il parole une parole; ont une parole porparlée; ö un cri crier. Ces

${ }^{1}$ Lcowig : Rig-Yeda, III, 95̈-99.

2 Barsow : Plači pohoronnyje i nadmogilnyje, Moskva, $18 \%$.

${ }^{3}$ Ueber die alliterirendem Verhindungen der lateinischen Sprache, 1887. Sitzungsb. d. k. Akad. zu München. 
quelques exemples sont puisẻs dans l'étude de M. Leiffholdt ${ }^{2}$.

On peutadmettre sans hésitation qu'une tendance vers cette figure était déjá née au sein de la langue aryenne commune, puisque les Hindous et les Slaves en ont conservé un certain usage, développé surtout chez les Romains. Mais il serait tèmèraire d'admettre que partout oú nous trouvons l'allitérationau lieu de l'adradication, cette conversion soit un faitautochtone et populaire. Le changement en question n'a pu être opérè que par une école de lettrés, qui ne se tenaient plus qu’à une forme vide de sens. L'allitération comparée à l'adradication n'est plus une figure psychologique affectant l'àme de l'auditeur, mais une figure purement écrite, saisissable plutôt par la vue que par l'entendement ou même par l'ouie.

Or, nous voyons que dans la versification germanique l'allitération a la valeur d'un principe. Y est-elle ou non autochtone? Question importante et difficile á résoudre. Pour y arriver, il faut avoir prèsentá la mémoire l'ėtat d'esprit des peuples germaniques á l'èpoque de leurs premiers essais littéraires, époque en même temps de leur conversion au christianisme. La langue, la poésie, la musique, tous les arts, toute la culture latine s'imposaient fortement à eux; ils étaient avides de se l'approprier ; ils se seraient bien gardès de puiser les éléments de leurs arts naissants dans l'esprit du peuple, qu'ils savaient inculte et barbare: leur souci dominant était de se parer de la science. qui ètait latine.

Beaucoup d'autres faits, que je ne pourrais tous exposer ici, corroborent l'hypothèse que l'allitération des Germains leur est venue du dehors. Les Slaves ne la connaissent pas, c'est donc un courant artistique occidental qui la porta aux Germains. Ne se prèsentant que sous la forme la plus dérivée elle ne se lie plus ici á l'adradication, comme chez les Romains. C'est donc sur la base de

1 Etymologische Figuren im Romanischen, 1883. 
la rhètorique latine, si bien connue par Bède, Aldhelm et d'autres, qu'on parviendra á l'expliquer d'une manière plus satisfaisante et plus scientifique que sur le sable mouvant de la spontanéitè.

Le chemin que suivit l'allitération pour arriver chez les Germains est facile à tracer. Il faut d'abord supposer connus dans la sphère d'influence de Rome tous les livres traitant le sujet en question, qui sont parvenus juscu'á nous et beaucoup d'autres encore qui sont perdus. Il faut se souvenir des écoles de rhètorique existant en Gaule au sixième et au septième siècle oú l'allitèration semble avoir étè tenue en estime. Voici des exemples qu'en donne Virgilius Maro: "Sapiens sapientiae sanguinem sugens sanguisuga venarum facta vocanalus est. demilius quoque rhetor, dit-il, eleganter ait: primae partis procerae pleni pupis erant". Considèrée comme élégante, l'allitération ètait recherchée par Venantius Fortunatus: "foedera fida fides formosat foeda fidelis ", par Grègoire le Grand, par Eugène de Tolède. Elle devint de plus en plus fréquente dans la poèsie latine de l'époque carolingienne et il suffira de citer ici les vers suivants de Milon de Saint-Amand:

\footnotetext{
Pastores pecorum primi pressique parore Conspicuos cires carmen caeleste canentes Audivere astris arrectis auribus ; auctor Id terras...
}

Elle passa de bonne heure chez les Irlandais, qui ell firent usage dans leur poésie latine et ensuite dans leur poèsie nationale. L'exemple des Irlandais fut suivi par les Anglo-Saxons, quoique ces derniers aient puisé les mêmes règles dans les écrivains latins. Virgilius Maro, le grammairien, se trouve citẻ deux fois par Aldhelm '. Les Anglo-Saxons, qui ont fourni la seconde série d'apòtres aux Allemands leur enseignérent l'emploi de l'allitération dans la póésie. Les Scandinaves, de leur còté, l'apprirent, eux aussi, des Anglo-Saxons.

1 Axgelo Mar, Scriptores class, V, p. ǰ20, 3̆46. 
D'ailleurs, est-il dejà définitivement établi que l'allitèration soit le principe rythmique proprement dit de la versification germanique? Nous en doutons, et il est fort possible qu'elle n'y ait èté qu'un ornement de style, tout comme chez les Romains. Lapplication de ce principe est bien autrement réglée dans l'ancienne poésie germanique qu'elle ne l'est dans la poèsie latine, nous l'admettons. L'objection est grave, mais elle n'est pas irréfutable. L'allitération germanique ne porte que sur des mots importants au point de vue syntactique, mais dẻjá Aquila Romanus nous a dit, en anticipant sur la règle germanique, que la $\pi$ жpovop.xsix s'effectue par les noms et par les verbes. Cette règle latine est bien fondée dans l'adradication parce que les dérivés des verbes et des noms sont presque toujours d'autres verbes ou d'autres noms ; elle n'est plus qu'une règle scolaire et arbitraire dans l'allitèration.

Autre différence : les vers germaniques ne contiennent que trois ou quatre mots allitérés, tandis que les vers latins en sont surchargés. Mais voici une remarque d'Isidore de Séville, qui est incontestablement antérieure á tout poème germanique allitéré ${ }^{1}$ : Paromoeon est multitudo verborum ex una littera inchoantium quale est apud Ennium: o Tite tute Tati tibi tanta tyranne tulisti; sed hoc bene temperat Virgilius, dum non toto versu utitu hac figura ut Ennius, sed nunc in principio versus tantum, nunc in medio, ut:

Quaeque lacus late | liquidos, quaeque aspera clumis nunc autem in fine, ut:

Sola mihi tales casus | Cassandra canebat.

C'est entièrement déjả la règle germanique.Il faut reinarquer, en outre, que nousn'a vons pas une connaissance. complète de tout ce qu'on enseignait dans les écoles de rhètorique ou dans les écoles monastiques depuis Isidore de Séville jusqu'à l'apparition des premiers poémes ger-

${ }^{1}$ Et ymologiarum, 1, c. XXXVI. 
maniques allitérés. Ces écoles monastiques n'ètaientelles pas des écoles latines? Nous avons vu que dans la poésie ancienne la rime étail accidentelle, et néanmoins elle est devenue obligatoire dans la poésie du moyen âge; or, n'est-il pas possible que l'allitération ait èté de la même manière rendue obligatoire dans la poésie germanique?

En examinant les vers longs d'Otfrid,nous avons émis l'opinion qu'ils ètaient une imitation de l'héxametre, et nous avons conclu de mème á l'égard du vers long germanique á allitèration. La preuve en est très difficile á faire, mais roici nos raisons : d'abord c'est l'hexamètre qui est considèré comme le vers principal et le seul digne d'être employé dans la poésie hẻroïque et il est incontestable que l'Héliand, le Béowulf appartiennent á ce genre de poésie. Nous avons pu remarquer en outre, que c'était dans l'hexamètre que la rime intérieure devint le plus tôt obligatoire, et il paraît aussi que c'ètait dans ce même vers, à en juger d'aprẻs les exemples chez Isidore, que l'emploi de l'allitération fut régularisè. C'est enfin l'imitation de l'hexamètre qui explique le nombre de syllabes trop variable dans les vers longs germaniques.

Il nous paraît donc démontré que la rime et l'allitération dans la poésie du moyen àge proviennent de la rhèto. rique latine. Mais les rhèteurs latins emploient très fréquemment pour les deux figures en question les noms

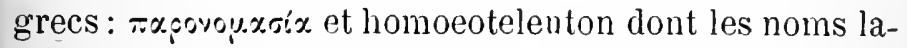
tins ne sont qu'une traduction. Il est donc clair que la rime, aussi bien que l'allitération, étaient connues des Grecs.Peut-être même faudrait-il remonter plus haut encore, car voici M. Ebers ${ }^{1}$ qui nous dit avoir trou vé dans des compositions égyptiennes des exemples non seulement de la rime,mais aussi de l'allitèration; bien que les spécimens qu'il en donne ne soient ni nombreux, ni

${ }^{1}$ Zeitschrift für ägyptische Sprache und Alterthumskunde, XV, 43. 
assurés. M. Schlottmann, de son côté, soutient que ces figures de rhètorique ont été de trés bonne heure adoptẻes par les Sémites, mais sa démonstration nous paraît trés faible. Il n'en apporte d'autres exemples que tohı vabohu'. Selon M. W. Meyer, ce sont pourtant les Sémites qui ont appris l'emploi de ces agréments de versification à l'Europe chrétienne. Il n'est certes pas impossible que l'antique Orient ait remarque de très bonne heure la valeur de ces ornements, pas plus que les nations sémitiques et même la Grèce, aient subi l'influence de l'Egypte : ce sont autant de questions qui ne sont pas encore èlucidées. Ce que nous savons seulement, c'est que ces deux ornements n'ont été nulle part aussi recherchès que dans la littèrature latine.

1 Zur semitischen Epigraphie, V, VI. 
La rythmique séparée de la métrique par la mesure abstraite du temps s'éloigne plus encore de son principe originaire sous la prédominance du chant, et tend à une transformation complète.

Les changements, que nous allons ètudier dans le présent chapitre, ont amenè la transformation définitive de la rythmique ancienne en celle du moyen âge. Il ne s'agit ici que de la rythmique latine.qui ayant converti les périodes rythmiques en vers métriques, ne présentait plus, mais seulement en apparence, de diffèrences essentielles entre les mètres et les rythmes. Rappelons-nous avant tout que le pied métrique était mesuré par les syllabes, et le même pied rythmique par les temps; l'unité moindre dans les premiers étant une syllabe brève et dans les seconds un temps bref. C'ètait dans la métrique, nous le savons déjả, qu’on observait précisément les règles rythmiques fondamentales. Cette rigueur dans la règle est constatẻe par Cicéron ${ }^{1}$ avec son éloquence habituelle : "Quae (metra) tam acrem curam diligentiamque desiderant, quam est illa poetarum, quos necessitas cogit et ipsinumeri ac modi sic verba versu includere ut nihil sit ne spiritu quidem minimo brevius aut longius, guam necesse est."

La loi des temps admettait la dissolution des longues en brèves et la contraction des bréves en longues. "Observabis autem ut terimporibus non syllabis pedes dividas ", dit Marius Victorinus ?. Cela permettait : " $U t$ solvantus.

1 De oratore, III, 48 .

? Gram. lat. VI. วั9. 
ducce longae in quatuor breves et tetrasyllabo pedo pro disyllabo utaris; parique vice quatuor syllabarum brevium tempora in duo contrahantur, quod per necessitatem fieri licet, ut aut divisae numero respondeant aut coniunctae temporum spatiis occurrant." Cette liberté de dissolution et de contraction portait surtout sur les rythmes, mais il paraît que c'est elle qui plaisait le moins aux Romains. Ils n'aimaient ni l'instabilité des périodes ni celle des pieds.y trouvant une ressemblance trop forte avec l'oratio soluta. C'est ici qu'il faut choisir notre point de depart. Comme nous ne voulons pas encombrer le terrain d'une hypothèse de plus, mais seulement mettre en lumière les opinions des écrivains anciens, nous donnerons á leurs paroles une part assez large, justifièe d'ailleurs par l'importance de la question.

Quintilien est le premier des écrivains anciens qui nous révèle la vraie trace de la transformation du principe rythmique. "Omnis structura ac dimensio et copulatio vocum constat aut numeris (numeros jutpois accipi volo) aut metro, id est dimensione quadam, quod etiamsi constat utmumque pedibus, habet tamen non simplicem differentiam, nam rythmi, id sst numeri, spatio tempore constant, metra etiam ordine; ideoque alterum. (h. e. rhythmus) esse quantitatis videtur, alterum qualitatis". Il y a des pieds dans les rythmes aussi bien que dans les mètres, mais les pieds rythmiques ne tiennent plus qu'à une quantitè, un total de temps, tandis que les pieds mètriques exigent une qualité constante, c'est-ả-dire un ordre constant entre les leux parties de chaque pied, entre la thésis et l'arsis. "Sed hoc interest,quodrhythmo indifferens dactylusne ille priores habeat breves an sequentes." Un vers ry thmique peut contenir un anapeste au lieu d'un dactyle : "Tempus enim solum metitur, ut a sublatione ad positione idem spatii sit. In versu pio dactylo poni non poterit anapestus aut spondeus, nec paean eadem ratione brevibus incipiet ac desinet. s La clarté de ces pa- 
roles ne laisse rien à désirer. Elles nous apprennent que la ry thmique ètait arrivèe á échanger entre eux les pieds de même $\mu_{s} \hat{s}_{3} \theta_{0}:$ : les trochées contre les ïambes, les dactyles contre les anapestes, les divers genres des péons entre eux. C'est un changement radical qui s'est opéré sur la base de la loi des temps. Il prouve de son côté que le prétendu ictus ne comptait point dans la rythmique ancienne. Ce point de vue ètabli, examinons maintenant qui a tort, de la philologie ancienne ou de la mo. derne, quand nous lisons dans Christ le reproche suivant": "Die alten Metriker und selbst der Musiker Aris. tides, p. 3\%, M. begingen die unbegreifliche Thorheit solche Verse ( lauler sweisylbige Füsse zu serlegen _...।_____ __-, und so gegen den obersten Grundsat: der Rhythmit zuverstossen, dass alle Fïsse einer $r$ hythmischen Reihe mit dem gleichen Takttheit beginnen müssen.Darüber. also, dass die Analyse der allen Rhythmiker zu, verwerfen und jener $\vec{V}$ ers vielmeher in folgende Füsse zu zerlegen ist - 1_-1_-1_kann unter vernünftigen Leulenkein Zweifelbestehen..Un savant de notre époque, fût-il même de la valeur de M.Christ, court bien souvent le risque de n'avoir pas compris l'idèe antique, quand il se trouve en contradiction avec la tradition ancienne.Car c'est èvidemment M.Christ qui a tort,l'analyse d'Aristide se trouvant dans un parfait accord avec l'explication de Quintilien, et avec toutes les autres régles de la rythmique transformèe. Lidèe de la rythmique que le célèbre philologue allemand veul introduire clans l'art antique n'est qu'une fantaisie de Bentley et de G. Hermann. C'est la notion de l'ictus confondue avec l'accent et avec l'arsis. Elle est naturellement étrangère à Aristide, comme á la rythmique ancienne tout entière.

Nous comprendrons dorénavant mieux pourquoi les grammairiens latins insistent de plus en plus sur la loi

1 Metrik, 373. 
des temps dans les rythmes, en l'opposant á la loi des pieds métriques. "Namque metrum certique pedes numerusque coërcent, dimensa rhythmum continet lex temporum ", dit Terentianus Maurus '. Nous lisons dans Mallius Theodorus " : Signa autem apud poetas lyricos aut tragicos quispiam repereril in quibus certa pedum conlocatione neglecta sola temporum ratio considerata sit, meminerit ea, sicut apud doctissimos quosque scriptum invenimus, non melra, sed rhythmus appelari oportere. "Il ajoute même encore une fois: "Si quid ergo praeter haec, quod non ad certam pedum legem, sed ad temporm rationem modumque referatur, vel scribet quispiam vel ab alio scriptum leget, id non metrum, sed "ythmon esse sciat."

Il faut bien se représenter toutes les conséquences de la liberté introduite dans la rythmique par la loi des temps. L'échange d'un pied contre un autre n'était pas borné á un seul pied par colon, ou par vers, il pouvait embrasser plusieurs pieds, tous même,pourvu que la mesure des temps fût gardèe. Un vers d'une telle composition était acceptable, mais seulement comme ry thmique.

Examinons maintenant l'influence du chant. Nous devons insister sur ce fait que,dans les rythmes, la composition du chant ètait l'ouvre principale." Inter metrum et rhythmum hoc interest, quod metrum circa divisionem pedum versatur, rhythmus circa somum, quod etiam metron sine psalmate prolatum proprictatem suam servat, rythmus autem numquam sine psalmate valebit ", dit Attilius Fortunatianus ${ }^{3}$. Or, les compositeurs anciens arrivèrent á manier le texte de la même façon que font les modernes, se souciant fort peu de la valeur quantitative des syllabes. Ils prolongeaient les longues et diminuaient les brèves : "Inter metricos et musicos propter spatia temporum, quae syllabis com-

1 Gram. lat. VI, 374 .

2 L. c., 583,583 .

${ }^{3}$ Gram. lat. VI, 2:0, 382. 
prehenduntur, non parva dissensio est, nain musici non omnes inter se longas et breves pari mensura consistere, siquidem et brevi breviorem et longa longiorem dicant posse syllabam fieri", voilá ce que nous apprend Marius Victorinus ${ }^{1}$. Il le répète encore une fois d'une façon un peu différente, en disant: " At hacc (syllabas) musici qui temporum arbitrio syllabas committunt in rhythmicis modulationibus aut lyricis cantionibus per circuitum longius extentae pronuntiationis tam longis longiores quam ruisus per correptionem breviores brevibus proferunt. "La mélodie s'affranchissait de la loi métrique, de même qu'elle s'était affranchie jadis de la limite des accents. Elle modulait les longues et les bréves de ses tons, non plus selon les syllabes du texte, mais selon l'impression qu'elle voulait produire. Elle prolongeait les longues et diminuait les brèves, et n'aurait-elle pas pu prolonger les syllabes brèves et diminuer les longues? Point de doute; voici, en effet, ce qu'en dit le même auteur" : "Rhythrnus autem ut volet, protrahit tempora, ita ut breve tempus plerumque longum efficiat, longum contrahat." A fin de ne pas nous borner au seul témoignage de Marius Victorinus, signalons ce passage de Saint Augustin, qui fut, on le sait, un des meilleurs rythmiciens de l'antiquité: " $A t$ vero musicae ratio, ad quam dimensio vocum rationabilis et numerositas pertinet, non curat nisi ut corripiatur vel producatur syllaba, quae illo vel illo loco est secundum rationem mensurarum suarum. Nam si eo loco, ubi duas longas poni decet, hoc verbum (cano), posueris, et primam quae brevis est, pronuntiatione longam feceris, nihil musica omnino offenditur ${ }^{3}$." Puisque le savant auteur a relâché un peu les liens qui unissent la musique á la rythmique, il faut la rétablir par un passage de Denys d'Halicarnasse oú nous ap-

1 L. c., 39.

2 L. C., 42.

${ }^{3}$ De musica, I. II, c, n. 1. Patrologia, XXXII, p. 1082. 
prenons en mème temps que la libertè rythmique, dont nous parlons, avait été connue et pratiquée dès l'èpoque classique de la littérature romaine, et même probablement avant lesGrecs, "Nam oratio soluta neque nominis, neque verbis illius tempora, vi illata, perturbat, sed et longas et breves syllabas, sicuti a natura acceperit,easdem conservat. Has vero $v$ hythmiconum et musicom scientia minuendo augendoque immutat, ita ut saepissime in contraria deventum sit; etenim syllabis non exigit tempora, sed temporibus syllabas ${ }^{1}$."

Le même fait est attesté par Longin ₹ que M.'Vincent a cité dans son important travail sur trois manuscrits

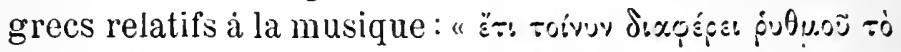

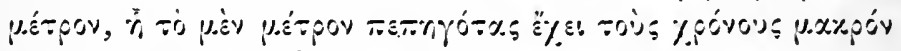

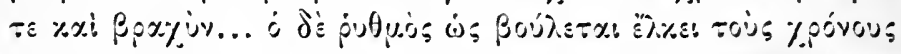

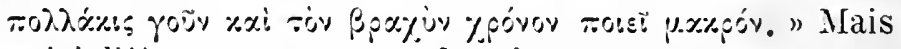
voici l'ètrange remarque dont le savant auteur accompagne sa citation: "Jamais ce rapport métrique de la quantité de syllabes longues et bréves, c'est-á-dire le rapport conventionnel de deux à un n'a èté admis dans la rythmique." G'est le contraire qui est vrai, parce que la loi métrique est bien la loi fondamentale rythmique, et tous ces changements, dont nous parlons à présent, n'appartiennent qu'à la rythmique transformèe.

Il nous semble donc maintenant ètabli que la nègligence dans l'observation des lois métriques ne provient pas de la corruption de la langue, comme on l'a souvent prètendu, mais bien des facteurs indiqués ici. 11 ètait permis de faire des rythmes exempts de la quantité déjá á l'èpoque classique, mais on n'a pas voulu se servir de cette liberté tant que la quantité resta sensible dans la langue. C'est pourquoi les rythmes de cette période classique ont d’ordinaire la régularité métrique; plus tard on profita volontiers de cette liberté, qui aidait $\dot{a}$ surmonter la difficulté mètrique.

1 Je comp. verb. XI, p. $13 \%$, el. Sicherek.

"Frag. III, cfr. Notices et extr. XYI. p. $19 \%$ 
mème. Nous savons dejjá que la scansio numerosa est ètrangère à l'accent, que la compositio modulata veut dire des vers avec une mélodie; ce qui signifie ad iudicium aurium. nous allons l'apprendre bientòt, en attendant, ajoutons quelques réflexions, Au temps de Marius Victorinus des poètes vulgaires, ignorant les régles mètriques, se mirent á composer des vers rythmiques, mais ce serait se méprendre gravement que de supposer que ce genre de versification soit sorti de l'esprit du peuple, car nous avons vu qu'il s'est formé sous l'influence de la technique musicale. L'opinion exposée dans nos préliminaires troure ici une éclatante confirmation.-Seconde rétlexion : selon notre grammairien le rythme ressemble de très près au mètre: "rythmus est aliquid consimile metro ": mais comme il n'y a pas de mètre unique, mais bien des mètres divers, il s'ensuit que les rythmes ressemblent aux mètres, c'est-à-dire un schème métrique quelconque à un schème rythmique. correspondant. Nous pourrions presque dèclarer qu'un rythme latin n'est rylhme qu’autant qu'il est calqué sur un métre. Pour le moment ce r'est qu'une supposition, que nous verrons vérifiée plus tard.

Nous avons encore á suppléer la fin de la description que Narius Victorinus donne du rythme: "Plerumque tamen casu quodam etian invenies rationem metricam in rhythmo, non artificii observatione sereata, sed sono et ipsa modulatione ducente. On rencontre, il est vrai, assez souvent dans les rythmes une certaine régularitè mètrique qui n'y est cependant qu'accidentelle. On la trouve, dit le grammairien, á l'aide de la mélodie, ou plutôt à l'aide du son qui diffẻre dans les voyelles longues el dans les voyelles brèves.

En éludiant los descriptions du rythme éparses, dans les écrits des grammairiens latins, on s'apercoit bientòt qu'ils entremèlent les définitions de presque toutes les phases parcourues par la rythmique; de sorte qu'il en résulte une confusion extraordinaire qui.jusqu’àpré- 
sent, a empêché les savants l'arriver à une juste notion du sujet. Pour lever les contradictions et faire le jour sur la matière, il fallait distinguer trois diffèrentes époques dans l'histoire du rythme: une oú il est identique avec les mètres, l'autre oú il s'est séparè des mètres par la loi des temps, et une troisième oú il s'est transformé sous l'influence de cette mesure abstraite et sous celle de la mèlodie prédominante. C'est ce que nous arons tâché de faire dans le prèsent travail.

La même confusion se rencontre aussi dans Dioméde, écrivain de la fin du troisième siècle. Nous trouvons pourtant chez lui une définition du rythme qui sert de base à la rythmique du moyen àge. Il dit d'abord: "Rhythmus estpedun temporunque iuncturacum levitate sine modo ". Que signifie l'expression "cum levitate" ? Avec négligence de la quantité. L'autre expression " sine modo " est éclaircie par cette autre phrase du même auteur: "Metrumest compositio Nodum positionis sublationisque conservans" ". Si donc positio et sublatio se rapportent á l'ictus, il s'ensuit nécessairement qu'il n'en avait pas dans les rythmes. Mais il faut prendre cette expression dans le sens d'une suite réglée de longues et de bréves, qui n'était pas ohservéenon plus dans les rythmes.

Avant lui dejá on donnait une autre définition du rythme qu'il répète: "A lii sic: hythmus est versus imago modulata, servans numerum syllabarum, positionem saepe sublationemque continens". Endisantrersus imago, une image, une copie du metre on ne faisait que répéter, tout en la précisant, l'idée de Marius Victorinus, Diomėde est le premier quimous a transmis la règle importante sur le nombre de syllabes.

Passons a saint Augustin qui nous fournira une explication de l'expression " ad aurium iudicium.$~ " N a m$. aurium iudicium, répond le disciple à son maitre, ad temporum momenta moderanda me posse habere non

1 Gram. lat. 1. 473.

2 L. c. 47 . 
nego, quae vero syllaba producenda vel corripienda sit, quod in auctor ilate situm est, ommino nescio ${ }^{1}$ ". L'èlève comprenait bien ce qu'étaient le temps long et le temps bref, mais, ne possédant plus le sentiment de l'antique quantité il ne savait quelles syllabes y mettre. Donc, et d'aprés son propre témoignage le sentiment de la quantitè n'ex istait dèjá plus au temps desaint Augustin.

A partir de Diomède la règle syllabique devient règle ètablie et fixe dans la ry thmique. Elle ètait l'expression la plus naturelle de toute la transformation subie, á la fin de laquelle le ry thme s'affranchit de la règle quantitative. Il y arait absence de pieds dans les rythmes sinon par accident. Du schème mėtrique qu'ils imitaient, ils ne gardaient plus que le nombre typique de syllabes, et la cèsure, s'il y en avait. Nous savons en outre que la cadence finale, jointe autant que possible á la rime, $y$ ètait obligatoire.

Voici la définition du rythme, que nous donne Béde le Vènérable: "Haec de metris eminentioribus commemorasse sufficiat ; videtur autem rythmus esse metris consimilis, quae est verborum modulata compositio non metrica ratione sed numero syllabarum ad iudicium aurium examinata, ut sunt camina vulgarium poetar um ". Il ne fait que répéter celle de Marius Victorinus, toutefois il y a changé numerosa scansio en numerus syllabarum. Il ajoute: "Quem vulgares poetae necesse est rustice, docti faciunt docte." Comment entendre le "facere docte" ? C'ètait suirre la forme du dimetre iambique ou du septénaire trochaïque ou bien d'autres mètres, c'était, à ce qu'il semble, observer la cadence finale.

On voit que le savant Anglo-saxon n'a d'autre notion sur le rythme que celle qui lui avail ètè transmise par les écrivains latins. Lui-même, comme son contemporain Aldhelm, a beaucoup contribuè à répandre la con-

1 Patrologia, XXXII, p. 1082.

a Gram. lat., VII. 258. 
naissance de la métrique et de la rythmique anciennes chez les Anglo-saxons.alors nouvellement entrés en contact avec la civilisation latine. Les formes, qui paraissent les avoir charmés ont sẻduit même des rois, tèmoin Aedilvald, qui envoyant a Aldhelm un poème rythmique latin avec deux poèmes mètriques, s'exprime ainsi ${ }^{1}$ : "Tertium quoque (sc. genus modulaminis carminum) non pedum mensura elucubratum,sed octonis syllabis in uno quolibet versu compositis una eademque littera conparis linearum tramitibus aptata, cursim calamo perarante caraxatum, tibi sagacissime sator transmittens dicavi:

\author{
liector casae catolicae \\ Atque ospes athletice \\ Tuis $p$ ulsatus precibus \\ Obnixe flagitantibus..."
}

Le souverain anglo-saxon, si amoureux de la poèsie, aurait-il abandonné l'usage des rythmes nationaux, s'il en avait existè de son temps ? Remarquons en outre, qu'il paraît suivre une régle d'allitération dẻjả assez précise, qui prescrivait de placer les mols à initiales identiques á la seconde et à la troisième place dans les vers octosyllabiques. Les cadences finales sont rimées et rythmiques, c'est-à-dire ayant la même quantitè.

Le tẻmoignage suivant nous est transmis par un ma-

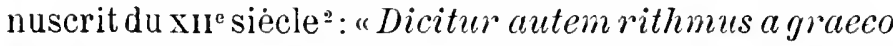
rithmos, i. e.numero, quoniam certa lege numerorum constituendus est. Numerus ergo in ipso notandus est, primo quidem in distinctionibus. postmodum in sillabis et consonanciis ". L'auteur éveille notre curiosité, comment expliquera-t-il le rythme, c'est a-dire le nombre, dans les vers, dans les syllabes et dans la rime, mais

1 JAFE, Monumenta moguntina, 37 .

- ZarNcke, Zwei miltelalterliche Abhandlungen über den Bau rythmischer Verse. Berichte d. k. sächs. G. der Wissenschaften, 1871, p. 34 . 
ceci ne l'embarrasse pas, car pour lui numerus ne représente que le nombre arithmétique. "In distinctionibus autem talis est numerus intuendus, quod plures distinctiones quinque vel pauciores duabus aliquis rithmus habere non potest". Il ne concède donc à une strophe que deux vers au moins et cinq au plus, règle qui nous paraît tout arbitraire, et dénuée de tout fondement historique.

"In sillabis vere talis est numerus adhibendus, quod nulla rithmorum distinctio pauciores quatuor vel plures sillabas sedecim habere prevaleat. Nous verrons plus tard la même règle répétẻe par les rythmiciens romains.

"In consonanciis quidem talis denotandus est numerus, quod in rithmom distinctionibus sillabae, quae penultimam forte producunt, consonantes quidem vel in duabus sillabis integris rel ad minus in una et dimidia esse necessario oportct". Levers "Gloriose rex coelorum " exige selon lui une rime en lorum, ou au moins en orum, "Si autem in rithmorum distinctionibus penultima corripiatur, necessarium est utique vel in tribus sillabis integris vel ad minus in duabus finalibus integris consonantia demonstretur". Le mot gloriae exige d'après lui une rime en oriae, ou au moins en riae, c'est-à-dire qu'il ne juge pas obligatoire que la rime commence à la syllabe accentuée.

La même publication de M. Zarncke contient un autre traité de rythmique un peu plus récent que le précédent. On y trouve les notions suivantes: "Rithmus est dictionum consonantia in fine similium, subcerto numero sine metricis pedibus ordinata". La première partie de cette définition traduite en français serait : Le ryhme c'est la rime appliquée á la fin des vers ; l'auteur lui-même confirme notre traduction en continuant : - Rithmus sumpsit originem secundum quosdam a colore rhetorico : similiter desinens... Quidam vero rithimus cadit quasi metvum iambicum, quidam quasi 
spondaicum lambus intelligitur in hoc loco dictio cuius penultima corripitur, constat enim iambus ex brevi et longa. Spondeus hic dicitur dictio cadens ad modum spondei ». Il distingue donc deux termes de la cadence finale.en donnant á l'une le nom de trochaïque, et à l'a.utre celui de spondaïque.Elles sont observées dans toute la poèsie rythmique du moyen àge avec une rigueur qui ne souffre pas d'exception. Les poètes rythmiques de ces époques ne comnaissaient pas toujours la quantité latine et l'on se demande comment ils ont pu trouver la juste cadence. Ils paraissent avoir été guidés par l'accent: Les mots accentués sur l'antépénultième ayant l'avant dernière syllabe brève, et la dernière se prolongeant dans la pause, ils trouvérent de cette façon la cadence iambique. Par conséquent ils regardaient comme trochaïques ou spondaïques les mots accentués sur la pénultiéme, même ceux de deux syllabes. Ils observaient done laccent dans les syllabes finales. mais seulement en tant qu'il les aidait á tronver la juste quantité. Ils ne l'observaient pas dans l'intérieur des vers si ce n'est par accident; ils ne se proposaient jamais d'imiter le rythme metrique par un rythme fondé sur l'accent. Les poètes dont l'oreille ètait fine érilaient de placer deux accents immédiatement l'un aprés l'autre, mais cette règle ètait inconnue des poètes médiocres.

Il faut toutefois accorder une large exception au rythme trochaïque. La langue latine ne possédant pas d'oxytons polysyllabiques, et les proparoxy tons n'y étant pas très nombreux. la cadence trochaïque est très fréquente et toute naturelle aux mots latins. Il y a donc beaucoup de vers latins rythmiques dans lesquels elle est presque régulièrement maintenue par les accents, mais dans les meilleures pièces, même de ce genre, on trouvera toujours quelques vers ou elle est brisée, bien qu'une légère transposition des mots eùt suffi pour la rétablir. Elle n'était done pas obligatoire, elle n'entrait pas dans la notion et dans la définition des vers rythmiques. 
C'est un fait que confirment tous les rythmiciensconnus de l'antiquitẻ et du moyen âge, sans exception. Et si même la régle des accents y ètait observée strictement, ce ne serait toujours qu'un phénomène secondaire et non pas un principe.

Après ces éclaircissements, je me permettrai de placer ici, comme épilogue à ce chapitre, une définition du ry thme contenue dans un glossaire celtique: ${ }^{1}$ "Sicut est rhythmus comparatus metro, sic sunt bardi comparati poetis doctis, sic sunt bardi sine mensura apud se (qui non didicerunt compositionem metricam) comparati poetis doctis ». Plus d'un lecteur, je l'espère, $\mathrm{y}$ trouvera matiére à réflexion.

1 Zecss, Gram. celtica, 1871, p. 93:. 


\section{VII}

\section{Les vers rythmiques sont calqués sur les mètres.}

La poésie rythmique latine dont l'importance grandit sensiblement à l'époque carlovingienne à côté de la poésie métrique, et qui la remplace presque entièrement au treizième siècle, nous présente une plus grande variété de formes qu'on ne le supposerait d'abord. Comparées aux formes métriques d'Horace et de Sénèque les formes rythmiques sont plus nombreuses : il s'agit d'expliquer la source de cette richesse.

Les exemples donnés par Horace et par Sénéque dans leurs compositions lyriques ont èté suivis non seulement par des poètes païens, comme Martianus Capella et Bö̈ce, mais aussi, et bien plus encore, par des poètes chrétiens dont le nombre est très considérable. Cependant ni les vers ni leur emploi ne sont exactement les mèmes. On y rencontre des mètres dont Horace et Sénèque ne se sont jamais servis. Il y a done des innovations qui révèlent en même temps une tendance archaïque. M. Lucien Mueller nous apprend qu'il y avait déjá au temps de Néron et d'Hadrien des auteurs, comme Fronton, Ammien, Septimius Serenus, qui s'efforçaient de surpasser Horace et Catulle en faisant revivre la variété des mètres employés jadis par Laevius et Varron. Voilá une première innovation.

La seconde innoration consistait dans l'emploi $x$ \%. oríg des vers mètriques qui n’ont jamais ètè employés auparavant rle cette manière, par exemple les pentamé- 
tres dactyliques dans Ausone et Martianus Capella, les vers adoniques dans ce dernier, le dimètre iambique dans Avitus et d'autres.

La forme des strophes ne resta pas non plus horatienne. Nous en trouvons de nouvelles composées de deux, trois, quatre ou cinq vers toujours égaux. Les vers sont des dimétres iambiques acatalectiques, des dimètres dactyliques ou anapestiques hypercatalectiques, des hendécasyllabes, des senaires, des septénaires etc. En écrivant sa strophe asclépiade, Horace lui-même clonnait le premier exemple d'une composition semblable.

La tendance vers une virtuositẻ métrique jointe à un goût archaïque est persomnifiée par Terentianus Maurus, ce grammairien qui dans son livre : De litteris, de syllabis, de metris ' a eu l'idée d'écrire chaque metre en se servant de ce mètre même:

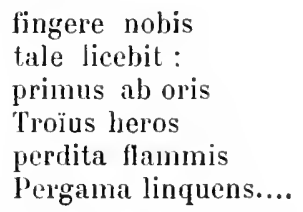

Ce sont des vers adoniques, employés pour la premiere fois $\% x \tau \dot{x}$ б $\%$ \%\%. Nous devons au grammairien que nous venous de nommer un précieux renseignement sur la popularité du dimètre iambique catalectique :

el condere inde carmen multi solent poetae.

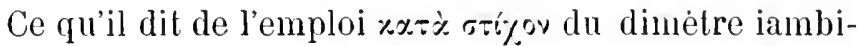
que acatalectique dans des pièces de quelque étendue ne manque pas non plus d'intérêt.

plerumque non carmen modo sed et volumen explicat.

Il nous apprend que le trimètre anapestique hyperca

1 Gram. lat., VI. 
talectique était une forme trés agréable à l'oreille des Romains :

\author{
anapaestica dulcia metra \\ cuicumque libebit ut istos \\ triplices dare sic anapaestos...
}

Ce vers compte presque toujours dix syllabes et il se divise en général en deux membres de cinq syllabes chacun. J'ajouterai ici encore un èchantillon puisé dans Sénéque :

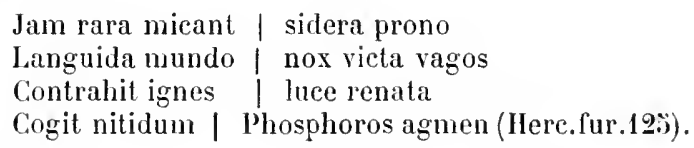

Ici, et aussi bien que dans les trimètres dactyliques, les anapestes remplacent les dactyles et vice versa, ce qui fait que ces vers revêtent un caractère rythmique.

Passons maintenant rapidement en revue les poètes lyriques de l'époque chrétienne, afin de bien nous convaincre que la poésie latine lyrique continua de virre sans interruption jusqu'au temps oú la poésie romane et la poésie nationale en général vinrent prendre place à ses côtés.

Le quatrième siécle a produit les deux meilleurs poètes métriques chrétiens : saint Ambroise et Prudence. Ils furent considérés, le second surtout, comme modèles par tous ceux qui les suivirent, ce qui donne une importance particuliére aux formes dont ils se sont servis.

Au cinquième siécle nous trouvons Paulin de Nole, Merobaudes, Aratus dans la Ligurie; Sedulius, Dracontius en Espagne; et les suivants en Gaule : Prosper d'Aquitaine, Marius Victor, Avitus, Paulin de Périgueux, Luxorius, Ennodius, Sidoine Apollinaire.

Après la victoire definitive des Goths et des Francs, il n'y a plus au sixieme siécle que Venantius Fortunatus en Gaule et Boëce en Italie.

Il faut chercher en Espagne et en Irlande les deux 
seuls poètes mètriques du septième siècle, ce sont: l'é vêque Eugène et Columban.

La fin du septième siècle et le commencement du huitième nous montrent la poésie latine métrique transplantée en Angleterre, oú nous trouvons Aldhelm, Béde et Winfrid ou Boniface, apòtre des Allemands.

Au temps de Charlemagne et aprés sa mort, on voit surgir dans le courant du neuvième siècle une foule de poètes latins. Le grand empereur lui-même a fait venir à sa cour Alcuin d'Angleterre; les diacres Paul et Pierre d'Italie, Angilbert, Eginhard; Amalarius d'Allemagne. Les noms poètiques dont se décorèrent quelques membres de cette Académie : Alcuin, Flaccus; Angilbert, Homère; Muaterin, Ovidius Naso; Charlemagne, David, nous indiquent les modèles qu'on s'efforçait d'y suivre,ils ne sont ni germaniques ni nationaux, mais bien classiques et bibliques.

Nous n'avons pas épuisé la liste des poètes de cette époque, car il faut citer : Paul de Frioul, Paulin, patriarche d'Aquilée, le pape Hadrien, Fardeulf, Dunbar et Theodulf, tous trois a St-Denis, Ermoldus Nigellus d'Aquitaine, Candidius, Raban Maur à Fulda, Wandilbert á Prüm, Walafrid Strabo à Reichenau, Smaragdus à Saint-Michel. Sedulius Scotus à Liège, Florus à Lyon, Andradus Modicus, archevêque de Sens, Milo, abbè de Saint-Amand, Heiric d'Auxerre. Ils cultivent pour la plupart la poèsie métrique, et s'inspirent de Prudence, mais ils citent trés souvent Virgile, Horace, Lucain et Stace, Martianus Capella s'appelle chez eux Marticinus noster, Boèce, autor noster. Leur inspiration artistique n'est alimentée que par des rèminiscences de l'antiquité. L'instruction littèraire et grammaticale,si ardemment encouragée par Charlemagne, semble avoir èté très cultivée dans les ècoles cathẻdrales et claustrales aprés la mort de ce prince.

Les vers principalement employès dans cette poésie sont l'hexamètre, l'hendécasyllabe, et le distique èlégia- 
que, tout comme au temps de Virgile, mais cest dans les pièces lyriques que nous rencontrons les mètres déjà relevès.

Le vers adonique se trouve dans Columban, Alcuin. Raban Maure, Walafrid Strabo. '

Le dimètre iambique catalectique dans Prudence. "

Le mètre phérècratien dans Wandilbert de Prüm. ${ }^{3}$

Le dimètre iambique est trés fréquent dans. les hymues.

Les trimètres dactyliques hypercatalectiques dans Prudence, Raban Maur et Walafrid Strabo. :

Les trimètres anapestiques dans Prudence. ${ }^{3}$

Les hendécasyllabes alcaïques et saphiques dans Prudence, Wandilbert de Prüm et autres. ${ }^{6}$

Les hendècasyllabes phaléciens, sans césure, dans Prudence, Florus de Lyon, Wandilbert de Prüm, Walafrid Strabo, Raban Maur. '

Les mètres asclépiades dans Prudence, en strophes de quatre vers, comme celles d'Horace, mais aussi $\% x \div \%$ r.y. puis dans Raban Maur et Wandilbert de Prüm.

Les senaires sont assez rares; Prudence en forme des strophes à cing rers. "

Les septènaires ont servi á Prudence à en former des strophes à trois vers :

1)a puer plectrum, choreis ut canam fidelibus

Dulce carmen et melodum, gesta Christi insignia

Hunc camoena nostra solum pangat bunc laudet lyra.

1 Poetae latini aevi Carolini (P'. C.), I, 257, 266, 394, 418.

2 Patrologie, LIX, 832.

s P. C. II, 619.

- Predexce, Peristrephanon, III ; Cathemerinon, III. - P. C.. I, $246,349$.

"Cathem., X.

${ }_{6}^{6}$ Perist. XIY. P. C. II, 244. 2:32, 381, 411, 412, 416, 418,44:,603.

T Cathem., IV. P. C., I, 248, 574 ; II, 3.44.

8 Cathem., 813; Praefatio libri I ad Srmmachum; Patrologic.L.X, P. C. I, 247, II, .:71.

3 Cathem., VII, Perist., $x$. 
La même strophe se trouve assez souvent dans Venantius Fortunatus et dans les poètes carlovingiens. Raban Maur, en répétant dans chaque strophe la troisième ligne de la première, en a fait un refrain. ${ }^{1}$

Voilà les modèles entre lesquels les poètes lyriques avaient à choisir. Ces modèles eux-mêmes, étant employés dans la poèsie lyrique, étaient dèjá en quelque sorte des rythmes. Mais les rythmiciens ne se tenaient pas exclusivement á ces formes; une fois habituès á calquer leurs vers sur les formes métriques, ils imitèrent presque tous les schèmes métriques, dont la connaissance leur parvint par les nombreux traités des grammairiens latins. Ils ne reculèrent même pas devant le mètre sotadéen.

Avant de commencer l'examen des rythmes du moyen âge, il ne sera peut ètre inopportun de placer ici quelques mots sur les plus anciens vers populaires des Iomains qui ont èté conservés par les ècrivains anciens et recneillis dans le savant ouvrage de M. Edèlestand du Méril intitulé: Poésies populaives latines antérieures au douzième siècle, Paris, 1843. La forme du septènaire $y$ prèvaut, on la trouve dans huit pièces $(4,5,6,7$, $14,18,19,21) .{ }^{2}$ Une seulement présente la forme clu distique élégiaque (D); trois celle du senaire $(9,10,11)$, deux celle du dimetre trochä̈que $(15,16)$; une celle du dimetre trochaïque catalectique (\$); une celle de l'hendécasyllabe (17). On voit que les vers populaires romains ont la forme mètrique.

Les vers vraiment rythmiques les plus anciens sont les liexamètres de Commodien et les octonaires de saint Augustin.s'il y avait une place pour l'accent dans la rythmique latine,c'est dans ces vers qu'elle ent dì bien ètre gardée, ce qui n’est nullement le cas. Seulement la cadence finale est strictement observée d'après la quantité.

1 Cathem., IX.

2 Les chiffres indiquent la place qu elles occupent dans la série; mais elles n'y sont pas numérotées. 
Accordons encore quelques lignes à la plus riche collection des rythmes postérieursà saint Augustin, mais antẻrieurs à Charlemagne. Elle est contenue dans le cèlèbre Antiphonaire de Bangor. ${ }^{1}$ Le vers qu'on y rencontre le plus fréquemment est l'octosyllabe, imitation du dimétre iambique (Terrorem tempus hoc habet et autres) : puis le septènaire (Audite omnes amantes Deum sancta merita); quelquefois le senaire, déjá avec l'assonance intérieure :

Sancti venite, Christi corpus sumite,

Sanctum bibentes quo redempti sanguinem.

Citons encore les fameux versiculi familiae Benchuir: c'est-á-dire : strophes de la congrègation de Bangor. Les vers sont heptasyllabiques, les strophes á quatre :

$$
\begin{aligned}
& \text { Benchuir bona regula, } \\
& \text { Recta atque divina, } \\
& \text { Stricta, sancta, sedula } \\
& \text { Summa, justa, ac mira. }
\end{aligned}
$$

Il n'est pas impossible que ce soient les premièresstrophes irlandaises de cette forme. Elles sont imitees de Prudence.Elies sont latines, et il nous semble que le rann irlandais n'en est qu'une application dans la langue nationale.

A partir de la fin du septieme siècle (c'est de ce siécle que date l'antiphonaire de Bangor) les rythmes deviennent de plus en plus nombreux. Nous ne les suivrons pas dans leur marche historique, nous bornant pour le moment à comparer leurs formes avec les schèmes métriques dont elles procédent.

L'auteur du premier traité publié par M. Zarncke nous apprend que : "Nulla rithmorum distinctio pauciores quatuor, vel plures syllabas sedecim habere prevaleat ". C'est donc par les vers de quatre syllabes qu'il nous faut commencer.

Comme il n'existe pas de métre correspondant aux

1 Mlratoki, Anecdota, VI, p. 119. 
vers tetrasyllabiques, ils ne peuvent dériver directement de la mètrique ancienne. Ils n'apparaissent pourtant qu’au dixième siècle, alors que les rythmiciens irlandais ont depuis longtemps domne l'exemple de la division des vers par la rime intérieure. C'est donc celte rime intérieure, qui placée á la quatrieme syllabe du vers octosyllabique, a donnè naissance aux vers en question :

Sancte sator suffragator

Legum dator largus dator. ${ }^{1}$

Le vers de cinq syllabes dérive du vers adonique dont nous avons relevé un assez fréquent usage $\% x-\dot{x} .5-\dot{\%} \%$ :

Herigèr urbis
Vaguntiensis

Le vers de six syllabes n'est pas une des formes principales. On pourrait le faire provenir du mètre ithyphallique $(-\cdots-\cdots-v)$ ou du vers eupolidion $(\cdots, \cdots-\cdots-)$, mais comme il n'apparaît quassez tard dans la poèsie rythmique, il est plus naturel de le dèriver du vers de douze syllabes coupé par la rime intérieure.

$\begin{array}{ll}\text { 0 Martine sancte } & \text { meritis praeclare } \\ \text { Juva me miserum } & \text { meritis modicum } \\ \text { Caream quo naevis } & \text { milhimet nocuis... }\end{array}$

L'allitération $m-m, n-n$ nous indique que les deux parties font un ensemble. Il est vrai cependant, que le vers hexasyllabique prend avec le temps une existence indépendante.

Le vers heptasyllabique procede du metrum choriacum, c'est-à-dire du dimètre iambique catalectique, l'autre scheme heptasyllabique : metrum pherecratium

1 1) MERIL, l. c., p. $16 \%$.

" Mclevnofr und Scheren, Menlimialer, 1873, p. 38. 
(_- - - n'ayant pas eu la mème popularité. Nous en avons cité déjá l'exemple le plus ancien. M. Wilhelm Meyer de Goettingue veut le dériver de la seconde moitiè du septénaire,mais il oublie,que cette seconde moitiè ne se sépare jamais de la première :

\section{Ad honorem Lum Christe \\ Recolat ecclesia \\ Praecursoris el baptislae \\ Tui natalitia}

Le vers octosyllabique se rattache au dimètre iambique, quoique les imitations rythmiques du mètre glyconique ou du dimètre iambique eussent domnè la mème forme rythmique. M. W. Meyer le fait sortir de la première partie du septénaire, mais comme la seconde moitiè de ce vers est toujours précédée par la première. aussi bien celle-ci est toujours suivie par celle-lá. Ni le rythme trochaïque ni l'iambuque ne sont jamais obser vès ici de suite par les accents, comme le montre l'exemple suivant :

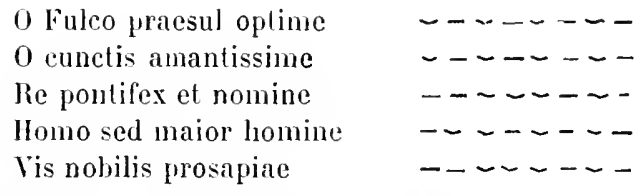

Le vers de neuf syllabes doit être rattachè aux anciens ennéasyllabes, surtout a l'ennéasyllabe alcaïque ( - - - =). Il est rrai que ce mètre n'ètait employè que rarement dans la litterature classique. et jamais $x x-\dot{x}$ s-iyo\%, aussi le rencontre-t-on bien rarement dans la poèsie rythmique. Les rythmiciens ont trouvé l'indication de ce mètre dans la mème source ou ils puisaient leur savoir, c'est-a-dire dans les grammairiens. Nous lisons dans Marius Victorinus : "Dimetrum iambicum si fucrit brachycatalcctum, eupolidion nominatur, sin vero catalecticum. anacreontion, sin autem hypercatalecton relcaicon dicitur". Les vers suivants sont du h uitième siècle : 
Audite versus parabolae

De qnondam puero nobili

Dum iret in solitudine

Aprum cum canibus querere...

Les vers dėcasyllabiques se rapportent aux deux schèmes métriques: le trimètre hypercatalectique dactylique, et le même trimètre anapestique (-- - - - 1 $-\sim 1-; \sim-1-\cdots-1-\cdots-1=$ ) qui donnent justement dix syllabes dans leur forme normale. Ce sont les rythmes classiques latins les plus nobles, et ils furent employés de préférence par Sènèque, Prudence, Martianus Capella et Boèce. Il est impossible qu'ils aient été abandonnés dans la rythmique du moyen âge. Aussi y trouvons-nous deux décasyllabes d'une forme un peu différente, l'un avec la:césure après la quatrième:

Flete viri lugete proceres

Resolutus est rex in cineres

Rex editus de magnis regibus

Rex Guillelmus bello fortissimus...

l'autre avec la césure après la cinquième :

Patricii laudes semper canemus

Ut nos cum illo semper viramus.

C'est un ephymnion au chant en l'honneur de saint Patrick dans l'antiphonaire de Bangor. Ajoutons encore un spècimen bien postérieur :

Orex regum qui solus in aevum
Regnas in coelis Heinricum nobis
Serva in terris ab inimicis?

La relation entre ce vers et le trimètre anapestique qui se divise, lui aussi, en deux membres égaux est donc clairement indiquée. Mais il n'en est pas de même du décasyllabe coupé après la quatrième que nous rapportons au trimetre dactylique. En voici un exemple mètrique, car nous n'en avons pas encore donné:

1 DU Méril, l. c., p. 294.

: ID., ibid., p. 294. 
Haec opulentia Christicolis

Servit, et omnia suppeditat. Absit enim procul illa fames Caedibus ut pecudum libeat Sanguineas lacerare dapes ${ }^{\text {. }}$

Tous les vers de cette strophe comptent dix syllabes, mais il n'y a pas de pause après la quatrième, excepté dans le cinquième vers et le troisième si l'on veut. D'un autre côté on pourrait admettre une pause aprés la sixième syllabe dans les trois premiers vers. A dire vrai, il n'y a dans ces mètres aucune césure. les rythmes analogues en ont pourtant. Comment expliquer cette difficultè? Considérons d’ajord que la lyrique latine possėdait deux espèces de mètres ou plutôt de rythmes, dont chacun comptait dix syllabes dans son schème typique. Convertis en rythmes du moyen âge ils n'auraient donné qu'une espèce de vers de dix syllabes, puisqu'aucun d'eux n’avait de césure fixe. Mais il y avait une prédisposition à une césure, une pause assez visible aprés la cinquième dans le trimètre anapesique, qui fut rehaussée par le chant. Cette césure une fois acceptée en provoqua une autre dans le second rythme décasyllabique, si on voulait les maintenir séparés. C'étaient donc des césures nouvelles, établies par les rythmiciens du moyen âge et indiquees par le chant, par les mélodies ".

Les vers de onze syllabes reposent sur l'hendécasyllabe classique, dont on distinguait trois espéces: le saphique, lalcaïque et le phalécien. Les deux premiers avaient une césure aprés la cinquième syllabe, le dernier n'en avait aucune. L'imitation rythmique des deux premiers sereconnaîtra doncà la fixité de la césure, celle du dernier par l'absence de césure. Les deux premiers ne donnent lieu à aucune remarque, mais nous devrons nous occuper du troisième qui est le plus important. Il

- Pridence, Cathem.. III.

: Voy. toutes les publications de Coussemaker. 
est imité dans les ver's suivants, firés d'un manuscrit du vill ${ }^{\mathrm{e}}$ siècle:

Amlegaris abbas esse dicitur

llle nomen primum tenet hominum

Ilunc fatentur vinum velle bibere

Super omnes Andegaris homines

lia. cia, eia laudes eia laudes dicamus Libero.

M. IV. Mejer' découpe ce vers dans le septenaire, en divisant son premier memure en deux parties égales; et rejetant une d'elles: $(\mathbf{t}+)^{\prime}+\boldsymbol{t} \mathbf{i}$. Au vers ainsi déduit. il attribue une césure après la quatrième : hunc futentur| rimun velle bibere. Mais un autre philologue pourait la placer apres $x$ inum, un troisieme, M. Bartsch, la place apres velle ${ }^{2}$. En analysant un hymne de provenance irlandaise ${ }^{*}$ :

Vox paterna super Christum sonuit

In columba spiritus apparuit,

il place la césure aprés Christum, et spiritus. bien que ce ne soit pas la mème, parce que la distinction qu'en fait M. Bartsch, appelant l'une masculine, lautre fèminine, est inadmissible. M. Meyer placerait la césure dans les vers en question après paterna et columba. Xi l'un ni l'autre de ces savants n'a raison, parce que le mème hymne contient nombre de vers qui contredisent lopinion de M. Bartsch:

maris magni velut | in periculo...

capitali centro | cartilagini...

renas, fibras fel / cum bucliamine...

et d'autres qui sopposent á celle de M. Meyer:

impenetrabili dens tuleli

mamillas stomachum et umbillicum

gigram cepplate cum iaris el conis...

1 Ludus de Anticluristo, p. 90.

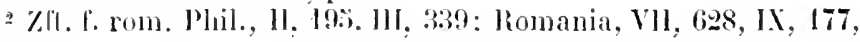
191.

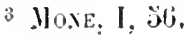


M. Bartsch peut allèguer des vers qui paraissent marcquer sa cèsure par la rime :

Gaude chorus omnium fidelium

Rosa fragrans lilium convalium.

Mais on trouve parmi les Cumina burana des hendécasyllabes, qui n'ont pas de césure aprés la cinquième. qui se rapportent done nécessairement au métre phalécien et dans lescuels pourtant la rime intérieure occupe une autre place ${ }^{1}$ :

Nemus revirescit frondent frutices hiems sera cessit laeti iuvenes.

Les vers hendécasyllabiques ètaient assez longs pour offrir plus d'une place à la rime intérieureá l'époque oú elle était á la mode. On sait qu'on finit par rimer les hendécasyllabes et d'autres vers de la facon suivante:

Deo meo raro paro titulum Astra castra regit egit seculum ${ }^{2}$.

Il y avait donc dans la poèsie rythmique latine un hendėcasyllabe sans cèsure et il nous importait de l'ètablir.

Les vers rythmiques de louze syllabes présentent deux modéles. Lun a la césure après la cinquième syylabe, imitant l'antique senaire:

0 tu qui servas arnis ista moenia

Toli dormire, moneo, sed rigila! 3

On pouvait $y$ introduire une rime à la césure:

Ad coeli clara non sum dignus sidera

Levare meos infelices oculos :

et en former ensuite une strophe de $5,7.5,7$; ou avec un redoublement du premier memije: $5,5,7,5,5, i$ :

$1 \mathrm{Nl} ., \mathrm{l}: 39$.

2 Zamicke, l. c.. Th.

${ }^{3}$ Du Meril, 1. c., 268.

+ P. c. Paula d'Agcllée. 
0 sanctissima

0 piissima

Virgo dulcis Haria

Mater amata

Intemerata

Ora, ora pro nobis?

L'autre dodécasyllabe avec la cèsure après la sixième, ne peut être que le reflet rythmique de l'asclépiade métrique, comme l'a dejjá déclaré M. Léon Gautier:

O roma nobilis, orbis et domina

Cunctarum urbium excellentissima

Roseo martyrum sanguine rubea... ${ }^{2}$

Rimé á la césure, il a pu donner un vers de six syllabes:

Mittit ad Virginem non quemvis angelum

Sed fortitudinem suam, archangelum

Amator hominis.

Le vers de treize syllabes n'apparaît que dans la seconde moitié du douzième siècle, c'est-à-dire à l'époque oú florissait la poésie française. La poésie antique ne nous prèsente aucun métre correspondant, or, pour lui trouver une explication, il faudrait a voir recours à l'alexandrin français, qui compte sourent treize syllabes. On pourrait donc supposer que c'est de l'alexandrin à la césure féminine que sort le vers latin, dont nous nous occupons. Il a èté construit par un poète qui savait bien qu'á chaque vers français correspond un vers latin, mais qui a vait oublié que l'alexand rin ètait une imitation de l'asclépiade. Voici un échantillon:

Flete omnes populi flete et non parum

Graves luctus facite planctum et amarum

Flumina effundite undas lacrymarum

Sic ruinam plangite urbium sanctarum ${ }^{3}$.

Coupé par la rime à la césure, il donna une strophe: $7,6,7,6$ :

1 MoNe, no 343.

2 Du Méril, l. c., p. 939.

` Id., ibid., p. 4ll. 
Concinamus pariter Et Deum laudemus Sebaldum alacriter Votis provocemus.

Il y a aussi des strophes dont le premier membre est redouble : $7,7,6,7,7,6{ }^{1}$.

Le vers de quatorze syllabes, avec une césure après la septième, n'est qu'un redoublement du vers heptasyllabique. Quelquefois même on se demande si le vers est de sept ou de quatorze syllabes:

Gaudens transiisse latos in campos prosae Vitam perlustrans plene loquelae spatiosae Ut vitulus solutus, vinculis obligatus

Metro relicto sanus vagus sum liberatus... ${ }^{2}$

On a trouvé un échantillon des vers á quatorze syllabes, mais avec une cèsure après la huitième:

Placidas dum perpensaret | quid illi faceret... ${ }^{3}$

C'est une imitation rythmique du mètre sotadéen, dont

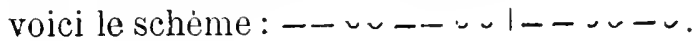

Le vers de quinze syllabes. une des formes principales usitées au moyen àge, provient du septénaire antique. Il a èté bientôt coupé par la rime, donnant l'origine à la strophe: $8,7,8,7$. Le redoublement du premier membre donna naissance à la strophe la plus gracieuse du moyen âge: 8,8, 7, 8, 8, \%, connue par le Stabat mater dolorosa. Voici les formes d'autres strophes qui en sont dérivées : $8,7,8,7,8,7$; ou $8,7,8,7,8,7,8,7$; ou $8,8,7$; $8,8,7 ; 8,8,7 ; 8,8,7$; ou bien 8887 ; il y en a aussi en $8,8,8,8,7 ; 8,8.8,8,7^{4}$. On a coupé encore le premier membre en deux parties par la rime pour obtenir la strophe: $4,4,4,4,7$ :

1 Mone, 1, p. 62.

2 Neues Archiv., IV, 238 ; cfr. Muratori, Antiq., III, 688 ; A. MAI, Classici auct., V, 405, 4l2; Mone, I, 41 .

3 Zft. f. Alterthum, XXIII, 273. Cfr. W. Meyer, Ludus, 102.

4 Mone, nos 312, 326, 360, 363, 380, 416, 457, 465, 479, 489, 510, $320,522$. 


\section{$-130-$ \\ Laetabundus \\ Plaudat mundus, \\ Plaudat Deo \\ - Cum tropeo \\ Decus omni saeculi '.}

Les strophes dans lesquelles Héloïse déplore la mort d'Abélard sont vraiment ingènieuses : 8, 8, 7, 4, 4, 7:

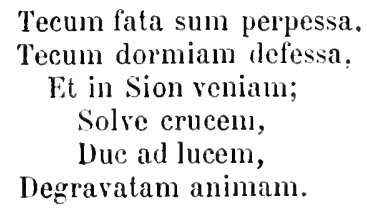

On rencontre quelquefois dans la poésie rythmique du moyen âge des vers de seize syllabes dont nous donnons l'échantillon suivant, qui est du commencement du onzième siècle :

Altrix sanctorum patria profulit Aquitania Sanctitate landabilem Emmeranum pontificem. ?

Est ce l'octonaire rythmique, comme ceux de saint $A u-$ gustin :

Omnes qui gaudetis pace morlo verum iudicate...,

ou bien deux octosyllabes liès par le sens?

Nous venons de voir que tous les vers rythmiques du moyen àge sont modelès sur un mètre antique, qu'ils gardent le nombre typique de syllabes, et la césure s'il en existait une dans le mètre correspondant. Ce sont les vers ì césure qui. reproduisant fidèlement le schéme antique. nous défendent de voir dans les vers sans césure des constructions arbitraires. Assures que nous sommes que les uns reproduisent les schemes metriques. nous sommes obligés d'admettre qu'il en est de même des alltres, puisque tous sont des rythmes. Il est rrai, comme

1 Daxiel, II, 240 .

2 Veues Apchir. für 1. Geschichte. 1881. p. 60\%. 
l'a fait remarquer M. Gaston Paris, ' que dans beaucoup de vers latins du moyen ige les accents produisent un rythme trochaïque presque régulier, mais dans la plupart des cas la place des accents n'est constante qu “a la cèsure et ála fin des vers. Voici ce que dit M. Bartsch : - Die nach dem Accent gebauten lateinischen Verse mittelalterlicher Gedichte sind. dieser (irundsatz ist festzuhalten, nur theilveise vom Accente beherrscht... Nur Versschluss und Caesur stehen unter dem Gesetze des Accentes, im übrigen werden die Silben nur gezinhlt ”. Nous avons tâché d'expliquer dans ce travail le vrai sens de cette régle, qui toutefois demancle une forte rectification, et de montrer comment elle s'est étabiie.

2 Bibliothèque de l'École' des Chartes, 1866, p. \$78 s. 


\section{VIII}

Les formes libres et variables de la rythmique grecque du moyen âge transportées dans l'occident $\mathrm{y}$ ont èté réduites peu à peu aux formes de la rythmique latine.

Nous croyons devoir commencer ce chapitre par l'analyse du dernier travail sur le sujet en question. Il a pour auteur M. W. Meyer, le sarant professeur de Goettingue, qui s'occupe avec prédilection de la rythmique du moyen âge. Il déclare, comme nous l'arons mentionné deją, que la versification rythmique ne peut dériver de la

- versification métrique, que les opinions reçues sur l'origine de la poésie rythmique sont erronèes et qu'il a trouvé la vèrité ${ }^{1}$. Il prend pour base de son examen les "Camina Visibena " d'Ephrem, cèlèbre théologien syriaque du quatrieme siècle. Il leur trouve une forme identique aux rorisix des Byzantins, et en conclut, que ces derniers, qui sont moins anciens. ont été modelés sur les premiers. En attribuant à la versification d'Ephrem le caraclère sémitique il fait sortir d'une poésie sèmitique générale l'origine de la versification rythmique et de tous ses traits caractéristiques, á savoir : le syllabisme, la mesure marquée par l'accent, l'ordre alphabétique des strophes. les acrostiches et la rime. Ce nouveau systeme le versification a passé, selon lui, des Syriens aux Bjzantins qui, á leur tour, l'ont transmis aux Romains. Il soutient que déjá Commodien et saint Augustin

1 Abhg. d. bayr. Als. d. Wiss., Philos. hist. Cl., XVII. 
avaient suivi ces nouveaux modéles - chose étrange, puisque l'un emploie l'hexamètre et l'autre l'octonaire, et ni l'un ni l'autre ne maintiennent l'ordre fixe des accents, excepté dans les cadences finales, en quoi ils observent une règle de la rythmique latine.

Toutes les autres assertions de M.IV.Meyer nous semblent aussi peu fondées. D'abord. l'auteur partage la grave erreur de la philologie allemande qui consiste à considérer la rythmique comme essentiellement diffèrente de la métrique. Il est indispensable que la philologie renonce á cette opinion erronée. Une fois la rythmique bien comprise, nous concerrons facilement sa transformation par les agents que nous avons tâché d'indiquer dans le présent travail. Le produit de cette transformation est bien le syllabisme limité par les modéles métriques. Au moyen âge, on connaissait encore á l'accent une fonction diffèrente, ce qui empèchait de lui donner une fonction rythmique. Les acrostiches ont été connus d'Ennius. et nous avons démontré que notre rime tire son origine de la rhétorique latine. Ainsi la versification rythmique, avec tous les signes que M. IV. Meyer considère comme caractéristiques, se déduit avec clarté de la poésie classique, et nous n'avons pas besoin de recourir á la source sèmitique.

Une objection des plus graves á opposer aux opinions de M. Meyer consiste dans lincertitude du nombre des syllabes et de la place des accents dans les anciens vers sémitiques. On sait que les langues sémitiques contiennent des voyelles pleines et des demi-royelles qu'on peut compter ou omettre, et que l'écriture sémitique ne marque pas. La versification syriaque restera donc à cet ègard une chose toujours obscure, et c'est une mauvaise méthode que de vouloir éclaircir une chose obscure par une autre qui l'est encore plus.

Ici se prèsentent á notre esprit deux réflexions d'un ordre plus général.Les Grecs regardaient tous les autres peuples comme barbares parce que ces peuples ne pos- 
sèdaient ni arts ni sciences. Ce juste orgueil derint plus tard lapanage des Romains, hèritiers de la culture grecque. Le prestige dont jouissaient les arts et les institutions gréco-romains auprés des peuples soumis á la domination romaine, et devenus peu à peu sensibles à la beauté de cette culture, a dû être considérable. La possession de ces arts, musicaux aussi bien que plastiques, entra pour beaucoup entre les mains des missionnaires chrètiens pour leur ceuvre de conversion.

Il est nécessaire, en outre, que notre science entre en harmonie avec l'histoire des autres arts, ses frères. Puisqu'il est démontré déjá que la sculpture, la peinture et l'architecture n'ont retrouvé un nouvel essor au moyen âge que sous le souffle des traditions antiques, ne se sont développées ensuite que sur la base et avec des motifs de l'art antigue, il faut à prior $i$ s'attendre $\dot{a}$ une analogie quelconque dans les arts musicaux. Notre point de vue nous est donc imposé par la loi psychologique de l'analogie, tandis que toute autre direction dans les recherches ne peut être inspirèe que par le hasard. Essayons donc avant tout d'éclaircir les formes et les sujets de la poésie nationale des peuples europeens : des Irlandais, des Anglo-saxons, des Allemands, des slaves sur la base des traditions antiques, et tout ce qui se refusera alors a l'explication entreprise de ce point de vue, vraiment historique, pourra être attribué á juste titre à une production indépendante et spontanée.

Si l'influence des arts gréco-romains a été si forte du côtè de l'Occident, en aurait-il été diffẻremment du côtè de lorient. Dans le cas qui nous oecupe nous avons heureusement un témoignage historique bien décisif : M. Meyer soutient que la versification d'Ephrem est l'origine sémitique.mais Eplıren ne faisait qu'imiter les vers et les strophes l'un de ses prédécesseurs nommè Harmonius, fils de Bardesanes, dont les poésies du conmencement du troisiéme siècle étant hèrétiques et proscrites ont completement disparu. C'est d'elles que parle 
d'abord un historien byzantin. Nicéphore Caliste Xantopoulos dans le passage suivant " : Et paterquidem nominis suis haeresim instituit, filius autem Graecis disciplinis satis eruditus, patriis vocibus, legitimis modis musicisque numeris inclusis, ordine circulari eas cani instituit, quos ex tempore hucusque Syri psallentes usurpant. Nam ille ad paternam delapsus haeresim... lyricis modulis doctrinam eiusmodi aspersit. Quibus multi ex syris propter verborum venustatem et sonor 'um numeros demulsi. paulatim opinionibus talibus recipiendis sunt assuefacti. Caeter um divus Ephraim ea re cognita, quamvis (iraecarum artium expers, Harmonii numeros moderatus est, atque eiusdem modulis caminibus ecclesiasticae sententiae consonis adiectis, Syiris ad hoc usque tempus ea canenda dedit. Nam divinos hymnos plurimos ad Har. monii caminum leges composuit ". L'historien byzantin veut dire que le fils de Bardesanes s'est chargé de la composition des chants pour la communauté parce qu'il ètait exercé dans les arts musicaux des Grecs. Il les a composés rour deax chours, á l'imitation des chants lyriques. Saint-Ephrem de son côtè en conserva la forme, tout en changeant le texte et en "modèrant" le rythme. Nous apprenons ici, en outre, que les modes et les échelles musicales grecques ètaient réputées seules lègitimes che $z$ les Syriens de cette époque.

Revenus sur le solide terrain des traditions antiques, nous pouvons esquisser maintenant lhistoire de la rythmique transformée chez les Grees. Cette tàche nous sera aisée après les savantes publications du cardinal .J.B. Pitra et de M. Christ. C'est au premier quappartient le mérite d'avoir ouvert un nouveau champ aux recherches d'histoire littèraire du moyen àge,celui de la poésie chrétienne chez les Byzantins, dont le second a considé-

1 Hisloriae ecclesiasticac libri XVIII. Basileae, 1\%:39, lib. IX, p. 4H. - Il vivail au quatorzième siècle, mais disposant de la bibliothèque de l'llagia Sophia il a pu puiser aux meilleures sources. 
rablement approfondi l'étude. Il faut joindre à ces deux noms celui dejà tant de fois prononcé de M. WV. Meyer qui de son côté en a élucidé quelques points importants, et ne pas oublier le Père Bouvy qui a enrichi la science de plusieurs données historiques. ${ }^{1}$ Nous avons dejà mis ces travaux á contribution en traçant les lignes générales de l'histoire de la musique dans l'église, que l'histoire des ry thmes byzantins suit d'une manière parallèle. Le chant et la poésie ont èté introduits simultanément dans l'église, les poètes byzantins ètaient à la fois mélodes et musiciens. La tradition antique s'y est maintenue encore sur ce point-là.

La poésie liturgique byzantine a èté précédée d'une poésie grecque, déjá chrétienne, mais personnelle. Les premiers documents remontent jusquau troisième siècle et les frères Apollinaires, Nonnos, Grégoire de Nazianze, Mèthode et Synésius en sont les auteurs. Suivant $M$. Christ ils ont employẻ dans leurs œuvres l'hexamètre, le vers anacréontique. le trimétre, et le septènaire, qui me paraît être plutôt ver's sotadéen. La plupart d'entre eux ne suivent plus les règles de la métriqueantique. Voici ce que dit le savant philologue à propos de l'un d'eux,tout en appliquant á d'autres la mème pensée" : Nullo vero modo in metricis versus leges verba huius orationis cogi possunt, unde, si qua lege oratio vincta est. accentu, non quantitate syllabarum numeros regi statuas necesse est ". Que le consciencieux savant nous dise lui-mème de quelle manière le rythme fondé sur l'accent s'y manifeste: ".....Jam si accentibus ducibus rythmum singulorum colorum et versuum definire coneris, non omnes versus iisdem numeris includi. sed alia cola iambicorum alia dactylicomum

1 J.-B. Pitra, L'hromnograplie de l'église grecque, 1867. - Analecta sacra, 1876. - W. Christ el Saraxikas, Anthologia graeca carminum Christianorun, 1871. - W. Neyer, l. c. - P. Boury: Poètes et mélodes, 1886.

Z L. c., XIV, cfr. XIII. 
alia et longe plurima logaedicorum versiculorum speciem imitari intellegas ». Peut-on vraiment supposer à ces auteurs l'intention d'imiter par les accents les pieds de la poésie métrique : puisqu'il n'y a pas de mètres de cette structure, comment ces vers rythmiques en seraient-ils l'imitation? Tous les mots qui composent un vers ayant des accents, ces accents doivent nécessairement se grouper de quelque façon, et a l'aide des accents secondaires on y trouvera toujours des pieds trochaïques, dactyliques ou autres, ce qui néanmoins ne constitue pas de rythmes suivant les données des anciens. Dans la premiére période rythmique ils exigeaient dans un vers rythmique l'égalité des pieds, dans la seconde l'égalité des temps dans les parties correspondant aux anciens pieds, dans la troisième un nombre de syllabes dèterminé par le schème métrique. Il n'y avait donc pas de place intermédiaire pour un rythme fondé sur l'accent, d'autant plus qu'on connaissait toujours à l'accent une fonction diffẻrente. La rythmique grecque transformée, en présence de laquelle nous nous trouvons ici.n'est pas plus basée sur l'accent que ne l'ètait la rythmique latine transformée: Rhythmus est versus imago servans numerum syllabarum. Cette règle de la rythmique latine est donc en même temps la règle de la rythmique grecque transformée. Les opinions des grammairiens latins que nous avons prèsentẻes plus haut sont donc en même temps autant de témoignages sur la rythmique grecque, parce que ces auteurs ne font pour la plupart que reproduire les règles de leurs maîtres en arts.

Passons á la poésie byzantine, à celles de ses formes surtout qui ont une importance très considèrable pour la poésie européenne. Ce sont les tropaires, strophes d'une étendue variable contenant jusqu'á vingt cola, mais quelquefois raccourcies á n'en contenir que quatre. La tradition en nomme Anthimos et Timoclés au cinquième siècle comme leurs premiers auteurs,mais le plus ancien tropaire connu est, d'après M. Christ, ce- 
lui de l'empereur Justinien lui-mème. ${ }^{1}$ Il est donc certain, qu'ils étaient en usage déjá au sixiẻme siècle, cependant les plus célébres auteurs de ce genre de chants: Sophronius, Sergius, Romanus, Anastasius, n'appartiennent qu'au siècle suivant. Cette poèsie fut développée plus encore au huitième siécle par André de Crète, Cosme de Jèrusalem, Jean de Damas. les premiers auteurs des canons. Les siècles suivants virent encore s'accroitre le nombre des poètes et celui des poèmes, et ce n'est qu'au onzième siècle que cette veine commenca à être abandonnée.

Les premiers tropaires, toujours pourvus d'une mèlodie. ont servi de modeles à d'autres strophes strictement calquées sur la strophe originaire, qui fut alors appelée hirme, tandis que l'imitation s'appellait automelon ou idiomelon. Plusieur's strophes composées sur le même hirme formaient une ode, et neuf odes, nombre qui correspondait aux neuf parties de l'office divin, formaient un canon. Toutes ces compositions avaient pour but dembellir la liturgie par le chant et par la poèsie qui lui manquaient encore. On intercalait les tropaires dans presque toutes les parties de la liturgie. mais particulièrement dans les matines et les rêpres.

La Grèce moderne qui se sert encore anjourdhui de ces compositions anciennes, ignorait elle-même, il n'y a pas longtemps encore, leur struclure artistique; et croyaient qu'elles étaient en prose. L'erreur a èté dissipée par le cardinal Pitra, qui y trouva des membres indicuès dans d'anciens manuscrits par des points et des astérisques. Celte observation a èté confirmée par $M$. Christ rui, aprés avoir soumis ces compositions a l'examen au point de rue rythmique, s'exprime ainsi " : $S u b$ finem huius capitis de colis eorumque numeris ut summam question is complectar et quibus numerom legibus camina illigatn fuerint. breri definiam, by-

1 1.. 1., p. :32.

2 L. c. LXXXVIII. 
santini melodi et cantores non rhyth mum sed rhythmi quandam umbram consecuti sunt. Atque adeo numerorum natura eos latebat, ul nee magristri cola in pe. des dirimenda esse monerent.nec musici lineis aliisve adminiculis rul modos in aequales particulas dissecondas uterentur. Pedum igitur divisionem cum spernerent, colorum divisio ultima eral". Lestropaires byzantins ne contiennent donc pas de pieds, et la senle subdivision des strophes qu'on y remarque est celle des cola, tout comme dans la lyrique chassique. Le rythme iambique fondè sur laccent serait vraiment facile à construire dans la langue grecque qui possede de non. breux oxytons, et pourtant voici ce qu'en dit M. Christ: "Colu qure iambicorum colorum similitudinem ite referrent, ut unoquoque pede acutam syllabam loco longae haberent, equidem nulla nori. 11 aurait raison de s'ètomner, si les mèlodes byzanlins n'avaient employé aucun signe pour le rythme: "Quameis paene innumeras notas musicas excogitaierint, quibus non solum altitudinem vocis sed etiam temporis spatium,et vocis varios flexus noturent, tamen uullo signo ad rhythmum numerosque indicandos usi sunl", mais le ry thme y ètait indique par les "notae temporis spatiorum". C'est bien le rythme du moyen àge, ce n'est pas le nôtre, mais il est vrai que nosidèes sont faussées sur cesujet par le ry thme vif et rapide de nos danses. Ce n'est pas sans raison que le moyen àge admirait son rythme car aujourd hui encore il charme quiconque sait l'apercevoir. Il faut le chercher daus le chant et ici dans des suites des notes longues et brèves et des figures mẻlodiques placèes aux endroits parallèles, ou à peu près, dans les vers d'une strophe. C'est Gui d'Arezzo qui en parle avec le plus de pénetration: "Sicque opus est, ut aliae voces ab aliis morulam duplo longiorem vel duplo breviorem habeant; ac summo opere caveatur talis neumarum dispositio ut aut in numero rocum ant in ratione tonorum neumue alterutrum conferantur atque responHYTHMS 
deant... Item ut reciprocata neuma eadem via, qua venerat redeat, ac per eadem vestigia recurrat.... ${ }^{1}$.

Repoussant l’ictus, nous saisirons l'occasion qui se présente de lui porter un nouveau coup. Voici ce que nous apprend le savant philologue ${ }^{2}$ : "Recentiorum Graccorum in cantilenis fere singulac syllabac singulis ictibus pedis feriuntur, rarissimeque duo soni correpti uno ictu comprehenduntur". C'est bien l'ictus de l'antiquité transmis jusqu'á nos jours, mais déjả des grammairiens antiques avaient enseignè que la thèsis aussi bien que l'arsis possẻdaient leur ictus : "Pes ictibus fit duobus ", ditTerentianus Maurus ; "Ictibus duobus žpass et Ásıs perquivenda est", dit Diomède ${ }^{3}$. Evidemment il ne représente pas l'élément rythmique, il indique ici, comme là, le mode d'énonciation des tons longs par des frappés prolongés et des tons brefs par des frappés brefs.

Le rythme fondé sur l'accent a trouvé un nouveau défenseur dans le P. Bouvy. La notion de l'accent que l'auteur s'est faite n'est pas exacte. Il est pour lui le principe logique qui fait du mot l'image de l'idée. Or, cette fonction logique, ou plutòt psychologique, appartient surtout à la syllabe radicale du mot. L'accent de son côté représente, ḋ notre sens, l'élėment exclusivement afLectif, qui relève tantôt l'idée du mot représenté par le radical, tantôt la relation exprimée par la désinence,tantôt le mode de la relation, en faisant ressortir la syllabe thèmatique. C'est cet élèment affectif qui l'a rendu le générateur du chant et de la musique.

Le P. Bouvy pense que l'accent avait été penclant la période classique l'auxiliaire de la quantité et servait principalement á introduire la varièté dans l'uniformitè du rythme. "Les correspondances toniques ", dit-il, " formaient un rythme de surcroît et de luxe qui sajou-

1 Grabert, Scriptores de musica, II, IJ̈; cfr. Lambillotre, l'esthétique, théorie et pratipue du chant grégorien.

2 L. c., I.XXXI.

3 I. c., VI, v. 1343,1, p. 47, cfr. Westrint, Theorie der inusischen Künste der IIellenen, 1885, § 24. 
tait au ry thme nécessaire pour en augmenter la richesse et la perfection ". Nous savons déja que dans la rythmique ancienne les thésis et les accents ne saccordaient pas ensemble, sinon par accident. Si tous deux ètaient des èlements constitutifs rythmiques, il se contrariaient trés souvent, ils s'annulaient au lieu de se renforcer. Admettre ces deux èlements rythmiques est donc un contresens. C'est ainsi qu'une fausse doctrine égare les meilleurs esprits, car le P. Bouvy ètait bien prés de saisir le vrai caractère de l'accent antique.

Examinant la disposition des accents dans les tropaires, ce savaint a fait une observation fort interes. sante. Il a remarique que les accents gardent un certain ordre, non seulement á la fin des cola, mais quelquefois (Sergius) dans toute l'étendue des strophes. La quantité des syllabes ètant indifférente, nous pouvons désigner les syllabes par des $x$, et voici d'aprés notre auteir la distribution des accents dans une strophe:

$$
\begin{aligned}
& \begin{array}{llllll}
\mathrm{x} & \mathrm{x} & \mathrm{x}^{\prime} & \mathrm{x} & \dot{x} & \mathrm{x} \\
\mathrm{x} & \mathrm{x} & \dot{x} & \mathrm{x} & \mathrm{x} & \dot{x}
\end{array}
\end{aligned}
$$

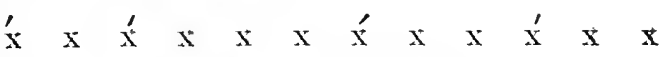

$$
\begin{aligned}
& \begin{array}{lllllllllll}
\mathrm{x} & \mathrm{x} & \mathbf{x} & \mathrm{x} & \mathrm{x} & \mathrm{x} & \mathrm{x}^{\prime} & \mathrm{x} & \mathrm{x} & \mathrm{x} & \dot{x}
\end{array}
\end{aligned}
$$

Tans cette strophe les accents ne se répètent pas dans un ordre domné, ils ne constituent donc pas un rythme, mais chaque strophe suivante de l'ode entiere place les accents aux mêmes endroits. Cette disposition des accents, pour n'être pras rythmique, ne laisse pas d'ètre prèméditée et doit avoir un sens. Sourenons-nous que pour les mèlodes byzantins les signes des accents ètaient en même temps des neumes, des signes de la notation musicale. Or, il parait probable qu'en répètant les mêmes accents dans toutes les stroplies; on diterminait la mèlodie, les faites de la mélodie du tropaire. Cela s'accorde trés bien avec la règle donnée par Théodore

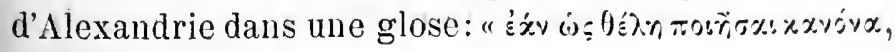




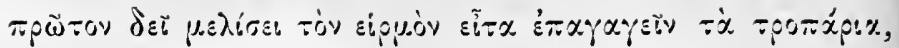

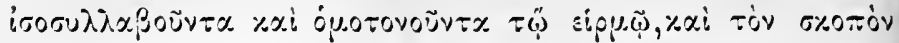
$\dot{\alpha} \pi \circ \sigma \dot{\omega}(0 v \tau \alpha)$; celui qui veut faire un canon doit choisir d'abord l'hirmus et composer ensuite les tropaires en conformant á l'hirmus le nombre de syllabes et les ac-

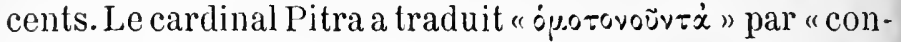
formant le mode musical ", ce que le P. Bouvy veut remplacer par "accent par accent" ou "avec des accents symétriques ", mais nous savons que les deux expressions ont le même sens.

Le mérite davoir reconnu que les cola ne sont pas les seules coupures de la strophe byzantine appartient à $\mathrm{M}$. W. Meyer de Goettingue, Il nous a montré que les cola se réunissent dans des périodes parallèles et égales par paires.L'ode " 'H $\pi$ жpg'vos" consiste en deux périodes de 15 syllabes, deux autres périodes de 13 syllabes, et un ephymnion de 20 syllabes. L'ode “"Ov oi $\pi p \circ \varphi \tilde{r} \tau \alpha_{\imath}$ » renferme selon l'auteur allemand la structure suivante:

$$
12 ; 12+12 ; 14+14 ; 22 .
$$

Voici encore la structure découverte par M. Meyer

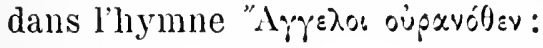

$\begin{array}{ll}\text { Proomion: } & 7+7+10 ; \\ & 8+6+3+3 \\ & 8+9 \\ \text { Strophe: } & 4+6 ; 4+6 \\ & 6+7 ; 6+7 \\ & 9+7 ; 9+7 \\ & 7+7 ; \quad 7+7 \\ & 4+7 ; 4+7 \\ & 4+7 ; 4+7\end{array}$

Ephymnion: 8 .

On voit que les strophes byzantines contiennent d'ordinaire un prohymnion et un posthymnion d'une forme et d'une étendue variables. Ces périodes additionnelles, aussi bien que le parallèlisme de la structure, leur donnent une forte ressemblance avec les chceurs antiques reconnue aussi par M. Christ. Il paraît en effet que le tropaire originaire n'est qqu'tune imifation timide d'un chant 
lyrique. Ceci admis et les chants syriaques d'Itarmonius n'ayant èté qu'une autre imitation des mêmes modéles, il n'y a pas lieu de s'étonner si les tropaires ressemblent al'x chants d'Ephrem puisque celui-ci ne faisait qu'imiter les formes d'IIarmonius.

Ce genre de poésie très goûté par l'église orientale, comme l'atteste son énorme développement, a été do bonne heure accepté par les papes et introduit dans l'église occidentale. Le fait est confirmé par un passage d'une valeur historique importante de la Vie du pape Adrien II ${ }^{1}$. Bien qu'il ait étė récemment cité par N. L. Gautier, je ne peux lui refuser ici une place, tant est grande la lumière qu'il jette sur l'introduction des tropaires dans la liturgie occidentale: "Hic(Adrianus II) constituit per monasteria ad missam majorem in solemnitatibus praecipuis, non solum in hymno angelico Gloria in excelsis Deo canere hymnos interstinctos quos Laudes appellant, verum etiam in psalmis Davidicis quos Introïtus dicunt intersecta cantica decantare, quae Romani "festivas laudes ", Franci "Tropos" appellant, quod interpretatur figurata ornamenta in laudibus Domini. "Melodias quoque ante evangelium concinendas tradidit. quas dicuntsequentias, quia sequitur eas evangelium. Et quia a domno papa Gregorio primo et postmodum ab Adriano una cum Alcuino abbate delicioso magni imperatoris Caroli, hae cuntilenae festivales constitutae ac compositue fuerant, multum in his delectato supradicto Caesare Carolo, sed negligentia cantorum jam intermitti videbantur, ab ipso almifico praesule de quo loquimur ita corroboratae sunt ad laudem et gloriam Domini nostri Jesu Christi, ut diligentia studiosorum, cum Antiphanario simul deinceps et Tropiarius in solemnibus diebus ad Missam maiorem cantilenis frequentetur honestis. M. Lèon Gautier a conteste a vec viva-

1 Ed. Leboeuf; cfr. L. Gautier, Les Tropes, p. 38. 
cité l’authenlicité de ces paroles dans un live riche en: nouveaux détails, et qui pourrait facilement devenir le point de départ de recherches nombreuses. Pour nous cependant. l'auteur de la biographie nous parait avoir ètè très bien informé parce que tout y est confirmé par d'autres documents. Il dit qu'Adrien II a rendu les tropes obligatoirespour les monastères et M.Gautier lui-mêne confirme que les tropaires latins proviennent surtout des cloîtres. Il dịt qu'Adrien Il et Aleuin s'occupaient á composer des séquences, et la première séquence latine a pour auteur Alcuin. Il parait aussi que c'est ce genre de composition qu'on appellait cantilemes. Il ajoute que Charlemagne aimait beaucoup ces chants de provenance greeque, a voyons ce quen dit le moine de St-Gall ${ }^{1}$ : "sum igitu? Girabei... secreto in sua lingua deo psallerent et illo accultatus in proximo caminum dulcedine delectaretur, praecepit cleviois suis, ut nihil ante gustayent, quam? eastem antiphanas in latinum conversas ipsi praesentarent. Il nous parait done hors de doute que ce fut Arlrien II qui établit définitivement la praticue des sécuences dans l' Occident.

Le nom mème de ces chants n’est qu'une traduction dụ grec xxonoufix. Noụs comnaịssoñ dèja la forme des séquences grecques; or voici la faclure de la séquence composé par Alcuin à la louange (laudes) de Saint Michel ?. Aprés un prooemion de syllabes: $8+3,8+3$ nous y trou vons une suite de periodes égales par paires:

$$
\begin{gathered}
9+10 ; 9+10 . \\
8+8+11 ; 8+8+11 . \\
6+7+10 ; 6+7+10 . \\
15+16 ; 10+10 . \\
6+5 ; 6+5 . \\
10 ; 10 \\
6+8 ; 6+8 . \\
10 ; 10 .
\end{gathered}
$$

1 Gesta Caroli, lib. Il. Monum. germ. hisl., II, 731 .

- Poetae aevi Garolipi, I, 3\%8. 
A la fin une période additionnelle, une épode de $5+16$. La structure et l'emploị des séquences sont donc exactement les mêmes que dans les tropaires.

Les séquences de Notker sont d'une facture plus sim. ple. La "Metensis" nous présente les périodes suivantes : $4-12,12 ; 14,14 ; 13,13 ; 14,14 ; 16,16 ;-8$. La facture de la "Romana " s'exprime par les chiffres qui suivent: $14-9,9 ; 18,18 ; 20,20 ; 18,18 ; 22,22 ; 19,19-8$. Lidentitẻ de forme entre les séquences latines et les tropaires byzantins ètant hors de doute, nous pouvons constater une très forte influence byzantine dans la littérature occidentale du moyen âge. On peut voir par les recueils de Daniel, Mone, Morel, Kehrein et dans le livre de M. Léon Gautier combien la vogue de ce genre de composition a été considérable au dixième siècle et aux suivants.

Cependant à dater du douzième siècle les séquences latines changent de forme. Leurs cola se trans'orment en vers fixes et rimés, leurs périodes en strophes. Mais c'est peu à peu que cette transformation s'opère. Déjá Notker en donnant á une de ses séquences la facture suivante:

$$
15,15,16,16,16 ; 16,16 ; 14,14 ; 15 ;-16 .
$$

s'approche visiblement d'une certaine égalitè de périodes. Mais celte égalité approximative n'aurait pu satisfaire le goùt esthétique occidental, on voulait fixer les cola, on voulait les réduire aux formes de la rythmique latıne. La rime fut introduite dans les séquences, et la rime ètant en même temps le rylime, les lois de la rythmique latine transformèe rèagirent sur les formes flottantes empruntèes à la rythmique grecque afin de les conformer à ses propres modèles. Voici la structure d'une sėquence de Päques: :

1 Kehrein, p. 89, n 93. 
cinq strophes de $7, \overline{7}, \overline{7}$, rimées : $a, a, b ; c, c, b ; d, d, b$; etc.

$\begin{array}{lll}\text { deux - } & 7,7.7,7, & a, a, b, b . \\ \text { deux - } & 8,8,7,8,8,7, & \left.(a) a,(a) a, b,(a) a,,^{\prime} a\right) a, b . \\ \text { deux - } & 8.8,8.8, & a, a, b, b . \\ \text { deux - } & 8,8,8,7, & a, a, b, c,-d, l, f, c .\end{array}$

un vers de 7 , rimé $c$.

Les strophes n'y sont ègales que par paires. en quoi le type originaire se manifeste encore mais les vers qui sont rimès appartiennent dejá aux formes les plus usitées dans la rythmique latine.

Certains auteur's ne s'en tenaient plus rigoureusement au parallélisme et introduisaient dans les séquénces des strophes non appariées. Nous donnous en exemple la facture d'une sèquence en l'honneur de Saint Nicolas ' :

quatre strophes de $(8+7=) 13,(8+7=)$ deux strophes de $8,8,7,8,8,7$.

une strophe $8,7,8, \overline{7}$.

une strophe $\quad 8,8,7,8,8,7$.

une strophe $8,7,4,8,7,4$.

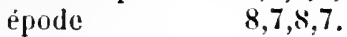

Le vers fondamental de cette composition entière est dèjá le sèptèmaire.

La plus riche varièté des formes intermediaires se trouve dans Adam de Saint Victor. Il compose une séquence le la manière suivante:

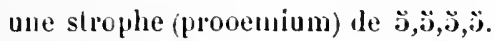

deux strophes de - $\quad 0,6, \ddot{0,6,7}$.

deux strophes de - $\quad 6,6,6,6,6$.

deux strophes de $-\quad(i+6=) 10,(4+t=) 10$.

une strophe de - $\mathbf{6 , 6 , 6 ; 0 ; , 6 , 6 .}$

ipode - $\quad 8,8,7,7$.

Une autre contient ${ }^{3}$ :

quatre strophes de $8,8,7,8,8,7$.

deux - $\mathbf{i , 6 , 6 , 6}$.

deux - $8,8,7,8,8,7$.

1 Kenreis, P. 449, no 663.

Id., 76 .

${ }^{3}$ L. c. p. 136. 


$\begin{array}{lll}\text { deux } & - & \mathbf{6 , 6 , 6 , 6} . \\ \text { deux } & - & 8,8,7,8,8,7 \\ \text { deux } & - & 8,7,8,7 \\ \text { épode } & - & 7,7 .\end{array}$

La strophe divisée du septénaire y prévaut dèjá, mais entremêlée aux paires de strophes hétérogénes. Il met dans une autre séquence ${ }^{1}$ :

$$
\begin{aligned}
& \text { une strophe de: } 7,7,7 ; 7,7,7 ; 7,7,7 \\
& \text { une - } 7,7,7 ; 7,7,7.7,7,7 \\
& \text { une - } \quad 7,7,7 ; 7,7,7,7 \\
& \text { deux }-8.8,7 ; 8,8,7 .
\end{aligned}
$$

Il construit une autre séquence de ${ }^{z}$ :

quatre strophes de : $7,7,7,7,7,7,7$.

$$
\text { deux - } 7,7,7,7 ; 7,7,7,7 \text {. }
$$

Il arrive à une composition de:

$$
\begin{aligned}
& \text { treize strophes de: } 8,7,8,7 \text {. } \\
& \text { épode - } 6,6,6,6, ;
\end{aligned}
$$

Il finit par se servir exclusivement de la strophe issue du septénaire : $8,8,7,8,8,7$, en la répètant $6,8,9,10 \mathrm{ou}$ 12 fois, sans épode. Cette strophe resta la plus usitée dans les sérquences du treizième siècle et plus tard encore. Or, persomne ne niera que le septénaire est un vers trés caractéristique pour la rythmique latine. Les auteurs des séquences latines postérieures en ramenant tous les cola, et toutes les périodes variables au septénaire coupé par la rime et á la strophe qui en est sortie, ont agi de la mème manière que l'a fait jadis Horace envers la rythmique grecque; cétait un acte analogue, inspiré par le mème sentiment, cest-a-dire, par une profonde aversion pour des formes chaucelantes. A l'èpoque classique latine on a converti les cola lyriques en métres, au douzieme siecle on a ramene les cola byzantins á la stabilite des rytlmes qui ètaient l'image des mètres.

$$
\begin{aligned}
& 1 \text { L. c., p. } 83 . \\
& 2 \text { L. c., p. } 86 .
\end{aligned}
$$


Il ne sera pas déplacé peut-être d'ajouter ạ la fin de ce chapitre une analyse sommaire d'un système de versification nouveau, qui, propagé au sixième siècle et au commencement du septième, n’a pas réussi alors à s'établir. Nous verrons plus tard que ce système n'est pas sans quelque liaison avec la rythmique byzantine dont nous venons de traiter. Dans le cinquième volume des Classicorum veterum fragmenta, Angelo Mai a publié un curieux traité de grammaire et de rhètorique, dont l'auteur. Virgilius Maro, ètait restè jusque-là, nous croyons, complètement inconnu aux savants. Son importance a bien diminué de nos jours. Nous l'avonscitè déjá deux fois dans le cours de ce travail, mais nous devons d'autant plus nous en occuper encore que son système n'a èté éclairci par personne : Le savant éditeur nous a appris que ce grammairien était un Gaulois de Toulouse. Cette ville paraît avoir èté alors le centre d'une école de rhètorique, dont les membres, vaniteux à l'excès à ce qui semble, prirent les noms des auteurs les plus célébres de l'antiquité, s'appelant: Caton, Cicéron, Horace, Maevius, Lucain, Térence, Varron, Virgile. C'est peut-être le premier exemple de l'adoption de noms littėaires, suivi plus tard par les savants de la cour de Charlemagne; seulement les rhéteurs toulousains ont poussé l'orgueil jusqu'à abandonner et oublier leurs propres noms. Virgilius Maro a eu pour maître un cerlain Virgilius Asianus, qui "pucrulo notas charaxavit $:$ ", pour disciple un certain Donat qui vivait à Rome.

Rien ne dénote mieux l'étrange direction d'esprit de cette école que les douze genres de latin dont parle Virgilius Maro ${ }^{3}$ " Latinitatis autem genera sunt xi, quo-

1 Cifr. Mever, Ludus.

z Ce mot caractéristique qui selon une juste observation de MI.

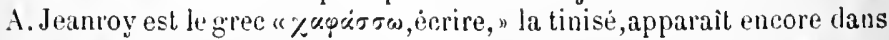
Aedilwald et dans un chant de provenance anglaise ; cfr. Du MériL, poés. popul. lat. du moyen àge, 1847, p. 123 .

${ }^{3}$ L. . .., p. 99. 
rum unum usitatum scitur, quo scipipturas Latini omnes atramentantur; ut autem xiI generum experimentum habeas, unius licet nominis monstrabimus excmplo. In usitata enim latinitate I ignis; II quoquevis habis; III ardon dicitur quod ardeat, IV calax ax calore, V spiridon ex spiramine, VI rusin ex mubore", puis "fragon, fumaton, ustrax de urendo, visius quia vivificat, selusens aeneon ". Cen'est pas de l'argot, comme l'on a voulu dire, c'est de la science grammaticale, mais de la plus fausse. Il est certainement permis d'appeler les choses d'aprés leurs qualitès et les circonstances qui les accompagnent, il est permis de faire de nouvelles dèrivations, mais il n'est pas nécessaire d'inventer douze noms pour qualifier une seule chose, il n'est pas permis de creer ces noms nouveaux en dehors de toute analogie. Virgilius Maro et ses compagnons n'avaient plus le sentiment de la langue et n'avaient aucune idée de la science grammaticale. Ce n’étaient que des charlatans, des hommes sans conscience, car ils enseignaient ce qu'ils n'entendaient pas et cherchaient, en outre, à rendre leur enseignement, obscur à dessein, accessible seulement aux adeptes.

Cependant le moyen âge ne jugeait pas de même. Il considérait ces circonlocutions comme des métaphores, des mètonymies rhètoriques et poètiques. Nous allons signaler bientôt la connaissance des ouvres du rhèteur en question chez les Anglo-Saxons, chez Aldhelm : or, l'usage,nous voudrions dire la rage de la métonymie est tellement forte dans l'ancienne poèsie anglo-saxonne et plus encore chez les scaldes scandinaves, que ces faits se rapprochent d'enx-mêmes et nous croyons $y$ voir rẻgner la même régle, passer le mème courant littéraire.

L'ignorance profonde de ces rhèteurs se cachait sous l'obscuritè et la redondance de leur langage. Virgilius Maroparlede mètres, mais c'est aux mots qu'il donne celte qualification.Il parle de pieds en entendant les sylląbes, Quelquefois il appelle les mots phonc ou soni, mais par 
endroitsillui arrive d'employer les mots : pieds et mètres dans leur vrai sens. Il en résulte une confusion parfaite. Mais laissons-lui la parole: "Metrorum quidem compositio multifaria est; non cnim ad eundem ordinem, naturam, numerum, finem, omnia respiciunt; rerumtamenunumnosse debet unusquisque cuntatorum, quod metiatur, inquacumquepensaturaphona sint». Chaque chanteur, c'est-á-dire chaque poète, doit donc savoir qu'on mesure le poids des mots. Il se peut qu'on doive donner au mot phona le sens que lui attribuaient les auteurs des traitès sur la musique au moyen àge, ou il signifie des tons musicaux. La "pensatura phonoinum" serait alors la longueur ou la brièveté des tons. "Metrum ex meta nomen accepit, cuius pedes sunt dicti velut quaedam medictates sonorum, quae quonian necessitute cantandi a poetis disparata sunt, in tantum ut extrema soni parte in alterum translata, nullum phonum incolume remaneat; hac de causa nullum me. trum planum inveniri potest». Le sens de ces paroles, si toutefois elles en ont un, nous paraîtêtre le suivant: les pieds,c'est-á-direlessyllabes, sont des partiesintermèdiaires desmots; les poètes les sèparent à cause du chant,c'està-dire ils réunissent des syllabes de divers mots dans un pied, de sorte cu'il ne reste aucun mot intact et a cause de cela il n'y a pas de métre plein, oi les pieds et les mots seraient d'accord, coïncidants. On nous accordera peut-ètre que tel pourrait ètre le sens approximatif de ce qu'a voulu dire le grammairien qui, ignorant les principes de la métrique, se sert pourtant de quelques notions de métrique, fort superficielles, il est vrai, pour domner à ses chimères une vagueapparence d'èrudition. "Multus enim a metro cantilenas, propter poetarum rhetorumque voluntatem eorum sectae declar ant. "Il y avait de son temps des sociètés de poètes et de rhèteurs qui avaient abandonné la forme traditionnelle des vers et des chants, et qui en composaient d'une maniere nouvelle. Nous sommes portés á croire qu'ils y ètaient déja 
poussès par le courant byzantir. Il faut insister ici sur son tèmoignage que les rhéteur's de son temps se mèlaient vraiment de la poésie et de cantilènes. "Quacdam enim prosa, quaedam liniata, quaedam etiam mederia, nonnulla perquam extensa ponuntur; gnorum pauca pro vestra utilitate exposituri sumus". Nous avons cité plus haut déjá son passage sur les moses. Ils ont quatre mots disyllabiques dans chaque vers, voilà leur régle. D'après l'auteur', les mots de deux syllabes sont des spondées. Venons au second genre de ses vers: "Mederiorum est versuum nec prosos nec liniatos fieri, quod magis pro cantuum modulatu, quam rationis respectu consueturn est. Varrone canente:

Festa deum sollemnia

Caram publica per compita

Quorum fistula modela

Poli persultant sidera.

Nunc metire per metra. Primus versus est trium membrorum, quorum primum per spondeum et duo sequentia per dactylos ponderantur, et sic per IV versus pari lance pensatos bis sena reperies metra et pedes trigintan. Les vers qu'il appelle mederiitiennent le milieu entre les prosae et les liniati.Ils se rapprochent des proses par le nombre égal de syllabes, des liniati par les mots trisyllabiques quils renferment, qui pour notre auteur sont tous des dactyles, comme tous ceux de deux syllabes sont des spondées.

"At liniati versusquinque semper metris metivi debent, secundum illud Catonis elegantissimi rhetoris:

Bella consurgunt poli praesentis sub fine

Preces tempuuntur senum suetae doctrinae Reges dolosi dolos fovent tyrannicos

Deum cultura multos neglecta per annos. "

Ces vers contiennent chacun treize syllabes en cind mots. On n'y compte pas les particules comme mots, mais comme syllabes. Ils nont pas de césure.

"Perextensi autem versus ornato quidem sed inva- 
tionabili circuitu paene usque ad XII perveniunt, secundum illud Lupi christiani ita affantis :

Veritas, vera aequitas, veraqne largitas, laudata fides, tranquillaque tenent tempora $\gg$.

Voilá un vers vraiment perextensus. Il contient douze mots; ornatus circuitus se rapporte à l'allitération et á la rime intérieure. Le grammairien parle ensuite des. vers triphones, dont voici l'exemple:

Arcadicus rex terrificus

Laudabilis laude dignissimus,

et de vers quadriphones:

Sol maximus mundi lucifer

Omnem aëra illustrat pariter.

Le premier genre est à trois, le second á quatre mots par vers. Mais il faut lire encore ce que V. Maro ajoute: "In quibusquidem non est derogandum, quia poetislibertas quaedam suos componendi versus a veteribus nostris permissa est; sed tamen indubia fides his non est adhibenda quia auctoritate canonum nulla suffulti, permissum magis sequi quam exemplum voluerunt-c'est-à-dire ceux qui en faisaient m. Tout ceci n'est qu'un pur bavardage, car les deux derniers genres de vers ont autant de valeur que les précédents. Tous sont basés sur le même principe,et nous ne connaissons aucun canon qui approuverait les uns ou condamnerait les autres. Le grammairien Virgilius Maro n'était pas sùr de son principe.

Puisque nous sommes en présence de ce principe, nous allons tâcher d'y faire la lumière. Ilexige un nombre dèterminé de mots pour chaque genre de vers, et ensuite que les mots de longueur égale occupent les mêmes places sur la ligne des vers. Cette régle de structure avait pour but de placer les accents sur les mêmes points de chaque vers d'un genre donné. Le nombre de syllabes n'est pas 
partout exactement le mème, mais la rime, jointe á une cadence rythmique régulière, n'est oublièe dans aucun vers.

Nous trouvons d'abord dans le grammairien toulousain des vers de trois mots, dont voici le schème:

$$
\mathrm{x} \mathrm{x}^{\prime} \mathrm{x} \quad \mathrm{x} / \mathrm{x}^{\prime} \mid \mathrm{x} \quad \mathrm{x}^{\prime} \mathrm{x} \mathrm{x} \text {, }
$$

puis deux genres de vers à huit syllabes dont l'un à trois, l'autre à quatre mots :

$x^{\prime} \mathrm{x}\left|\mathrm{x}^{\prime} \mathrm{x}\right| \mathrm{x} \quad \mathrm{x}^{\prime} \mathrm{x} \mathrm{x}, \quad \mathrm{x}^{\prime} \mathrm{x}\left|\mathrm{x}^{\prime} \mathrm{x}\right| \mathrm{x}^{\prime} \mathrm{x} \mid \mathrm{x}^{\prime} \mathrm{x}$; un autre genre de vers á quatre mols, mais à neuf syllabes:

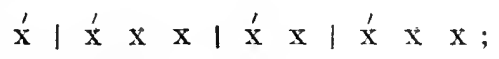

enfin, des vers à cinq mots :

$$
\mathrm{x}^{\prime} \mathrm{x}\left|\mathrm{x} \quad \mathrm{x}^{\prime} \mathrm{x}\right| \mathrm{x}^{\prime} \mathrm{x}\left|\mathrm{x} \quad \mathrm{x}^{\prime} \mathrm{x}\right| \mathrm{x} \quad \mathrm{x}^{\prime} \mathrm{x} \text {. }
$$

Les accents ne forment pas des pieds rythmiques réguliers, mais ils se retrouvent aux mêmes points de tous les vers de chaque genre, comme nous l'a vons dit déjà. Voilà le lien qui rattache la versification exposée par Virgilius Maro à la versification des tropaires byzantins. En examinant la structure des tropaires, nous a vons trouvé que la distribution des accents servait á en déterminer la mélodie, or le mème moyen doit avoir eu le même but dans la versification de V. Maro. Il ne le dit pas formellement, mais il parle à plusieurs reprises de cantatores, de cantilenae, de la necessitas cantandi, du pro cantuum modulatu. Horum ordines versuum, quia non ad certam auctoritatem sed ad varietutes poëticiorum cantuum manifestandas positi sunt, indagari a me necesse non est. Il paraît donc que cette pensée y est partout sous-entendue, qu'elle y est supposée connue. Constatous encore que nulle part il ne donne à ses vers les noms de metrum et de rhythmus. 
Si nous examinons les conditions de la mélodie déterminée ainsi par des accents ègaux et placés aux mêmes points dans tous les vers, nous trouverons quelle n’a pu être que monolone. Tous les vers d'une pièce se chantaient á peu prés sur le mème air. Elle a vait alors une forte analogie avec le chant des anciens aejdes et on na pu chanter plus tard les chansons de geste d'une manière diffèrente. Voilá ce qu'on peut déduire de la doctrine de Virgilius Maro, et cette supposition est confirmée par la notation qui aceompagne les cliants dans les drames liturgiques du moyen àge oú, en vérité, tous les vers du mème chocur (car il y avait des chours) étaient chantès sur la même mélodie.

La structure des vers sur la base du nombre de mots et des accents mélodieux est donc démontrée. Mais faudrait-il en conclure que Virgilius Maro et les allteurs des tropaires byzantins n'ont fait que suirre une tradition fort anciemne et qui présidait déjá à la composition des vers saturniens? Je ne saurais le dire.

Le grammairien toulousain n'est pas le seul auteur latin du moyen àge qui ait placé avec soin les a:cents mèlodieux dans les vers, la mème tendance ayant èté remarquée par M. Bartsch dans quelques sèquences ' ${ }^{\text {. Cela }}$ constitue un nouveau lien qui rattache notre auteur a la poètique des tropaires byzantins. Il faut remarquer cependant que la régle des accents mélodieux, bien qu'évidente, n’ètait générale ou obligatoire ni dans les tropaires ni dans les séquences.

Notre auteur semble vaiment avoir joui de quelque autoritedanslestemps qui l'ont suivi, car il setrouve cité plus d'une fois par Aldhelm ", plus tard par Abbo et (iainfredus. Outre l'intluence dont nous arons deja jarlé, cest a lui et a son école qu'il faut attribuer encore la propagation de la rime et de l'allitération dans l'ouest et le nord-ouest de l'burope. Son systeme de versification

- Dic lateinischen Serfuenzen.

- Auct class. $\mathrm{V}, \ddot{3} 20, \mathrm{Z}$ ffi. 
pourtant n'a pas été accepté, car il ètait exceptionnel, hors du courant métrique et rythmique $t$ sujours prédominant en France. Ce courant fut renforce un peu plus tard par Charlemagne qui ouvrit largement les portes de son empire a l"influence de la littérature classique et qui peut ètre considéré, à bon droit. comme le vèritable iniliateur de cette revivification des études classiques, qu'on appela plus taril la Renaissance.

A l'époque de floraison de lancienne litterature française, l'accent latin parait aroir perdu sa valeur musicale. Au quatorzième siécle, non seulement il ne dèterminait plus la mélodie, mais il en ètait ignoré. "Car lo can de musica. dit Molinier ', regula"men no te ni garda accen, segon que podet: veser en lo respos : benedicta et venerabilis, car mays trobarets de ponhs en lo ta, que es breus naturalimen que en to be, ni en lo dic, quanque laccens principals sia en aquela sillaba. Aqro meteysh podetz verer en to ver's d'aquel ineteysh respos que commensa virgo, car en lo go troburets gran re de ponles et ch lo vir: on es liaccens principals, non trobarels mas un".

${ }^{1}$ L. c., 58 . 
La versiflcation romane tireson origine de la rythmique latine, mais la plupart des formes lyriques romanes sont postérieures à l'introduction des séquences latines.

Il serait superflu de s'occuper ici de la technique des vers romans, des vers français surtout, parce que cette matière a été dèjá élucidèe suffisamment dans les excellents ouvrages de M.M. Quicherat, de Gramont, Th. de Banville, Becq de Fouquières, Gaston Paris, Tobler, Lubarsch, Blanc, Fracarolli, marquis de Pidal, Alfred Maury. L'appréciation esthétique n'entre pas dans le. cadre de ce travail et les peuples romans, euxmèmes, en sont les meilleurs juges. Il importe cependant d'examiner la relation historique non encore bien établie entre la versification latine et la versification romane, et aussi entre les différents systèmes de versification que possède chaque littérature romane en particulier. Une autre question pourrait encore nous tenter: à savoir la provenance des compositions romanes lyriques, des chansons, des pastourelles, des ballades et d'autres. Ce ne sont pas seulement des questions purement romanes, mais elles intèressent au plus haut degrè toute la littérature européenne.

Commençons par les versifications provençale et fran- • çaise, qui reposent sur la même base et qui possèdent les mêmes formes, le sorte que ce qui sera prouré pour l'une le sera aussi pour l'autre. Ici comme ailleurs je m’appuierai de préférence sur des témoignages indigè- 
nes et les moins éloignés de l'époque originaire pour apprendre non pas ce qu'on pourrait y supposer contenu, mais plutòt ce dont les contemporains avaient conscience.

Nous savons dejjá, que le mot rhythmus signifiait au moyen âge l'imitation d'un vers métrique, or, si nous trouvons qu'on donnait le même nom aux vers français et provençaux, nous $\mathrm{y}^{*}$ aurons une preuve quon les considèrait aussi comme des imitations des mètres. Cette preuve nous est fournie par Molinier. seulement, comme il écrit en provençal, le not rima ou rims doit signifier pour lui a la fois la rime et le rythme. Néanmoins il n'ignore pas la signification fondamentale': "Rims es certz nombres de sillabas, ajustat a luy autre bordo pér pario d'aquela meteysha acordansa e paritat de sillabas ... un nombre défini de syllabes et la consonance finale voilá ce que compread sa notion du rims. Les autres rythmiciens de son temps paraissent n'avoir pas donné d'autre sens au mot rims que celui de rime; il se sent donc obligé de réfuter leur opinion en disant; qu'il y a vait des auteurs «lequals no rolon cutendre que rims sia engaltatz de sillabas ses acordansa final". II seconformait donc á l'opinion des anciens grammairiens latins pour lesquels le "similiter rlesinens" n'entrait pas nécessairement dans la définition du rythme.

Ce que nous appelons le rythme du vers lui est à peu près incomnu, quelques élèments de cette notion se trouvent pourtant dans son traité sous les nots : compas, bela cazensa, accens. Nous allons examiner ce qu'il en dit.

Il entend par compas la longueur du vers mesurée par le nombre de syllabes avec les pauses obligatoires, dont il distingue trois especes; puraus suspensivas dans l'intérieur du vers; à la césure, pauzas planas à la fin du vers, "por far plus pleniara alcumala, et pausas

1 Las flor's del gay saber p. 180. 
finals, qu'om fay à la fi de cobla». Il ne demande pas que les pauses du vers coïncident avec les pauses logiques, il exige seulement qu'on évite de placer à la fin des vers des mots comme : car, quand, c'est-à-dire, d'y commencer une nouvelle proposition, il exige en outre que la phrase finisse arec la strophe.

D'après lui certains vers comme ceux de neuf syllabes n'ont jamais une belle cadence,mais il ne peuten donner aucune raison: "Bordo en nou sillabas no podem trobar am bela cazensa, per que no trobaretz que degus dels antics haian pauzat aytal bordo:

Mayres de Dieu los mieus precs enten Et am to filh tu donam defen..

Nous en avons indiqué déjá la cause probable, c'est que l'ennéasyllabe n'était usité ni dans la métrique, ni dans la rythmique. Il continue: "Encaras vos dizem que apenas ha bela casensa pauzut que d'aquestas ix sillabas fassa hom dos bordos, lo primier de $\mathrm{v}$ et l'autre de quatre o per lo contrari'.

Tu mayre de Dieu

Mos precs enten

Et am lo filh tieu

Aram defen o : Mayre de Dieu

Los mieus precs enten Am lo filh tieu

Tu donam defen.

Ceci prouve pertinemment qu'en roman aussi bien qu'en latin des vers nouveaux ont èté formés par la coupure rimée des vers plus longs, mais en ce cas le vers suivant sert toujours de complement au vers précédent de manière à déterminer la forme d'une strophe.

Il enseigne encore un autre moyen de donner aux yers de neuf syllabes une meilleure cadence : "Limpero ab rimas multiplicadas poyria be estar etadoncs haurian bela cazensa seyon qu'om pot vezer ayssi en aquestz versetz:"

L. L. $\mu \cdot 11 \Psi_{\text {; }}$ 
Lo mon veg maladreg o destreg

Quar apleg franh hom dreg per naleg.

Molinier connaît l'importance de l'accent dans les vers, et ce qu'il en dit pourra être décisif pour nous aussi. Il reproduit d'abord toute la théorie antique sur l'accent, puis passant aux vers romans il dit: "Per so cove que digam en qual loc dels boidos deu hom gardar accen et en quals no. E devets saber ques en la fi dels bordos de quantas que sillabas sian, deu hom gardar accen. Quar silaus bordos fenish en accen agut, l'autres qu'es sos parios per accordansa de" ysshament fenir en accen agut o si fenish en accen gieu. aquo meteysh", L'accent doit être observé encore dans la césure: "Item en bordos de $\mathrm{Ix}$ sillabas e de $\mathrm{x} e$ de XII deu hom tosteimps pausa: accen agut, en aquels locs en los quals cazon las pauzas suspensivas". Cette régle est trop res. treinte parce qu'on plaçaitaussi des mots paroxy tons dans la césure,mais outre ces deux places á la fin des vers et á la césure la place de l'accent ètait parfaitement libre.

Les mots français ètant toujours accentués sur la dernière syllabe sonore et les vers y finissant par conséquent toujours par une syllabe accentuée, il s'ensuit qu'il n'y a pas dans la versification française de pieds descendlants, de trochées, de dactyles et autres semblables, si aprés tout nous voulons parler de pieds fondès sur laccent. - La versification française possède donc seulement des pieds ascendants de la forme : $\sim-(v), \sim \sim-(v)$, $\sim \sim-(\sim), \sim \cdots \sim-(\sim)$; assez souvent $\sim \sim-,-\sim-$ et même --. Ils se présentent dune manière spontanée dans tous les vers français depuis le moyen âge jusqu'à nos jours, avec cette diffẻrence cependant. que dans les vers modernes la modulation est plus soigneusement recherchèe, le choc des syllabes accentuėes plus évité qu'il ne l'était autrefois. Pourtant on n'y répète pas et on n'y a jamais répété le même pied,quel qu'il soit,d'une manière constante. Les vers romans, puisque c'est 
une particularité commune á tous, ne sont donc pas rythmiques dans le sens moderne du mot qui exige, l'imitation d'un pied métrique. La notion du pied dispa. rut entièrement de la versification rythmique latine, aussi ètait-elle abandounée dans la versification romane. Les vers français et romans ne sont pas rythmiques, mais ils sont des rythmes. I!s le sont au mệme titre que les rythmes latins, parce qu ils conservent le scheme de mëtres antiques, leur ètendue mesurée par le nombre de syllabes, puis la césure et la cadence finale régulière. S'il en est ainsi quel ròle $y$ jonent donc des accents qui toutefois y produisent une modulation trés agrèable et très sensible ? Ce mol. nos lecteurs l'ont déjá prononcé, ils $y$ produisent une modulation, la même dont parlent dejjáles rythmiciens latins et qui se rapportait á la mélodie, aux accents. Les vers romans, a en parler suivant la tradition romaine, sont modulés. c'est-á-dire mélodieux par les accents.

Nous lisons dans Molinier: "Bordos es una partz de rima quel al ma!y conte xu sillabas et a tot lo mens qualie, wi doncs no so empeutal o biocat, quar adones pódon esser no solamen de quatro, mays de tres o de mens tro ad una sillaba ". Une règle semblable a èté domée par un des grammairiens latins pour la rythmique latine, à ceci prés que Molinier omet les vers de treize et le seize syllabes. Il mentionne en leur place les vers entés et brisés que nous ne connaissons pas encore et dont nous devrons parler lans la suite.

La même origine que nous avons trourèe au vers latin de quatre syllabes doit ètre attribuée ėgalement au tètrasyllabe roman, lui aussi dẻrive de loctosyllabe coupé par la rine. Les vers romans de cincl syllabes se rapportent au métre adonien, ceux de six a la moitie d'un asclépiade, ceux de sept au métre choriaque, ceux de huit à l'ancien dimètre, ceux de dix au trimètre dactylique et au trimetre anapestique, ceux de onze syllabes répondent à l'hendécasyllabe et les alexandrins á 
l'asclépiade '. Les rythmes latins servaient de modéles pour la plupart de ces vers, mais nous ne croyons pas devoir insister sur ce point parce qu'on a pu faire des rythmes romans immédiatement sur les schèmes métriques que les créateurs des vers romans connaissaient probablement. Yous croyons pouvoir nous dispenser de donner des èchantillons de vers français ou provençaux, très bien connus d'ailleurs de nos savants lecteurs.

Nous entreprendrons encore d'examiner ici brièvement une question assez difficile, au risque de n'arriver qu'à un résultat douteux. Les cadences finales des vers rythmiques latins étaient. on le sait, toujours ègales dejjà bien avant l'introduction de la rime, et bien plus après. On faisaitrimer alors les mots paroxytons exclusi vement avec des paroxytons et les proparoxytons de même. On continua à observer une règle semblable dans la versification romane, en ne permettant $d y$ accoupler par la rime que des mots á accent égal. La rythmique latine et la rythmique romane sont donc encore daccord sur ce point. Nais on comptait dans les rythmes latins toutes les syllabes du mot final, tandis qu'on ne compte plus dans la versification française et provençale les syllabes posttoniques.Cette particularité n'est fondée sur aucune raison rythmique et elle ne peut dejpendre que de la sonorité des syllabes. Elle s'explique très bien par la nature de la langue française ou les syllahes posttoniques sont presque muettes, insaisissables pour l'oreille, mais il n'en est plus ainsi danș la langue provençale. Faudrait-il en conciure que cette règle soit née dans la versification francaise et qu'elle se soit assujettie la versification provençale, et mème dans quelque mesure toute la versification romane, comme nous le verrons dans la suite? La versification francaise est-elle donc plus ancienne que la provençale? Les monuments ne s'oppo-

1 Les plụs anciens alexandrins paraissent ètre ceux qu'on trouve dans « Les vierges sages et les vierges folles n. 
sent pas formallement á ce qu'on le pense. L'élablissement de cette régle a pu d'ailleurs être facilitè par le plus grand nombre des mols oxytons existant dans les deux langues, mais après tout c'est la faiblesse phonètique des syllabes posttoniques qui seule a pu la produire.

Passons á la versification italienne. Nous nous appuicrons ici sur le traite d'Intonio da Tempo'. beaucoup plus détaillè que celui de Dante. Ecrit en latin il nous montrera que les vers romans ont èté vẻritablement considerés comme rythmes. On y lit ": "Quod de rithi. mis vulgaribus per aliqun artem, quae meis oculis anit auribus intimata, non fuit per aliquos pracedentes, aliquid sub regulis aut determinato modo vel exemplis hucusque theorice muneupatum... sed solum quidam cursus et consuctudo, quae ut puto a bonis et dignis veteribus hubuit primitivam, quod quidem est per rithimatores quasi accidentaliter non autem magistraliter usitatum, idcirco ea quae circa hoc per. experimenta rerum et practicam per alios rithimantes vidi hactems observari in quaredam licet parrem "retem et dochinam et regulas redigere meditarin. Il deduit l"origine des rythmes italiens des exemples donnés par les premiers poètes en langue vulgaire et non pas d'une poésic populaire ilalienne, nous savons cependant que les premiers poètes italiens s'inspiraient de la poesie provencale et francaise.

L'auteur italien dil ensuite: "Dictaminum literalium serundum rheturicos tria sunt genera. scilicet proscicum, metsicum. rithimicum, de quormm materiis ad praseus literaliter tracture non expedit, quia per alios grammaticos et rhetoricos sutis tractatum est. sed quia de vulgaribus rithimis dicendum est, primo quacrendum est. quid sit rithimus. Ad quod dic. quod literalis, rithimus secundum grammaticos est conso1869.

' Delle rime velgari, tratlato compusto nel anno 1332 , cel. Grion,

${ }^{2}$ I. 69 s. 
nans paritas syllabarun certo numero comprehensarum ". Les renseignements que nous venons de lire sont très précieux. Na Tempo dit d'abord qu'on puisait alors les doctrines poétiques dans les écrits des rhèteurs, que nous ne comnaissons plus tous probablement: il confirme que la poésie rythmique appartenait au domaine littéraire.et il définit le vers rythmique conformémentaux règles latines et provençales. Dans ce qui suit il s'attache plus encore á l'art et á la science des Latins: "Item sciendum est, quod quilibet vulgaris rithimus constare debet in qualibet parte sui ex orationibus perfectis sicut rithimus literalis, et sicut quilibet literalis semo. Practerea sciendum est, quod quemad. modum in dictamine literali possunt componi colores rhetorici, sic et in vulgari rithimo quod etiam disputare non intendo... unum tamen loquor, quod non poterit aliquis esse bonus rithimator vulgaris, nisi saltem grammaticalibus studiis sit imbutus et quanto melius alias liberales artes et alias scientias noverit positivas, tanto magis, si haec vulgaris dictaminis scientia eius ingenio placuerit, perfectus inter caeteros apparebit". Ce long passage nous fait entrevoir jusqu’à quel point les esprits du moyen âge obèissaient à la science latine. Molinier, Da Tempo, Dante, Raimon Vidal, Uc. Faidit, tous s'unissent pour nous en démontrer le prestige. Avant leur temps la dépendance n'ètait probablement que plus grande. Nous pouvons nous en assurer par induction: Da Tempo déclare qu'il va tirer ses règles des exemples d'anciens et célébres poétes; il les met dans un ordre théorique et tous sont en accord parfait avec la théorie latine. Il faut donc que les "Veteres cligni et boni" aient ètè dirigès par la même thèorie. En général on envisageaitau moyen ìge la poésie et sa relation avec la rhetorique d'une manière bien diffèrente de la nòtre, car voici ce qu'en dit un homme extrêmement compètent, l'auteur de la "Divine comédie ": "si poësim recte consideremus, nihil aliud 
est, quam fictio rhetorica in musicaque posita '.

Il s'agit maintenant de retrouver les motifs qui ont amenè les premiers auteurs de vers italiens á adopter la règle d'après laquelle ils les ont construits et qui est constante depuis les premiers vestiges de cet art jusqu'à nos jours. On y distingue trois formes de vers suivant leurs cadences finales: piani, tronchi, sdrucciuoli. Dans les vers plains, qui sont toujours terminés par un mot paroxyton, on compte toutes les syllabes jusqu à la fin du vers, ce qui donne le nombre normal des syllabes et constitue la forme normale du vers. Dans les vers tronqués, le dernier mot y ètant toujours oxyton, il manque une syllabe au nombre normal prescrit; quant aux vers glissants ils en contiennent une de plus que le nombre normal, parce que leur dernier mot est toujours proparoxyton. On roit que ces trois formes dépendent de laccent du dernier mot. Or, cette régle ne provient pas de la rythmique latine ou toutes les syllabes sont toujours comptées, et oú chaque vers, quel qu'il soit, terminé par un mot oxyton, paroxyton ou proparoxyton doit contenir le mème nombre de syllabes. Elle ne dépend pas non plus de la nature de la langue italienne, puisque toutes les royelles y sont sonores et qu'il n'y a lá aucune raison de supprimer du compte la dernière syllabe des nols proparoxytons. Mais cette régle s'accordeavec les règles françaises en plusieurspoints: d'abord elle dépend de l'accent du dernier mot, puis le nombre de syllabes jusquau dernier accent est constant; en outre elle admet des vers d'une syllabe de plus que le nombre normal. La différence entre la versification frangaise et la rersification italienne consiste en ce que dans les vers italiens une syllabe posttonique est toujours comptée au nombre prescrit de syllabes. La régle italienne, dans son ensemble, est donc une règle de compromis entre les modèles de la versification

4. De vulgari eloquio, II, c. 5 . 
française et la nature de la langue italienne. On ne peut nier qu'en trouvant cette règle, la pensėe italienne n'ait èté très bien inspirèe.

La versification italienne présente une prédilection marquèe pour les vers au nombre impair de syllabes, $\dot{a}$ l'exception du vers ennéasyllabique. " $E t$ licet hoc endecasillabum celeberrimum camen... principatum. obtinet ; et dicimus eptasillabum sequi illud, quod maximum est in celebritate; post hoc pentasillabum et deinde trisillabum or dinamus ; enneasillabum vero, quia triplicalum trisillabum videbatur, vel nunquam. in honore fuit, vel propler fastidiun obsolevit; parisillabos vero propter sui ruditatem non utimur, nisi r(t)o"; voilá ce qu'en dit Dante '.

Cette préférence accordée au nombre impair de syllabes est en rapport avec une préférence semblable donnée au rythme impair dans la musique oú, jusqu'au quatorzieme siècle, l'on n'admettait pas de mesures aux temps pairs. "Perfectum est, quod est in tres partes aequaliter divisibile vel in duas incequales ", dit Jean de Muris; "Numero deus impare gaudet ", dit Adam de Fulda $*$ En adoptant cette doctrine, les Italiens ont donné un trait particulier á leur versification, tout en l'appaurrissant un peu. Les vers les plus usités y sont donc l'hendécasyllabe, le vers de sept et de cinq syllabes. Nous y trouvons aussi des vers brisés pareils aux vers biocats des Provençaux.

L'hendécasyllabe, ce vers dominant dans la versification italienne.que l'art de Dante, de Pétrarque et de l'A rioste ont rendu si célébre, provient, comme tous les vers de onze syllabes dans la poésie européenne, de l'hendècasyllabe classique, nous ferons seulement remarquer que ce n'est pas le vers saphique à la césure fixe qui lui a servi de modèle, puisqu'il manque à l'hendècasyllabe

1 De vulgari cloquio, lib. II, cap. ̈.

z Geraert : Scriptores ferum musicarum; Musica practica, $22 \%$. 
italien. En émettant cette opinion, nous sommes, il est rrai, en contradiction avec tous les savants qui ont traitẻ de ce vers jusquả Fracarolli, qui lui attribuent une césure ou même deux, ce qui est rraiment trop ${ }^{1}$. Mais il n'a pas de césure, parce qu'il n'augmente ni ne diminue pas d'une syllabe lorsque le mot qui termine le premier colon est proparox y ton ou oxyton. Cette régle a la mème valeur á l'ègard de tous les vers romans, arec le petit changement que demande l'accont francais et provencal. Elle est observèe dans le seul vers italien á césure, ce qui nous oblige á nous occuper un moment du vers italien de quatorze syllabes, assez rare d'ailleurs. Il nous fournira la preure catégorique de l'exactitude de notre opinion. On le trouve employé dans la jolie romance. ou plutôt tençon, de Ciullo d'Alcamo dans des strophes qui finissent par deux hendécasyllabes. En roici une comme exemple :

Se di meve trabigliati, follia lo ti fa fare;

Lo mar potresti arrómpere aranti a semenare,

L'abere d'esto sécolo tutto quanto assembrare, Averme non poteria este monno, Irantili carelli miaritonno.

On troure ici une césure après des mots constamment proparoxytons, mais aussi le vers augmente-t-il d'une syllabe, de sorte qu'il en compte quinze.

Ce fait a entraine Blanc a le prendre pour un septénaire, et Nanucci semble être du mème aris. Mais le même vers se trouve encore dans Jacopone da Todi, oú, a côté des vers a la façon de Ciullo d'Alcamo :

Perchè gli nomini dimindano detti con brevitate racello per provertii dicendo veritale..,

on trouve dans la mème pièce quelques vers composés de la facon normale:

1 Cfr. Blaic, 1. c.

I primi secoli... p. 401 . 
Chi vuole il cor sicúro

thi ruole esser amito porti da puritate

mostri stabilitate...

Les premiers vers ont quinze syllabes tandis que les autres en ont quatorze. Cela prouve non seulement que ces vers sont vraiment de quatorze syllabes, mais en mème temps que les vers romans augmentent ou diminuent d'une syllabe suivant que la césure est masculine ou féminine.

Nous arrivons á l'exposition de quelques remarques sur la versification espagnole,qui nous semble le còté le plus faible de l'histoire littéraire espagnole, cultivèe par tant d'hommes éminents et distingués. Ici aussi on a roulu avoir une forme autochtone ou qui, au moins, se rattachât directement à l'antiquité romaine. Les faits les plus clairs ont disparu sous d'épaisses tènèbres qui ne se dissiperont que lorsqu'on osera abandonner ce faux point de vue.

On prend gẻnéralement pour point de départ le Poema del Cid, supposé, ce qui est douteux, le plus ancien de tous les monuments de la littèrature espagnole. Sanchez avait déjá reconnu que le vers employé dans ce poème est l'alexandrin, seulement il le dérivait de l'hexamètre et du pentamètre latins ${ }^{1}$ :

De los $\mid$ sos $0 .|-j o s \tan |$ fuerte $\mid$ mientra $110-\mid$-rando, Tornaba | la cabe- | za | estaba | los catan- | do.

Ferdinand Wolf admet, lui aussi, que l'auteur du poème tend a se rapprocher du vers alexandrin, mais il lui semble que le septénaire trochaïque, forme nationale autochtone, $y$ occupe une place dominante. Ce mème septénaire serait, suivant lui, la base des vers appelés "rendodillos ": telle est la confusion. Néanmoins, cette manière de voir fut acceptèe par Duran et a cours encore aujourd'hui.

Il nous importe de connaitre l'opinion de niez sur ce

1 Coleccion de poesias castellañas anteriores al siglo $\mathrm{XV}, 1$, p.11:3.

2 Wiener Jahrbücher, CXIVII, p. 93, s. 


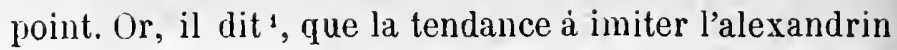
n'est que trop manifeste dans le Poema del Cid, quoique l'auteur, encore peu expérimentè dans l'art rythmique, ne garde pas toujours le nombre de syllabes prescrit. D’après Diez, seul le Poema del Alejandro est à sillabar. contadas, mais il ajoute qu'on y trouve encore des vers arec deux syllabes de plus qu'il n'en fallait à la césure:

conosco bien grammitica / se bien toda natura, ou même à la césure et á la fin du vers á la fois :

en fer a dios servicio | metia toda femencia.

Le célébre savant a fait erreur car les deux vers sont bien réguliers, seulement il faut compter leurs syllabes d'après la régle française, c'est-à-dire jusqu'à la derniëre syllabe accentuée.Commeles mots de la langueespagnole sont oxytons, paroxytons ou proparoxytons, on peut $y$ trouver des vers avec une ou deux syllabes de plus dans chaque pause, de sorte que l'alexandrin espagnol peut compter 6-6 syllabes :

Mandol luego prendér | e fizolo-enforzár...

oll $i-6$ :

Debe de lo que sábe | ome largo seér...

ou 7-7:

Mester es sen peccido / ca est de derecia,

Fablar curso rimádo | per la quaderna via.

ou 8-7. 8-8, comme ceux qu'à cités I)iez. Non seulement donc on imitait le vers alexandrin dans la première période de la litterature espagnole, mais on le construisait d'aprés la régle française, ce qui est tout diffèrent. Nous poutons en conclure que la même rẻgle y était suivie dans tous les autres vers et nous arrivons

3 Altromanische Sprachdenkmale, p. 107. 
ainsi à un criterium de la mesure des vers espagnols qui nous faisait complètement défaut jusqu’á prẻsent.

La remarque de Diez touchant la défectuositè de l'art rythmicue espagnol dans cette première période est très juste, d'ailleurs. Les poètes, je ne dis pas tous, éprouvaient de la difficulté á trouver le juste nombre de syllabes et à garder la césure. Tantòt ils effectuaient l'élision et la synérése, tantòt ils admettaient l'hiatus, irrégularité bien souvent embarrassante.

L'alexandrin reste la forme caractèristique,quoique non unique, de cette pẻriode. Le vers octosyllabique se trouve employé dans la Vida de Santa Maria Egipciaca et dans Lo libre de los tres Reys d'Orient ${ }^{1}$ :
A Jesu Christo que_era nado
Una estella los guiando
Lt de la grande maravilla
Que les a vino en la villa
Do_Crodes era_el traïdor
Enemigo del Criador...

Ces quelques vers nous révélent la forme á laquelle l'auteur parait avoir visé, mais qu'il n'a pourtant atteinte que rarement.

Une chose qui étonne, c'est l'ałsence de décasyllabe. Il s'en trouve, il est vrai, dans l'Arcipreste de Hita, mais avec une rime à la césure ${ }^{2}$ :

Quiero seguir

Siempre decir

Non me partir

De te servir mejor de las mejores.

La rime fut introduite encore dans l'alexandrin par Rabbi Don Santols:

Comunalmente trobado de glosas moralmente, De la filosofia sacado seguns que va siguiente...

1 Revista de Madrid, IV, p. 302.

* Böhl de Faber: Floresta de rimas antiguas castellañas, 1, n" 1 . 
Les rers heptasyllabiques deviennent de plus en plus fréquents durant le quinzième siècle '.
Del mundo salud e vida
be muerte destruimiento
He gracia llena e cumplida
De euitudos salvamiento

tels sont les vers quion y peut distinguer à l'aide du criterium que nous venons d'établir.

La seconde époque de la littérature espagnole est caractérisée non seulement par l'introduction des formes de la poésie italiemne de l'hendécasyllabe, de la terzine, de la stance, du somnet et de la canzone, mais surtout par l'application de la régle italienne, d'après laquelle on mesurait dès lors les vers espagnols. On ne complait donc plus les syllabes d'un vers jusquà la dernière accentuée, mais la dernière accentuée devint désormais l'avant dernière syllabe du vers, qui peut ètre piano, tronco ou sdrucciuolo tout comme les vers italiens. L'hen. décasyllabe, le vers dominant de cette période peut donc contenir dix, onze ou douze syllabes. On trouve dans les canciones à côté de l'hendécasyllabe, l'heptasyllabe et des vers brisės de diffèrentes formes. L'octosyllabe prévaut, d'aprés la régle italienne. dans les romances. Lalexandrin est presque completement abandonné, et ce n'est que dans Francisco d'Ocaña, qu'on en trouve une faible application :

Caminad esposa rirgen singulur

Que los gallos cantan cerca_esta el_lugar.

L'alexandrin pouvait donc, d'apres la régle italienne, compter au moins dix syllabes :

Alla muy bien podreis reposar

au plus quatorze. A joutons encore que bien souvent on

1 I'EKO LOPE\% de I YALA, F'loresta: I, noy.

2 Floresia, I, 1!). 
ne peut determiner un vers que par l'époque á lacguelle il appartient, parce qu'un heptasyllabe, d'après la règle francaise, est tout á fait conforme á loctosyllabe d'apres la règle italienne.

Entre ces deux époques il y a encore au quinzième siècle un espace intermédiaire a constater. 11 est caractérisè par l'application de l'hendecasyllabe, mais construit d'après la règle française. Un des plus anciens exemples nous en est offert dans la "ladanca generaldelos mucrtos ", dont voici la premiere strophe :

Yo soy la muerte cierta a todas cri_aturas

Que son y seran en el mundo durante :

Demando y digo o_omine porque euras

I) vida tan breve en punto passante?

pues non ay tan fuerte nin resiogigante

Que deste mi arco se puede_emparar!

Conviene que mueras quando voy tirar

Con esta mi frecha cruel transpassante.

Excepté le premier vers, ou la contraction $i_{\text {_ }}$, est un peu accentuée,tous les autres vers sont règuliers comme hendécasyllabes á la francaise, ce rfui serait le contraire si on les considerait comme des alexandrins ou des hendécasyllabes à l'italienne. Ticknor les compare vaguement une fois aux octosyllabes, une autre fois aux vers de arte mayor qui pour lui sont des vers longs qui se ressemblent dans loutes les épopèes. ${ }^{1}$ Le même vers que dans "La danza" nous semble employè aussidans la $C o-$ medicta de Ponza,dans la Revalacion d'un he'mitano, dans las T'rescicntas, et encore au xvie siècle dans Cristobal de Castillejo, l'adversaire de l'ècole italienne. * On est quelquefois tente de les considerer comme des alexandrins composés d'aprés la règle italienne, mais plusieurs raisons sy opposent. Ce ne sont pas des alexandrins, parce quil sont employes dans les stances. tandis que l'alexandrin espagnol forme presque toujours

1 I, p. 306, II, p. 70)3, de la tradurtion allemande, rev. pitr lil. IIOLF.

= Billioteca, XIXII, p. Ili;.

BTTINES 
des strophes de quatre vers; ce ne sont pas des alexandrins, en raison même de leur irrégularité ; mais ce ne sont pas non plus des liendécasyllabes d'aprés la régle italienne, parce que cette règle ne fut introduite qu'au seizième siècle et parce rqu'ils n'obẻissent pas á cette régle.

Nousnous sommes efforcéde soumettre la versification espagnole à un rapprochement historique avec les autres systemes de vers romans, au lieu de la tirer avec $\mathrm{F}$. Wolf d'une poèsie populaire hypothètique, ou de lui attribuer une origine purement latine avec Amador de los Rios. Certes l'amour-propre national est flattė par ces mirages d'une indèpendance de son art, mais la vérité historique n'y gagne rien. La littèrature espagnole est assez belle et assez riche d'ailleurs pour négliger ces petits moyens.

Apres avoir éclairci le rapport entre les vers dans les différentes littėratures romanes d'un côtẻ et le rapport entre la versification romane et la versification latine de l'autre, nous pourrions être tenté d'ajorder le probléme qui s'y raltache immédiatement, celui d'élucider la provenance des formes de la lyrique romane, de la chanson (canzone), de la pastourelle, de la ballade, du rondeau. Si l'on accepte les opinions qui ont cours aujourd'hui ce problème est rẻsolu depuis longtemps; ces formes proviennent tout simplement de la poésie populaire.Quelque commode qu'elle soit, cette explication n'est nullement satisfaisante.

Appuyè sur les principes que nous suivons ici et conformément aux explications dẻjá données,nous jouvons supposer á priori, que les formes lyriques romanes doivent être en relation avec les formes de la lyrique latine. A l’èpoque la plus rapprochée de la création de la lyrique romane la ly rique latine contenait deux affluents, dont un venait de source latine, l'autre de source byzantine. Les formes d'origine latine se caractérisaient par une structure homomorphique : les strophes étaient égales, et il en ètait de mème des vers dans les strophes. Les strophes 
étaient accompagnėes assez souvent d'un refrain, placé á la fin de chaque strophe comme dans le Pervigilinm Veneris, dans une èglogue de Virgile, dans quelques pièces de Nartianus Capella, dans une pièce de Raban Maur, quoiqu'il pùt la précéder, comme dans la piéce connue de Saint-Augustin. Les formes d'origine byzantine ètaient de structure métabolique.

Nous savons déjá que dans les séquences les vers n’etaient pas égaux, que d'abord ce n'etaient pas des vers mais des cola. Nous sarons aussi quie les strophes n'y ètaient égales que par paires, mais que plus tard les strophes aussi bien que les cola furent ramenėes à une structure homogène. Les piéces de cette provenance ne possé. daient pas de refrain mais délutaient par un prooemium avec un ephymnion a leur fin, quelquefois seulement elles ne possédaient que l"un des deux.

Munis de ces régles générales, aborklons maintenant la lyrique romane. Existe-t-il des pieces contenant dans les strophes des vers inégaux ? Evidemment oui, puisque les chansons et surtout les canzone italiennes se caractérisent par la structure métabolique de leurs strophes. Voici la strophe d'une des chansons de Crestien de Troies :

$$
\overline{7}, \because, 7, \pi, ;, \pi, \pi, 7, \pi .
$$

C'est dejjá un indice et puisque la chose est connue, les exemples rous sont peu nécessaires. Mais $y$ a-t-il des piéces arec un prooemium, ou arec un posthymnion? Oui, car roici la canzone de Rinaldo d'Aquino, qui se compose de quatre strophes egales:

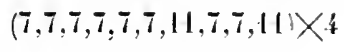

avec une strophe additionnelle de :

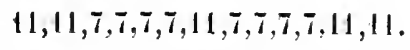

Il $y$ a plus: nous trourons dans le recueil de Nanucci

1 I, 98 . 
une canzone du même auteur composée de stroplies ègales par paires :

$$
\begin{aligned}
& (7,7,3) \times 2-(6,6,6,6,4) \times 2-(7,7,3) \times 2-(6,6,6,6,4) \times 2 \\
& (7,7,4) \times 2-(6,6,6,6,4) \times 2-(7,7,3) \times 2-(6,6,6,6,4) \times 2 .
\end{aligned}
$$

Ceci est convaincant, car cette structure reproduit exactement les formes des sėquences en mi-voie de trans. formation. Ceux qui adoptaient dejjà l'égalité des strophes conservaient le souvenir de la structure originaire en liant les strophes en paires par des rimes égales, comme on le voit dans Guillaume de Poitiers et chez d'autres encore.

Dounons pour exemple l'ordre des rimes dans la chanson : "Ben voill que sapchon li pluzor" de Guillaume de Poitiers :

$$
\begin{array}{r}
(a a a a b a b) \times 2 \\
(c c c c b c b) \times 2 \\
(d d d d b a b) \times 2 \\
(f f f f b f b) \times 2 \\
(f a f a f a) \times 1
\end{array}
$$

Nous avons vu que la forme employée de préférence dans les séquences latines transformées était une strophe issue du septénaire, or la strophe suivante de Bernart de Ventadour a la même origine :

$$
\begin{array}{cc}
\text { Estat ai cum hom esperdulz } & 8 . \\
\text { Per amor un lonc estatge. } & 7 . \\
\text { Mas era'm sui reconegutz. } & 8 . \\
\text { Qu'ieu avia fait follatge. } & 7 . \\
\text { Ga totz era ades salvatge } & 7 . \\
\text { Car m'era de chan recrezulz } & \mathbf{8 .} \\
\text { Et on ieu plus estera mulz } & \mathbf{8 .} \\
\text { Plus feira de mon damnatge } & 7 .
\end{array}
$$

Dans la belle chanson : Quan la douss aure venta, le mème troubadour a employe une strophe semblable $(6,6,6,6,6,6,6,6)$ á celle dont s'est servi Abẻlard dans une de ses séquences: $(6 ; 6,6,6,6)$. Des trouvères, comme Narcabrun ${ }^{1}$ ou Raimbaul d'Orange ${ }^{2}$, eux aussi, coupaient le vers octosyllabique par la rime pour en former

$$
\text { 1; } 2 \text { M.M1, 1, p. } 82,79 .
$$


une strophe dèrivèe :

$\begin{array}{cc}\text { D'aiso lau Dieu } & 4 . \\ \text { E santz Andrieu } & 4 . \\ \text { Qu'om non es de maior albir, } & 8 . \\ \text { Qu'ieu suy,so'm eug } & 4 . \\ \text { E non fas brug } & 4 . \\ \text { E volrai vos lo perque dir. } & \mathbf{8 .}\end{array}$

On en use de même avec le décasyllabe,pour en cons. truire des strophes : 4,6,4,6,10, comme B. de Ventadour, ${ }^{1}$ ou 4,6,4,6,4,6,4,6-4 comme Narcabrun' ' L'Ar. cipreste de IIita les suit de près. Ajoutons encore le schème de la chanson la plus connue du roi Richard: $(10,10,10,10,10,6) \times 6$ avec un envoi de $10,10,6,10,6$. L'envoi correspond ici, comme dans bien d'autres chansons à l'ephymnion, il en est sorti par l'entremise d'une invocation directe au saint dans l'ephymnion de quelques séquences. $\mathrm{Au}$ lieu d'un envoi nous trouvons une tornada impersonnelle, ou un ritornello qui semblent avoir la même origine.

On remarquera encore, que plusieurs poètes italiens du treizième siècle persistaient á imiter dans leurs chansons la forme originaire des séquences plutôt que la forme nouvelle,tandis que les poètes provençaux et francais avaient pris pour modèles les séquences transformées. Il y a donc dans la canzone italienne une certaine indépendance de la chanson provençale et française, à en juger d'après les documents que nous connaissons. Des formes semblables á celle de Rinaldo d'Aquino se trouvent dans Federigo II, Pier delle Vigne,Pugliesi, Semprebene. ${ }^{3}$ Voici la structure bien remarquable d'une canzone, attribuée à Bonagiunta Urbiciani."

$$
\begin{array}{r}
11,11,11 ; 11,11,11 ;-7,7,7,11 ; 7,7,7,11 ;-11,11,11- \\
7,7,7,11 ; 7,7,7,11 ;-11,7,7,11- \\
7,7,7,11 ; 7,7,7,11 ;-11,11,11-
\end{array}
$$

\footnotetext{
1,2 Mahn, I, p. 41, 60.

3 Cfr. Nanucci.

4 Naxucci, p. I, p. 148.
} 
Après aroir mis en tète un prohyminion de six vers en deux groupes, le poète italien compose sa chanson de trois strophes égales, chacuire consistant en deux groupes de quatre vers, ce qui lui jermet de maintenir la règle du parallèlisme; mais en ajoutant à chacune d'elles un ephymnion particuliér, il leur donne un caractère individuel, et les rapproche des strophes des odes luzzantines qu'il parait avoir connues.

Les pastourelles sont en gènèral d'une forme presque identique à celle deschansons. Leurs strophes sont composées de vers inètaboliques: 1

OU :

$$
\bar{\imath}, \bar{\imath}, \bar{\imath}, 7,: 3, \ddot{3}, 1, \bar{\imath}, \ddot{3} ; 7, \bar{\imath}
$$$$
\text { . } 6,6,6,6,6,6,6,8,8,6
$$

queliquefois mente on y rencontre unr structure consistant dans uin cerlain parallèlisme des vers sans ègalite des strophes: :

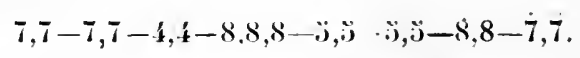

Il semble donc que les pastourelles, quant á leur forme, proviennent aussi des séquences.

Passons maintenant aux ballates et aux danses. Ici sans loute, on pourrait plus facilement admeltre une crëation populaire, mais voici la structure d'une ballade dans Guido Cavalcanti : 3

$$
11, \bar{I}, 7,7.7, \bar{\imath},-(11,11,11,11,11,7,7,7,7,7,) \times 1
$$

c'est-a-dire un prooemion et quatre strophes de chansons ou de sequences. (Gianni Alfani nous donne une danza diune forme qui prouve plus clairement encore son origine puisqu'elle possède en mème temps un prooemion el un ephymmion : :

$$
11,7,7,11-(11,7,11,11,7,11,11,7,7,11) \times 3-11,7,7,11 .
$$

1 Baвtsch, Romanzen und Pastourellen, I, 37; II, 40.

2 ID., ibid., l. c., p. 28 .

s Navecci, vid. Guido Cavalcanti.

- Naxicar, p. 304 s. 
La ballatteta du même auteur n'en diffère que par une forne plus restreinte:

$$
7,11,11-(11,11,11,11,7,7,11) \times 3 .
$$

Raynouard nous donne une ballade composée d'une avant-strophe et de quatre strophes égales: ${ }^{1}$

$$
10,10,10,4,10,4,10,10,4-(10,4,10,4,10,10,4) \times 4 .
$$

Nous indiquerons encore les "Dansas denostra Dona" danses en l'honneur de Notre-Dame, dont les "Monuments " contiennent plusieurs exemples. Elles présentent la forme typique des séquences transformées :

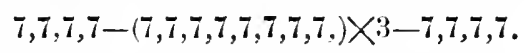

Il $y$ avait non seulement des danses pieuses, mais aussi des chansons et des sirventes, à la mère de íieu, ${ }^{3}$ et cette liaison étroite entre la poèsie religieuse et la poésie mondaine s'éclaircit surtout par leur origine, que nous exposons ici.

Les exemples ne nous sont plus nécessaires pour apprendre ou il faut chercher l'origine d'une grande partie des formes de la lyrique romane. Les trouvères ètaient des poètes de séquences romanes ou de tropes. Nous pouvons ici appeler á notre aide l'étymologie ingénieuse proposée par M. Liaston Paris pour le mot "trouver", qu'il, dérive de tropare. Cette étymologie nous rappelle les rors:s byzantins, dont l'influence a dùs être considèrable en (jccident, puisqu'ils ont donné son nom á la classe de poètes la plus célébre au moyen âge, qui n ètaient des trouvères, que parce qu'ilsimitaient les troparia.

Si nous admettons que les vers métaboliques, les vers brisés indiquent toujuurs l'origine byzantine de la strophe ou ils figurent, les "lais " derraient nécessaire-

1 Choix, II, p. 949.

2 Monum., 18 49 , p. 187, s.

${ }^{3}$ L. c.. Mayres de Dieu, verges pura. 
ment y trourer place. Ils possèdent quelquefois non seulement des vers mètaboliques mais des strophes inégales, ce qui les rapproche des tropes. Une affinité trés ètroite entre les séquences et les lais a ètẻ déjá admise et constatee par Ferd. Wolf dans son livre sur ce sujet, de sorte que le doute n'est pas permis. Maais en abandonnant l'ètymologie "lais-luoid" du savant allemand, aussi arbitraire que ses idées sur l'origine des littératures européennes, ne pourrions-nous rapprocher le lais de la laisse dans les chansons de geste? Les deux mots nous paraissent un doublet en deux genres, analoguea bien d'autres, et le sens, celui d'un faisceau de vers.

Lorigine du second type dans la lyrique romane a èté indiquée déjic plus haut. Il estreprèsenté surtout par les charmantes romances françaises, dont les vers et les strophes sont homogenes, et accompagnèes d'un refrain.

Nous ne serions pas ètonné de rencontrer parfois un entrecroisement de ces deux types provenant de deux sources différentes, surtout lans l'emploi du refrain et de la tornada. La prèdilection latine pour les formes règulières s'accuse ici une fois de plus, parce que nous trourons beacoup de chansons et de pastourelles soumises á la forme du second type, à l'homogènèitè des vers. ${ }^{1}$ Les exemples de chansons ainsi règularisées sont très nombreux; quant aux pastourelles, en voici un schème, le premier qui se présente à nous : :

$$
(10,10.10,10,10,10,10,10) \times 8-10,10,10,10 .
$$

ef enrore celui l'un sirvente

$$
(110.10,10,10,10,10,10,10) \times 3-10,10,10,10 .
$$

On donnait mème assez souvent anx charisons et autres formes semblables un refrain qui ne leur appartenait pas originairement.

Apres avoir reconnu les deux types qui dominent

1 Scheler, Trouvères belges, 1819, p. $90,30,36,39,43$.

2 Monuments de la littérature romane $1849, \mathrm{p} .73,89,171$. 
toutes les formes de la lyrique romane, nous ajouterons quelques observations et quelques renseignements ullèrieurs. Le premier type, représentè par la chanson, sa forme principale, est le plus fécond; il a donné naissance en premier lieu á la pastourelle, qui ne diffèrait de la chanson que par son sujet un peu plus populaire et d'une allure plus gaie et même plus légère, sans toutefois toucher ni au commun ni au grossier : "ses dive viltat o desonestat" selon l'avertissement de Molinier. Elle s'en séparail encore par une mélodie plus vive. un peu dansante mème. "Pastorela requier tostemps noel sô $e$ plazen e gay, no pero ta lone (lent) cum vers o chansos, ans deu haver sò un petit cursori e viacer. D De la pastourelle sortirent des sous-genres nombreux et de plus en plus populaires, des chansons de paitres, de vachers, de chévriers, de gardeurs de porcs, d'oies, de chansons de jardiniers, de nonnes: " E daquesta pagela son vaquieras, vergieras, porquieras, auquieras. cabrieras, ortalanas, monjas et en ayssi de las antias loi's semblans.

L'air vif et sautant de la pastourelle nous conduit á la ballade. De la ressemblance de sa forme à celle de la chanson nous avors conclu á une affinité qui est directement attesteje par $A$. da Tempo: "laigo enim modo suscepto vocabulo cuiuscumque geneiris ballatre possunt appellari et vulgariter appellantur cantiones. "Les danses de leur côté s’èloignaient peu de la forme de la ballade: "Item alq fan bals ala maniera de dansa umb un respos et am motas coblas. "Toutes les diffèrences que Molinier dit exister entre le bals et la dansa, comme entre toutes les autres formes lyriques (il ne parle pas de la romance) ne se rapportent qu'au nombre des couplets et au genre de la mélodie qui ètait tantôt plus lente, tantòt plus alerte. Quant ả laair des ballades il remarque qu'il etait plus vif " $e$ mays apte per cantar amb esturmens que dansa. "

Toute ballade possédait " un respos e la tornada." 
C'ètaient deux strophes additionnelles, diffèrentes des strophes principales, mais ègales entre elles-nuèmes, dont une ouvrait le chant et l'autre le suivait, conformément au prooenion et á l'éphymmion des séquences grecques et latines. On exposera plus loin la cause qui a vait fait domner le nom de réponse à la strophe qui servait de dèbut.

Nous avons remarqué que la tornada et lạ réponse ètaient de formes ègales. "E la tornada deu esser semblans al respos, " dit Molinier en enseignant; "que la dansa en lo respos deu arer III bordose $V$ al may, al qual respost es la tomada semblans. "Ces trois vers obligatoires et les plus usitès dans la tornada méritent notre attention surtout quand nous saurons, que tous ces genres de compositions pouvaient manquer de rẻponses. On y domnait alors deux tornadas ègales. L'une d'elles formait l'envoi oi l'auteur pouvait s'adresser directement á la personne à laquelle la pièce ètait destinèe. Dans l'autre il avait le droit de parler de lui-même; cependant les auteurs étaient libres de leur donner le sens qu'ils roulaient, ne laissant de permanent que les deux strophes ègales à trois vers cliacune. C'ètait une sorte de pseudomorphose, comme on en connait en minéralogie, oú les formes cristallines persistent tout en se chargeant d'une substance nouvelle. Supposons maintenant une chanson composée de deux strophes à quatre vers, ajoutons-y les deux envois a trois vers, et nous avons alors la forme célèbre du sonnet italien.

L'ancienne lyrique italienne possèdait, on le sait, des compositions dont le corps ne consistait que de deux strophes avec une réponse et une tornada; nous $y$ reconnaissons encore le type de la. ballade, et nous sommes disposés à admettre une ètroite parenté entre cette dernière et le sonnet, ả dire même que le somnet n'est qu'une ballatle intervertie. Nous allons éclaircir la question en rapportant un passage d'Antonio da Tempo très instructif sur la manière d'exécuter les anciens 
chants lyriques italiens, la même dont se servaient sans doute les Provençaux et les Français.

Secundum sciendum est, quod ballatu quaelibet dividitur in quaturor partes, scilicet quia prima pars est repilogatio, quae vulgariler appellatur ripresa, quod idem est dicere quan repilogalio, sive repetitio. C'est la "respos" de Molinier. Secunda pars appellatur prima mutatio, tertia pars secunda mutatio. Et appellantur mutationes eo quod somus incipit mutari in prima mutatione et secunda mutatio est ciusdem tonus et cantus, cuius est pi ima. Inlgariter tamen appellantur pedes. C'ètaient les deux strophes princijales, et il est remarquable quion leur dome le nom de pieds comme dans les sommets. "Quarta et ullima par's appellatur volta, quate habet eandem sonoritatem in cantu, quam habet repilogatio sive ripresa. "Cètail la tornada ou l'enroi. Les Italiens l'appelaient volta, jar conséquent les deux voltes dans les somnets ne sont autre chose que deux envois. Finito cantu alterius vollae vel onmium erborum aicuius ballatae cantores reasumunt et repilogant ac repetunt primum partem in cantu et ipsam iterate canunt.

Un exemple schèmatique nous fera mieux comprendre la description précèdente :

repilogalio, ou ripresa; , nonbre de syllalies $11,11,7,11$. quatre rers.

rimes..............

prima mutatio, le pre-

mier pied ou la première

strophe; trois vers.

nombre le syllabes $11,7,11$.

rimes......... c. d, e.

secunda mutatio ou la , nombre de syllales $11, \quad 7,11$. second pied; trois vers. $\{$ rimes.......... c, d, c.

volta, tornada, ou l'en- f nombre de syllabes $11,11, \bar{T}, 11$. voi; puatre vers.

rimes......... a, b, b, a.

On chantait donc la ripresa sur une mélodie donnèe, puis les deux strophes sur une mélodie égale, mais différente de la première; l'envoi était chanté sur l'air 
de la réponse,et pour augmenter l'agrẻment on répétait la ripresa, ce qui explique son nom italien. Elle s'appelait réponse en provençal, parce qu'elle répondait à l'envoi.Chaque ballade avait donc deux mélodies : l'une chantée deux fois et l'autre trois.

Revenons au sonnet. On sait qu'il consiste en deux strophes de quatre vers et de deux autres á trois vers. On donne aux deux premières le nom de pieds, et celui de voltes aux deux autres. Tous ces éléments figurent dans le schème que nous avons reproduit, et il ne faut que changer les voltes en strophes et les strophes en voltes. Il a èté d'autant plus facile de procéder à ce changement que d'aprés la règle générale les voltes devaient être plus courtes que les strophes. Telles sont les raisons qui nous portent $\dot{a}$ envisager le sonnet comme une chanson composée de deux strophes et de deux envois, et á le relier à la ballade. Les vers métaboliques ne sont pas une objection car beaucoup de sonnets italiens sont construits en vers hétéromorphiques et courts. Tant qu'on a chantè le sonnet,on a dù le faired une manière semblable à celle de la ballade.

Laquestion du rondeau francais, genre de composition créé par un sentiment artistique très délicat, et qui compte des productions charmantes. est peut-être plus difficile a aborder. Procede-t-il aussi du type de la séquence? C'est ce que nous allons tîcher d'élucider. Voici la facture d'un des plus anciens, qui date du XIIJ siecle et qui a pour auteur Guillaume d'Amiens ; il nous aplanira la difficultè. ${ }^{1}$

$$
\begin{array}{r}
\text { reprise }\left\{\begin{array}{l}
7 \mathrm{a} \\
3 \mathrm{ae}
\end{array}\right. \\
\text { strophe }\left\{\begin{array}{l}
7 \mathrm{a} \\
7 \mathrm{a} \\
7 \mathrm{a} \\
3 \mathrm{ae}
\end{array}\right. \\
\text { envoi }\left\{\begin{array}{l}
7 \mathrm{a} \\
3 \mathrm{ae}
\end{array}\right.
\end{array}
$$

${ }^{1}$ P. Herse, Romanische Inedita, 1856, p. 5'. 
Cette facture démontre clairementl'affinitè du rondeau avec le type dominant. Il faut pourtant remarquer, que la reprise est identique dans les paroles á l'envoi. Cette diffèrence s'explique par le progrès de l'art, car c'en était un que de répéter des petites strophes identiques au commencement et à la fin de la pièce, en lui donnant par ce procédé une belle unité de sentiment, et une forte couleur artistique.

La liberté de composition dans les rondeaux ètant trés grande, le progrès ne s'arrèta pas lá. On faisait consister la piéce en trois strophes, en donnant à la reprise un seul vers qu'on plaçait au dèbut de chaque strophe à laquelle il était ètroitement liè par le sens : "concordans cum intellectu et verbis atque sententia pruecedentibus et sequentibus ". A. da Tempo en donne l'exemple suivant:

Mille mercedi quiero

Al mio signor ognora

I pur lo trovo fiero.

Mille mercedi quiero

Ed orni mio pensicro

Come suo dio l'adora,

Suo modo e tutto altiero.

Mille mercedi quiero

Ma tanto di lui spero

Quanto mio ben lavora.

Le mème auteur enseigne : "Dicitur autem rotundellus, quia totus est uniformis sicut votunditas. Nam sicut est facta prima pars in rithmis et cantu ita et omnes aliae. Et sic cantatur una par's quemadmodum et alia. Et non diversificant sonum. Et primus versus primae partis semper repilogatur in cantu...". Il veut dire que dans le rondeau il n'y avait pas deux différentes mélodies, comme dans la ballade ou le sonnet, mais qu'il y en avait une seule qui, dans l'exemple que nous donnons, était répétée trois fois. La premiere strophe contenant trois vers, la mélodie a dù avoir trois membres ou phrases musicales, et comme la seconde 
strophe comptait un vers de plus, on chantait ses deux premiers vers sur la première phrase de la mélodie.Tels étaient le mode d'exécution du rondeau et l'origine de son nom.

L'auteur italien en cherche encore une autre cause en disant : "P'ossunt etiam appellari rotundelli quia plerumque contantur in rotunditate chorheae sive balli et maxime per ultramontanos qui valde utuntur rotundellis septenariis. "D'après ce témoignage,c'ètait en France que le rondeau était le plus en vogue,il appartenait au genre de la ballade, qu'on distinguait en * $b c l$ latae magnae, mediae, minores et minimac." Les dernieres ne comptaient que sept ou huit vers, mesure que les rondels les plus développés ne dépassaient que fort peu.

Un procédé opposé á celui dont les rondeanx nous offrent l'exemple, et par cela même analogue, se trouve employè dans les aubades, les albas provençales. Elles aussi n'ont qu'une tornada qui, cependant, n'est pas placèe au commencement, mais à la fin de chaque strophe dont elle fait partie intègrante:

Reis glorios, verais lums e clartalz, Deus poderos, senher, si a vos platz Al meu companh sias fizels ajuda Qu'eu non lo vi pos la noitz fon venguda Eit ades sera l'ulba.

Bel companho, si dormetz o velhatz, Non dormatz plus, suau vos ressidatz, Qu'en orienl vei l'estela creguda

Qu'amenal jorn, qu'eu l'ai ben conoguda, Et ades sera l'alba!.

Une des plus anciennes aubades françaises présente la facture suivante $:(5,4,6 ;-5,4,6)-7,4,6 ; 7,$.6 . Elle appartient donc au type de la chanson-séquence. Comme on le sait, les séquences ètaient principalement cultivèes dans les cloítres, où la règle obligeait aux offi-

1 Gurant de Bohneli, rlans Bartsch, 99.

2 Leroux de Lincr, Recueil de chants historiques, I, 139. 
ces des heures canoniales, des matines, des vèpres; on ne trouvera donc pas extravagant d'entrevoir quelque analogie entre les matines et les aubades, entre les vèpres et les sérénades, entre les saluts de l'église et ceux de la lyrique romane. La source de la poésie antique résidail dans la poèsie religieuse, et chose ètrange, qui nous rèvẻle une profonde ioi psychologique, le même phénomène se répète au moyen àge, comme si l'humanitè y commençait une vie nouvelle. Derons-nous en conclure que le sentiment religieux forme le fond de l'àme humaine, et qu'il est la source la plus féconde de l'art?

Parmi les compositions du premier type, on en rencontre quelquefois de fort singulières. Elles se distinguent par l'absence du sens logique. La pensẻe $y$ agit par bonds, poussee par le seul souci de la rime, qui doit relier dune consonance égale trois par trois vers:

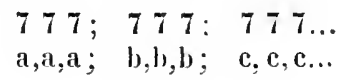

ou quelquefois a, a, a, b; b b b c; c, c, c, d; $d, d, d, e .$. Ce sont les motets, qu'on appelait aussi "frotole." "Quidam tamen istos motos confectos vulgariter. appellant frotole". Nous rapprocherons de ce fait un autre, non moins singulier, qui occupe aussi une place dans l'art musical du moyen âge. Les motets appartenaient non seulement á la poésie, mais aussi á la musique, d'oú ils nous semblent être originairement sortis. C'était un genre de chant polyphone, a deux, trois ou quatre voix. La premiére roix disait la mélodie et le texte principal, la seconde disait une autre nèlodie connue, avec un texte entierement autre, la troisième ajoutait un troisiéme air avec ses paroles á lui. L'art du compositeur consistait dans l'arrangement de ces diverses roix dans un ensemble. On sait d'ailleurs que l'oreille du moyen àge, tres fine en fait de mélodies, n'ètait pas difficile à satisfaire au point de 
rue harmonique, car elle se laissait charmer par des suites ininterrompues de quintes et de quartes: que nous trourons dètestables. Quelle qu'en fùt l'harmonie. le chant simultané de trois chansous diverses n'a pu produire qu'un effet bigarré. Néanmoins, un sourenir de ce procédẻ vit dans les motets de notre époque. La première voix y commence seule le chant, et quand elle est arrivée à la seconde phrase du texte et de la mélodie la seconde voix attaque la premiere phrase, de sorte qu'á l'entrée de la troisième voix la première est á la troisieme phrase, la seconde á la seconde et la troisième á la première phrase du texte et de la mélodie.Les voix courrent lune apres liautre par loute la pièce formant un ensemble plein de mourement et d'agitation d'un caractère très moderne. En revenant aux motets du moyen àge, si nous imaginons qu'il vint à l'idèe d'un des chanteurs de faire une strophe de tous les premiers vers des trois chansons dites ensemble, d'agir de même avec les trois seconds vers et ainsi de suite, nous nous approchons de la frotola. Tout en rapportant ces faits curieux en eux-mêmes, nous ne regardons pas cette explication comme concluante, surtout parce que loccasion d'étudier les frotole de près nous a manquẻe.

Nous croyons aroir épuisé les principales dérivations du premier type, il nous reste à ajouter quelques mots sur le second. II ne contient qu'une seule forme, mais qui depasse en beautè toutes les autres. La romance consiste en strophes de trois, quatre ou cinq vers homomorphiques, qui sont toujours des decasyllabes ou des alexandrins. Jamais il n'y entre d'autres vers, jamais de vers brisés, à ce que nous savons, si ce n'est dans le refrain. Celui-ci peut contenir un, deux, trois vers, et nous commaissons des romances modernes qui comptent jusquà cinq alexandrins dans le refrain.

L'exemple de laubarle, que nous avons donnẻ plus haut, se rapproche tellemenl d'une romance.quion pour. 
rait ètre tentè de penser à une affinitè entre ces deux genres. Mais c'est un exemple exceptionnel, toutes les autres s'en èloignent par leurs vers courts et hétéro. morphiques. L'envoi de l'aubarle entre étroilement dans la facture de la strophe. sa mélodie ne peut ètre que la dernière phrase de la mèlodie rle la strophe. tandis que le refrain forme un petit ensemble à part, séparé comme ill'est daus les paroles. dans la forme de ses rers. dans sa mélodie. La strophe de la romance nous raconte un fait personnel, le refrain porte ce fait à la pensée génerale, au sentiment de l'hmmanite on de la nature entière. La strophe cherche á nous intèresser au fait qu'elle raconte. le refrain s'empare de notre sympathie, de notre consentement, il fait battre notre cour, nous unit dans un chweur sonore, puissant. sa destination est d'ètre chantè en chceur.

Le plus ancien exemple du refrain se trouve, croyons. nous, dans Eschyle, qui fait rép iter quelquefois à une certaine distance, par le chreur entier, la mème pensèe dans les mêmes paroles:

"Malheur, malheur. quel lit de vepos. oie la hache a. double tranrhant t'a frappes dans un bain sanglant, comme si tu étais esclure .

Mais les Grees ont négligè de lui donner cette forme précise qu'il a recue chez les Romains. I e llernier exemple que nous en avons rapportè plus laut èlait de liaban Maure, composé a l’èpoque ou les séfuences commençaient à peine a être connues dans l'Europe occidentale et qualors elles gardaient entière leur forme primitive. Toutes ces raisons nous portent à considerer la romance avec son refrain obligatoire comme un type a part et de caractere roman, ce qui nous semble confirme par son non mème de romancr.

La richesse des formes que nous avons passèc en revue est admirable. Si lon $y$ ajoute les drames liturgiques avec leurs chours, les épopèes arec leurs laisses, les nombreux romans, les fabliaux; les poèmes didactiques, 
si l'on contemple dans la perspective de leurs puissantes voùtes ces imposantes cathèdrales romanes et ogivales, en écoutant les échos des chants liturgiques qui y retentissent, on reste confondu de la prodigieuse force créatrice de ces temps. Ne considérant que la poésie nous ne nierons pas qu'elle n'ait tourne bientôt au pur formalisme, mais les chansons de geste, la chanson de Roland avec son héroïsme et son amour si touchant de la patrie, les romans de la Table ronde avec ses chevaliers et leurs prouesses, le roman de Renart avec son incomparable ironie qui consolaient encore Goethe des vicissitudes de la vie publique, la lyrique entiere enfin sont autant de créations de premier ordre dans l'histoire littéraire. Leur nombre étonne et celui des productions atteste certainement l'activitè littéraire d'un peuple; mais plus que le nombre c'est la création des genres nouveaux, la production des formes nouvelles qui constituent des titres supérieurs à la gloire, qui décident de l'importance historique d'une littérature. Honneur au moyen âge, au douzième et au treizième siècle, époque qui, à l'exception de l'àge d'or de la Grèce, n'a pas son ègale dans l'histoire de l'Europe, honneur au génie roman à qui nous devons tant de belles formes poètiques, honneur au gènie français qui s'est montré le plus créateur.

Seulement, toutes les nations modernes ont le tort d'être venues après les Grees et les Romains, et à dire vrai, aucune des formes dont nous venons d'esquisser le tableau n'a une origine romane, car c'est toujours en Grece qu'il faut en chercher le berceau. Les sujets ont èté empruntes un peu partont, depuis l'Irlande jusqu'aux Indes. L’originalité des littératures les plus indépendantes en Europe n'est done que relative.

D'un autre côté, il serait inadmissible de vouloir dire que la Gréce antique rit eu des romances, des chansons, des ballades; que l'Irlande ait donné naissance à des romans de clıevalerie et que les Indes aient déjá possédè 
un roman de Renart. C'est ici le moment de constater que l'originalité littéraire des nations modemes dépend de la curiositè et de l'intérèt qu'elles portent aux ouvres de l'esprit, que cette originalité consiste dans le choix qu'on fait entre les divers sujets, lans la préfẻrence qu'on accorde aux uns plutôt qu'aux autres, dans la manière dont on facomne, qu'on transforme et qu'on perfectionne les formes recues ou empruntées. Il y a un développement presque naturel des sujets et des formes qui leur est inhèrent, donné en germe dans les sujets et les formes originaires; il ne fallait qu'un esprit assez fin pour deviner et effectuer ce développement possible. Il en a aussi un autre qui est voulu et soumis aux principes artistiques. Mais tout: sujets, formes. principes artistiques est dominé par la manière d'envisager le monde et la vie humaine par une certaine philosophie, qui peut être naïve ou profondément étudièe, et qu'on ne peut refuser même aux produits littéraires les plus primitifs. Nous persistons a tenir les auteurs des premiers produits littéraires el artistiques pour les lommes leș mieux douès de leur sociète et de leur èpoque.

Là vie historique n'a pas le temps d'attendre partout le développement spontanè d'une culture autochtone. La curiosité humaine ètant naturellement portée vers l'étrange et l'étranger, vers l'hétérogène, un tel développe. ment nètait possible que chez une nation isolee, dans un lieu et á une époque oi rien du dehors ne l'attirait. Tel était peut-être le cas de l'ancienne Égypte. Si un peuple au moment du premier contact avec une autre nation n'a pas encore réglé ses mours, s'il n'est pas arrivé á une manière d'envisager le monde, s'il n’a pas une religion qui est en même temps sa science et sa philosophie, el si la nation étrangère lui est supérieure sous ces rapports, la marche du progrés autoch thone s’arrêtera chez lui,il sulsira l'influence extèrieure et som caractère ne sera plus que relativement sien. Il en a èté ainsi de toutes les nations modernes de l'kurope. 
Cette manière de voir nous sẻpare de la philosophie contemporaine de l'histoire, elle nous met aussi en désaccord avec les idejes du comte Nigra, contenues dans un èlégantarticle plein d'amour du sujet,intitulé : La poesia popolare italiana. "L'auteur nous dit: "La poesia popolare, al pari della lingua, è una creazione spontanea, essenzialmente etnica. Razza, lingua e poesia popolare sono tie forme successive della nicdesima idea, e seguono nella loro genesi e nel loro sviluppo un procedimento analogo ". Les races, les langues et la poésie sont, d'après l'auteur, des créations spontanées, indépendantes de notre volontè, des produits analogues de la nature. Cette opinion, qui est celle de la science actuelle, résistera-t-elle à la critique ? C'est ce que nous allons examiner.

La pensée contemporaine cherche á établir une homo. génèitè parfaite entre les phènoménes historiques et les phénomènes physiques. Elle $\mathrm{y}$ arrive en subordonnant $\grave{\imath}$ priori les premiers aux seconds: l'histojre á la science naturelle, subordination trop précipitée á notre avis. Les phénoménes ou les faits historiques, qui ont toujours une personnalite pour source, sont soumis aux lois psychologiques, les phénoménes physiques le sont á celles de la nature. Nul doute qu'il doit y aroir une concordance parfaite entre ces deux séries de lois et il est à supposer qu'elles n'en font qu'une. Les lois physiques ont pour principe la causalitè, la cause $y$ est aveugle, l'effet involontaire, inévitable. Le trait essentiel des lois psychologiques, et partant historiques, réside dans la finalitè. Chaque instant de notre existence tend vers un but que nous cherchons a atteindre. Ce but qui n'existe d'abord que dans notre pensẻe, et n'est qu'une reprèsentation, une pensée lui-même, est néanmoins le seul moteur de nos actions. Nous arrivons au but final par la force de notre volonté qui nous y méne par le moyen des actions intermédiaires. Ainsi la force n'agit pas aveuglément. elle est conduite par la représentation de la fin. 
Suivant l'importance de la personnalité le but est noble ou mesquin, il ne dispose que de sa propre force ou il sait commander á une nation entiére et lui imposer le même but. Cette proposition peut être constatée á tout instant par tout homme réflèchi 'en observant chaque jour dans les sociétés humaines l'action des tendances élevées ou mauvaises, profitables ou destructives.

La causalité régne dans le monde physique, notre corps lui-même lui obéit á ces moments oú la lassitude l'améne à résister à notre volontè. Le merveilleux enchaînement des causes et des effets nous a fait comprendre dans une certaine mesure la nature entière, nous a fourni les moyens de la maîtriser, de l'asservir à notre usage, à nos fins. En la maîtrisant, en l'exploitant nous nous servons de la causalitè et cela seul prouve assez clairement combien sa connaissance est supérieure, mais tout en s'en servant, et n'exploitant les forces naturelles que dans un but,nous sommes nousmêmes gouvernés par la finalité. Remarquons maintenant que nous ne connaissons la vie intèrieure que d'un seul objet, qui est nous-même, et que la surface seule de tous les autres nous est accessible. Nous nous sentons, nous sentons notre existence et ce qui se passe en nous, mais nous ne connaissons pas le sentiment de la nature extérieure. N'est-il donc pas possible que le même enchaînement des faits. qui re. gardẻ de dehors apparaît comme causalité, devienne finalité,considèré du point de la vie intérieure? Telle ètait probablement la pensée d'Aristote, quand il dit que le but est en mème temps la cause première des choses.

Il $y$ a plus: Lenchainement causal n'est clair et èvident que dans des groupes de phénoménes, dans des pièces de la chaine universelle. Aussitòt qu'on embrasse l'ensemble de la nature, et qu'on énonce une loi générale on se trouve, sans le vouloir, hors de la causalite et sur le domaine de la finalité. Ainsi toutes les lois générales, comme la gravitation, l'affinité chimique, la loi de la 
conservation de' la force, de la moindre action, toutes elles expriment une tendance, une finalite et non pas une causalité: Un des psychologues contemporains les plus autorisès, $M$. Wundt, partisan de la causalitè et de $\mathbf{M}$. Darwin. a fait preuve d'une grande perspicacitè critique en dèclarantque les lois naturelles ètablies par lecèlèbre naluraliste anglais sont au fond des lois finales.

Cette relation entre la causalitė et la finalité persistera peut-ètre toujours. Les recherches causales sont indispensables, et les partisans de la causalité universelle tiennent trop obstinėment à leur principe pour l'abandonner sur nos lutroles, mais nous pouvons soupconner, rien que soupçonner, qu'un jour lidentite des lois psychologiques et des lois physiques deviendra plus apparente et que le principe du microcosme, que nous connaissons intimement, se lévoilera comme le principe du macrodosme entier. En attendant nous avons le droit de nous défendre contre la tyrannie que les sciences naturelles veulent imposer aux recherches historiques.

Cet exposẻ métaphysique a pour Jut de motiver notre - opposition á l'analogie énoncée par le conte Nigra entre la race, la langue et la poésie. L'origine des races appartient au domaine de la nature physique, elles sont le produit de leurs causes et nous devons nous contenter de cette explication. Il n en est pas de mème en ce qui - regarie les langues qui sont du domaine historique.

La connaissance des langues est aujourd'hui assez a vancée pour nous permettre d'y voir un peu plus clair. Pour entrer immédiatement en matière, appuyons-nous sur des exemples. Trenere designe un mouvement du corps causé par la peur. Faut-il donc supposer quá l'époque de la formation des mots tout le peuple latin. ou plutit aryen, en sentant ce mouvement, ou en le voyant, l'ait qualifié spontanement par le mot tremere? Un verbe dérivè d'une autre racine n'aurait-il pu rendre le même service? Et c'est positivement le cas; puisque presque chacune des langues aryennes désigne ce mou- 
vement par un verbe tout a fait différent. Les racines les plus originaires sont les onomatopoétiques, noms des bruits, des mouvements. Mais les bruits, les mouvements se ressemblent, tandis que leurs noms diffèrent. comment expliquer cela? C"est quaucun nom n'est absolu. En imitant les bruits par la voix, des esprits inventifs ont créé plusieurs racines acceptables, dont la signification spéciale fut déterminée par convention, comme le dit Whitney, ou peut-être par l'autorité de cliefs ou de personnes renommées pour leur esprit. Nous croyons aussi que toujours une nourelle racine a été inventée par une seule personne, puis adop. tée par la masse, heureuse d'avoir á son service une expression de plus. Telle est l'histoire probable de tous les mots et de toutes les formes.

Pour expliquer ensuite la division d'une langue originairement unique en dialectes et en patois, il faut admettre d'abord une séparation locale, amenée par l'accroissement de la population, il faut admettre plusieurs cercles, cliacun avec son centre particulier, oú ètait établi le domicile du chef, ou le lieu de réunion pour les cérémonies religieuses. Il y avait dans chacune de ces localités une personnalité dominante, dont la manière divergeante de prononcer pouvait ètre dèterminé par quelque particularité dans la structure des organes de la voix et á laquelle toute sa famille pouvait déjả participer yar hérédité. Les autres membres de la tribu adoptèrent par imitation le même mode de prononcer qui se propagea ainsi aussi loin que portait l'influence du centre. Nais nous ne pouvons qu'effleurer ce sujet qui demanderait à être traité à part. Nous n'avons donnè que rleux exemples et nous ne prétendons nullement en dérluire une règle gènèrale; nous croyons seulement qu'il en est de mème pour tous les autres cas et qu'il faudra toujours les attribuer à une personnalité unique. Quelle que lattée que soit cette explication, nous n'avons pu l'éviter, parce que les partisans de la 
spontaneilé du chant jopulaire en appellent tress sourent a cette analogie entre la naissance de la langue et celle de la poésie. Cette analogie existe, mais en notre sens et non pas au leur.

Nous avous suffisamment exposé notre opinion sur la poésie populaire, et la poésie populaire italienne ne fait que corroborer ce que nous avons dit. Ses formes ne sont que des débris de la poésie artistique, le strambotto d'une tencon, le ritornello d'une volte. "Hue antem cantiones ut plurimum fiunt cum quadam parte inferiori, quae est minor aliis partibus et appellatur vul. gaviter retorizellus, alii appellant ipsam voltam ", dit A. da Tempo. Le stornello parait être le produit des chambres de rhètorique ou des cours d'amour et représente un motet ou une chanson minimale. Le comte Nigra lui même n'est pas èloigné de cet avis.

Les formes lyriques les plus populaires en France sont toujours la chanson et la romance. La chanson contemporaine se caracterise, comme celle d'autrefois, par des vers brisés et par un air vif et léger, la romance par sa strophe homomorphique, par son refrain et par une mélodie pathélique. Sortez le dimanche hors de Paris, il n'est pas rare de rencontrer le ménestrel moderne chantant une romance. avec un camarade l'accompagnant du violon, tout comme au moyen àge. Les vieilles traditions se continuent et devraient ètre protégées.

Nous arons tiché d'ètre bref. mais l'espace que nous avons parcouru, les questions que nous avons examinées ne se laissaient pas renfermer dans moins de pages. Partis les vers les plus rudes, nous sommes arrivé pas a pas aux formes brillantes du sonnet et de la romance. Nous avons cherchè à tirer des accents la mélodie primilive des aédes pour toucher á la fin aux airs sonores des chansons, des ballades et des romances qui sont tantôt d'une telle vigueur, tantìt d'une telle grace, qu'aujourd'hui encore ils feraient une forte impression sur un public commaisseur. Ils satisfont par- 
faitement à la demande de Molinier qui dil : "Vers deu aver lonc sò e pausat e noel amb belas e melodiozas montadas e deshendudas et amb belas passadas». IIs ne sont pas enchaînés par l'accord de la tonique et de la dominante. comme le sont les airs modernes, ils ont un mouvement plus libre, des cadences insolites et hardies, une riche figuration. Ils ne sont d'ailleurs qu'une application du chant lilurgique à des paroles mondaines, mais le chant liturgique appartient aux plus grandes créations de l'art universel. Etant fondès sur les lııit modes grégoriens. qui ont èté convertis sous linfluence de l'harmonisation en nos deux modes modernes, ils ont, pour ainsi dire, quatre fois plus de varièté que les mélodies de nos jours.

Chaque poète liturgique; chaque trouvère était en même temps compositeur, musicien, et nous n'arriverons jamais á bien comprendre la littérature du moyen âge sans la connaissance du chant liturgique. Ne portant notre attention que sur les paroles, nous ne saisissons qu'un côtè de chaque persomnalitè poètique, le côté musical de leur àme nous échappe entièrement. L'intèrèt littéraire, qui est en mème temps éminemment artistique, nous oblige donc d'ètudier la musique du moyen àge.

Ce point de vue nous perinet de nous occuper un moment de ce sujet. La cause en est un livre, dont lautorité est reconnue dans tout le monde catholique, et nous regrettons de n'en avoir eu commaissance qu'au moment ou nous terminions nos recherches, car il $y$ aurait eu lieu d'en parler dans un des chapitres précédents ou nous nous serions appuyé de son autorité. Mais le chant grègorien n’etant pas le sujet propre de notre essai, cette circonstance pent nous servir d'excuse de ce qu'un tel ourrage ait échappé à notre attention. Il s'agit du livre de dom Pothier sur le chant grègorien, sa forme originaire et sa tradition historique'. Nous

I Isa traduction allemande porte le titre : ler Gregorianische Cho. ral. Tournay. 1881. 
sommes heureux de nous trouver d'accord sur plus d'un point avec le savant auteur. Son objet principal est le chant, le rythme n'y figure que d'une manière accessoire, le contraire était notre cas, et toutefois nous nous sommes souvent rencontrés en arrivant aux mêmes résultats. Dom Pothier trouve une trés grande ressemblance entre le rythme du chant grégorien (dont le texte est en prose) et le rythme oratoire des Romains. Or, nous avons tâché d'éclaircir la relation entre $1 \mathrm{e}$ rythme poètique et le rythme oratoire, et nous croyons aroir clairement dèmontré que ce dernier a fortement contribué à la formation du rythme poétique du moyen àge. A notreavis, ce rythme transformé ne comprenait pas de pieds; par conséquent, les mesures devaient être absentes dans les mélodies liées á ces rythmes, fait confirmé par dom Pothier. Selon lui, le rythme dans les chants grégoriens ne dépend que du texte dont il suit les membres, les coupures, les phrases, et nous croyons, en jugeant d'après la structure de vers rythmiques, qu'il n'en pouvait ètre autrement.

- Notre accord n'est pas cependant complet et le dissentiment porte sur un point capital, capital au point de vue de dom Potlier plutòt qu'au nôtre. Le chant liturgique tout entier est-il vraiment identique avec le chant grègorien, comme le veut le savant Père? C'est une question bien grave que nous n'abordons quavec hẻsitation.

La musique moderne nous est assez bien connue. Les compositions de Berlioz, de Gounod, de Wagner, qui n'aurait jamais su trouver ses remarquables motifsducteurs (qu'on nous passe ce mot), ses caractéristiques mélodies des maitres-chanteurs (plutôt maitres du puy ou maîtres rlıetoriciens) sans une profonde connaissance du chant liturgique, ont pour nous un grand intèrèt. Nous connaissons les ceuvres des classiques modernes depuis Chopin, Schumann et Schubert, jusqu'á Beethoven, Mozart et Haydn. Les célébres compositions pour 
l'orgue de J. S. Bach, ont pour nous un charme particulier, et nous avons toujours cherché l'occasion d'assister á l'exécution des grands oratorios de Händel, de Bach, de Haydn. Nous croyons sentir la gràce rèpandue dans les pièces de Rameau, de Couperin, de Grétry et de Lully,de Graziolli,de Matielli,de Scarlatti et de Galuppi. Nous admirons l'art avec lequel Josquin de Près, Goudimel, Palestrina, Allegri, ont su donner une harmonisation inimitable aux chants liturgiques, tout en leur gardant leur austèrite. Les chants religieux dans les langues nationales nous sont connus, aussi bien que les chants populaires de plusieurs pays de l'Europe. A force d'ètudes, et pour les avoir entendu chanter trés souvent, nous nous sommes familiarisés avec les cliants liturgiques eux-mêmes, avec ceux des matines, des processions, de la messe, des vèpres et de la semaine sainte. Nous avons étudiè l'antiphonaire de Saint-Gall, l'ouvrage de Gerbert: De cantu et musica sacra, les Scriptores de musica publiès par Gerbert et par Coussemaker. Nous connaissons les mélodies des drames liturgiques, celles d'Adam de la Halle, quelques-unes de Gaucelm raidit et de plusieurs autres Trouveres et Minnesinger. Le lecteur voudra bien nous excuser de lui faire part de nos connaissances musicales, et peutêtre nous taxera-t-il d'un sentiment de pédantisme bien èloigné de notre pensée, notre but ètant uniquement de justifier un profane et lui donner le courage d'aborder un sujet aussi spécial.

Le savant Père identifie à plusieurs reprises le chant grégorien avec le cliant liturgique proprement dit, en lui attribuant pour trait essentiel la figuration ou le groupement de plusieurs sons sur une seule syllabe. Les recherches auxquelles nous nous sommes livré et que nous venons d'exposer nous ont amené à une conclusion opposée. En examinant l'ensemble des mélodies liturgiques, nous y rencontrons deux types bien distincts. Lun est caractérise d'abord par son texte qui 
n'est jamais versifié. Il est tirè à peu d'exceptions près de l'Ecriture Sainte, ce qui explique sa forme. On y voit le sentiment de répugnance professé par le pape Grégoire le Grand à l'ègard des formes profanes, èchos du paganisme et de la mondanité. Tout en adoptant les modes de la musique grecque, le pape organisateur a enfermé ses mélodies dans l'espace d'un tẻtracorde qu'elles ne dépassent jamais. Les mélodies sont en principe syllabiques, n'ayant qu'un son par syllabe, à l'exception de rares endroits, des cadences surtout, ou elles sont embellies par de petites figures mélodiques qui consistent en deux sons sur une syllabe et jamais plus. Liègalité de tous les sons est une régle générale. Nous comptons á ce type tous les chants de la messe, les mélodies des psaumes et une partie des antiennes qui s'y rattachent immédiatement. Il faut pourtant en excepter le "Glonia in excelsi.s, "le "Ite, missa est," le "Benedicamus Domino" et le psaume "Laudate pueri Dominum ", dont les mélodies ont dû être postérieurement ornementées; tels sont le caractére et le domaine du chant grégorien proprement dit, et nous croyons qu'en dehors des pièces que nous venons de citer, aucune de celles du chant liturgique actuellement en usảge n’appartient plus à la période de Grégoire le Grand.

Maintenant que nous a vons établi la véritable position du chant grégorien, nous pouvons procéder à l'explication du rom du plain chant qui n"a pas encore èté donnée d'une manière satisfaisante. Le nom du plain chant n'appartient qu'au chant grégorien proprement dit. Il est "planus, " uni : $1^{\circ}$ parce qu'il n'est ni mesuré, ni mème coupé en vers ; $2^{\circ}$ parce qu’il est enfermé dans l'espace d'un tétracorde; $3^{\circ}$ parce qu'il est unison et jamais harmonisé ; $\mathbf{4}^{\circ}$ parce qu'il n'est pas figuré ou que sa figuration est des plus modeste. Il ne manque pourtant pas de beauté, il exprime les sentiments de piété, de soumission, de modestie, de l'amour de Dieu, et d'une 
tendresse presque timide.Au temps de Grégoire leGrand, l'église menacèe dans sa capitale mème, tantôt par des patriciens batailleurs, tantôt par les rudes ariens Longobards, n'avait pas encore le sentiment de triomphe.

Le second type se distingue du premier par plusieurs traits essentiels. Ses mélodies dépassent toujours non seulement les bornes du tetracorde, mais parfois ceux d'une octave. Les figures n'y sont pas limitées aux cadences, mais souvent la mélodie entière ne consiste qu'en figures, comme dans les chants de processions. C'est à peine si l'on apercoit les figures á deux sons, inl* perceptibles parmi celles plus riches, ou le nombre des sons monte jusqu'à quarante-huit sur une seule syllabe, comme dans l'antienne : Pax acterna.Nous savons dejả que le texte des chants grégoriens était en prose; cet usage fut encore continué dans la seconde pèriode, en adaptant aux textes en prose des mélodies á la nouvelle façon.C"étaient des "tractus, " des "proses", qui ne sont au fond que des antiennes avec une riche mèlodie. La forme principale, dominante de ce second type sont les séquences, dont nous connaissons déjà la facture, pẻriodique d'abord, puis versifièe, rimée et strophique. C'est ici qu'il faut classer tous les hymnes en usage, aussi bien que les plus belles antiennes, telles que le Salve Regina, la Regina Coeli, l'Alma Redemptoris mater, tous les chants de processions, l'Officium defunctorum, et bien d'autres chants et offices qu'on peut facilement reconnaître aux traits que nous avons signalès. Le Te Deum laudamus, ce chant le gloire de l'èglise triomphante, ne peut appartenir qu'ả cette seconde jériode.

Les séquences étant la forme principale de cette époque, leurs mèlodies servant de modéles à toutes les autres, nous en pouvons conclure que ce fut sous leur influence et celle des mélodies grecques que le chant liturgique prit un nouvel essor. Ainsi que nous l'avons dit plus haut, en parlant de l'introduction des séquences dans l'ouest de l'Europe, c'est au pape 
Adrien II qu'il nous faut rapporter la date de la nouvelle époque du chant liturgique auquel nous ne refusons pas le nom de grégorien, mais seulement en tant qu'il est fondé sur les huit modes grégoriens.

Il ne nous reste que quelques remarques particulières à faire. Nous avons reproché au Père Bouvy le rythme de surcroît, fondé sur l'accent, qu'il croyait avoir trouvè dans la poésie byzantine, et même dans la poésie classique, or. ce rythme de surcroit est tiré du livre de Dom Pothier, chapitre XIV et nous nous en rapportons à ce qui a èté dit plus haut sur ce sujet. De l'autre còté, si nous avons reconnu que le pére Bouvy avait étè bien prés de saisir le ròle de l'accent,c'est à son maître que se. référe aussi cel aveu. Les opinions modernes sur l'accent ont conduit Dom Pothier á une autre proposition que nous ne croyons pas juste. Il veut que dans le chant liturgique on renforce les syllabes accentuées. On sait que d'après la doctrine des anciens chaque syllabe a son accent qui, prolongé et relevé par le rythme, a donné naissance á la mélodie. Relever un seul accent dans chaque paroledu chant,c'est faire tort aux autres accents. Aux compositeurs seuls appartientledroit,s'ilsle veulent, de relever les accents aigus par des figures, ou par des sons plus hauts, et ce n'estpas aux clianteurs á les corriger. Nous croyons que ce renforcement des syllabes accentuées ne s'accorde pas bien avec les mélodies liturgiques qui demandent qu'on relève leurs figures, leurs cadences; Dom Pothier lui même insiste et dit avec raison quil faut faire résommer avec quelque lenteur toutes les cadences finales des vers, des distinctions, des césures, des groupes mélodiques. Dans ces cadences toutes les syllabes sont atones, puisqu'elles sont les dernières, et dèjá relevées elles-mêmes elles ne souffrent pas le relèvement des autres, si le chant ne doit prendre l'air d'une agitation insupportable. En contròlant notre opinion par la pratique nous avons trouvé que seuls les mots proparoxytons admeltent quelque relévement 
de leurs accents afin de ne pas faire trop prévaloir la syllabe finale, mais cela doit se faire d'une manière presque involontaire.

Plus encore que toutes les autres, les mèthodes liturgiques demandent une émission claire et pure des sons. Cette règle générale gouverne aussi les figures, les groupes, les cadences. Dom Pothier, tout en reconnaissant et en démontrant l'égalité des notes du chant liturgique veut cependant que lous les tons appartenant au mème groupe soient dans le chant ètroitement liés entre eux. Nous craignons que cette demande, bien que juste dans une certaine mesure, ne soit mal comprise. Nous croyons avoir remarqué qu'en voulant obèir à la régle posèe par Dom Pothier on commence à hâter l'émission des groupes en émoussant les sons particuliers, en effaçant la clarté et la beauté des inflexions. ${ }^{1}$ Pour obvier á cette faute il faut insister sur l'ègalité des sons, même si elle n'était pas mathématique.

Ces remarques faites nous admirons la connaissance et le sentiment intime que le savant Pèrea de son sujet.

Malgré nos longues observations sur les séquences, ce vaste sujet n'est pas encore épuisé. Nous aurions aussi voulu exposer nos opinions sur le mode et le temps de formation de la mytlologie scandinave, mais des circonstances independantes de notre volontè nous obligent d'interrompre ces recherches. Du reste la partie des séquences non encore élucidèe n'occupe qu'une très faible place dans le domaine des litteratures romanes,et les recherches de mythologie n'appartiennent pas á celui du rythme. Nous croyons donc pouvoir sans scrupule nous arrêter.

On ne niera pas peut-ètre, qu'un bon nombre de questions n'aient reçu ici une solulion satisfaisante, mais si

1 Nous pensons it l'école du chant liturgique de kempten. 
c'est le cas, nous u'avons pu arriver à ce résultat qu’à la condition de rejeter les idèes préconçues, qui ont fait dérier tant d'éminents savants dans leurs conclusions. Chaque question résolue sur la base de nouveaux principes est donc en mème temps une preuve en leur faveur, et ils paraissent mieux ètablis a la fin de notre travail, qu'ils ne l'étaient quand nous les exposions. Espèrons qu'il en sera de même dans l'avenir, car ces principes seuls rendront possible lapplication rigoureuse de la mėthode historique aux sciences historiques. Il nous faudra en outre connaitre mieux les lois josychologiques,et les mieux appliquer dans nos travaux. Elles devraient nous tenir lieu du calcul qui vérifie, et qui guide d'une maniere si efficace les recherches physiques. C'est alors que nous entreverrons sous son véritable jour le lien qui relie l'antiquité aux temps qui l'ont suivie. La Gréce n'est pas seulement la mére de nos sciences, elle est aussi celle de nos arts. Le premier fait est incontestable, et cela même donne une grande probabilité à l'autre. La mème force créatrice, le mème puissant esprit se manifestent chez eux ègalement dans les deux domaines.

Notre education scientifique a actuellement pour base l'etude du monde antique, il faut seulement ne pas affiablir l'effet de ces ètudes en méconnaissant la dépendance de nos arts de cenx de l'antiquité, et en défigurant ainsi l'intime relation qui existe entre la civilisation moderne et celle du monde antique. La civilisation humaine semble de date plus récente qu'on ne le suppóse, et si l'on réussit,ce qui est à désirer,á élucider les origines de la culture grecque, on touchera probablement en mème temps aux origines de la culture europèemne, nous aurions presque dit de la culture en gènèral.

Faris, le 13 aout 1887. 


\section{TABLE ANALYTIQUE DES MATIİRES}

(Les numéros renvoient aux pages).

Accent : dans la versificalion syriaque : $: 3,138 ;-$ germanlque : 37,4 . - Théorie des accents : 62, 63, 64. - Relation des accents avec le chant et la musique : $6 \ddot{3}, 66,1 \% \pi$. - Rỏle de l'accent dans les tropaires : 1'6, 1'7; - dans les vers de Virgilius Naro de Toulouse : $1399 ;-$ dans les séquences : $160 .-$ Les accents et les neumes ou notes musicales : 73 . - La fonction mélodique des accents eflacée: $69,73, \pi$ t. - Les accents et le rythme: $37,13 \pi$, $138,146,206 ;-$ dans la versilication romane : 16 $, 166,167 ;-$ dans le chant liturgique : 2106. - Accentuation romane : 167: - francaise : 167: - provençale : 167; - italienne : $168 ;-$ espagrnole : 17i.

Acrostiches : 138 .

Adnominatio : 100 .

Adradicatio : 100 .

Alexandrins : 13i, 166, 17't; - alex, espagnols : 17ílii。

Allitération : 8, 98, 102, 10'.

Antiphonaire de Bangor : 127, 130.

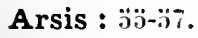

Arts : leur division : 2 ; - - leur principe ginérateur : $2,4,1: 2$; - arts musicaux : 1;0; - arts grecs : 1'10, 208; - egalisation des parties dans les arts : : ; - symétrie dans les arts : 2 ; spontanèité des arts : 10. - Priorité des arts populaires : 13 .

Aubades : 190, 193.

Autochthonéitè : 12 .

Ballades, bals : 162, 182, 183, 18\%, $18 \%$.

Cadences finales dans les vers : $110,126,139,16 j ;$; - dans le chant liturgique : $20 \mathrm{t}$.

Canzone : 179, 150, 181.

Carmina burana : 133 .

Causalité : 196. 
Césure, dans les rythmes latins : 131,$132 ;-$ dans les vers italiens : 172.

Chansons : 162, 1i9, 188, 200; - chansons dc geste : $2 \ddot{0}, 160$, 184.

Chant, primitif : 11, 3i, 78 ; - chant dans les discours oratoires antiques : 92 ; - chant fonde sur les accents : $160 ;-$ chant liturgique : $201 ;$ - grégorien : $203 ;-$ le prlain-chant : 204 ,

Cola lyriques : $: 3 ; ;-$ convertis en mètres : $8 \dot{z} ;$ - en rythmes : 1:33, 18:1.

Culture primitive : 10 - culture antique, son influence: $22,26,208$.

Danse : 2,$12 ;-$ la danse grecque : $; 8 ;-$ son rythme : 79 ; - danse romane : 182.

Décasyllabes : 130,$131 ;-$ décas. espaønols : 173.

Dimètre, iambique : $41,123,166 ;-$ trochaïque : 126.

Distique èlégiaque : $12,4,126$.

Echelles musicales, antiques : $67,68,72 ;-$ modernes : it; leur provenance : $;: i-i \pi$.

Edda : 8.

Epopee, allemande : 21, 26; - française : $23 ;$ - serbe : 26 .

Enuéasyllabes : 129 .

Envoi : 179, 181, 187, 189.

Ephymnion : 148, 179, 182.

Finalité : 196.

Formes lyriques, romanes : $170 ;-$ leur provenance : 179 .

Formules magiques : 3 i.

Frotole : 191.

Hendécasyllabes : 12' 1 , 12:, 126, 131, 166, 171.

Heptasyllabes : $12 \pi, 128 ;-$ redoublès : 1330 ; espagnols : $176 ;--$ italiens : 171.

Hexamètres : $8,43,: 3 \mathrm{k}, 10.3,121,126,139 ;-$ espagnols : 173 .

Hirmes : 14t.

Hypothèses, comme conditions dans les recherches : 6,7 .

Ictus : $500-60,80,146$.

Idées historiques directrices : 6 .

Influences historiques : $30 ;-$ préhistoriques : 31 .

Inventions primitives : $17 ;-$ individuelles : 13 ; - leur rareté : 16 .

Imitation : comme action psychologique principale dans les sociétés : $17 ;-$ dans les arts : $: 8 ;-$ imitation internationale : 20,30 .

Jongleurs : 20 .

Lais : 183 ; - laisse : 181 .

Langues, leur formation : $198 ;-$ leur division en dialectes : 199'. 
Langzeile : $7,41,10 \%$.

Littératures, allemande : $21,2 \mathbf{2} ;$ - anglaise : 28 ; - romanes : 28 ; - leur importance : 194 ; - européennes, leur originalité : 19 4.

Lois littėraires : 6 ; - métriques : 107 ; - historiques : 1930 ; - physiques : $196 ;--$ psychologiques : 208.

Lyre grecque, son influence sur la formation des gammes greeques : 67 .

Mélodies, formée des accents : $630,66,72 ;-$ mélodies des chansons de geste : 160 ; - des ballades: 187 ; - des rondeaux : 188, $189 ;$ - des sonnets : $188 ;-$ des motets : $101 ;-\ldots$ dans les drames liturgiques : 160 ; - dans le chant liturgique : 204 .

Mesure rythmique : v. Rythme.

Métrique : วั0, วั1, วั4, 107 ; - mètres les plus anciens : รั4; rapport entre la rythmique et la métrique : 83, 126, 136.139, 143 ; - mètre ehoriaque : 166 ; - innovations dans la métrique latine : $121 ;-$ dans les poètes chrétiens : 123.

Métriciens : 82, 83.

Métaphores, dans Virgilius Maro de Toulouse : 1ə̋ว̈; - chez les Scaldes : 1 öö.

Minstrels : 13, 14, 20.

Motets : 191.

Musiciens antiques : 83.

Musique,sa relation avec la poésie : $3 \dot{4}$; - origine du système musical grec : 68 .

Mythologie aryenne primitive : $8,9$.

Nombre: v. Rythme.

Octonaires : $126,136,139$.

Octosyllabes : 4t, 12\%; - espagnols : $17 \%$, 176.

Ossianisme : 13 .

Parques, changées en fẻes : 29 ; - en filles-cygnes : 29.

Pastourelles : 162, 178, 182, 18' 18 ' 18.

Pauses dans les vers : 163.

Pervigilium Veneris : 179 .

Pieds rythmiques : 8, 48, 49, 50, 81, 109;-leur ćehange dans les rythmes : 109; - pieds dans Virgilius Maro de Tou louse : 130 .

Plain-chant : 204.

Poésie aryenne primitive : $: 3,178,200 ;-$ sémitique : ä; 一 syriaque : $\ddot{5}, 140 ;-$ populaire : 13,$200 ;-$ byzantine : 1 \& 1 , 178 ; - romane : 19'. - La poésie selon Dante : 170.

Procemium : 148, 179, 18:.

Proses : 2000 . 
Quantite rythmique : $\%$, 82, 8\%, 107 .

Rythme, naturel : 1 ; - fondé sur l'accent: $\ddot{3}, \mathbf{i 2} ;-$ son origrinc : 4,33 ; - rythme antique : 47, 60, 82, 83, 107 ; - lans le chant : is; - dans la danse : 79 ; - mesure ryth-

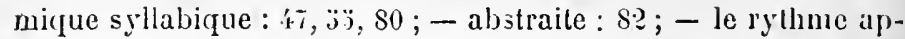
proximatif : 113 ; - oratoire : 90,$92 ;$ - en roie de transformation : 108-112; - transforme : 114, 126, 136. - liythues mèliques chez les Romains : $\$ \tau$, , 88 . - Rythme dans la poésie byzantine : $143 ;$ - dans le chant liturgique : 202; - dans la versilication romane : 163, 166-168; - italienne : 168, 171; gelmanicpue : 41 .

Rythmiciens: $8: 2,8: 3,126$.

Rythmique, son domaine : $8 \%, 87 ;-\operatorname{transformce~:~} 126,136$.

Rann : $7,127$.

Refrain : $86,148,179,184,192,193$.

Respos:148, 18:;, 186, 188.

Rhéteurs : 00,$1 ; 37$.

Rhètorique : 90 ; - ornements rheloriques : $9 \%, 98$; - chant dans les discours orutoires antiques : 91 ; - membres d'un discour's oraloire : 96 .

Rime : it, 43, 93, 9i, 97, 138, 163.

Ripresa : $187-189$.

Ritornello : 181, 200 .

Rondeau : 178, 188.

Romance : 192. 200 .

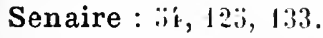

Septenaire : $; i$, 12:; $126,129,13 \pi, 172$.

Séquences : 149, 1\%2, $190 ;-$ d'Aleuin : 130; - de Noilicl : $131 ;$ - d'Adam de st-Victor : 132 . - Leur influenee dans la litterature romane : $179 ;-$ dans le chant liturgique : 20.7.

Sigfrid modelè sur Jason : $2 \%$.

Sirventes: 18.3, $18 \%$.

Sonnet : 18i, is8.

Spontanéité : 10 ; - le la poisio : 11; - du chant:11;de la danse : 12:- comme principe litteraire : 2 i.

Strambotto : 200 .

Strophes : 3,7 ; - dans la lyrique greeque : $83 ;$ - latine : 122, 120̈, 127, 133-136; - dans les séquences : 13\%, 131, 178; dans les tropaires : 1:7, 1:\$, 179; - dans les chansons : 179; dans les romances : $18 \%, 193 ;$ - pastourelles : 182; - dans les sonnets : 188 ; - dans la poésie espagnole : 176 ; - strophes homogines : 18' ; - mélaboliques : 179, 183.

Syllabisme : ; 39,$138 ;-$ quantitc des syllabes : 40 , 116 ; soumises au chant: $111 ;-$ maniere de les compter dans la ver- 
sification françaisc et prorençale : 167; - italienne : 170; espagnole : 17 亿, $17 \%$.

Symétrie dans l'art : ?, '.

Temps, fort et faible: 4,60 ; - comme mesure rythmique : 82:- - sa dissolution et sa contraction dans les rythmes : 108.

Tẻtracorde grec : $6 \%$, $6 \pi, 70,72,201 ;-$ ptoléméen : 72.

Tétrasyllabes : $128,166$.

Thésis : $\because: i,: \% \pi, 1 \%$.

Tornada : 181, 184-18i.

Trimètre dactylique : 11:3, 130, 160; - anapestique : 12:3, 130, 166.

Tropaires byzanlins: 138, 1'3, 14' 1 1't8;- - leur introduction dans l'Occident : 1 t'9, 160.

Trouvères : $183,201$.

Vers : $8 ;$ - son origine : $33 ;$ - son perfectionnement : 3 f́ $;-$ parallélisme entre les vers et les propositions : 36 ; - vers primitifs : $31 ;, 3 \tilde{i} ;$ - vers saturniens : $38 ;$ - vers à nombre égall de mots : 39 ; - de syllabes: $39-4$; - rers rythmiques: $4: 3-48 ;-$ métriques : $8,46,109 ;-$ germaniques : 8, 13, 27;à allitération : 10t. 117 ; - vers adoniens : 12:., 166 ; - pentasyllabiques : 166,$171 ;$ - saphiques : $171:-$ soladėens : $13 . ; ;-$ versentés : 166, 171;- brisés : 166. 171, 176, 179, 183. - Vers italiens à quatorze syllabes : 172 .

Versification syriaque : 138 ; - byzantine: 138,1 k $\mathrm{k} ;-$ rylhmique latine : $87,114,127,128,136,139 ;-$ dans Virgilius Maro de Toulonse : 19\%, 1:3\%. - Versification romane: 162,$166 ;$ provencale : 162, 167; - italienus: $168,111,172$;-espagnole: $173,174,176$.

Volta : 18i, 188. 


\section{TABLE DES CHAPITRES}

Questions préliminaires.................... 1-32

CHAPITRE I.

Le vers est issu de la proposition et le vers rythmique est né du vers syllabique.......................... $33-49$

\section{CHAPITRE U.}

Le mètre n'était originairement qu'une mesure, un terme fixe du rythme .............................. 50.61

\section{CHAPITRE III.}

L'acceut formait la mélodie du vers et semble avoir donné naissance au système musical grec.............. 62-77

CHAPITRE IV.

La mesure ry thmique ayant à répondre à trois différents objets : trois rythmizomena, a étẻ amenée à une abstraction qui provovoqua une séparation entre la rythmique et la métrique. Les Romains écartèrent cette division en soumettant les rythmes aux lois métriques........................... 78.89

\section{CHAPITRE V.}

La rhétorique latine contient quelques notions et quelques élèments particuliers qui se retrourent dans la poésie latine et surtout dans la poésie du moyen àge................ 90-106

\section{CHAPITRE VI.}

La rythmique séparée de la métrique par la mesure abstraite du temps s'éloigne plus encore de son principe originaire sous la prédominance du chant et tend à une transformation complète. 


\section{CHAPITRE VII.}

Les vers rythmiques sont calqués sur les mètres.... $\quad 120-137$

\section{CHAPITRE VIII.}

Les formes libres et variables de la rythmique grecque du moyen âge transportées dans l'occident y ont été réduites peu à peu aux formes de la rythmique latine............ 138-161

\section{CHAPITRE IX.}

La versification romane tire son origine de la rythmique latine, mais la plupart des formes lyriques romanes sont postérieures à l'introduction des séquences latines....... 16:2008 


\section{TABLE DES AUTEURS}

(Cités aux pages indiquées par les numéros).

Abélard : 180.

Adam de Fulda : 171.

Adam de St-Victor : $1: 32$.

Adrien $1 \mathrm{I}: 124,149$.

Aedilvald : 117 .

Aleuin : 124, $12 \%, 150$.

Aldhelm: 21, 116, 12', 160 .

Amador de los Rios : 178 .

Amalarins : 12't.

Ambrosins : 122.

Ammien : 121 .

Anastasius : 144.

Andradus Modicus : 124.

André de Crèle : 1't't.

Angilbert : 124.

Angelo Mai : $39,103,13 \%$.

Anthimos : 143 .

Antonio da Tempo: 168, 169, 187. 189, 191.

Appolinaire : 142 .

Aquila Romanus : 97,98 .

Aratus : 123 .

Arcipreste de Hita : 173, 181 .

Aristides Quint : 3, 47, $31,: 32$. $79,109,113$.

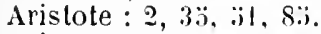

Arisloxène: $2,64,79,81,8$ '

Athénèe : 7\%.

Attilius Forlunatianus : 38 , 110.

Augustin S. : $: 31,66$, S1i, 111, 11:i, 1:21, 1:7, 138, 17!.

Aulu-lielle : is.

Ausone : 12:2.

Avilus : 123.

liacchius : 47, iii.

Bang : 8 .

liardesanes : 110.

Barsow : 101.
Barlsch: 41, 132, 160, 182.

Beeq de Fouquières : 33 .

liède : 21, 43, 116, 124.

Renfey : 10 .

Benloew : 62, 8\%.

Bentley : $: 3 \pi, 60$.

Bernart de Ventadour : 180, $18:$.

Blane: 172.

lioèce : $123,130$.

Böhl de liaber : $17 \%$.

Bonagiunta Urbiciani : 181.

Bonifice : 12'.

Boucherie : 't3.

Bouvy P. : 14: 1:6, 206.

Bugre: 8 .

Caesius Bassus : 38 .

Candidius: 121 .

Capperomnier : $\ddot{0} 6$.

Ca!on : 36 .

Caton, le rhéteur : 1:i7.

Catulle : 121 .

Censorinus : $6 \pi$.

Charisius : äl.

Charlemagne : 21, 124, 12\%.

Christ. W.: $48,33 . ; 3,: 3 i, 73$, 87. 109, 1'1-1't.

Cicéron : ‘ö, 8\%, 94, 93, 97, $10 \pi, 113$.

Ciullo d'Aleamo : 172.

Clandien : 2'3.

Colomban : 10.t, 1:i.

Commodien : 1:6, 138 .

lonnilicius : !:̈.

Corsen : 62, lit.

Cosme de Jirusalem : l'ti.

Coussemaker : $73,76,131$.

Crestien de Troies : 179 .

Cristobal de Castillejo : $17 \%$. 
Danicl : 136, 1331.

Dante : lis 1il.

Dèmétrius : 96 .

Denys d'Haliearnasse : 4.:i, :31, 6ï, 69, 8i, 93, 112.

Deseartes : 6 .

Diderot : 16.

Diez: 173 .

Diomede: : :2, 63, 11 $30,116,146$.

Dracontius : 123.

Dunbar: $12 \mathrm{i}$.

Duran : 173 .

libers : $10 \ddot{3}$.

Edélestand du Méril : 126, $128,130,133,134$.

Eginhard : 22, 124.

linnodius : 123.

Ephrem : 138, 1'to, 1 19.

Ermoldus Nigellus : 12'.

Esehyle : 193.

Eugène de Tolède : 12'́.

Fardulf : 12't.

Federigo !1: 181 .

Forus : 12+, 123̈.

Fracarolli : 172.

fragmenta Parisiana: :

Francisco d Ocaña : 176.

fronton : 121 .

liancelm Faidit: 13.

Cautier, L.: 13r. 149, 1̈̈1, 1\%.

Cierbert: 1'ti, 171, 20:.

Gevaërt. : 6i. 31.

Cianni Alfani : 18?.

Goethe : 1', 18, 28, 19'.

Gottsehed : 23 .

Cioudimel : 13.

Grégoire de Nazianze : 1 '?

Cirimm, .J. : l0, l'́t.

Grimm, W. : 14, 9'.

liui d'Arezzo : 1'5.

fuido Cavaleanti : 182.

Guillaume d'Amiens : 188 .

Guillaume de Poitiers : 180.

Guiraut de Borneil : 190.

llarmonius : 1q0, l's.

llehn, Y. : 10.

Heiric : 12i.

Ilelmholiz: 68 .

Herder : 13.

Ilermann Godfried : : 88,60 .

Homère: is.

llorace : $88,1 \cdot 1-12 . ; 1,133$.

llugo, V. : 17.

Huemer : : $; 7$.

lsidore de Séville : 10, 10'.
Jacopone da Todi : 172.

Jean de Damas : 1 't't.

Jean de lluris : 171.

Jordan : 36 .

Iulius Rufianus : 9\$.

Justinien : lit'

kawezynski, ‥ : 18.

liehrein : $13 ̈ 1,13 ̈ 3$.

lieller : 38 .

Lachmann: $\{1$, '2.

Laevius: : $: 21$.

l.ambillotle : 14 .

lavoix, II. : I't.

Leillhoilt : 102.

l.eroux de lincy : 190.

l.essing : 2,28 .

longin : : $: 1,112$.

Lopez de Ayala : 176.

lucain : 23,124 .

Luxorius : 123.

Jialin : 180.

Malherbe: $3 \ddot{\text {.i. }}$

Mallius Theororus : 110.

Marcabrun : 180, 181.

Marius Vickor : 123.

Marius Vietorinus : $38,: 30,: 3 i$. $86,10 \tau, 111,113,114,129$.

Martianus Capella : 66, 99, $113,121,122,130,179$.

lleibom: $3,113$.

Merolsaudes : 123.

llethode : l'te.

.leyer, W. de foeltingue: :;, $96,106,129,132,133,138$, $1,148$.

Milon de St-Amand: 103, 12'.

Moine de St-Gall : 1.30.

Holinier : 46, 161, 163, 166, $169,18 \ddot{3}, 186,201$.

llone : 13:-133̈.

IIorel : l:il.

Nuatewin : 12.'.

Muellenholl : 3\%, 128.

Mucller, L. : : 37, I21.

Muratori : 127, 137.

Nanucei : 172, 179, 181.

Yicefor Caliste Xantopoulos, lí!.

Nicolas de Jeroschin : $\{$.'.

Nigidius ligullus : 63 .

Nigra : 19:\%

Nonnos : 1'2.

Notker : $1:$ il.

Otfrid de llissembourg : 21, 23039,41 . 
Palestrina : 12 .

Paris, Gaston : $\{2,13 \%, 162$, 183.

Paul de Frioul : 12'.

Paul Diacre : 124 .

Paulin d'Aquilèe : 12', 133.

Paulin de Nole : 123 .

l'ercy : 13.

Pero Lopez de Ayala : 176.

Pictet : 10.

Pier delle Vigne : 181 .

Pierre Diacre : $12 \mathrm{k}$.

Pindal'e : 23.

Pitra, J.-13.: 1'1, 144, 143.

Platon: 79,81 .

Plaute : 94.

Pothier : 201-207.

Priscien : 63.

Procope : 10.

Properce : 9:.

Psellus : 80.

Ptolémée : 6 .

Quintilien : 44, 48, 31 , ; 4 4, 91, $93,108$.

Raban Maur : 21, 12', 123̆, 179.

Rabubi Don Santob : 17ö.

Raimbaut d'0range : 180.

Rameau : 12.

Raynouard : 183.

Richard Cour de Lion : 181.

Rinaldo d'Aquino : 179.

Ritschl : 57 .

Rousseau, J.-J. : 16.

Sanchez: 173.

Schleler : 18 '.

Sclicrer : $37,62,128$.

Schiller : 28.

Schlottmann : 103.

Sedulius : 123 .

Sedulius Scotus : 124.

Seelmann : 62 .

Sénèque : 88, 121, 123, 130.
Septimius Serenus : 121.

Sergius : $6 \dot{x}$.

Sergius Byzantinus : $1 \mathbf{x}$.

Servius : $64,66,82$.

Sidoine Apollinaire : 123.

Sievers : 62.

Smaragde : 124.

Sophronius : 144.

Stace : 23,124.

Suidas : $: 1$.

Suger : 12 .

Synesius : 1.22.

Tacite : 10, 22:

Taine : 1̈̈, 29, 30 .

Tardieu : 18.

Terentianus Maurus : 38, כั4, $110,122,146$.

Théodore d'Alexandrie : 147.

Théophylacte, lisez Maurice le Stratige : 10 .

Théodulf : 1 ?'t.

Thimoclès : 143 .

Thurneysen : 38 .

Uc Faidit : 169.

Usener : 42.

Varron : 96, 121.

Venantius Fortunatus : 123, 126.

Vincent : $\check{1} 1,112$.

Virgile: 124,120,179.

Virgile A sianus : $10 \ddot{z}$.

Virgile Maro de Toulouse : 39 , 103, 1304 .

Walafrid Strabon: $21,124,123$.

Wandilbert : 124, $12 \%$.

Weil: 62.

Westphal: 1, 2, 7, 36, 38, ว̈ $1+6$.

Whitney : 6i, 199.

Wolf, Frd.: $173,17 \%, 178,184$.

Zarncke : 117, 127, 133.

Zeuss : 120.

Zielenslii : 12. 


\section{ERRATA}

\begin{tabular}{|c|c|c|c|}
\hline Page & ligne & au lieu de: & lisez: \\
\hline 7 & 29 & Langzeitz & Langzeile \\
\hline 10 & 17 & Théophylaete & Maurice \\
\hline 11 & 13 & en & un \\
\hline 11 & 16 & parties & mots \\
\hline 41 & 3 & thaz & tház \\
\hline 41 & 3 & serip & scríp \\
\hline 41 & 3 & breitin & breitin \\
\hline 46 & 6 & oa & coma \\
\hline 47 & 18 & sิyus:opos & 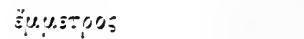 \\
\hline$»$ & $2 \ddot{3}$ & $-\xi_{0 \nu}$ & - \\
\hline$\ddot{31}$ & 1 & $\dot{\varepsilon} \tau \div i$ & 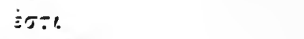 \\
\hline 37 & $2 \ddot{a}$ & $\pi / 50 \%$ & $5 \% 30 \%$ \\
\hline 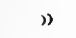 & $"$ & 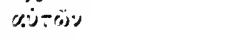 & ט:- \\
\hline 63 & 21 & ex & et \\
\hline$n$ & $3 \ddot{z}$ & sine & sive \\
\hline bí & 10 & \multicolumn{2}{|c|}{$\begin{array}{l}\text { Il faut se représenter la première note plus } \\
\text { haute, la seconde plus basse. }\end{array}$} \\
\hline$"$ & 16 & d'une & une \\
\hline$»$ & 32 & $9 \% 0$ & jup \\
\hline 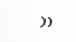 & $"$ & $2.0 \%(1,0) \div 3$ & $200 \% 000$ \\
\hline $60 ̈$ & 1 & s. & $3 \%$ \\
\hline$"$ & 17 & ùsis?ui & 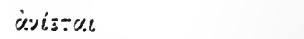 \\
\hline 66 & 4 & 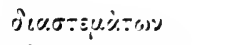 & 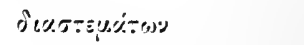 \\
\hline 79 & $1 \hat{\mathrm{t}}$ & 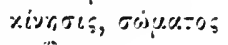 & 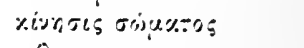 \\
\hline $8 \mathrm{t}$ & 32 & $0 \% \frac{10005}{3}$ & परेश०: \\
\hline 81 & 33 & p.3. & $\mu \vdots \hat{y}_{0}$ \\
\hline 83 & 20 & grees & Grees \\
\hline 101 & $3 \ddot{i}$ & alliterirendem & alliterirenden \\
\hline 109 & 17 & Taktheit & Takttheil \\
\hline$"$ & 19 & vielmeher & vielmehr \\
\hline 12't & 11 & Eginhard; & Eginhard. \\
\hline$"$ & 18 & Muaterin & Muatewin \\
\hline " & 20 & Fardeulf & Fardulf \\
\hline $12 \ddot{3}$ & 19 & x:\% & xuris \\
\hline
\end{tabular}




$$
-220 \text { - }
$$

\begin{tabular}{|c|c|c|c|}
\hline Page & ligne & au lieu de: & lisez : \\
\hline 129 & $233^{\circ}$ & Vis & vir \\
\hline $1 \div 0$ & 30 & l'Orient. & l'orient? \\
\hline $1+8$ & 6 & \% & 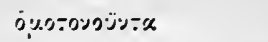 \\
\hline $1: 32$ & 3 & , a) &,$(a)$ \\
\hline 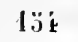 & n. 2 & 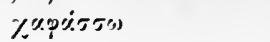 & 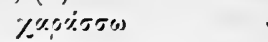 \\
\hline 163 & $3 \ddot{3}$ & pleniara & pleniera \\
\hline 172 & $3 t$ & Perche gli uomini & Pelche gli uomin' \\
\hline $17 t$ & 20 & fizolo-enforzilr & tizolo_enforzár \\
\hline 173 & 18 & Crodes & Erodes \\
\hline 176 & 28 & esta el_lugar & esta_el lugar \\
\hline 177 & 11 & cri_aturas & criaturas \\
\hline$"$ & 19 & $\mathrm{i} \smile \mathrm{a}$ & ia \\
\hline$n$ & 28 & Revalacion & R̄evelacion \\
\hline 183 & $2 \ddot{2}$ & dùs & dì \\
\hline 190 & n. 1 & Guirant & Guiraut \\
\hline $19: 3$ & 16 & par & , par \\
\hline 207 & $\dot{t}$ & méthodes & mélodics \\
\hline
\end{tabular}




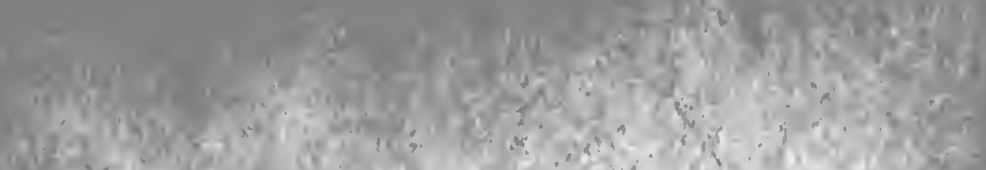

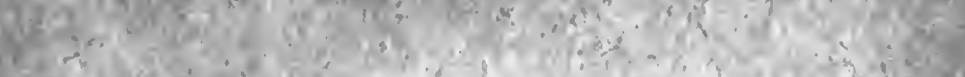

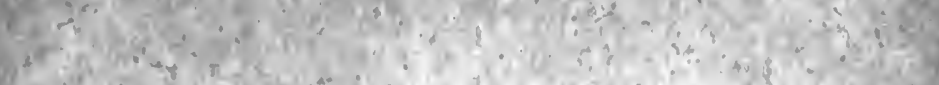

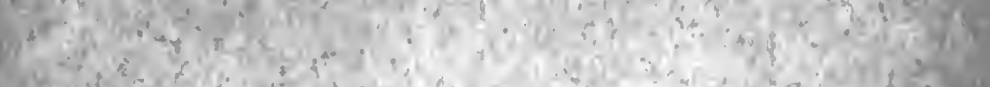

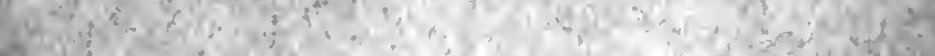

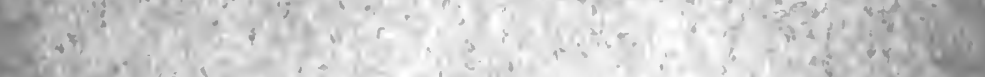

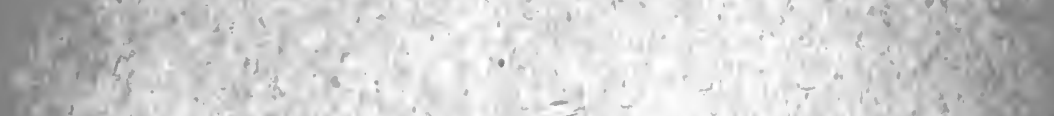

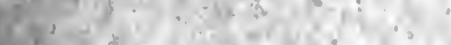

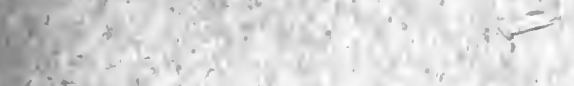
a.t.

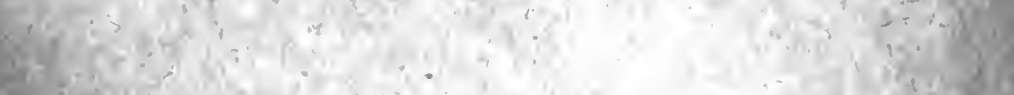

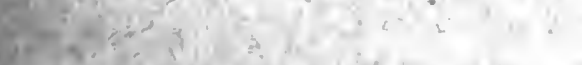

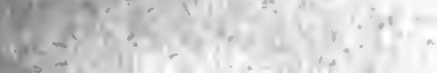
1 n.

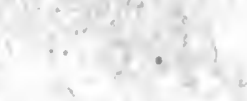

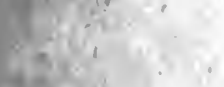

ther 1

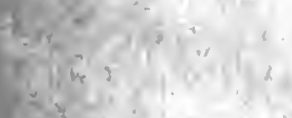

$-8 y^{2}=9.7$

10 itivis.

8

$2 \operatorname{lin}^{2} x+2$

8

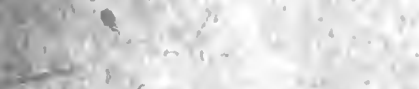

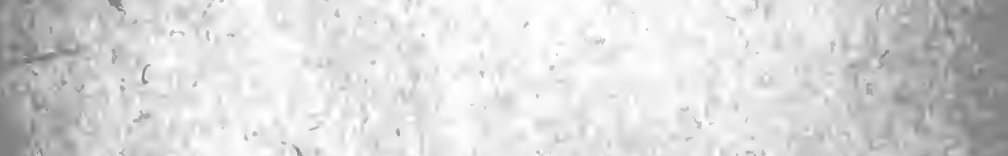

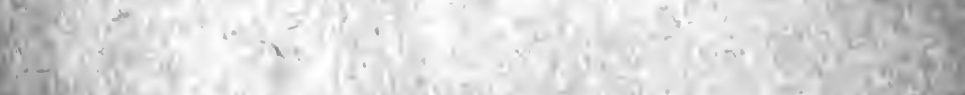

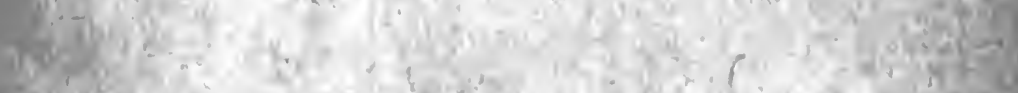
W.0.

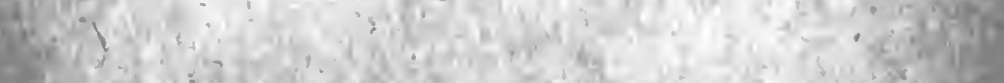

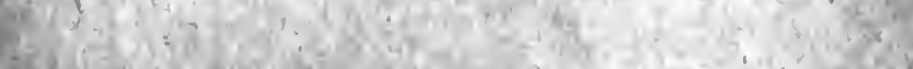

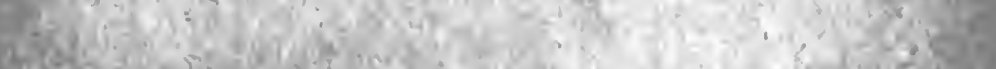

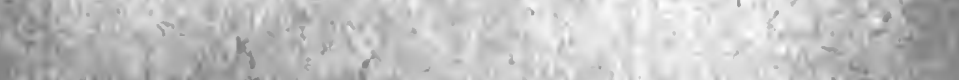
Q⿻日木

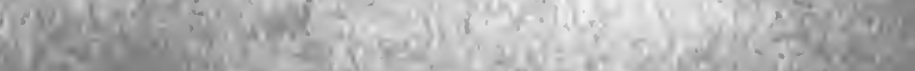




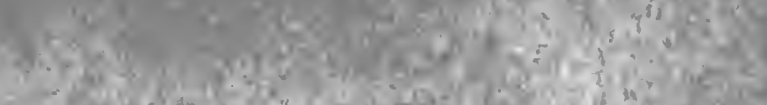

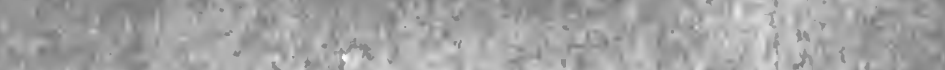

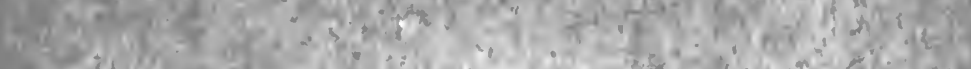

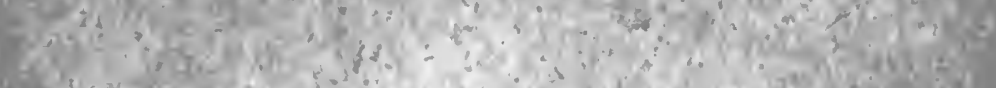

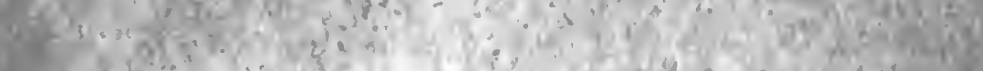

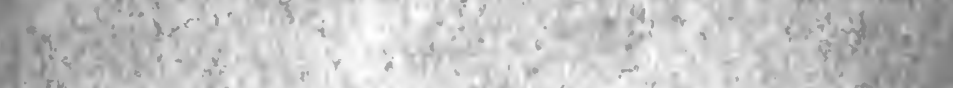

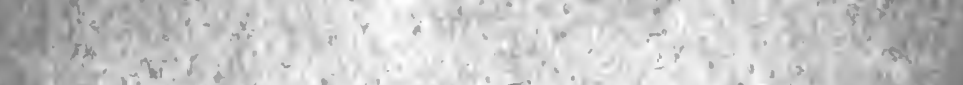

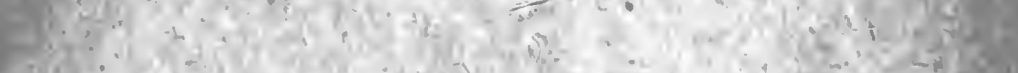

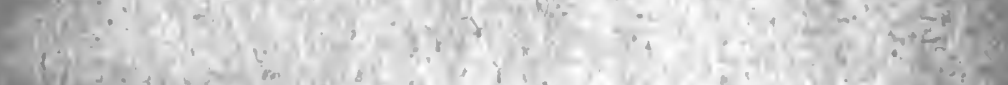

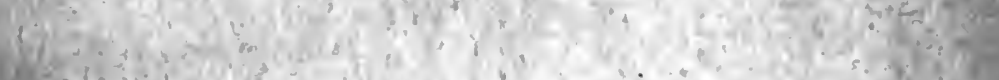

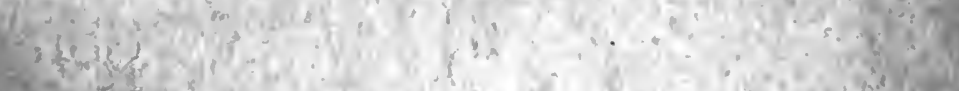

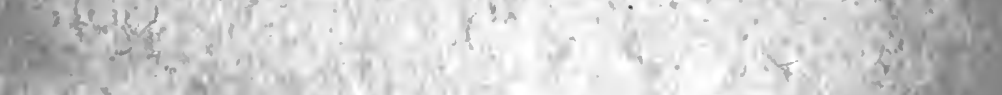

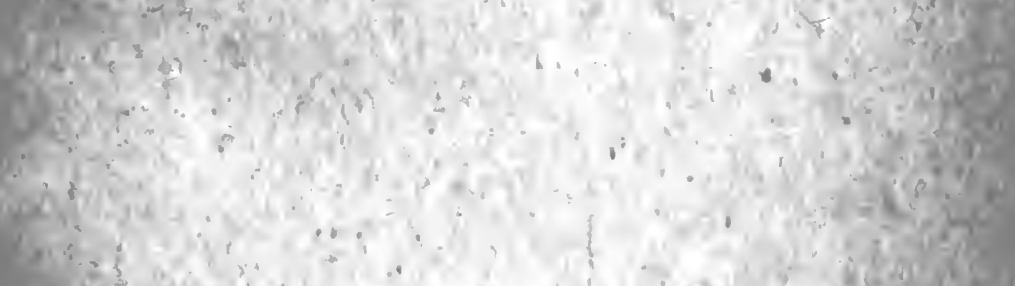

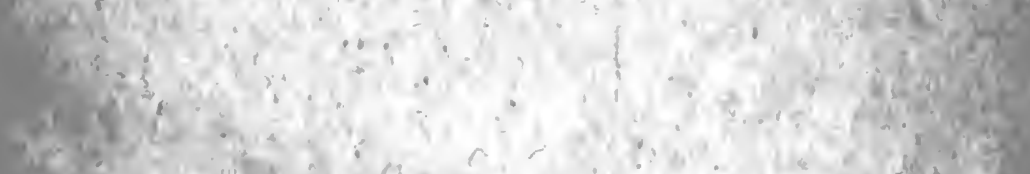

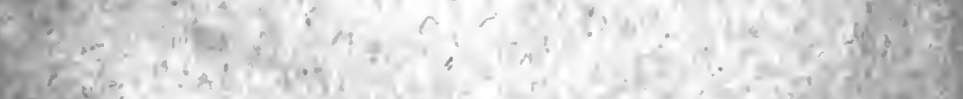

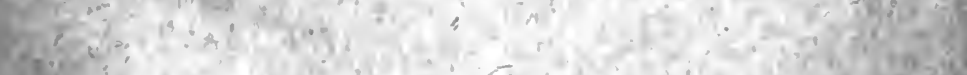

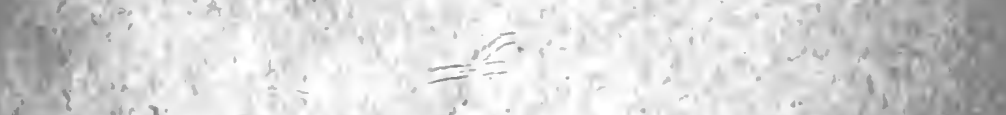

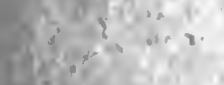

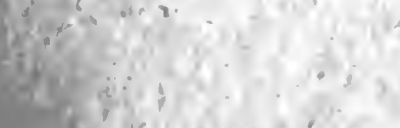

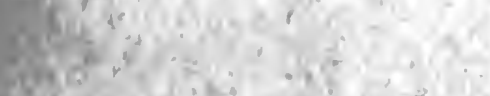

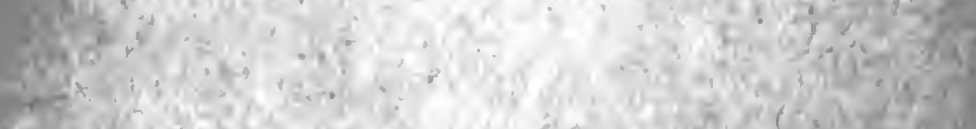

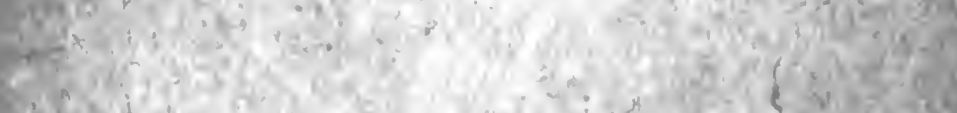

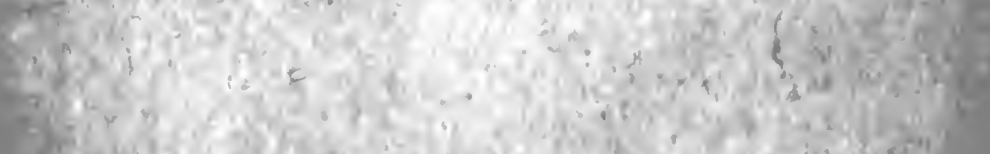

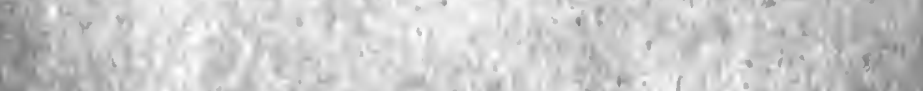
(n)

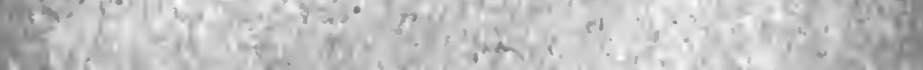

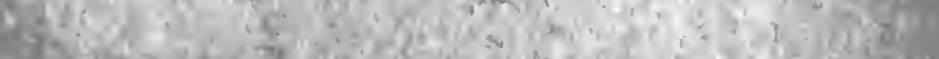

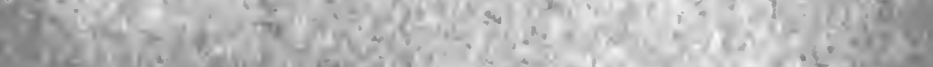

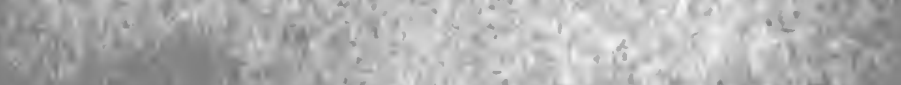
4an

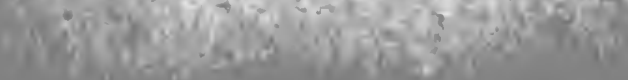





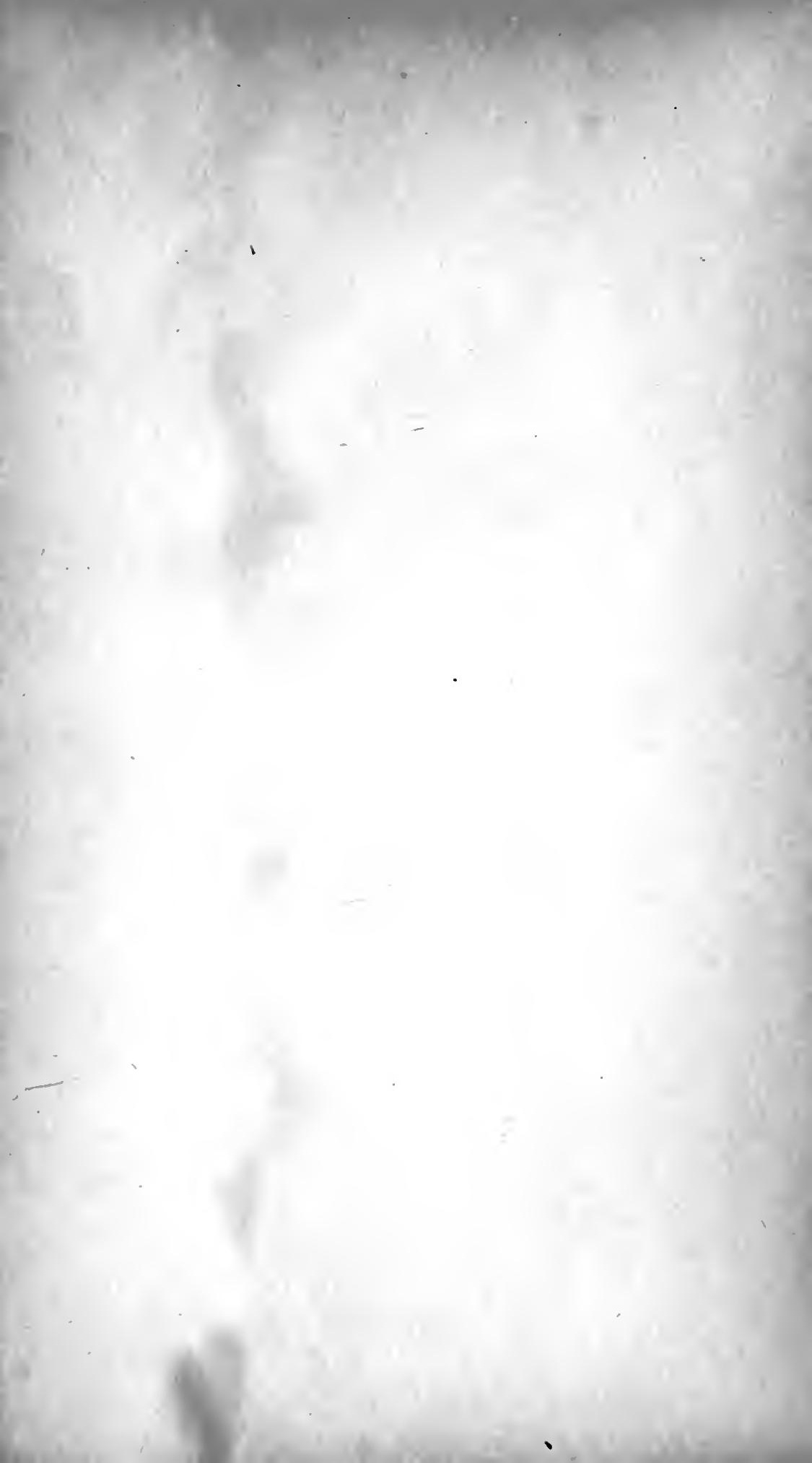




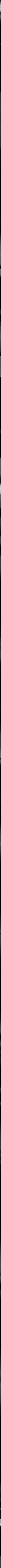



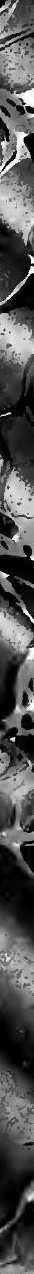

$-1+4 \times 1 x^{2}$

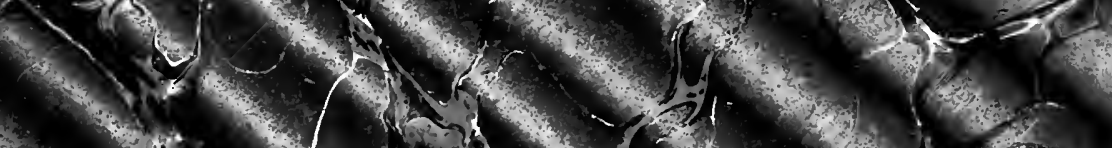

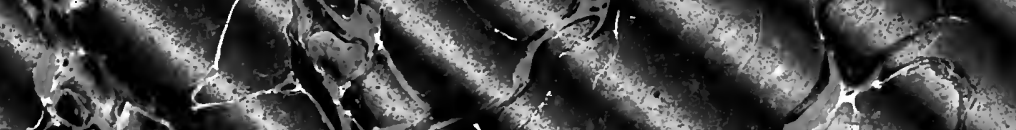

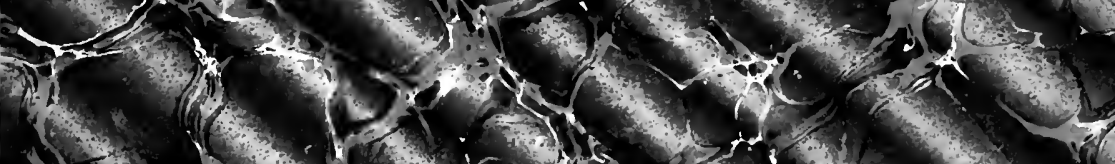

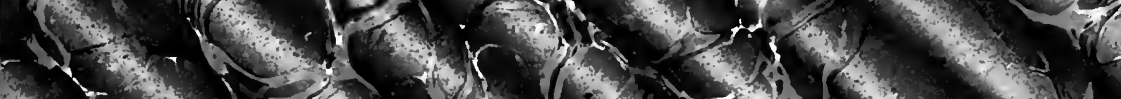
1) $1-10$ $42=10+110$. (1) $y^{3}+1$. (1) $x^{3}+2$ 
